598.2
DIBL

\title{
Leitfaden $\square$ a $\square$
}

zum Bestimmen der Vögel Mittel-Europas von Friedrich Dahl 


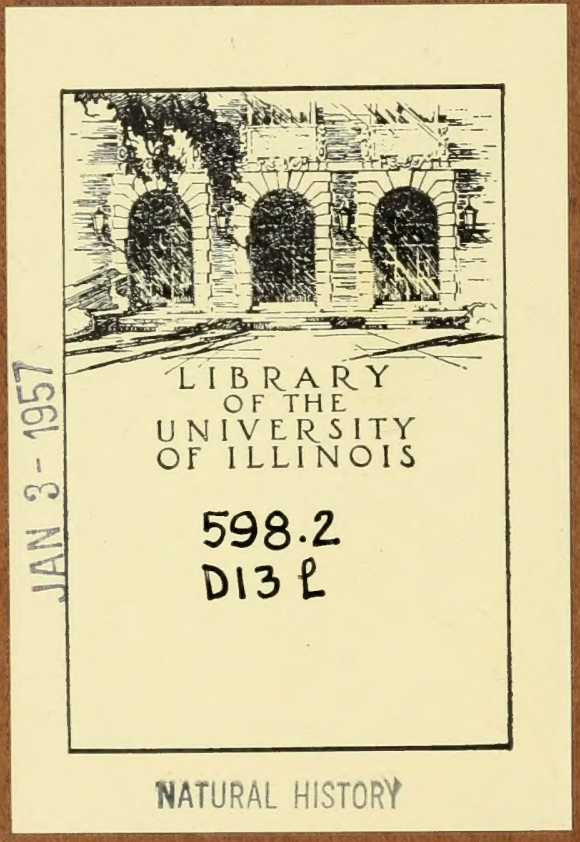


(1)

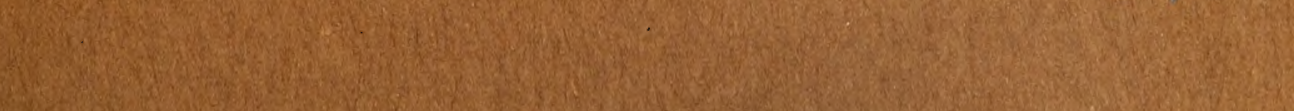

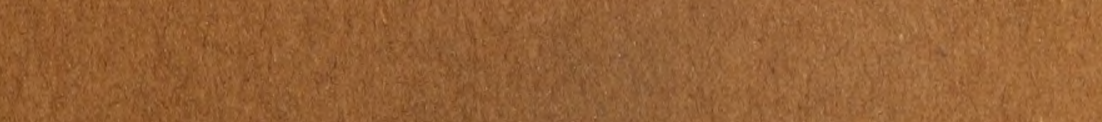
W.

6. 1) (2)

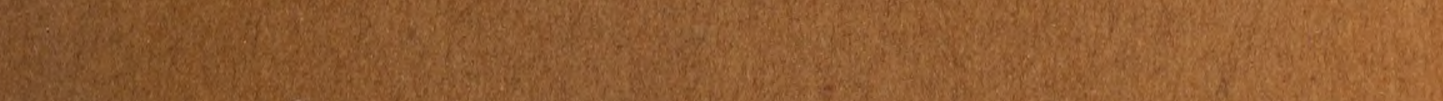

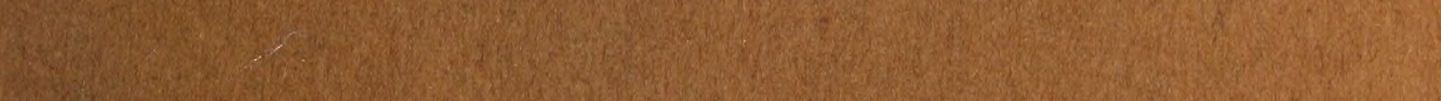

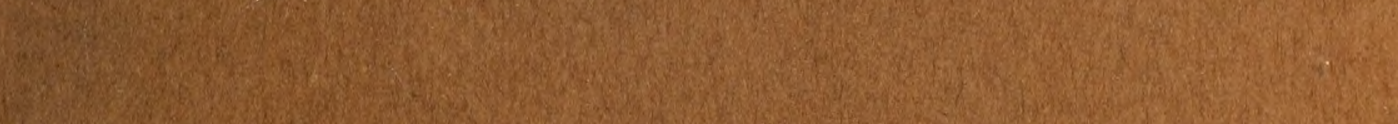

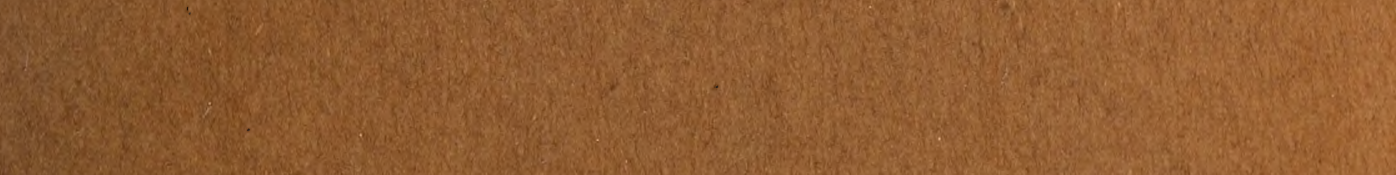

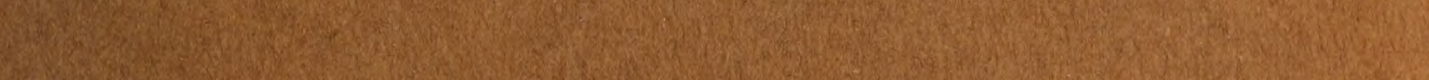
4. 6.

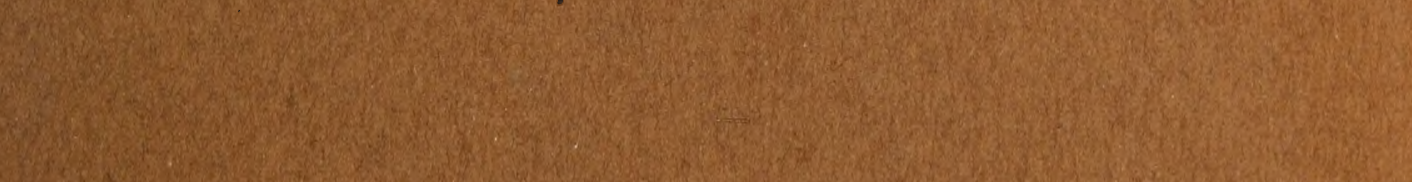
Q

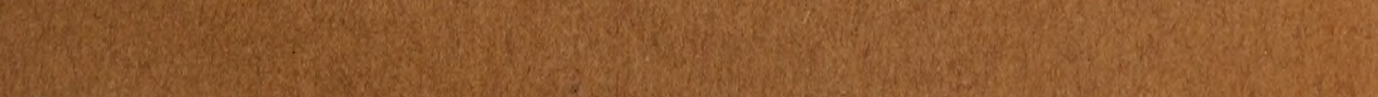

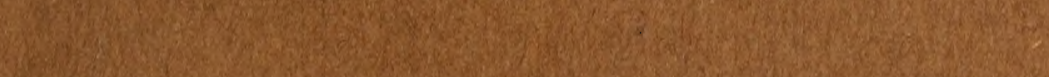
(2)

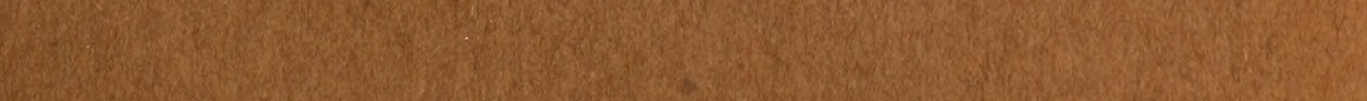

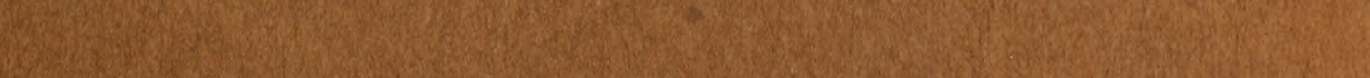

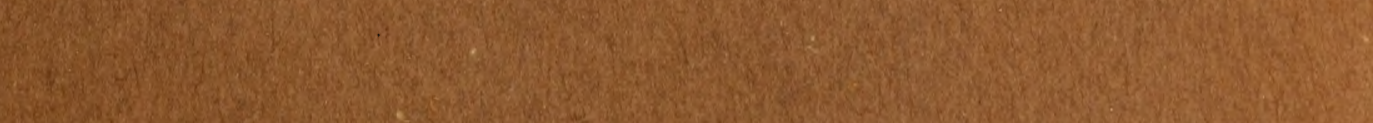

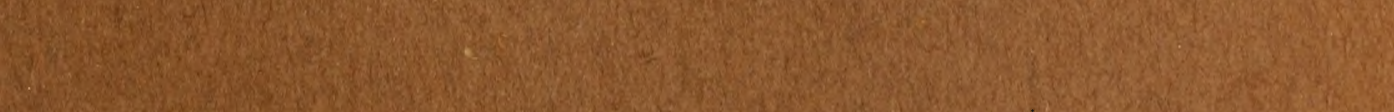

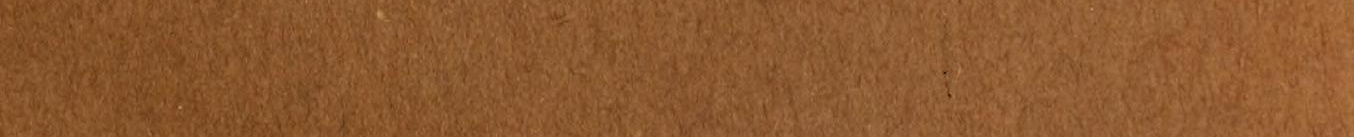

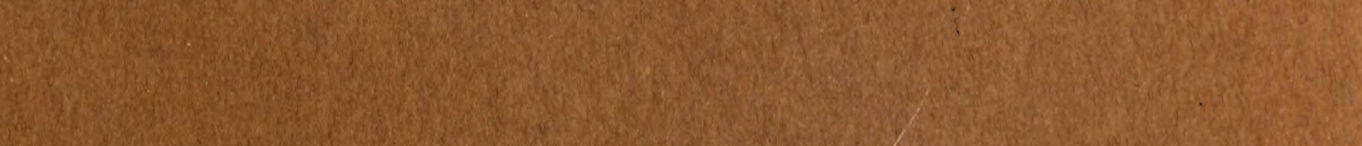

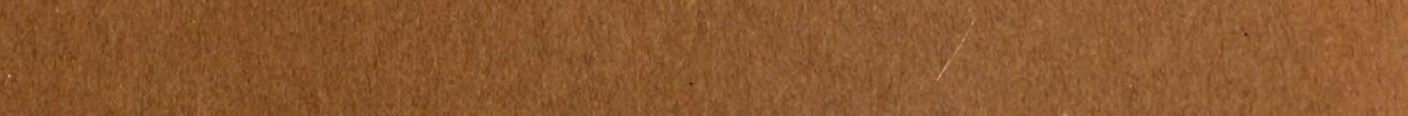
S(x) 20

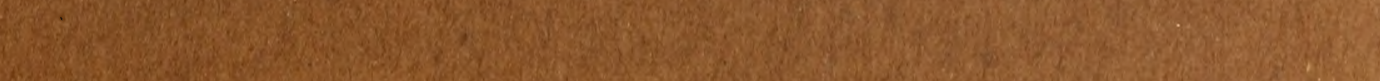

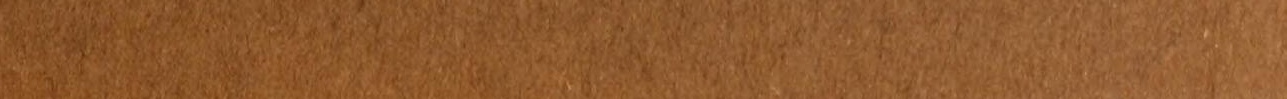





\section{Leitfaden zum Bestimmen}

\section{der \\ Vögel Mittel-Europas \\ ihrer Jugendkleider und ihrer Nester}

nach leicht und sicher erkennbaren Merkmalen

von

Professor Dr. Friedrich Dahl

Mit 55 Abbildungen im Text

Berlin

Verlag von Gebrüder Borntraeger

W 35 Schöneberger Ufer 12 a

1912 
Alle Rechte,

insbesondere das Recht der Übersetzung in fremde Sprachen, vorbehalten Copyright, 1912, by Gebrüder Borntraeger in Berlin 


\section{2 D 131}

Nat.thist,

\section{Vorwort}

An Büchern zur Bestimmung der deutschen Vögel fehlt es keineswegs. Trotzdem schien ein neues Buch nötig. - Die bisher vorliegenden Bestimmungsbücher sind nämlich für den A n fäng er (z. T. auch für den Fortgeschritteneren) wenig geeignet. Erstens sind in ihnen die Jugendkleider, die doch dem Anfänger, da sie häufiger sind, besonders in die Hände fallen, in unzureichender Weise berücksichtigt. Manche Tabellen sind sogar unter Zugrundelegung nur der männlichen Hochzeitskleider ausgearbeitet. Zweitens wird in ihnen beim Bestimmen die Kenntnis anderer als des vorliegenden Vogels vorausgesetzt, indem oft allgemeine Ausdrücke wie „kurz", „lang“, „stark gebogen“, "wenig gebogen" usw. vorkommen, die nur im Vergleich mit andern Vögeln eine bestimmte Bedeutung erlangen. Drittens bleiben die Nester, welche naturgemäß auch für den Anfänger großes Interesse haben, stets völlig unberücksichtigt.

Ich habe versucht die genannten Mängel zu vermeiden und zwar nach folgenden Grundsätzen: Soweit die Jugendkleider z. Z. sicher unterscheidbar sind, habe ich die Unterschiede in den Bestimmungstabellen zum Ausdruck gebracht. Die Unterscheidungsmerkmale habe ich, wenn möglich, nach absolutem Maß gegeben oder in Form eines Unterschiedes, den man an verschiedenen Teilen des vorliegenden Vogels feststellen kann. War beides nicht möglich, so habe ich eine schematische Zeichnung beigegeben, die den Gegensatz veranschaulicht. Soweit es möglich war, habe ich mehrere Merkmale genannt, um dem Anfänger eine größere Sicherheit zu geben. Nur Lokalformen und Unterarten ließen sich bisweilen nicht mit einer derartigen Schärfe voneinander abtrennen. Was die Nester anbetrifft, so habe ich nach dem Nistplatz, der Bauart, dem Baumaterial, der Zahl, Größe und Farbe der Eier eine Bestimmungstabelle geschaffen, die in den allermeisten Fällen auch den Anfänger zum sichern Ziele führen dürfte, zumal da auch die häufigeren Ausnahmen von der Regel berücksichtigt sind.

Farbige Abbildungen ganzer Vögel können beim Bestimmen der Vögel einen sehr verschiedenen Wert haben. Zur Bestimmung auffallend gefärbter 
Arten und namentlich der auffallenden Hochzeitskleider können sie vorzügliche Dienste tun. In allen andern Fällen aber lassen sie schon bei Feststellung der Gattung im Stiche, da Unterschiede in Form und Zeichnung bei Wiedergabe ganzer Tiere selten zum Ausdruck gelangen können. Immerhin habe ich in meinen Tabellen überall auf die Bilder eines der größeren neueren Bilderwerke, des von Hennicke herausgegebenen neuen „Naumann" verwiesen, zurnal da in diesem Werke auch die Lebensweise, die Synonymie und die Literatur ausfuihrlich zur Darstellung gelangt. Ich kann die Anschaffung eines solchen Werkes selbstverständlich sehr empfehlen. Ein Ersatz für ein gutes Bestimmungsbuch wird jenes Werk aber niemals sein. Um das zu zeigen, mag hervorgehoben werden, daß gerade die Besitzer des genannten Werkes dem Herausgeber gegenüber den Wunsch äußerten, neben den Abbildungen Bestimmungstabellen zu besitzen, und daß das gegenwärtige kleine Buch diesem Wunsche seine Entstehung verdankt.

Kurz mag auch das hervorgehoben werden, was das vorliegende Büchelchen nicht bieten kann und nicht bieten will: - A A die Lebensweise wird, abgesehen vom Nestbau nicht eingegangen. Wer Übersichten der einheimischen Vögel nach der Lebensweise besitzen möchte, den verweise ich auf ein kleines Buch „Die lungenatmenden Wirbeltiere Schleswig-Holsteins und der Nachbargebiete" (Kiel 1906). Auch auf die Synonymie und Literatur wird nicht eingegangen. Alles das (sowie ausführliche Angaben über die Lebensweise), findet man u. a. in dem neuen "Naumann". - Sogar die Autorennamen habe ich fortgelassen. Es stellt sich nämlich immer mehr heraus, daß das Anhängen des ursprünglichen Autornamens an den Artnamen ein wissenschaftlicher Unsinn ist, der nur noch durch die Eitelkeit der Systematiker aufrecht erhalten wird. Die Nomenklatur ist etwas historisch Gewordenes und an der klaren Benennung einer Art haben zahlreiche Autoren, nicht einer oder zwei mitgewirkt. Meist sind die Arbeiten der späteren Autoren viel wichtiger als die des ursprünglichen Autors.

Was die Anordnung des Stoffes anbetrifft, so gebe ich zunächst eine Übersicht der Gruppen. Ich habe dabei nicht rein systematische Gruppen sondern biologische Gruppen im Auge, weil die Lebensweise den Bau dermaßen beeinflußt, daß die mit ihr in Beziehung stehenden Merkmale bei der Bestimmung die allerwichtigsten sind. So habe ich die Eulen wegen ihres Hakenschnabels bei den Raubvögeln belassen, obgleich sie nach neueren Untersuchungen den Nachtschwalben nahestehen sollen. In den Übersichten der Gattungen innerhalb der Gruppen sind diejenigen Gattungen, die sich nicht nach leicht erkennbaren Merkmalen als Ganzes trennen ließen, vereinigt geblieben, um erst in den Übersichten der Arten analysiert zu werden. In den Artübersichten sind die Namen aller Arten, die in Deutschland nur als sehr seltene Gäste zu betrachten sind oder die nach ihrer Verbreitung nur ausnahmsweise auch bei uns einmal gefunden werden könnten, durch schwächeren 
Druck kenntlich gemacht. Fortgelassen wurde keiner von ihnen, da erst die Zukunft lehren muß, inwieweit die Aufnahme dieser Arten als wirklich bei uns zugeflogener Gäste berechtigt ist. Bei jeder Art wurde auf das schon genannte Naumanssche Werk verwiesen. Von Synonymen sind nur die allerbekanntesten angefügt, da man alles Weitere im "Naumann" oder in irgend einem andern Spezialwerk nachschlagen kann. Den Anfänger kann die Synonymie zunächst wenig interessieren; er möchte nur den gewöhnlich verwendeten und den jetzt gültigen Namen wissen.

Was die Herstellung der Tabellen anbetrifft, so werden die schon zitierten, sich nur auf die Formen des nordwestlichen Deutschlands erstreckenden Tabellen hier gewissermaßen in neuer, stark erweiterter Auflage gegeben. Jene Tabellen wurden frïher nach dem Material des Kieler und z. T. auch des Hamburger Nuseums ausgearbeitet. Bei Ausarbeitung der jetzt vorliegenden Ausgabe stand mir das reiche Material des Berliner Nuseums zur Verfügung. Herrn Prof. Dr. Reichenow, der mir die Benutzung desselben in vieler Hinsicht erleichterte, sage ich auch an dieser Stelle meinen besten Dank.

Steglitz, im November 1911 
Digitized by the Internet Archive in 2010 with funding from University of Illinois Urbana-Champaign 


\section{Inhaltsübersicht}

Die Gruppen der einheimischen Vögel.

Die Gattungen der Singvögel .

Die Gattungen der Segler, Nachtschwalhen, Kuckurke, Eisvögel. Bienenfresser, Racken und Hopfe . . . . . . . . . . . . . 1:3

Die Gattungen der Raubvögel . . . . . . . . . . . . . 14

Die Gattungen der Tauben und Hühner . . . . . . . . . . . . 1 T

Die Gattungen der Stelzvögel . . . . . . . . . . . . . 1!

Die Gattungen der Flamingos und Schwimmvögel . . . . . . . . ㄴ.

Die Arten der Singvögel . . . . . . . . . . . . . . . . : :1

Die Arten der Segler und Nachtschwalben . . . . . . . . . . . T1

Die Arten der Klettervögel . . . . . . . . . . . . . . †1

Die Arten der Eisvögel und Bienenfresser . . . . . . . . . . . . T.2

Die Arten der Racken, Hopfe und Kuckucke . . . . . . . . . . . 7:

Die Arten der Raubvögel . . . . . . . . . . . . . . . . . it

Die Arten der Tauben . . . . . . . . . . . . . . . . . . \$”'

Die Arten der Hiihner . . . . . . . . . . . . . . . . . . \$.;

Die Arten der Stelzöögel . . . . . . . . . . . . . . . . it

Die Arten der Flamingos und Schwimmvögel . . . . . . . . . . . !

Übersicht der Nester der in Deutschland brütenden Vögel . . . . . 11!!

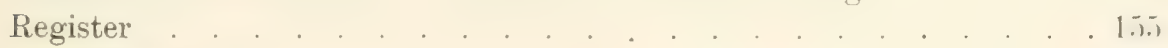

Berichtigungen . . . . . . . . . . . . . . . . [1ㄴ] 


\section{Erklärungen für den nachfolgenden Text}

Soweit möglich, sind im Nachfolgenden nur Ausdrücke verwendet worden, die ohne weitere Erklärung auch dem Anfänger verständlich sind. Zu seiner Orientierung mögen noch folgende Angaben dienen:

Der anliegende Flügel wird gemessen, wie dies die Fig. 15, S. 5, durch die Linie $l^{\prime} l^{\prime \prime}$ zum Ausdruck bringt. Man mißt von der Beuge bis zum Ende der festen Schwingen oder Schwungfedern (h), auch dann, wenn einzelne Schulterschwingen (s) etwas weiter vorragen, wie dies die Figur zeigt. An den Schwingen unterscheidet man den festen Schaft, die schmale Außenfahne und die breite Innenfahne. Auf den Schwingen liegen die oberen Flügeldeckfedern (d). An der Unterseite der Flügel befinden sich entsprechende untere Flügeldeckfedern, die bei Ruhelage des Flügels der Körperbefiederung anliegen und gewöhnlich kleiner und weicher sind. Die erste Schwinge oder Schwungfeder ist oft verkiimmert (vergl. Fig. 25 I, S. 9) und kann dann für eine untere Flügeldeckfeder gehalten werden, weil sie unter der ersten größeren Schwinge (II) liegt. Sie ist aber stets viel fester, auch verhältnismäßig schmaler als die unteren Flügeldeckfedern, selbst dann, wenn sie sich durch Größe von diesen nicht unterscheidet- Die nackte Schnabelfirste mißt man von der äußersten Grenze der feinen Befiederung mitten auf dem Schnabel bis zur Spitze oder zum Endrand des Oberschnabels. Ist der Schnabel gebogen, so mißt man mit biegsamem Maß uiber den Bogen. - Am Fuß nennt man den einfachen Wurzelteil, von der Ferse bis zur Wurzel der Zehen, den Lauf. Über dem Schwanz befindet sich der Bürzel, unterhalb des anliegenden Flügels und von diesem teilweise bedeckt, befinden sich an den Körperseiten die Weichen. Die Zahlen verweisen auf Naumaxx, Naturgeschichte der Vögel Mitteleuropas, neue Ausgabe herausgegeben von C. R. Hexicke (Gera-Untermhaus, 1897-1905). Ich glaube durch Einfügung dieser Zitate denjenigen, welche dieses umfangreichste Werk der einschlägigen Literatur besitzen oder denen es in irgend einer Bibliothek zugänglich ist, einen Dienst erwiesen zu haben. Zur sicheren Bestimmung nötig ist das Werk keineswegs. 


\section{Die Gruppen der einheimischen Vögel.}

I. Zwischen den Zehen befinden sich Häute (Schwimmhäute) (Fig. 1 und 2), deren Ausdehnung, bei gespreizten Zehen aus dem Zehenwinkel bis zur Mitte des Außenrandes gemessen, wenigstens halb so groß ist, wie die Länge der längsten Zehe ohne Kralle.

A) Die Innenzehe ist an der Innenseite mit zwei rundlichen Lappen versehen (Fig. 1) (N. Bd. VIII, Tafel 14 und 15)

\section{Wassertreter, Phalaropus, S. 19 (Stelzvögel).}

B) Die Innenzehe ist nicht mit rundlichen Lappen versehen (Fig. 2).

a) Der Schnabel ist sehr stark aufwärts gebogen (Fig. 3)

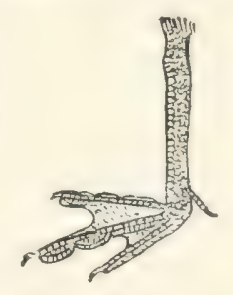

Fig. 1.

Fuß vom Wassertreter. (N. Bd. VII, Tafel 13)

Säbler, Recurvirostra, S. 20 (Stelzvögel).

b) Der Schnabel ist nicht aufwärts gebogen.

a) Der Schnabel ist in der Mitte stark abwärts gebogen; die Beine sind, von der Grenze der Befiederung bis zur Zehenwurzel gemessen, über $40 \mathrm{~cm}$ lang (N. Bd. VI, Tafel 29) . . . . . Flamingos S. 24.

ק) Der Schnabel ist in der Mitte nicht stark abwärts gebogen, höchstens am Ende umgebogen (Fig. 4); die Beine sind kürzer (N. Bd. IX, Tafel 18 bis Bd. XII)

Schwimmvögel S. 24.

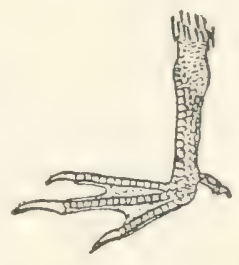

Fig. 2. Fuß einer Seeschwalbe.

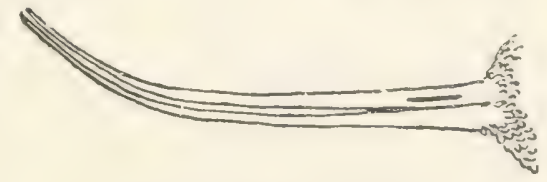

Fig. 3. Schnabel vom Säbler.

II. Die Schwimmhaut fehlt entweder ganz oder sie ist viel weniger ausgedehnt.

A) Alle Zehen sind mit breiten Nägeln und einfachen, nicht gelappten Hautsäumen versehen (Fig. 5) (N. Bd. XI, Tafel 8-12)

Lappentateher, Colymbus S. 27. Dah1, Buch zum 13estimmen der Vögel

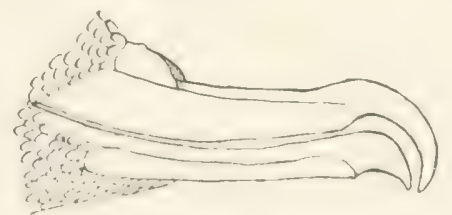

Fig. 4. Schnabel des Sturnitauchers. 
B) Die Zehen sind entweder mit gelappten Hautsäumen (N. Bd. VII, Tafel 10) versehen oder sie sind nicht gesäumt; die Krallen sind nie breitnagelförmig.

AA) Der Oberschnabel ist hakenförmig gebogen und ragt mit seiner Spitze iber das Ende des Unterschnabels nach unten vor (Fig. 4 und 6-8).

a) Der Schwanz ist so tief gegabelt, daß die mittleren Federn mindestens $20 \mathrm{~cm}$ kürzer sind als die äußersten; die erste Schwungfeder der Flügel ist die längste, die anliegenden Flügel sind mindestens

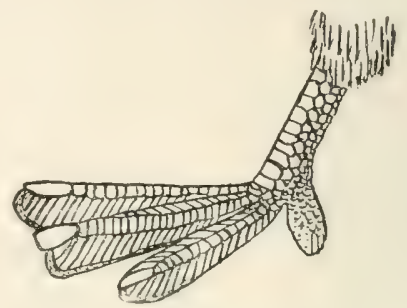

Fig. 5. Fuß eines Tauchers. $70 \mathrm{~cm}$ lang; der Schnabel ist lang gestreckt, nur am Ende hakenförmig (vergl. Fig. 4) (N. Bd. XI, Tafel 3, Fig. 2)

Fregattvogel, Fregata S. 27 (Schwimmvögel).

b) Die äußeren Federn des Schwanzeș sind höchstens $6 \mathrm{~cm}$ länger als die mittleren, meist aber weniger lang; die erste Schwinge ist nie die längste.

aa) Die Beine sind bis zur Zehenwurzel oder bis zu den Krallen befiedert oder beborstet (N. Bd. V)

Raubvigel S. 14.

bb) Der untere Teil des Laufes ist stets nackt.

a) Vor den Nasenlöchern befindet sich ein Absatz quer über den Schnabel (Fig. 6), welcher den festen Endteil von dem weichhäutigen Basalteil (der Wachshaut) trennt (N. Bd. V) . . . Raubvögel S. 14.

B) Der Oberschnabel ist bis zur Federgrenze fest, es ist kein Absatz, keine Wachshaut vorhanden (Fig. 7 und 8). Man bestimme unter BB) weiter.

BB) Der Oberschnabel ist oft gebogen, ragt aber nicht hakenförmig über das Ende des Unterschnabels nach unten vor (vergl. Fig. 13 S. 3 und 34 S. 18).

a) Von vier Zehen sind zwei nach vorn, zwei nach hinten gerichtet (Fig. 9), selten von drei Zehen zwei nach vorn, eine nach hinten (N. Bd. IV, Tafel 29 bis 36 und Tafel $41-44$ ).

Klettervögel und Kuckucke S. 13.

b) Es ist nur eine oder gar keine Zehe nach hinten gerichtet, drei oder vier sind nach vorne gerichtet. aa) Von den drei nach vorn gerichteten, eng an-

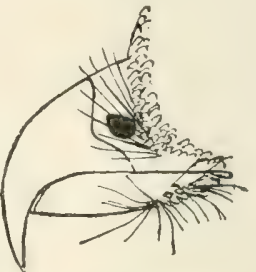

Fig. 6.

Schnabel rom Bussard.

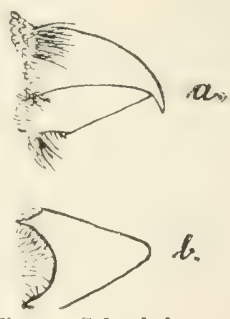

Fig. 7. Schnabel vom Fichtengimpel.

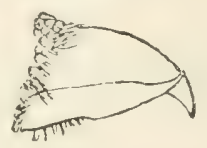

Fig. 8. Schnabel vom Kreuzschnabel.

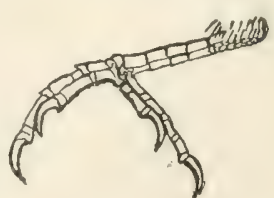
einander liegenden Zehen sind die Außen- und Fig.9. Fuß romWendehals. 
Mittelzehe bis zur Mitte fest und unbeweglich miteinander verwachsen, so daß das freie Endstück der Außenzehe nicht länger ist als die Kralle (Fig. 10); der feste Schnabel ist etwa doppelt so lang und, von der Seite gesehen, doppelt so dick wie der Lauf (N. Bd. IV, Tafel 37-39)

Eisvögel und Bienenfresser S. 13.

bb) Die äußerste Zehe ist vollkommen frei oder doch nur durch eine biegsame Haut an

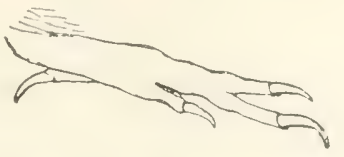

Fig: 10. Fuß vom Eisvogel. der Basis mit der Nittelzehe verbunden.

a) Die Beine sind vorne bis iber die Fersenbeuge aufwärts unbefiedert (Fig. 1 u. 2 S. 1) (N. Bd. VI, Tafel 20-31, Bd. VII, Bd. VII und Bd. IX, Tafel 1-7) . . . . . . . . . . Stelzvïgel S. 1\%.

$\beta)$ Die Beine sind wenigstens bis zur Fersenbeuge abwärts, oft bis zu den Zehen seltener bis zu den Krallen befiedert.

« die Haut ist hinten der Länge nach netzartig gefeldert bezw. quergetäfelt (Fig. 11).

* Der Schnabel ist sehr lang und dünn (Fig. 12), entweder gerade oder der Länge nach schwach gebogen.

$\dagger$ Die erste Schwungfeder des Flü-

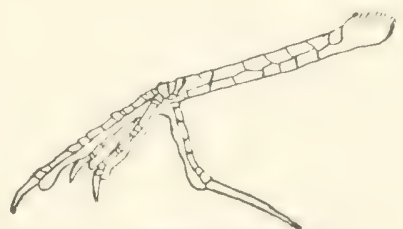

Fig. 11. Fub der Haubenlerche. gels ist die längste; der Oberschnabel ist, von der Seite gesehen, vor dem Ende nach unten verdickt (Fig. 12); der Kopf trägt keine Haube (N. Bd. IX, Tafel 17).

Waldschnepfe, Scolopax S. 23.

\section{(Stelzvögel).}

it Die erste Schwinge ist nur halb so lang wie die zweite und diese viel kürzer als die dritte; der Oberschnabel ist bis zum Ende allmählich verjüngt, der Kopf ist mit einer aufrichtbaren Haube versehen $(\mathrm{Bd} . \mathrm{IV}$, Tafel 41$)$

ILopfe S. 13.

** Der Schnabel ist weniger schlank, am Ende mehr oder weniger nach unten gebogen (Fig. 13).

+ Der Mundspalt reicht bis weit unter die Augen; der Hinterwinkel desselben ist von der Schnabelspitze mindestens doppelt so weit entfernt, als die unbefiederte mittlere Firste des Schnabels lang ist.

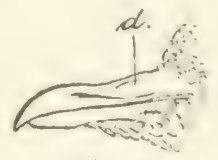

Fig. 13.

Schuabcl cincr Taube. d Nasenklappe. 
Die erste Schwinge ist deutlich länger als die zweite; der Hinterrücken des Körpers ist weiß (N. Bd. IV, Tafel 25, Fig. 1 u. 2)

Haussehwalbe, Chelidonaria S. 69 (Singvögel).

00 Die zweite Schwinge ist mindestens $3 \mathrm{~mm}$ länger als die erste; der Hinterriicken ist nicht weiß gefärbt.

$\sim$ Die größte Zehe ist mit Kralle um die Hälfte länger als die benachbarten Zehen (ebenfalls mit der Kralle gemessen); die Kralle der längsten Zehe ist am Innenrande beim erwachsenen Vogel kammartig eingeschnitten; die mittleren Schwanzfedern sind nicht kürzer als die seitlichen (N. Bd. IV, Tafel 28)

Nachtschwalben S. 13.

$\approx$ Die drei größten Zehen sind wenig an Größe verschieden; die Krallen sind einfach; die mittelsten Schwanzfedern sind mindestens $1 \mathrm{~cm}$ kürzer als die seitlichen (N. Bd. IV, Tafel 27)

Segler S. 13.

$\dagger$ Der Mundspalt reicht nicht bis weit unter die Augen und ist vom Mundwinkel bis zur Schnabelspitze gemessen, nicht doppelt so lang wie die nackte Schnabelfirste.

Die Schnabelfirste ist nur in der Endhälfte hornartig fest, im Basalteil weich, häutig (Fig. 13 S. 3), (N. Bd. VI, Tafel 1-4)

Tauben S. 17.

O० Die Schnabelfirste ist mitten auf der Firste bis zur Federgrenze hornartig fest.

$\sim$ Die vierte Zehe fehlt entweder gänzlich oder sie ist mit ihrer Kralle nicht oder kaum halb so lang wie die größte Zehe (ebenfalls mit der Kralle gemessen) und steht etwas höher als die drei vorderen Zehen (vergl. Fig. 1 u. 2 S. 1) (N. Bd. VI, Tafel 5-19a und Bd VI, Tafel 3 u. 4) . . . . . . . Hüihner S. 17.

$\approx$ Die vier Zehen entspringen alle auf gleicher Höhe und die nach hinten gerichtete ist über halb so lang wie die größte der nach vorn gerichteten Zehen.

\ Der Lauf ist hinten wie vorn mit einfachen Quernähten versehen (quergetäfelt) (Fig. 11 S. 3) (N. Bd. IП, Tafel 1-5)

Lerchen S. 51 (Singvögel).

(1) Der Lauf ist hinten entweder gefiedert oder netzartig gefeldert (vergl. Fig. 1 und 2 S. 1).

$\odot$ Die erste Schwinge ist wenig kürzer als die zweite; die zweite ist die längste; das Gefieder ist z. T. blau; drei Zehen sind dauernd nach vorn gerichtet (N. Bd. IV, Tafel 40)

Racken S. 13. 
$\odot \odot$ Das Ende der ersten Schwinge ist mindestens $5 \mathrm{~cm}$ von der Flïgelspitze entfernt; die dritte Schwinge ist die längste; das Gefieder enthält kein Blau. Hier könnte man die Kuckucke (N. Bd. IV, Taf. 42-44) suchen, da die äußerste Zehe eine Wendezehe ist.

S. 13.

$\beta \beta)$ Der Lauf ist ganz oder fast ganz ungefiedert und höchstens vorn quergefeldert oder getäfelt, hinten immer der Länge nach mit ungefelderter, hornartiger Haut bekleidet (Fig. 14) (N Bd. 1-IV, Tafel 26) .

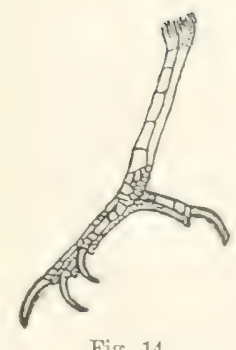

Fig. 14. Fuß vom Sperling. Singrögel S. 5.

\section{Die Gattungen der Singvögel.}

I. Der Lauf ist hinten wie vorn quergetäfelt (Fig. 11 S.3) (N. Bd. III, Tafel 1-5)

Lerchen, Otocorys, Melanocorypha, Calandrella, Lullula, Galerida und Chersophitus

II. Der Lauf ist hinten nicht getäfelt und nicht durch Quernähte geteilt (Fig. 14)

A) Die erste Schwinge reicht ganz oder fast bis zur Flügelspitze, sie ist jedenfalls nicht um die Länge der Mittelzehe (ohne Kralle) von der zweiten verschieden (nur bei noch nicht ausgewachsenen Jungen oder in der Mauser kann die erste Schwinge bedeutend kleiner sein; dann steckt die Schwinge am Grunde aber in einer häutigen Scheide und die Dicke dieser Scheide läßt annähernd auf die künftige Länge der Schwinge 'schließen).

AA) Der Schnabel ist kurz und flach, am Vorderende der Nasenlöcher etwa doppelt so breit wie hoch (N. Bd. IV, Tafel 23-26) Schwalben, Hirundo, Chelidonaria, Biblis und Clivicola S. 69.

BB) Der Schnabel ist nicht von oben flachgedrickt, am Vorderrande der Nasenlöcher höher oder doch etwa so hoch wie breit.

a) Die breiten Schulterschwingen (Fig. 15s) r'eichen mindestens bis zum Ende der füntten Schwinge, oft bis zum Ende der Flügel (Fig. 15h); der Schnabel ist lang und dünn (Fig. 16).

aa) Die Schwanzfedern sind, von der Wurzel (die man durch die unteren und oberen Deckfedern hindurch fühlt) bis zum Ende gemessen, mindestens etwa $2 \mathrm{~cm}$ kürzer als die Länge der anliegenden Flügel (Fig. 15 $l^{\prime} l^{\prime \prime}$ ); die Brustfedern sind $z$. 'T'. auf der Mitte mit dunklem Längsfleck (Schaftfleck) versehen (N. Bd. III, Tafel 6-8) . . . Pieper, Anthus S. 53.

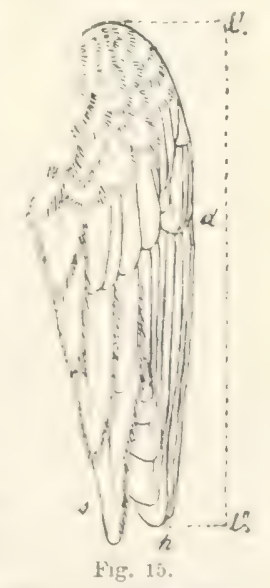

Flügel der Schafstelze. d Deckfedern, $s$ verlängerte schulterschwinsen. $l^{\prime} l^{\prime \prime}$ Länge. 
bb) Die Schwanzfedern sind von der Wurzel bis zum Ende gemessen nicht $1 \frac{1}{2} \mathrm{~cm}$ kürzer als der anliegende Flügel; die Brustfedern sind entweder weiß oder schwarz oder gelb, niemals mit dunklem Schaftfleck gezeichnet (N. Bd. II, Tafel 9 bis 16) . . Stelzen, Motacilla und Budytes S. 55.

b) Die Schulterschwingen sind kurz, sie reichen nicht bis zum Ende der 10. Schwinge.

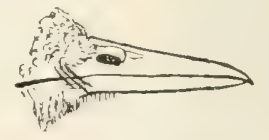

Fig: 1 .

aa) Der Schnabel ist dünn (vergl. Fig. 16); der an- Schnabel der Schafstelze. liegende Flügel ist $6-6^{1} / 2 \mathrm{~cm}$ lang (vergl. Fig. $15 l^{\prime} l^{\prime \prime}$ )

(N. Bd. III, Tafel 16, Fig. 5)

Waldsänger, Dendroeca S. 57.

bb) Der Schnabel ist sehr kräftig, (Fig. 7, 8, 17 u. 19); der anliegende Flügel ist mindestens $7 \mathrm{~cm}$ lang.

a) Die Schwanzfedern sind mehr oder weniger zugespitzt (N. Bd. IV, Tafel 1, Fig. 1 u. 2)

Reisvogel, Dolichonyx S. 65.

B) Die Schwanzfedern sind nicht zugespitzt, sondern am Ende gerundet.

$\alpha \alpha)$ Die 5. bis 7. Schwinge ist am Ende eigentümlieh geformt (Fig. 18); der Schnabel ist sehr kräftig, $15 \mathrm{~mm}$ hoch (N. Bd. III, Tafel 33) Kerubeißer, Coccothraustes S. 65.

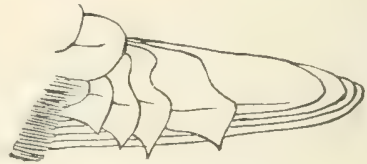

Fig. 18.

Flügelende vom Kernbeißer.

$\beta \beta)$ Die 5. bis 7. Schwinge ist am Ende gerundet oder gestutzt.

* Die Schnabelfirste ist der Länge nach stark gebogen (Fig. 19, 20, 7 u. 8 S. 2).

$\uparrow$ Die befiederte Kehlgrube ist hinten breiter als die Entfernung ihres Vorderrandes von der Spitze des Unterschnabels (Fig. 20b); der Hinterrücken ist rein weiß (N. Bd. III, Tafel 32)

Gimpel, Pyrrhula S. 65.

$\uparrow$ Die befiederte Kehlgrube ist nicht so breit wie die Entfernung ihres Endrandes von der Spitze des Unterschnabels (Fig. 76 S. 2).

$X$ Der Unterrand des Oberschnabels ist von der Seite gesehen, stark gekrümmt und die Spitze greift weit über den Oberrand des Unterschnabels nach unten über (Fig. 7 u. 8 S. 2).

$\bigcirc$ Die Spitze des Unterschnabels wird durch den Oberschnabely von oben überdacht (Fig. 7) (N. Bd. III, Tafel 30)

Fichtengimpel, Pinicola S. 64.

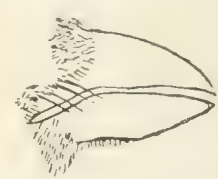

Fig. 19. Schnabel der Gimpelammer.
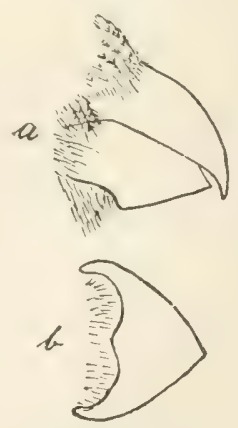

Fig. 20. Schnabel vom Dompfaff.

a von der Seite 
$\bigcirc$ Die Spitzen des Ober- und Unterschnabels kreuzen sich (Fig. 8) (N. Bd. III, Tafel 27-29)

Kreuzselmaibel, Loxia S. 63.

$\times \times$ Der Unterrand des Oberschnabels ist kaum gebogen (Fig. 19 S. 6) (N. Bd. II, Tafel 31, 34 und 26)

Girlitz, Karmingimpel usw.,

Serinus, Carpodacus und Erythrospiza S. 64.

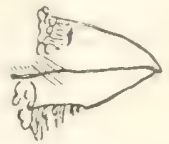

** Die Schnabelfirste ist höchstens vor dem Ende Fig.21. Schnabel etwas stärker gebogen (Fig. 21) (N. Bd. III, Tafel 17 rom Sperling. bis 25 und Tafel $35-43$ )

Ammern, Finken und Sperlinge, Calcarius, Plectrophenax, Miliaria, Emberiza, Chrysomitris, Carduelis, Acanthis, Fringilla, Chloris, Passer und Molothrus S. 57.

B) Die erste Schwinge ist wenigstens um die Länge der Mittelzehe (ohne Kralle) kürzer als die zweite Schwinge (Fig. $22 I$ u. II); oft ist sie äußerst klein; sie liegt dann aber stets unter dem Schaft der ersten größeren Schwinge und unterscheidet sich durch die schlankere, oft spitzere Form und die geringere Biegsamkeit von den unteren Flügeldeckfedern.

AA) Der Lauf ist vorn (von der Innenseite gesehen) der Länge nach quergetäfelt (Fig. 14 S. 5).

a) Der anliegende Flügel (vgl. Fig. $15 l^{\prime} l^{\prime \prime}$ ) ist mindestens etwa $15 \mathrm{~cm}$ lang.

aa) Das Gefieder ist mehr oder weniger gelb gefärbt; wenigstens die unteren Schwanzdeckfedern und die Enden der Schwanzfedern selbst sind schön gelb; hinter dem Nasenloch befinden sich keine nach vorn gerichteten Fieder-

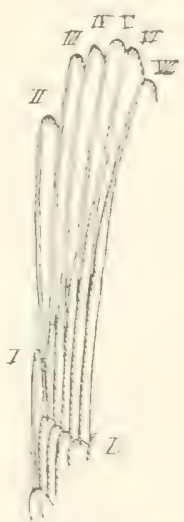

Fig. 22. Der rordere Flẗ̈gel. teil der Blaumeise, $I, I I, I I I$ usw. erste. zweite, dritte usw. Schwinge, $D$ Flügeldeckfedern. borsten (N. Bd. IV, Tafel 5) . Pirol, Oriolus S. 66. bb) Das Gefieder enthält kein Gelb; hinter dem Nasenloche befinden sich nach vorn gerichtete steife Fiederborsten (Fig. $23 a$ ), die nur bei der alten Saatkrähe abfallen (Fig. 23b).

a) Die beiden mittleren Schwanzfedern sind mindestens $22 \mathrm{~cm}$ lang und $9 \mathrm{~cm}$ länger als die äußerste Schwanzfeder: das Gefieder ist schwarz und weiß gefärbt $(N$. Bd. IV, Tafel 10, Fig. 1) Elster, Pica S.67. ק) Die beiden mittleren Schwanzfedern sind höchstens $6 \mathrm{~cm}$ länger als die äußerste: das Gefieder ist nicht schwarz und weiß.
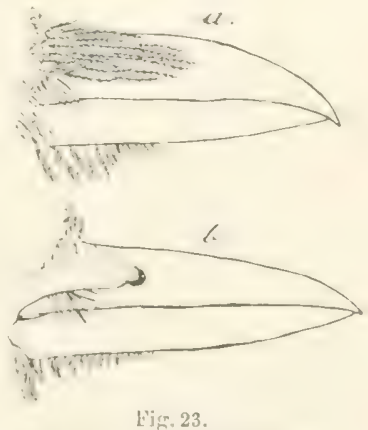

Schnabel a der Rabenkrihe b) der siatkrïhe. 
a oder violettem Schimmer versehen; die dritte Schwinge ist bedeutend länger als die sechste (N.Bd.IV, Tafel 6 und Tafel 10, Fig. 2 bis Tafel 14)

Dohlen und Kriilen, Pyrhocorax, Lycus und Corvus S. 66.

$\beta \beta)$ Die Stirn und die seitlichen Schwanzfedern sind nicht kohlschwarz; die dritte Schwinge ist etwas kürzer als die sechste.

* Die äußerste Schwanzfeder ist am Ende breit weiß gerandet (meist auch die andern Schwanzfedern); die nackte Schnabelfirste ist mindestens $40 \mathrm{~mm}$ lang (N. Bd. IV, Tafel 7)

Tammenhaiher, Nucifraga S. 67.

** Die äußerste Schwanzfeder ist am Ende nicht rein weiß gerandet; die nackte Schnabelfirste ist höchstens $25 \mathrm{~mm}$ lang.

$\doteqdot$ Die Schwanzfedern sind, mit Ausnahme der beiden mittelsten, rostrot; der anliegende Fligel ist 14-15 cm lang; er zeigt keine blauen Teile (N. Bd. IV, Tafel 8)

Unglückshäher, Perisoreus S. 67.

$\doteqdot$ Nur die äußersten Schwanzfedern sind etwas bräunlich, die andern schwarz; der anliegende Flügel ist etwa $18 \mathrm{~cm}$ lang; auf seiner Oberseite befinden sich schön blau und weiß gebänderte Federn (N. Bd. IV, Tafel 9) . . . . . Eichelhäher, Garrulus S. 67.

b) Der anliegende Flügel ist nicht $15 \mathrm{~cm}$ lang.

aa) Die erste Schwinge ist nicht sehr klein, ihre Spitze ist nicht oder kaum viermal soweit von der Spitze der zweiten Schwinge wie vom Ende der den ersten Schwingen aufliegenden oberen Flügeldeckfedern entfernt (Fig. 22 S. 7).

a) Die beiden mittelsten Schwanzfedern sind fast doppelt so lang wie die äußerste Schwanzfeder; der Schnabel ist sehr kurz und dick (N. Bd. II, Tafel 18, Fig. 2-6) . Schwanzmeise, Aegithalus S. 48. ß) Die beiden mittelsten Schwanzfedern sind nicht um die Hälfte länger als die äußerste Schwanzfeder.

r $\iota$ ) Der anliegende Flügel, meist auch der Schwanz, ist über $8 \mathrm{~cm}$ lang.

* Der anliegende Flůgel ist über $13 \mathrm{~cm}$ lang; der Unterrand des Oberschnabels ist fast gerade (N. Bd. IV, Tafel 8)

Unglückshäher, Perisoreus S. 67.

** Der anliegende Flügel ist höchstens $12 \mathrm{~cm}$ lang; der Unterrand des Oberschnabels ist, von der Seite gesehen, am Ende ziemlich stark gebogen (Fig. 24).

$\uparrow$ Der Schnabel ist sehr kräftig; der Oberschnabel vor dem Ende meist mit einem deutlichen Zahn versehen (Fig. 24) (N. Bd. IV, Tafel 15-18)

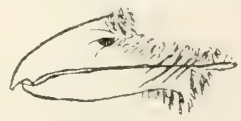

Fig. 24. Schnabel vom Wuirger. 
$\doteqdot$ Der Schnabel ist lang und dünn, schwach gebogen; der Oberschnabel hat keinen Zahn (N. Bd. I, Tafel 30, Fig. 2)

Spottdrossel, Harporhynchus S. 40.

$\beta \beta)$ Der anliegende Flügel ist nicht $8 \mathrm{~cm}$, der Schwanz nicht $7 \mathrm{~cm}$ lang.

* Die Kehle ist dunkler als der Halsteil hinter dem Auge, selten ist sie, wie dieser, weißlich oder gelblich; dann ist der Schnabel kräftig (vergl. Fig. 17 S. (i) (N. Bd. II, Tafel 1s, Fig. 1, 2, 7 und $\triangleleft$ und Tafel 19-22) . . . . . . . . . Meisen, Parus S. 48.

* Die Kehle ist weißlichgrau oder bräunlich und nicht dunkler als der Halsteil hinter dem Auge; der Schnabel ist dünn (vergl. Fig. 16 S. 6). $\div$ Zwischen dem Nasenloch und dem Mundwinkel stehen stets einige starre Borsten, d. h. einige Federchen, deren Mittelstrahl mindestens doppelt so lang und dick ist wie die Nebenstrahlen (vergl. Fig. 24). C Die beiden äußersten Schwanzfedern sind am Ende breit weiß gerandet und davor mit großem schwarzen Fleck versehen (N. Bd. II, Tafel 11 a, Fig. 3) . . . . Cistensänger, Cisticola S. 48.

O Die Schwanzfedern sind alle grau, kaum lichter gerandet.

๑ Der Schwanz besteht aus 10 Federn (N. Bd. II, Tafel 1, Fig. 3) Cettirohrsänger, Cettia S. 40.

$\odot(\cdot)$ Der Schwanz besteht aus 12 Federn.

5 Die äußerste Schwanzfeder ist nicht oder kaum kürzer als die beiden mittelsten (N. Bd. II, Tafel 5, Fig. 3 und Tafel 6, Fig. 3) vergl. die Laubvögel, Phylloscopus rufus und trochitus S. 43.

SS Die äußerste Schwanzfeder ist mindestens $3 \mathrm{~mm}$ kürzer als die beiden mittelsten (N. Bd. II, Tafel 1 a, Fig. 1 und 2).

Lusciniola S. 4 ).

$\div$ Zwischen dem Nasenloch und dem Mundwinkel stehen keine starren Borsten (vergl. Fig. 27 S. 11).

O Die Schwanzfedern sind am Ende gerundet und dicht hell und dunkel quergewellt (N. Bd. II, Tafel 13) . . Zaunkönig, Anorthura S. 47.

OD Die Schwanzfedern sind am Ende zugespitzt und einfarbig grau (N. Bd. II, Tafel 25)

Baumliufer, Certhia S. 51.

bb) Die erste Schwinge ist sehr klein, ihre Spitze ist wenigstens fünmal soweit von der Spitze der zweiten Schwinge wie von dem Ende der oberen Flügeldeckfedern entfernt (Fig. 25); oft ist die erste Schwinge sogar kürzer als die oberen Flügeldeckfedern.

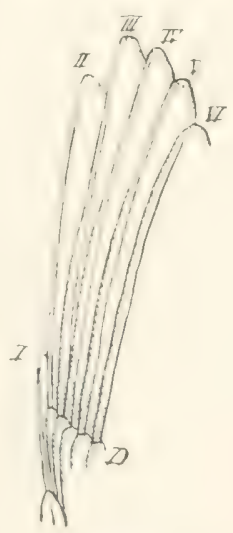

Fig. 25.

Der vorilero Flïgelteil

des Fitislaubrogels,

$I, I I, I I I$ usw. erste, zweite, dritte usw. Schwinge, $D$ Fliggelileckiedern. 
( ) Die 11.-18. Schwinge oder doch einzelne dieser Schwingen sind am Ende mit einer schön roten Platte versehen (Fig. 26); das Ende der Schwanzfedern ist schön gelb (N. Bd. IV, 'Taf. 22)

Seidenseliwanz, Ampelis S. 69.

$\beta$ ) Die Schwingen sind nicht mit einer roten Endplatte versehen: die Schwanzfedern sind am Ende nicht schön gelb.

r(x) Zwischen dem Nasenloch und dem hinteren Mundwinkel stehen am Oberschnabelrande einige starre, schräg nach unten vorragende Borsten; es sind das Federchen, deren Hittelstrahl wenigstens $2 \mathrm{~mm}$ über die Seiten- oder Fieder-

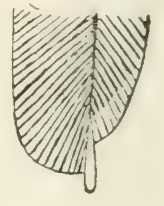

Fig. 26. Ende d. 12. Schwinge rom Seidenschwanz. strahlen vorragt und viel dicker ist als die Seitenstrablen (vergl. Fig. 16 S. 6 und Fig. 24 S. 8).

- * Die mittleren Schwanzfedern sind über $2 \mathrm{~cm}$ länger als die seitlichen, rostrot; die nackte Schnabelfirste ist $9 \mathrm{~mm}$ lang (N. Bd. II, Tafel 16) . . . . . . . Bartmeise, Panurus S. 48. * Die mittleren Schwanzfedern sind nicht $1 \frac{1}{2} \mathrm{~cm}$ länger als die seitlichen.

$\doteqdot$ Die Hinterzehe reicht, an den Lauf angelegt, mit der Spitze der Kralle weit über den nackten Teil des Laufes hinaus; das Gefieder ist bleigrau, unter dem Schwanze mehr oder weniger roströtlich (N. Bd. II, Tafel 11 a, Fig. 4 und Tafel 23)

Spechtmeisen, Sitta S. 50.

$\rightarrow$ Die Hinterkralle reicht, wenn man sie an den Lauf angelegt denkt, nicht bis ans Ende des unbefiederten Teils auf der Vorderseite desselben.

$\times$ Der Schnabel ist kräftig und die Firste stark gebogen (Fig. 24 S. 8) (N. Bd. IV, Tafel 17, Fig. 1 und 2)

vergl. den grauen Wïrger, Lanius minor S. 67.

$\times \times$ Der Schnabel ist dünn, die Firste wenig gebogen (vergl. Fig. 16).

Einige Federn auf den Flügeln sind am Rande weißlich gefleckt; am Schaft sind sie immer bis zum Ende dunkel (N. Bd. I, Tafel 8 und 9$)$.

Braumelle, Accentor S. 34.

$\bigcirc \bigcirc$ Die Federn auf den Flügeln sind am Ende oft weißlich oder gelblich gerandet, aber nicht gefleckt.

- Die Außenfahne der vierten Schwinge ist $1 \mathrm{~cm}$ vor dem Ende der Feder nicht breiter als die der zweiten Schwinge an der breitesten Stelle (Fig. 25 S. 9).

5 Die äußerste Schwanzfeder ist rotbraun, am Ende weiß, vor dem weißen Ende schwarz gefleckt (N. Bd. II, Tafel 12)

Heckensänger, Agrobates S. 47.

SS Die äußerste Schwanzfeder ist nicht dreifarbig. 
$\sim$ Die Federchen an der (dem Körper bei Ruhelage des Flügels anliegenden) Unterseite der Flügel nahe der vorderen Beuge sind schrvefelgelb gefärbt (N. Bd. II, Tafel 4-7)

Laubvögel, Hypolais und Phylloscopus S. 42.

$\approx$ Die unteren Flïgeldeckfederchen sind nicht gelb (N. Bd. II, Tafel 8-11a, Fig. 1 und 2). Grasmiicken, Sylvia S. 44.

$\odot \odot$ Die Außenfahne der vierten Schwinge ist $1 \mathrm{~cm}$ vom Ende der Feder entfernt, doppelt so breit wie die der zweiten Schwinge an der breitesten Stelle (N. Bd. II, Tafel 1, Fig. 1, Tafel 2-3)

Rohrsainger, Calamodus und Acrocephalus S. 41.

$\beta \beta)$ Am Oberschnabelrande stehen vor dem Mundwinkel keine starren Borsten, d. h. der Mittelstrahl der Federchen ist nicht doppelt so lang wie die Seitenstrahlen und ragt nicht $2 \mathrm{~mm}$ über diese vor.

* Der anliegende Flügel ist höchstens $10 \mathrm{~cm}$ lang; die nackte Schnabelfirste ist 8-12 mm lang; das Gefieder ist grau oder bräunlich.

$\div$ Die mittelsten Schwanzfedern sind die kürzesten; die Außenfahne der fünften Schwinge ist $1 \mathrm{~cm}$ vor dem Ende der Feder nicht breiter als die der zweiten an der breitesten Stelle (vergl. Fig. 25 S. 9); die nackte Schnabelfirste ist $8-9 \mathrm{~mm}$, der anliegende Flügel nicht $6 \mathrm{~cm}$ lang (N. Bd. II, Tafel 17)

Beutelmeise, Remizus S. 48.

$\uparrow$ Die mittleren Schwanzfedern sind die längsten; die Außenfahne der fünften Schwinge ist $1 \mathrm{~cm}$ vor dem Ende der Feder fast doppelt so breit wie die schmale Außenfahne des zweiten Schwinge an der breitesten Stelle; die nackte Schnabelfirste ist $10-12 \mathrm{~mm}$, der anliegende Flügel über $6 \mathrm{~cm}$ lang (N. Bd. II, Tafel 1, Fig. 2 und

Tafel 1 a, Fig. 3-7) . . Heuschreckensiinger, Locustella S. 40.

** Der anliegende Flügel ist über $12 \mathrm{~cm}$ lang, die nackte Schnabelfirste über $15 \mathrm{~mm}$; das Gefieder des ausgefärbten Vogels ist schwarz und weißlich.

$\doteqdot$ Der Schnabel ist wenig gebogen (Fig. 27); über dem Nasenloch sind nur an der Wurzel Federchen vorhanden; das Loch ist nur zur Hälfte mit einer Schuppe geschlossen; der ausgefärbte Vogel hat schwarze, z. T. weiß gerandete Federn (N. Bd. IV, Tafel 2 und 3)

Stare, Sturnus S. 65.

$\because$ Der Schnabel ist stïrker gebogen; in einem Spalte über dem Nasenloch stehen bis vorn hin

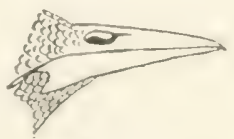

Fig. 27. Schnabel rom Star. feine Federchen; das Nasenloch ist nur mit einem schmalen Rande versehen; das Gefieder des ausgefürbten Vogels ist teilweise weiß, rosig angehaucht (N. Bd. IV, Tafel 4) . Rosenstar. Pastor S. 65. 
BB) Der Lauf ist (von innen gesehen) an der Vorderseite nur im unteren Teil getäfelt (Fig. 28), im oberen ist höchstens eine schwache Erhöhung vorhanden, die an der Außenseite des Laufes sehr stark nach der Beinwurzel zu verläuft. a) Über das Nasenloch ragt eine einzelne Feder nach vorn vor (Fig. 29): der Kopf ist beim ausgefärbten Vogel oben mit einer gelben Längsbinde versehen (N. Bd. II, Tafel 15) . Goldhähnchen, Regulus S. 48.

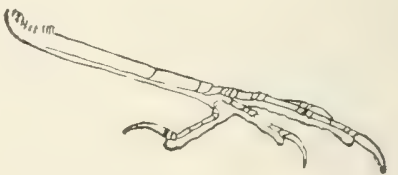

Fig. 28. Fuß des Steinschmätzers.

b) Das Nasenloch ist entweder frei oder von Borsten überragt: der Kopf zeigt oben keine gelbe Längsbinde.

aa) Der anliegende Flügel ist über $25 \mathrm{~cm}$ lang; die Nasenlöcher sind von dichten Borsten überdeckt (N. Bd. IV, Tafel 6) . . . . Alpenkrïhen, Pyrrhocorax S. 66. Goldhähnchen bb) Der anliegende Fluigel ist nicht $20 \mathrm{~cm}$ lang.

a) Zwischen dem Nasenloche und dem Hinterwinkel des Mundspaltes stehen am Rande des Oberschnabels keine Borsten (vergl. Fig. 27). $r \alpha)$ Die nackte Schnabelfirste ist nicht $2 \mathrm{~cm}$ lang; das Gefieder des Flïgels zeigt keine rote Farbe (N. Bd. II, Tafel 14)

Wasseramsel, Cinclus S. 47.

$\beta \beta)$ Die nackte Schnabelfirste ist über $2 \mathrm{~cm}$ lang; der Flügel ist $\mathrm{z} . \mathrm{T}$. mit schön roten Federn versehen (N. Bd. II, Tafel 24)

Mauerlïufer, Tichodroma S. 51.

ß) Zwischen dem Nasenloch und dem hinteren Mundwinkel stehen am Rande des Oberschnabels feine Borsten, die freilich oft ohne Lupe kaum erkennbar, aber doch über doppelt so lang sind wie die meist von ihrer Wurzel entspringenden Seitenstrahlen (vergl. Fig. 29).

$\alpha(x)$ Der Hinterriicken bezw. der Bürzel zeigt rein weiße Federn (N. Bd. I, Tafel 10 und 11) . . . Steinschmäitzer, Saxicola S. 34.

$\beta \beta)$ Der Bürzel ist nicht rein weiß.

* Der anliegende Flügel ist nicht $9 \mathrm{~cm}$, die nackte Schnabelfirste höchstens $12 \mathrm{~mm}$ lang (N. Bd. I, Tafel 1-6 und Bd. IV, Tafel 19-21) Siinger, Rothsehwïnze, Wiesenschmäitzer und Fliegenfïinger, Erithacus, Ruticilla, Pratincola, Nemura und Muscicapa S. 31.

* Der anliegende Flügel ist uiber $9 \mathrm{~cm}$, die nackte Schnabelfirste meist über $12 \mathrm{~cm}$ lang.

† Die unteren (bauchständigen) Schwanzdeckfedern sind schön goldgelb gefärbt . . . . . . . . . Pycnonotus xanthopygus.

† Unter dem Schwanze sind keine goldgelben, oft aber braunrote Federn vorhanden (N. Bd. I, Tafel 13-30, Fig. 1)

Drosseln, Monticola, Geocichla, Turdus und Mimus S. 36. 


\section{Die Gattungen der Segler.}

(N. Bd. IV, Tafel 27.)

Apus und Chaetura S. 70.

\section{Die Gattung der Nachtschwalben.}

(N. Bd. IV, Tafel 28.)

Caprimulgus S. 70 .

\section{Die Gattungen der Klettervögel und der Kuckucke.}

I. Die Schwanzfedern sind am Ende mehr oder weniger zugespitzt und hart strahlig (Fig. 30b); über die Nasenlöcher ragen dichte Borsten nach vorn vor (Fig. 30a) (N. Bd. IV, Tafel 29-35)

Spechte, Picus, Dendrocopus, Picoides und Dryocopus S. 71. II. Die Schwanzfedern sind am Ende gerundet, nicht hartstrahlig; über die Nasenlöcher ragen keine Borsten vor.

A. Der anliegende Flügel ist $9 \mathrm{~cm}$ lang; die nackte Schnabelfirste ist gerade, nicht $14 \mathrm{~mm}$ lang; die erste Schwinge ist sehr kurz, sie reicht nicht uiber das Ende der Federn, welche den ersten Schwingen

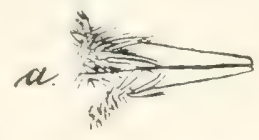
aufliegen, hinaus (N. Bd. IV, Tafel 36).

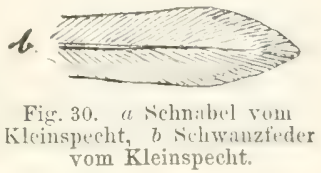
die nackte Schnabelfirste ist stark gebogen, über $17 \mathrm{~mm}$ lang; die erste Schwinge ragt $3-7 \mathrm{~cm}$ über die oberen Flügeldeckfedern hinaus (vergl. Fig. 25 S. 9) (N. Bd. IV, Tafel $42-44$ )

Kuckucke, Cuculus, Coceystes und Coccyzus S. 73.

\section{Die Gattungen der Eisvögel und Bienenfresser.}

I. Der anliegende Flügel ist 6-12 cm lang; die Schnabelfirste ist fast gerade; die Unterseite des Körpers ist nie blaugrün, die Kehle weiß bis gelbbräunlichweiß (N. Bd. IV, Tafel 38-39)

Eisvögel, Alcedo, Halcyon und Ceryle S. 73.

II. Der anliegende Flügel ist über $14 \mathrm{~cm}$ lang; die nackte Schnabelfirste ist gebogen; die Unterseite des Körpers ist blaugrün, die Kehle z. T, schön gelb (N. Bd. IV, Tafel 37) . . . . . Bienenfresser, Merops S. 72.

\section{Die Gattung der Racken.}

(N. Bd. IV, Tafel 40.)

Blauracke, Coracias S. 73.

\section{Die Gattung der Hopfe.}

(N. Bd. IV, Tafel 41.)

Wiedehopf, Uprua S. 73. 


\section{Die Gattungen der Raubvögel.}

I. Am Kinn befinden sich $2-6 \mathrm{~cm}$ lange herabhängende schwarze Haarborsten; ebenso ragt über die Nasenlöcher ein dichter schmaler Büschel langer schwarzer Borsten nach vorn und unten vor; der anliegende Flügel ist 77-91 cm lang (N. Bd. V, Tafel 60 u. 61) Bartgeier, Gypaëtus S. 81.

II. Am Kinn sind keine langen schwarzen Barthaare vorhanden; die Nasenlöcher sind entweder sichtbar oder die über dieselben vorragenden Borsten bilden einen Strahlenkranz um das Auge.

A) Die Beine sind wenigstens bis zur Zehenwurzel, oft bis zu den Krallen befiedert oder beborstet.

AA) Auch die Zehen sind größtenteils befiedert oder beborstet.

a) Die Außenfahne aller Schwingen verschmälert sich gegen das Ende der Feder ganz allmählich; die Brustfedern sind gelblich bis weiß, an den Seiten fast alle mit einem bis $2 \mathrm{~mm}$ breiten dunklen Fleck versehen (N. Bd. V, Tafel 1) . . . - . . Schleiereule, Strix S. 74.

b) Die Außenfahne der 2. oder 3. Schwinge ist in der Mitte oder wurzelwärts von der Nitte oder vor dem distalen Ende der Feder plötzlich verengt (Fig. 31 u. 32v): die Brustfedern sind mit Längs- oder Querbändern versehen.

aa) Die Verengung der Außenfahne der 2. Schwinge ist dem Ende des Flügels immer näher, oft doppelt so nahe wie dem Ende der den ersten Schwingen aufliegenden Deckfedern (Fig. 31v); die Außenfahne ist jenseits (distal) der Flügeldeckfedern immer breit hell ockerbraun gerandet (N. Bd. V, Tafel 9)

Ohreulen, Asio S. 75.

bb) Die Verengung der Außenfahne der 2. Schwinge ist entweder dem Flügelende und dem Ende der oberen Fliigeldeckfedern gleich nahe (Fig. $32 v$ ) oder sie ist dem Ende der Flügedeckfedern näher; mitunter befindet sie sich auch ganz an der Wurzel der Feder.

( ) Der Kopf ist jederseits mit einem $5-7 \mathrm{~cm}$ langen, vorstehenden Ohrbüschel versehen; der "anliegende Fluigel ist $44-48 \mathrm{~cm}$ lang; an den Seiten des Körpers hängen über die Beine breite Federn herab, die

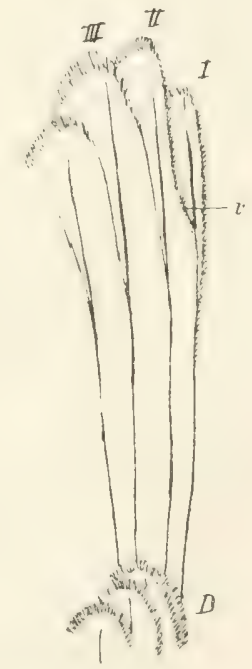

Fig. 31.

Flügelvorderrand der Sumpfolireule, $I, I I, I I I$ erste, zweite und dritte Schwinge, $v$ Verengung der AuBenfahne, $D$ Flügeldeckfedern.

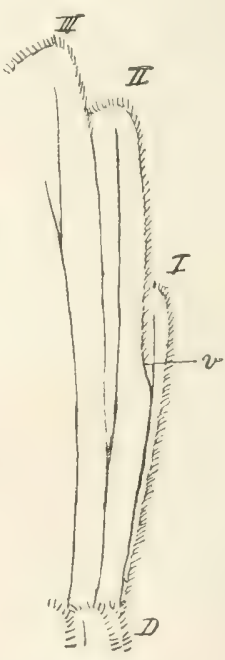

Fig. 32.

Flügelvorderrand vom Rauhfußkauz, vergl. Fig. 31 . 
mit etwa 10 feinen dunklen Querwellen von höchstens $2 \mathrm{~mm}$ Breite, nicht aber mit einem dunklen Längsstreif versehen sind (N. Bd. V, Tafel 10) . . . . . . . . . Thu, Bubo S. 75.

3) Der Kopf trägt lieine Ohrfederbiischel: die an den Seiten des Körpers über die Beine herabhängenden Federn sind entweder alle mit einem breiten dunklen Schaftstreif oder mit höchstens 7 dunklen Querbändern versehen, die dann aber mindestens $3 \mathrm{~mm}$ breit sind; der anliegende Flügel ist meist kürzer.

a ) Die Verengung der Außenfahne der dritten Schwinge ist kaum wahrnehmbar (Fig. $32 I I I$ ) und nur etwa $3 \mathrm{~cm}$ vom Ende der Schwinge entfernt; auf der 4. Schwinge ist keine Spur einer Verengung mehr vorhanden; vor dem Auge befindet sich ein schwarzer Fleck (N. Bd. V, Tafel 2, Fig. 2) . . . . . . Raulfußkauz, Nyctala, S. 75.

p̧) Die Verengung auf der Aubenfahne der 3. Schwinge ist sehr deutlich ausgebildet; auch auf der 4. Schwinge ist noch eine deutliche Ausschweifung vorhanden; vor dem Auge sind höchstens einige schwarze, den hellen Grund nicht deckende Federborsten vorhanden (N. Bd. V, Tafel 2, Fig. 1, Tafel 3, Fig. 3 und Tafel 4-8)

Kauze, Glaucidium, Surnia, Nyctea und Syrnium S. 74.

BB) Die Zehen sind vollkommen unbefiedert und unbeborstet.

a) Der anliegende Flügel ist $14-16 \mathrm{~cm}$ lang; die längste Fußkralle ist, über den Bogen gemessen, höchstens $9 \mathrm{~mm}$ lang; der Kopf ist eulenartig und mit vorstehenden Ohrfederbüscheln versehen (N. Bd.V, Tafel 3, Fig. 1)

Zwergohreule, Pisorhina S. 75.

b) Der anliegende Fliigel ist mindestens $40 \mathrm{~cm}$ lang; die größte Fußliralle ist, über den Bogen gemessen, mindestens $2 \mathrm{~cm}$ lang; der Kopf ist nicht eulenartig und nicht mit vorstehenden Ohrfederbiischeln versehen ( N. Bd. V, Tafel $38-50$ )

Adler und Rauhfufbussard, Aquila, Nisaëtus und Archibuteo S. 79.

B) Der Lauf ist wenigstens in dem unteren Viertel seiner Lïnge unbefiedert und unbeborstet.

AA) Die Seiten des Kopfes und des Oberhalses (oft auch der ganze Hals) sind nackt oder mit feinen Dunen bekleidet.

a) Der anliegende Fligel ist $48-52 \mathrm{~cm}$ lang; das Nasenloch ist in der Längsrichtung des Schnabels gestreckt (N. Bd. I, Tafel 62)

A asgeier, Neophron S. 81.

b) Der anliegende Flïgel ist 66-80 cm lang; das Nasenloch ist entweder kreisrund oder fast senkrecht zur Längsrichtung des Schnabels gestreckt. aa) Der anliegende Flügel ist $66-71 \mathrm{~cm}$ lang; das Nasenloch ist lang oval, fast senkrecht zur Längsrichtung des Schnabels gestellt; das Gefieder ist gelbbraun bis grau (N. Bd. V, Tafel 63 und 64)

Giiusegeier, Gyps, S. 81. 
bb) Der anliegende Flügel ist $78-80 \mathrm{~cm}$ lang; die Nasenlöcher sind fast kreisrund; das Gefieder ist schwarzbraun (N. Bd. V, Tafel 67)

Kuttengeier, Vultur, S. 82.

BB) Der Hals ist, wie der übrige Körper, ganz mit Federn bekleidet.

a) Der Oberschnabel ist vor der Spitze am Unterrande mit einem Zahn versehen (Fig. 33) (N. Bd. I, Tafel 11-22)

Falken, Falco S. 75.

b) Der Oberschnabel ist nicht mit einem Zahn versehen (Fig. 6 S. 2).

aa) Die nackte Schnabelfirste ist, über den Bogen gemessen, über $70 \mathrm{~mm}$, der anliegende Flügel mindestens $60 \mathrm{~cm}$ lang; der Schwanz ist beim alten Vogel ganz

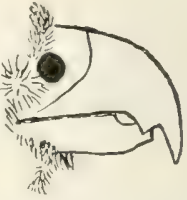

Fig. 33. Schnabel vom IVanderfalk. weiß (N. Bd. V, Tafel 28-31) . . . . Seealler, Haliaëtus, S. 78.

bb) Die nackte Schnabelfirste ist, über den Bogen bis zur Spitze gemessen, nicht $60 \mathrm{~mm}$, der anliegende Flügel nicht $60 \mathrm{~cm}$ lang.

a) Der Lauf ist vorn netzartig gefeldert.

$\alpha \alpha$ Z Zwischen dem Auge und der Schnabelwurzel befinden sich borstenartige Federn.

*) Die erste Schwinge ist kürzer als die sechste; die Außenfahne der letzteren ist $6 \mathrm{~cm}$ vor dem Ende der Feder nicht halb so breit wie $16 \mathrm{~cm}$ vor dem Ende derselben; das Auge ist $2 \frac{1}{2} \mathrm{~cm}$ vom Nasenloch entfernt; hinter dem Auge befindet sich kein schwarzes Längsband (N. Bd. V, Tafel 32) . . . . . . Natternadler, Circaëtus S. 78.

**) Die erste Schwinge ist länger als die sechste, die Außenfahne der letzteren ist vor dem Ende kaum verengt; das Auge ist $1 \frac{1}{2} \mathrm{~cm}$ vom Nasenloche entfernt; vom Auge zieht ein schwarzes, weiß begrenztes Band oder ein schwarzer Streif nach hinten.

$†$ Der anliegende Flügel ist 26-28 cm lang; der beim alten Vogel gelb gefärbte Lauf ist größtenteils in der langen Befiederung verborgen; die Schwanzfedern sind nicht quer gebändert, die mittlere kürzer als die seitlichen (N. Bd. V, Tafel 24) Gleitaar, Elanus S. 78. $\doteqdot$ Der anliegende Flügel ist 45-52 cm lang; der blaugraue Lauf ist nur in seinem obersten Teil von Federn verdeckt; die gleichlangen Schwanzfedern sind quergebändert (N. Bd. V, Tafel 27)

Fischadler, Pandion, S. 78.

$\beta \beta$ ) Zwischen dem Auge und der Schnabelwurzel befinden sich nur rundliche Federchen, keine in Borsten ausgezogenen Federn (N. Bd. V, Tafel 25 und 26)

Wespenbussard, Pernis S. 78.

ß) Der Lauf ist vorn entweder mit einer Längsreihe großer Schilder versehen oder gar nicht gefeldert. 
au) Die mittleren Schwanzfedern sind wenigstens $1 \frac{1}{2} \mathrm{~cm}$ kürzer als die seitlichen; der anliegende Flügel ist $39-52 \mathrm{~cm}$ lang $(\mathrm{N} . \mathrm{Bd} . \mathrm{V}$, Tafel 23)

Milan, Milvus S. 77.

$\beta \beta)$ Die mittleren Schwanzfedern sind nicht kiirzer als die seitlichen. * Der Schwanz reicht um $1 / 3{ }^{1} / 2$ seiner Länge unter der Spitze der aufliegenden Flügel vor (die Wurzel der Schwanzfedern kann man leicht feststellen, da sie durch die oberen und unteren Deckfedern hindurch fühlbar ist) (N. Bd. V, Tafel 51-55)

Sperber und Habicht, Accipiter und Astur S. 80 .

** Der Schwanz ragt nicht um $1 / 4$ seiner Länge unter der Spitze der aufliegenden Flïgel vor.

$\div$ Der nackte Teil des Laufes ist, von vorn gesehen, mindestens $8 \mathrm{mal}$ so lang wie an der dünnsten Stelle dick (N. Bd. V, Tafel 56-59)

Weihen, Cireus S. 81.

$\uparrow$ Der nackte Teil des Laufes ist, von vorn gesehen, von Gelenk zu Gelenk gemessen, höchstens 6 mal so lang wie an der schmalsten Stelle breit (N. Bd. V, Tafel 33-37) . Bussarle, Buteo S. 78.

\section{Die Gattungen der Tauben.}

I. Die mittleren Schwanzfedern sind etwa $10 \mathrm{~cm}$ länger als die äußersten und laufen sehr schmal aus; die äuße1ste Schwanzfeder ist auf der Innenfahne mit rostrotem Fleck versehen - Wandertaube, Ectopistes S. 83.

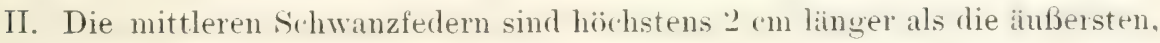
am Ende breit gerundet; die äußersten Schwanzferlern zeigen keinen braunroten Fleck.

A) Die drei äußersten Schwanzfedern jederseits sind auf der Innenfahne am Ende scharf abgesetzt, heller (N. Bd. VI, Tafel 4)

T'urteltauben, Turtur S. 82.

B) Die Schwanzferlern sind am Ende nicht scharf abgesetzt, heller gefärbt (N. Bd. VI, Tafel 1-3) . . . . . . . Feldtauben, Columba S. 82.

\section{Die Gattungen der Hühner.}

I. Der Schnabel ist über dem Nasenloch dicht gefiedert, meist ist das Nasen loch ganz mit einer dicht befiederten Klappe verdeckt; die Beine sind wenigstens bis zur Wurzel der Zehen befiedert.

A) Die Fiiße sind entweder bis zu den Krallen befiedert bezw. beborstet oder sie zeigen in der Wurzelhälfte der Zehen keine Quertäfelung; an den Seiten tragen die Zehen keine nach abwärts gerichteten Plättchen. 
AA) Die mittleren Schwanzfedem sind, wie die andern, am Ende gerundet; die Füße sind mit vier Zehen versehen, von denen die hintere allerdings oft zwischen den Federn fast verborgen ist (N. Bd. VI, Tafel 5-7)

Sehneehiihner, Lagopus S. 83.

BB) Die beiden mittelsten Schwanzfedern sind am Ende verschmälert und stehen weit vor; die Füße sind mit nur drei kurzen Zehen versehen (N. Bd. VII, Tafel 3) . . . . . . Steppenhuhn, syrhaptes S. 86.

B) Die Zehen sind unbefiedert und am Rücken von der Kralle bis zur Wurzel getäfelt, an den Seiten meist mit nach unten gerichteten Plättchen versehen.

AA) Die Hinterzehe ist sehr kurz, mit ihrer Kralle nicht $5 \mathrm{~mm}$ lang; die beiden mittelsten Schwanzfedern sind zugespitzt (N. Bd. VII, Tafel 4)

Flughühner, Pterocles S. 86.

BB) Die Hinterzehe ist mit Kralle mindestens $1 \mathrm{~cm}$ lang, an der Rückseite getäfelt; die mittleren Schwanzfedern sind, wie die andern, am Ende breit gerundet.

a) Der anliegende Flïgel ist 16-17 cm lang; der untere Teil des Laufes ist vorn unbefiedert (N. Bil. VI, Tafel 8). . Haselhuhn, Bonasa S. 83.

b) Der anliegende Flügel ist $23-43 \mathrm{~cm}$ lang; der Lauf ist bis zu den Zehen befiedert orier beborstet. (N. Bd. VI, Tafel 9-13)

Waldhiihner, Tetrao S. 83.

II. Der Schnabel ist über dem Nasenloch nicht gefiedert, meist wird das Nasenloch von einer nackten Schuppe überragt (Fig. 34); der Lauf ist nur bei einigen Rassen des Haushulns bis zu den Zehen gefiedert, sonst ungefiedert, nur getäfelt.

A) Der anliegende Flügel ist höchstens $18 \mathrm{~cm}$ lang.

AA) Es sind nur drei Zehen vorhanden.

Laufhühnchen, Turnix S. 84.

$\mathrm{BB})$ Es ist stets eine vierte, hintere Zehe vorhanden.

a) Das Gefieder der Rückenseite des Körpers, namentlich auf den Flügeln, ist mit einzelnen oder zahlreichen scharf hellen,

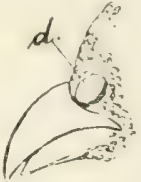

Fig. :1.

Schmabel rom Rebhuhn, d Nisenklappe. der Länge nach dunkel begrenzten Federschaftstreifen gezeichnet.

aa) Der anliegende Flügel ist $9-11 \mathrm{~cm}$ lang; die Schwanzfedern sind bunt, schwärzlich und gelblich weiß (N. Bd. VI, T'afel 14)

Wachtel, Coturnix S. 83.

bb) Der anliegende Flügel ist $13^{1} / 2-16 \mathrm{~cm}$ lang; die Schwanzfedern sind, mit Ausnahme der mittleren, fast ganz rostrot (N. Bd. VI, Tafel 15)

Rebhuhn, Perdix S. 83.

b) Das Rückengefieder ist nur bei jungen Vögeln zum Teil gegen das Ende der. Federn mit hellen Schaftstreifen gezeichnet; diese hellen Streifen sind dann aber unregelmäßjig dunkel begrenzt. 
aa) Die Federn auf den Flügeln sind vor ihrem Rande mit scharfen hellen Binden versehen Francolinus S. 8 t.

bb) Die Federn auf den Flïgeln sind vor ihrem Rande nicht mit einer hellen Binde gezeichnet (N. Bd. VI, Tafel 16 und 17)

Steinhiilnner, Cacentis S. 83.

B) Der anliegende Flügel ist über $18 \mathrm{~cm}$ lang; die nackte Schnabelfirste ist mindestens $2 \mathrm{~cm}$ lang; zwischen den beiden Nasenlöchern befindet sich zuweilen ein fleischiger Kamm.

AA) Der Kopf und die obere Hälfte des Halses sind nackt oder nur mit einzelnen diinnen Borsten bekleidet.

a) Auf der Mitte der Stim befindet sich ein herabhängender fleischiger Zapfen; die Schwanzfedern sind $30 \mathrm{~cm}$ lang, sie ragen weit aus dem Federkleid vor; die Federn (ler Körperoberseite sind breit gestutzt (N. Bd. VI, Tafel 19b)

'T'ruthahn, Meleagris S. 84.

b) An den Seiten les Oberkiefers befindet sich hinten je ein herabhängender Hautlappen; der 16-fedrige Schwanz ist höchstens $15 \mathrm{~cm}$ lang und ragt nicht unter den Deckfedern vor; die Federn der Körperoberseite sind gerundet

Perllıulı, Numida.

BB) Der Kopf ist nicht ganz unbefiedert.

a) Auf der Mitte des Schnabels befindet sich ein zwischen oder vor den Nasenlöchern beginnender fleischiger Kamm . . IIaushulun, Gallus.

b) Auf dem Schnabel befindet sich kein fleischiger Kamm.

aa) Der Kopf ist oben mit aufgerichteten Federn versehen; der 20 -fedrige Schwanz wird, namentlich beim Männchen, von den mit schöngefürbten Augenflecken gezeichneten Schwanzdeckfedem überragt. Plau, Pavo.

bb) Der Kopf trïgt keine aufgerichteten Federn; der 18-fedrige Schwanz. ragt $20 \mathrm{~cm}$ und weiter unter den Deckfedern vor (N. Bd. VI, Tafel 19a).

lasan, Phasianus S. 84.

\section{Die Gattungen der Stelzvögel.}

'1. Es ist stets eine vierte, hïherstehende, oft sehr kleine Zehe vorhanden (Fig. 1 S. 1).

A) Es ist wenigstens die Mittelzehe innen mit $2-3$ halbmondförmigen Hautlappen versehen (Fig. 1).

AA) Die Mittelzehe ist innen mit zwei Hautlappen versehen und im Zehenwinkel durch eine breite Bindehaut mit der Innenzehe verbunden (Fig. 1); der anliegende Fliigel ist nicht $15 \mathrm{~cm} \operatorname{lang}(\mathrm{N}$. Bd. VIII, Tafel 14 und 15 )

Wassertreter, Phalaropus S.91.

BB) Die Mittelzehe ist imnen mit drei Hautlappen versehen; eine breite Bindehaut ist nicht vorhanden; der anliegende Flügel ist iiber $20 \mathrm{~cm}$ lang (N. Bd. VIII, Tafel 10) . . . . . Wasserhulın, Fulica S. 88. 
B) An den Zehen befinden sich keine halbmondförmigen Hautlappen.

AA) Die Kralle der Mittelzehe ist am Innenrande kammartig gezähnt (N. Bd. VI, Tafel 20-28)

Reiher,

Ardea, Herodias, Ardeola, Ardetta, Botaums, Nycticorax und Bubulcus S. 84.

BB) Die Kralle der Mittelzehe ist an beiden Seiten ganzrandig.

a) Zwischen der Mittel- und der Außenzehe der Füße befindet sich eine Bindehaut, welche, bei gespreizten Zehen scharf aus dem Winkel bis zur Mitte des Randes gemessen, wenigstens $3 \mathrm{~mm}$ breit ist.

aa) Der nackte Schnabel ist, in der Mundspalte gemessen, über $4 \mathrm{~cm}$ lang.

a) Der Schnabel ist stark aufwärts gebogen (Fig. 3 S. 1); seine Firste ist über $7 \mathrm{~cm}$ lang; zwischen den Zehen ist eine fast bis zu den Krallen reichende Bindehaut vorhanden (N. Bd. VIII, Tafel 13, Fig. 4 und 5)

Siibler, Recurvirostra S. 91.

$\beta)$ Der Schnabel ist entweder abwärts gebogen oder gerade oder doch nur wenig aufwärts gebogen (vergl. N. Bd. IX, Tafel 8, Fig. 1).

$\boldsymbol{\alpha} \alpha)$ Der Schnabel ist stark ab. wärts gebogen (Fig. 35).

* Der Kopf ist zwischen der Schnabelwurzel und dem Auge unbefiedert (N. Bd. VII, Tafel 22 und Tafel 20)

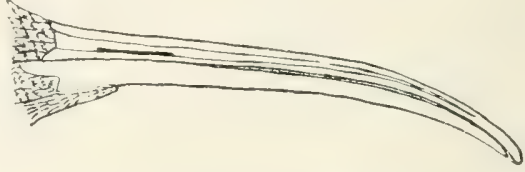

Hig. 35. Schuabel rom Brachrogel.

Sichler, Plegadis und Geronticus S. 86.

** Der Kopf ist bis zur Schnabelwurzel gefiedert (N. Bd. IX, Tafel 12 und 13) . . . . . . . Brachvögel, Numenius S. 96.

$\beta \beta$ ) Der Schnabel ist entweder gerade oder sehr schwach gebogen (vergl. N. Bd. IX, Tafel 18, Fig. 5 u. 6).

* Der Schnabel ist vor dem Ende flach gedrickt und stark verbreitert, beim jungen Vogel, von oben gesehen über $9 \mathrm{~mm}$ breit, beim alten Vogel $4 \mathrm{~cm}$ breit (N. Bd. VII, Tafel 1).

Löffler, Platalea S. 86.

** Der Schnabel ist vor dem Ende nicht oder kaum verbreitert.

$\uparrow$ Der anliegende Flügel ist über $40 \mathrm{~cm}$ lang.

$X$ Vor und hinter dem Auge befinden sich unbefiederte Hautstellen; die nackte Schnabelfirste ist $14-20 \mathrm{~cm}$ lang; das Gefieder ist wenigstens am Bauch weiß (N. Bd. VI, Tafel 30 und 31, Bd. VII, Tafel 8, Fig. 2) . Störche (und Mönchkranich), Ciconia S. 85.

$X \times$ Die Umgebung des Auges ist überall befiedert; die nackte Schnabelfirste ist höchstens $12 \mathrm{~cm}$ lang; das Gefieder ist am Bauche nicht reinweiß (Bd. VII, Tafel 8 und 9)

Kraniche, Grus S. 87. 
$\div$ Der anliegende Flügel ist nicht $25 \mathrm{~cm}$ lang; der Schnabel ist weniger kräftig.

$\times$ Die vom Nasenloch ausgehende Furche reicht, wenn man den Schnabel vom hintern Mundwinkel bis zur Spitze mißt, kaum über die Schnabelmitte hinaus (vergl. Fig. 38 S. 22) (N. Bd. IX, Tafel 4-8) . . . . . . Wasserliufer, Totanus S. 94.

$\times \times$ Die Nasenfurche reicht bis auf $3 / 4$ der Schnabellänge (vergl. Fig. 36) N. Bd. IX, Tafel 9-11)

Uferschnepfen, Terekia, Limosa und Macrorhamphus S.95.

bb) Der nackte Schnabel ist, im Mundspalt gemessen, nicht $4 \mathrm{~cm}$ lang.

a) Der Schnabel ist sehr schlank (Fig. 36); der Lauf ist nur hinten netzartig gefeldert, vorn laufen die Tafeln queriiber und biegen in der Mitte der Außenseite meist nach unten um.

« $\boldsymbol{\alpha})$ Die aus dem Nasenloche entspringende Längsfurche reicht, wenn man den Schnabel aus dem hinteren Mundwinkel mißt, kaum iuber die Mitte der Schnabellänge hinaus (vergl. Fig. 38 S. 22)

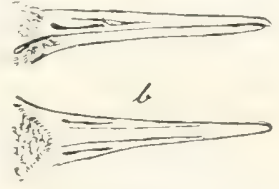

(N. Bd. IX, Tafel 4-8) .

Wasserläufer, Totanus S. 94.

$\beta \beta)$ Die Nasenfurche reicht fast bis $\mathrm{zu}^{3} / 4$ der Schnabellänge (Fig. 36).

* Der Lauf ist, von der Oberseite der Zehenwurzel bis zur Mitte des oberen Gelenks gemessen, über 3,5 cm lang; die Mittelzehe ist mit Kralle mindestens $3 \mathrm{~cm}$ lang (N. Bd. VIII, Tafel 22-24, Bd. IX, Tafel 2, Fig. 1 u.2 und Tafel 3, Fig. 1)

Kampfläufer, Philomachus und Bartramia S.94.

** Der Lauf ist nicht $3^{1} / 2 \mathrm{~cm}$ lang, die Mittelzehe mit Kralle höchstens $2^{1} / 2 \mathrm{~cm}$ (N. Bd. IX, Tafel 1, Fig. 5 u. 6 und Tafel 2, Fig. 1-3)

Uferläufer, Tringoides (und Terekia) S.94.

ß) Der Schnabel ist weniger schlank (Fig. 37); der Lauf ist vorn entweder netzartig gefeldert oder die Quertafeln sind zum Teil vorn in der Mitte unterbrochen oder sie reichen nicht bis zur Mitte der Seite.

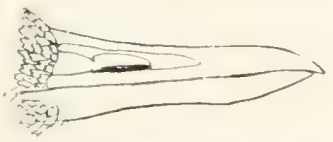

Fig. 37. Schnabel vom Kiehitzregenpfeifer.

$a(\iota)$ Der Schwanz ist tief ausgeschnitten, d. h. die seitlichen Federn sind etwa $4 \mathrm{~cm}$ länger als die mittleren; die nackte Schnabelfirste ist nicht $2 \mathrm{~cm}$ lang (Bd. VII, Tafel 11) . Giarol, Glareola S.91. $\beta B)$ Die mittleren Schwanzfedern sind nicht oder kaum kürzer als die seitlichen; der Schwanz ist also nicht ausgeschnitten; die nackte Schnabelfirste ist über $2 \mathrm{~cm}$ lang (N. Bd. VIII, Tafel 1, Fig. 3 u. 4 und Tafel 3, Fig. 1)

Kiebitz (und Kiebitzregenpl'eif'er), Vanellus S. 88. 
b) Die Bindehaut zwischen der Nittel- und Außenzehe ist, aus dem Winkel gemessen, nicht $3 \mathrm{~mm}$ breit oder sie fehlt ganz.

aa) Die Mittelzehe mit Kralle ist länger als die nackte Schnabelfirste.

( ) Auf der Stirn zieht sich von der Schnabelwurzel aus eine, auch schon bei jungen Tieren deutlich erkennbare nackte Platte bis zwischen die Vorderränder der beiden Augen; die Mittelzehe ist, mit Kralle, uiber $5 \frac{1}{2} \mathrm{~cm}$ lang.

r $\boldsymbol{x}$ ) Die Nittelzehe mit Kralle ist 10-11 cm lang, der anliegende Flügel 22-28 cm lang; das Nasenloch ist nur doppelt so lang wie breit Sultanshuhn, Porphyrio S. 88.

$\beta \beta)$ Die Nittelzehe mit Kralle ist höchstens $7^{1} / 2 \mathrm{~cm} \mathrm{lang,} \mathrm{der} \mathrm{an-}$ liegende Fliigel 15-18 cm lang; das Nasenloch ist eng, mindestens dreimal so lang wie breit (N. Bd. VII, Tafel 11)

T'eichlıuhı, Gallinula S. 88.

ß) Über der Schnabelwurzel befindet sich keine nackte Platte; die Mittelzehe mit Kralle ist nicht $5 \frac{1}{2} \mathrm{~cm}$ lang.

a $\iota$ ) Die nackte Schnabelfirste ist 33-45 mm lang (N. Bd. VII, Tafel 16)

Ralle, Rallus S. 88.

$\beta \beta)$ Die nackte Schnabelfirste ist $20-31 \mathrm{~mm}$ lang.

* Die Mittelzehe mit Kralle ist nicht $3 \mathrm{~cm}$ lang; der Schnabel ist schlanker (Fig. 38 und 39).

† Die vom Nasenloche ausgehende Furche reicht nur bis zur Schnabelmitte (Fig. 38); der Schnabel ist kräftiger; die zweit- und drittäuberste Schwanzfeder sind vor dem $3-7 \mathrm{~mm}$ breiten weißen Endrande schwarz gefärbt (N. Bd. VIII, Tafel 5, Fig. 2 und Tafel 8, Fig. 3 u. 4)

Steinwäilzer, Arenaria S. 90.

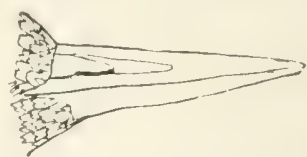

Fig. 38.

Schuabel vom Steinwälzer.

$\rightarrow$ Die Nasenfurche reicht über $3 / 4$ der Schnabellänge hinaus (Fig. 39) und der Schnabel ist schlanker; die Schwanzfedern sind nicht schwarz und weiß gezeichnet (N.Bd. VIII, Tafel 17-21)

Strandlauler, Tringa S. 92.

** Die Mittelzehe mit Kralle ist über $3 \mathrm{~cm}$ lang; der Schnabel ist etwas weniger schlank (N. Bd. VII, Tafel 12-15)

Wachtelkönig und Sumpfluulı, Crex und Ortygometra S. 88.

bb) Die Mittelzehe mit Kralle ist kürzer als
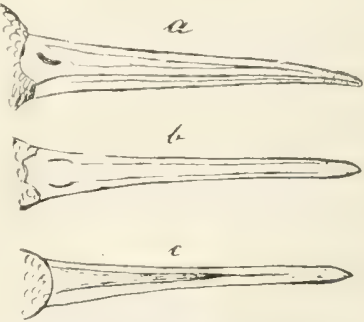

Fig. 39. Schnabel vom Alpenstrandläufer, $a$ von der Seite, $b$ von oben, $c$ von unter. 
a) Die Befiederung reicht an der Vorderseite des Beines bis zur Fersenbeuge, d. h. bis zur Wurzel des Laufes; der anliegende Flügel ist 171/2 bis $20 \mathrm{~cm}$ lang (N. Bd. IX, Tafel 17). Waldsehmepfe, Scolopax S. 97.

ß) Die Beine sind nicht bis zur Wurzel des Laufes gefiedert (vergl. Fig. 1 u. 2 S. 1); der anliegende Flügel ist höchstens $16^{1} / 2 \mathrm{~cm} \mathrm{lang.}$ « Ende desselben; die nackte Schnabelfirste ist über $4 \mathrm{~cm}$ lang (N. Bd. IX, Tafel 14-16). . . . Sumplschnepfen, Gallinago S. 96. $\beta \beta)$ Die Mittelfurche an der Unterseite des Unterschnabels reicht kaum iiber $3 / 4$ der Schnabellänge hinaus (Fig. 39c); die nackte Schnabelfirste ist meist unter $4 \mathrm{~cm}$ lang.

* Der Oberschnabel ist etwas von oben flachgedrickt und deshalb in der Mitte seiner Länge, von oben gesehen fast $4 \mathrm{~mm}$ breit; der obere mediane Teil der Nasengrube reicht nicht bis auf $1 / 3$ des nackten Teils; der untere (oder äußere) Rand dieser Grube läuft als feine Rille, oft bis fast an das Ende des Schnabels; sieht man den Schnabel von oben, so ist diese Rille kaum vom Seitenrande des Schnabels getrennt (N. Bd. VIII, Tafel 16)

Sumpflïufer, Limicola S. 92. * Der Schnabel ist nicht flachgedriickt und deshalb in der Mitte kaum $2 \mathrm{~mm}$ breit; vom oberen (medialen) Teil der Nasengrube verläuft eine Rinne mindestens über $1 / 3$ des nackten Schnabelteiles, von oben gesehen lassen diese (beiderseitigen) Rinnen höchstens die Hälfte der Schnabelbreite in der Nitte frei (Fig. 396 ).

$\div$ Die vom Nasenloch ausgehende Furche reicht bis auf $3 / 4$ der Schnabellänge (Fig. 39 a u. b); die. Schwanzfedern sind nicht quergebändert (N. Bd. VIII, Tafel 17-21)

Strandläufer, Tringa und Tryngites S. 92.

if Die Nasenfurche reicht höchstens bis auf $2 / 3$ der Schnabellänge; die Schwanzfedern sind hell und dunkel quergebändert (N. Bd. IX, Tafel $4-8$ ) . . . . . . Wasserläifer, Totanus S. 94.

II. Es sind nur drei Zehen vorhanden.

A) Der Lauf ist vorn mit queriiber verlaufenden 'Tafeln versehen, d. h. es ist vorn keine Längsteilung vorhanden.

AA) Der Lauf ist nur $1 \frac{1}{2}$ mal so lang wie die Mittelzehe mit Kralle; der Schnabel ist gerade; der Innenrand der Mittelkralle ist nicht gesägt (N. Bd. VIII, 'Tafel 15, Fig. 3 und Tafel 16, Fig. 1 u. 2)

Sanderling, Calidris S.91.

BB) Der Lauf ist über doppelt so lang wie die Mittelzehe mit Kralle; der Oberschnabel ist am Ende stark abwärts gebogen; die Kralle der Mittelzehe ist am Innenrande gesägt (N. Bd. VIII, Tafel 10)

Rennvogel, Cursorius S. 91. 
B) Der Lauf ist vorn entweder netzartig gefeldert oder doch in der Mitte vorn mit gebrochener Längsnaht versehen.

AA) Die Bindehaut zwischen der Mittel- und der Innenzehe ist, aus dem Winkel bis zur Nitte des Randes gemessen, mindestens ebenso breit wie diejenige zwischen Nittel- und Außenzehe; der Schnabel ist meist kürzer als Fig. 37 S. 21 (N. Bd. VII, Tafel 5-7) Trappen, Otis und Houbara S. 87.

BB) Die äußere Bindehaut ist breiter als die innere; der Schnabel ist schlanker, wie Fig. 37 S. 21 oder noch dünner.

a) Der Schnabel ist über $50 \mathrm{~mm}$ lang, um die Hälfte länger als die Mittelzehe mit Kralle.

aa) Der Schnabel ist länger als der Lauf (N. Bd. VIII, Tafel 9)

Austernfischer, Haematopus S. 91.

bb) Der Schnabel ist nur halb so lang wie der Lauf (N. Bd. VIII, Tafel 13)

Stelzenlïufer, Himantopus S. 91.

b) Der Schnabel ist nicht $40 \mathrm{~mm}$ lang, nicht oder kaum länger als die Mittelzehe mit Kralle.

aa) Die Bindehaut zwischen der Mittel- und der Innenzehe ist, aus dem Winkel bis zur Mitte des Außenrandes gemessen, mindestens $3 \mathrm{~mm}$ breit; der Lauf ist über $7 \mathrm{~cm}$ lang; die zweite Schwinge ist am längsten, die erste ein wenig kürzer (N. Bd. VIII, Tafel 12)

Triel, Oedicnemus S. 91.

bb) Die Bindehaut zwischen der Mittel- und der Innenzehe ist nicht $2 \mathrm{~mm}$ breit; der Lauf ist bis $4 \mathrm{~cm}$ lang; die erste Schwinge ist die längste (N. Bd. VIII, Tafel 2-8) . . Regenpleifer, Charadrius S. 89.

\section{Die Gattung der Flamingos.}

(N. Bd. VI, Tafel 29)

Flamingo, Phoenicopterus S. 97.

\section{Die Gattungen der Schwimmvögel.}

1. Es ist eine vierte, meist etwas höherstehende Zehe oder wenigstens die Kralle einer solchen vorhanden (Fig. 2 S. 1).

A) Die vierte Zehe ist nicht durch eine Schwimmhaut mit den anderen Zehen verbunden (Fig. 41).

AA) Der Oberschnabel ist jederseits am Innen- oder Unterrande mit Hornzähnen (Fig.40) oder mit Querlamellen versehen.

a) Die Hinterzehe ist unten nicht mit einem Hautlappen versehen und deshalb, von der Seite gesehen, nicht

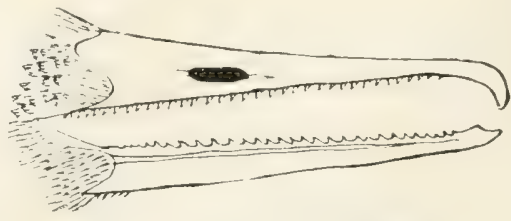

Fig. 40. Schnabel vom Günsesäger. 
doppelt so breit wie von oben gesehen; der ventrale Ballen dieser Zehe ist, von der Seite gesehen, nicht breiter als die Zehe selbst (Fig. 41). aa) Die Mittelzehe ist mit Kralle über $11 \mathrm{~cm}$ lang; das Gefieder ist beim ausgefärbten Tier ganz weib; der Hals ist sehr lang und biegsam ( $N$. Bd. IX, Tafel 18-20)

Schwïne, Cygnus S.97. bb) Die Mittelzehe ist mit Kralle höchstens $10 \mathrm{~cm}$ lang, meist viel kürzer; der Hals ist viel weniger lang.

๙ D) Die feste nagelförmige Platte vorn auf dem Schnabel (vergl. Fig. 43 und 44 S. 26) ist an ihrer breitesten Stelle uber halb so breit wie der Schnabel am Hinterrande des Nagels breit ist; der Nagel nimmt deshalb die ganze Breite des von der Mitte nach vorn stark verschmälerten Schnabels ein.

«

Gäinse, Chen, Anser, Branta und Chenalopex S. 97.

$\beta \beta)$ Der anliegende Flügel ist $21-24 \mathrm{~cm}$ lang; die nackte Schnabelfirste ist, in gerader Linie gemessen, $2^{1 / 2}-3^{1} / 2 \mathrm{~cm}$, die Mittelzehe mit Kralle 4- $4^{1} / 2 \mathrm{~cm}$ lang; die Außenfahne der Schwingen, von der zweiten an, ist größtenteils grau (N. Bd. X, Tafel 1, Fig. 4 und 5)

Braut- und Mandarinenente, Aix S.99.

ß) Der Nagel des Schnabels ist an seiner breitesten Stelle höchstens (und zwar nur bei Anas penelope, N. Bd. X, Tafel 1, Fig. 2, Tafel 3, Fig. 2 und 3) halb so breit wie der Schnabel am Hinterrande des Nagels, meist viel schmäler (vergl. Fig. 43); der Nagel nimmt also nur einen Teil des Schnabelvorderrandes ein und der Schnabel ist von der Mitte nach vorn nicht oder kaum verschmälert.

uc) Der Schnabel ist vorn etwa $28 \mathrm{~mm}$ breit, fast doppelt so breit wie an der Wurzel (N. Bd. X, Tafel 6, Fig. 2, Tafel 7, Fig. 2 und Tafel 8, Fig. 1). . . . . . Lïflelente, Spatula S. 102.

$\beta \beta)$ Der Schnabel ist vorn nicht oder nur wenig breiter als an der Wurzel (N. Bd. IX, Tafel 29 und 30 und Bd. X, Tafel 1-8)

Enten, Anas, Dafila und Tadorna S.99.

b) Die Hinterzehe ist unten mit einem breiten Hautlappen versehen (Fig. 42).

aa) Der Oberschnabel ist unten mit spitzen Hornzähnen versehen (Fig. 40); er ist schmal, die nackte Firste iiber dreimal so lang wie der Oberschnabel vor dem Nasenloch breit (N. Bd. X, Tafel 27-29) Säiger, Nergus S. 104.

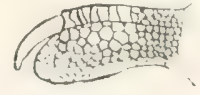

Fig. 12. Hinterzole einer 'Tauchente. 
bb) Die Ränder des Oberschnabels sind an der Innenseite mit hornigen Querrippen versehen; der Schnabel ist höchstens dreimal so lang wie breit.

( ) Der Schwanz besteht aus 16 oder 18 Federn: der Nagel vorn auf dem Schnabel ist sehr schmal (Fig. 43).

$\alpha(x)$ Der Schwanz besteht aus 18 Federn; dieselben sind nicht $1 \mathrm{~cm}$ breit und ragen oft bis 8 cm unter den Schwanzdeckfedern vor ( $N$.

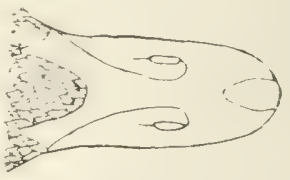

Fig. 13.

Sinahel der Schellente. Bd. X, Tafel 26) Ruderente, Erismatura S. 104.

$\beta \beta)$ Der Schwanz besteht aus 16 Federn, die z. T. breiter sind als $1 \mathrm{~cm}$ und höchstens $4 \frac{1}{2} \mathrm{~cm}$ unter den Schwanzdeckfedern vorragen (N. Bd. X, Tafel 12, Fig. 1 und 2 und Tafel 16, Fig. 1)

Schellenten, Fuligula (Clangula) S. 102.

ß) Der Schwanz besteht aus 14 Federn.

$r(x)$ In die Befiederung der Stirn ragt von vorn jederseits der Schnabelmitte ein unbefiederter Teil spitzwinklig über $15 \mathrm{~mm}$ tief hinein (N. Bd. X, Tafel 20-22) . . . . Eilerenten, Somateria S. 104.

$\beta\left(\beta^{\prime}\right)$ In die Befiederung der Stirn ragt entweder gar kein unbefiederter Teil spitzwinklig hinein, oder dieser Winkel ist, vom Ende der Befiederung am Schnabelseitenrande gemessen, höchstens $5 \mathrm{~mm}$ tief.

* Der Oberschnabel ist, $1 \frac{1}{2} \mathrm{~cm}$ vom Ende entfernt gemessen, nicht $1 \frac{1}{2} \mathrm{~cm}$ breit; das Ende desselben ist queriber fest, hornig und der feste Teil nicht deutlich als Nagel abgesetzt.

$\dagger$ Die nackte Schnabelfirste ist über $3^{1} / 2 \mathrm{~cm}$ lang; der Schnabel ist $1 / 2 \mathrm{~cm}$ vor dem Ende uiber $1 \mathrm{~cm}$ breit (N. Bd. X, Tafel 19)

Scheckente, Eniconctta S. 104.

$\square$ Die nackte Schnabelfirste ist nicht $3 \mathrm{~cm}$ lang: der Schnabel ist

$1 / 2 \mathrm{~cm}$ vor dem Ende nicht $1 \mathrm{~cm}$ breit (N. Bd. X, Tafel 18)

Kragenente, Histrionicus S. 103.

** Der Oberschnabel ist $1 \frac{1}{2} \mathrm{~cm}$ vor dem Ende über $1 \frac{1}{2} \mathrm{~cm}$ breit; meist ist ein dunkler Nagel abgesetzt (Fig. 4t).

$\dagger$ Der Nagel ist über $12 \mathrm{~mm}$ breit; das Gefieder ist größtenteils schwarz oder dunkelbraun (N. Bd. X, Tafel 2:3 25)

Schwarzenten, Oidemia S. 104.

$\uparrow$ Der Nagel ist höchstens $11 \mathrm{~mm}$ breit (Fig. 44); das Gefieder ist am hinteren Teil des Bauches nie schwarz oder dunkelbraun.

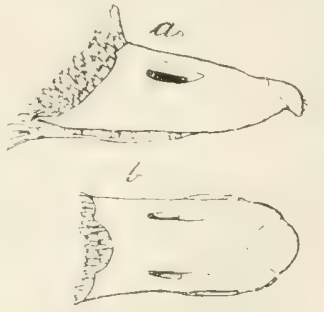

Fig. 44. Schnabel der Eisente. $a$ von der Suite, $b$ von oben. 
Der Schnabel ist $1 \mathrm{~cm}$ vor dem Ende iiber $1^{3 / 4} \mathrm{~cm}$ breit; die nackte. Schnabelfirste ist uiber $3 \mathrm{~cm}$ lang (N. Bd. X, Tafel 10-16)

Tauchenten, Fuligula S. 102.

Der Schnabel ist $1 \mathrm{~cm}$ vor dem Ende nicht $1 \frac{3}{4} \mathrm{~cm}$ breit; die nackte Schnabelfirste ist nicht $3 \mathrm{~cm}$ lang (N. Bd. X, Tafel 17)

Eisente, Harelda S. 103.

BB) Die Schnabelränder sind nicht mit hornigen Querlamellen und nicht mit Reihen von Hornzähnen versehen.

a) Die beiden Nasenlöcher sind entweder nach vorn oder schräg nach oben geöffnet: (Fig. 4 S. 1) und durch eine Scheidewand getrennt, die selten dicker ist als der Durchmesser des Nasenloches (N. Bd. XI, Tafel 2-6)

Sturmvögel, Daption, Ossifiaga, Fulmams, Buluevia, Aestrelata, Puffinus, Procellaria, Oceanordioma, Oceanites und Pelagodroma S. 114.

b) Die Nasenlöcher sind an den Seiten des Schnabels geöffnet, nie röhrenförmig und nie schräg nach vorn und oben gerichtet (Fig. 45).

aa) Die Schwanzfedern ragen nicht oder kaum unter den Schwanzdeckfedern vor.

a) Die Zehen sind mit breiten Lappen gesäumt

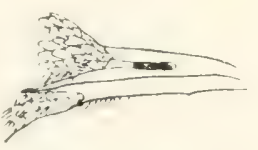

Fig. 45. Schnabel der Zwergmöve.

(Fig. 5 S. 2), nicht durch eine Schwimmhaut verbunden (N. Bd. XII, Tafel 8-12) . . . . . Iappentancher, Colymbus S. 116.

B) Die Zehen sind durch eine breite Schwimmhaut miteinander verbunden (N. Bd. XII, Tafel 13 und 14) . Seetancher, Gavia S. 117.

bb) Die Schwanzfedern ragen um die Länge der Außenzehe oder weiter unter dem Rückengefieder vor.

a) Die Schwimmhaut zwischen der Nittel- und Innenzehe ist, aus dem Zehenwinkel bis zur Mitte des Randes gemessen, nicht halb so breit wie die Innenzehe mit Kralle lang ist (Fig. 2 S. 1).

ua) Der anliegende Flügel ist über $50 \mathrm{~cm}$ lang, die nackte Schnabelfirste, über den Endbogen gemessen, über $10 \mathrm{~cm}$ lang; der Schwanz ist mindestens $20 \mathrm{~cm}$ tief gegabelt; die Nasenlöcher öffnen sich sehr eng spaltartig an der Wurzel des Schnabels (N. Bd. XI, Tafel 3, Fig. 2 und 3) . . . . Fregattvogel, Fregata S. 106.

$\beta \beta)$ Der anliegende Flügel ist höchstens $25 \mathrm{~cm}$ lang, die nackte Schnabelfirste nicht $10 \mathrm{~cm}$ lang; die äußeren Schwanzfedern sind nicht $10 \mathrm{~cm}$ länger als die mittleren; das Nasenloch ist nicht eng spaltförmig (Fig. 46) (N. Bd. XI, Tafel 8 und 9)

'I'ranerseesehwalben, Hydrochclidon S. 106.

$\beta)$ Die Schwimmhaut zwischen der Mittel- und der Innenhaut ist, aus dem Winkel gemessen, über halb so breit wie die Innenzehe mit Kralle lang ist. 
ar) Der Vorderrand des Nasenloches ist, in gerader Linie gemessen, doppelt soweit von der Schnabelspitze wie von den nächsten Federchen an der Schnabelwurzel entfernt (vergl. Fig. 46); die Schnabelfirste ist weniger gebogen (N. Bd. XI, Tafel 11-17)

Seeschwalben, Sterna S. 107.

$\beta \beta)$ Der Vorderrand des Nasenloches ist nicht doppelt soweit von der Schnabelspitze wie von den nächsten Federn an der Schnabelwurzel entfernt (Fig. 45 und 47); die Schnabelfirste ist stärker gebogen.

* Der Schnabel ist von der Federgrenze an der Wurzel bis zum Vorderrande des Nasenloches weichhäutig; beim trockenen Balg verläuft deshalb ein Absatz von einem Nasen-

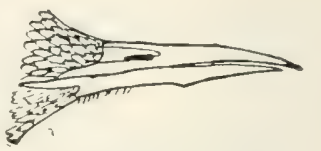

Fig. 46. Schnabel der 'I'ratierseeschwalbe.

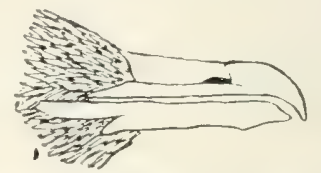

Fig. 47. Schmabel der Spatelraubmöve. loche zum andern über den Schnabel (Fig. 47) (N. Bd. XI, Tafel 30-32) . . . Raubmöven, Stercorarius S. 112.

**) Der Schnabel ist von der Spitze bis hinter die Nasenlöcher gleichmäßig fest, und zwischen den Nasenlöchern befindet sich oben auf dem Schnabel kein Absatz (Fig. 45).

$\div$ Die mittleren Schwanzfedern sind 2,5 cm kürzer als die äußersten; der Schnabel ist an der Wurzel schwarz, im Enddrittel scharf abgeschnitten hell (N. Bd. XI, Tafel 28, Fig. 2 und 3 und Tafel 29, Fig. '2) . . . . . Gabelschwanzmöve, Xema S. 112.

$\div$ Die mittleren Schwanzfedern sind nicht merklich kürzer als die äußersten; der Schnabel ist selten im Enddrittel scharf abgesetzt heller.

$\times$ Die äußerste Schwanzfeder ist $3-5 \mathrm{~cm}$ kürzer als die längsten der mittleren Federn.

O Das Gefieder ist fast ganz schwarz; die beiden mittelsten Schwanzfedern sind etwas kürzer als die benachbarten

Noddi, Anous S. 109.

O Das Gefieder ist größtenteils weiß; die beiden mittelsten Schwanzfedern sind $2 \mathrm{~cm}$ länger als die beiden benachbarten (N. Bd. XI, Tafel 28, Fig. 1 und Tafel 29, Fig. 1)

Rosenmöve, Rhodostethia S. 112.

$X \times$ Die äußerste Schwanzfeder ist nicht oder kaum kürzer als die längste $(\mathrm{N} . \mathrm{Bd}$. XI, Tafel 18-27)

Möven, Larus und Pagophila S. 109.

B) Die vierte Zehe ist durch eine deutliche Schwimm- oder Bindehaut mit der dritten Zehe verbunden. 
AA) Die nackte Schnabelfirste ist über $30 \mathrm{~cm}$ lang und der Oberschnabel im Enddrittel mindestens $3 \mathrm{~cm}$ breit, über doppelt so breit wie hoch (N. Bd. XI, Tafel 1 und 2) . . . . Pelikane, Pelecanus S. 105.

BB) Die nackte Schnabelfirste ist nicht $15 \mathrm{~cm}$ lang, und der Oberschnabel ist vor der Nitte seiner Länge nicht oder kaum breiter als hoch.

a) Die mittleren Schwanzfedern sind mindestens $20 \mathrm{~cm}$ kürzer als die äußersten: die Schwimmhaut zwischen der Mittel- und Außenzehe ist, aus dem Zehenwinkel bis zur Nitte des Randes gemessen, nicht halb so breit wie die Mittelzehe mit Kralle lang ist; der anliegende Fliggel ist $50 \mathrm{~cm}$ lang (N. Bd. XI, Tafel 3, Fig. 2 und 3)

Fregattvogel, Fregata S. 106 .

b) Die mittleren Schwanzfedern sind länger als die seitlichen; die Schwimmhäute zwischen den Zehen sind alle bis zu den Krallen entwickelt; der anliegende Hlügel ist nicht $50 \mathrm{~cm}$ lang.

aa) Die äußerste Zehe ist mindestens um ihre Kralle länger als die Mittelzehe; der Oberschnabel ist am Ende stark gebogen, etwa wie Fig. 4 S. 1 (N. Bd. XI, Tafel 5-7) . Scharben, Phalacrocorax S. 106. bb) Die Mittelzehe ist nicht kürzer als die Außenzehe; der Schnabel ist am Ende wenig gebogen.

a) Der Raum zwischen dem Auge und der Schnabelwurzel ist unbefiedert; die nackte Schnabelfirste ist $8-9 \mathrm{~cm}$ lang (N. Bd. XI, Tafel 4)

Tölpel, sula S. 106.

ß) Der Raum unter dem Auge ist befiedert; die nackte Schnabelfirste ist 6-7 cm lang (N. Bd. XI, Tafel 3, Fig. 1)

Tropikvogel, Phaëton S. 106.

II. Es sind entweder nur drei Zehen vorhanden, oder es befindet sich eine kleine krallenlose Warze hinten am Lauf.

A) Die nackte Schnabelfirste ist, über den Endbogen bis zur Spitze gemessen, über $10 \mathrm{~cm}$ lang; vor dem Ende ist der Oberschnabel stark nach unten gebogen (Bd. XII, Tafel 1)

Albatrosse, Diamedea und Thalassogeron S. 113.

B) Die nackte Schnabelfirste ist höchstens $6 \mathrm{~cm}$ lang und am Ende wenig gebogen.

AA) Die vierte Zehe ist als kleine Warze hinten am Lauf vorhanden: der anliegende Flügel jst $31-34 \mathrm{~cm}$ lang (N. Bd. XI, Tafel 28, Fig. 4 und 5 und Tafel 29, Fig. 3) . . . . Dreizelımïve, Rissa S. 112. BB) Von der vierten Zehe ist keine Spur vorhanden.

a) Der Schnabel ist schlank (Fig. 48); der Oberschnabel ist, vom äußersten Ende der Stirnbefiederung bis zur Spitze in gerader Linie gemessen, 4-5 mal so lang wie an der Federgrenze hoch.

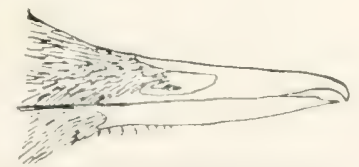

Fig. 48. Schnabel der'Irottellumme. 
aa) Die nackte Schnabelfirste ist $26-34 \mathrm{~mm}$ lang; die Füße sind rot (N. Bd. XII, Tafel 20) .

Teiste, Cepphus S. 118.

bb) Die nackte Schnabelfirste ist $40-55 \mathrm{~mm}$ lang (Fig. 48); die Füße sind heller oder dunkler grüngelb (N. Bd. XII, Tafel 18 und 19)

Lummen, Uria S. 118.

b) Der Oberschnabel ist nicht dreimal so lang wie hoch (Fig. 49-51). aa) Der nackte Teil des Oberschnabels ist am Grunde breiter als hoch (Fig. 49); die nackte Firste ist, uiber den Bogen gemessen, nicht $2 \mathrm{~cm}$ lang (N. Bd. XII, Tafel 15, Fig. 3 und Tafel 16, Fig. 3)

Krabbentaucher, Mergulus S. 117.

bb) Der nackte Teil des Oberschnabels ist zwei bis mehrmal so hoch wie breit (dick) (Fig. 50 und 51); die Firste ist mindestens etwa $3 \mathrm{~cm}$ lang.

«) Der Unterschnabel ist stark nach oben gebogen und läuft in eine Spitze aus; die Befiederung ragt nahe dem Oberrande am weitesten nach dem Ende vor: der anliegende Flügel ist $13^{1} / 2-14^{1} / 2 \mathrm{~cm}$ lang (N. Bd. XII, S. 242)

Papageiall, Fhaleris S. 118.

ß) Der Unterschmabel ist am Ende nicht in eine lange Spitze nach oben ausgezogen; die Befiederung am Oberschnabel ragt in der Nähe des Unterrandes am weitesten nach dem Ende vor (Fig. 50 u. 51); der anliegende Flügel ist $15-21 \mathrm{~cm}$ lang.

ar ) Die beiden mittelsten Schwanzfedern sind zugespitzt und mindestens $5 \mathrm{~mm}$ länger als die andern; der anliegende Flügel ist $171 / 2-21 \mathrm{~cm}$ lang; der Schnabel ist mindestens $2 \mathrm{~cm}$ über den Hinterwinkel des Mundspaltes nach vorn gefiedert; es ist gestreckter (Fig. 50) (N. Bd. XII, Tafel 15, Fig. 1 und 2; Tafel 16, Fig. 1 und 2 und Tafel 17-17 b)

Alken, Alca S. 118.

$\beta \beta)$ Die mittelsten Schwanzfedern sind nicht zugespitzt und ragen nicht vor; der anliegende Flügel ist $15-17^{1} / 2 \mathrm{~cm}$ lang; der Schnabel ist höchstens $1 \mathrm{~cm}$ über den Hinterwinkel des Mundspaltes nach vorn gefiedert; er ist, namentlich beim ausgewachsenen Vogel, viel höher (Fig. 51) (N. Bd. XII, Tafel 21)

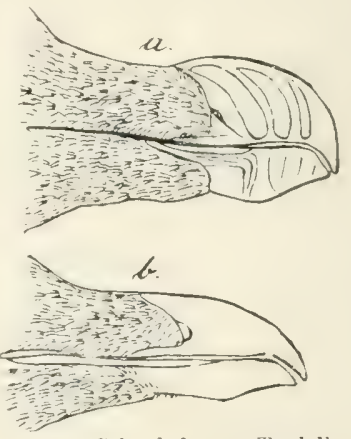

Fig. 50, Schnabel vom Tordalk, $a$ vom alten, $b$ fom jungen Vugel.

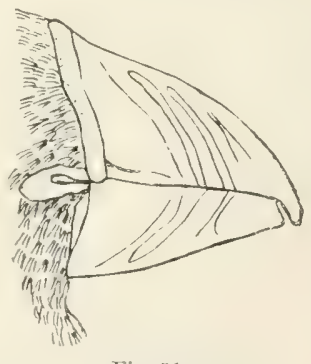

Fig. 51. Schnabel yom Larventancher

Lund, Fratercula S. 118. 


\section{Die Arten der Singvögel. \\ Erithacus, Ruticilla, Pratincoln, Mrescicrun und Nemure.}

I. Die Wurzelhälfte (bezw, $2 / 3$ ) der iußersten Schwanzfedern ist scharf abgesetzt anders gefärbt als die Endhälfte (bezw. 1/3), entweder rostrot oder weiß; das Ende ist entweder schwarz oder grau, nur die Außenfahne der äußersten Schwanzfeder ist bisweilen ganz grau.

A) Die Wurzelhälfte (bezw. $2 / 3$ ) der äußeren Schwanzferlem ist weiß.

a) Der anliegende. Flügel ist nicht $7,5 \mathrm{~cm}$, meist nicht $7 \mathrm{~cm}$ lang; die Oberseite des Körpers ist entweder einfarbig grau oder auf den einzelnen Federn befindet sich vor dem Ende ein heller Querfleck; iiber den Augen befindet sich kein weißer Längsfleck (Bc. IV, S. 174, Tafel 21); östliche Art

\section{Muscicuna parva, Kleimer Fliegenfïinger.}

b) Der anliegende Flügel ist über $7,5 \mathrm{~cm}$ lang; die einzelnen Riickenfedern sind mit dunklem Längsfleck bis fast zur Spitze versehen, ihre Seitenränder sind breit hell; ïber den Augen befindet sich ein weißlicher Lïngsstreif (Bd. I, S. 106, Tafel 12, Fig. 1 und 2)

Protincola rubetı, Bramkehliger Wiesenschmaitzer.

B) Die Wurzelhälfte der äußern Schwanzfeder ist rostrot.

a) Beim Männchen ist die Kehle und die Kropfgegend schön blau, entweder einfarbig (var. E. wolfi) oder mit weißem Fleck; beim Weibchen ist die Kehle weißlich, von schwarzen Flecken umgrenzt (Bd. I, S. 31, Tafel 5)

Lrithacus cyaneculus, Weilisterniges Blaukehlehen.

b) Beim Männchen befindet sich an der blauen Kehle ein braunroter Fleck: das Weibchen ist zurzeit nicht von dem der vorhergehenden Art unterscheidbar (Bd. I, S. 43, Tafel 7); in Deutschland nur auf dem Zuge

Evitherens smecirns, Rotsterniges Blaukehlchen.

II. An den iußersten Schwanzedern ist die Wurzelhälfte nicht scharf, in der Farbe von der Endhälfte verschieden.

A) Die Außenfahne der fünften Schwinge (der vierten längeren) ist vor dem Ende oder in der Mitte nicht plötzlich verschmälert, wie die der beiden vorhergehenden, sie ist deshalb $1 \mathrm{~cm}$ vor dem Ende viel breiter als die der zweiten Schwinge an der breitesten Stelle.

AA) Die längsten Borsten vor dem Mundwinkel am Oberschmabel (vgl. Fig. 16 S. 6) sind über $5 \mathrm{~mm}$ lang; der Schnabel ist am Vorderrande der Nasenlöcher breiter als hoch; die Schwanzfedern sind alle dunlielgrau (Bd. IV, S. 158, Tafel 19)

vergl. unten Muscicupa grisolı, Gefleckter Fliegenfiinger. 
BB) Die längsten Borsten vor dem Mundwinkel am Oberschnabel sind nicht $3 \mathrm{~mm}$ lang; der Schnabel ist im Durchschnitt höher als breit; die seitlichen Schwanzfedern sind dunkelrotbraun.

a) Die kleine erste Schwinge endet spitz und wird mindestens $2 \mathrm{~mm}$ von den den ersten großen Schwingen aufliegenden oberen Flügeldeckfedern überragt; der anliegende Flügel ist über $8,5 \mathrm{~cm}$ lang; die Oberseite des Körpers ist mehr grau gefärbt (Bd. I, S. 6, Tafel 3, Fig. 2); östliche Art

\section{Erithacus philomela, Sprosser.}

b) Die kleine erste Schwinge endet gerundet und überragt meist die oberen Flügeldeckfedern; der anliegende Flügel ist nicht $8,5 \mathrm{~cm}$ lang; die Oberseite des Körpers ist mehr rostfarbig (Bd. I, S. 12, Tafel 3, Fig. 1); westliche Art . . . Erithacus luscinia, Nachtigall.

B) Die Außenfahne der fünften Schwinge ist wie die der vorhergehenden vor dem Ende oder in der Mitte ziemlich plötzlich verengt und deshalb $1 \mathrm{~cm}$ vor dem Ende nicht breiter als die der zweiten Schwinge an der breitesten Stelle (vergl. Fig. 22 S. 7 und 25 S. 9).

AA) Die beiden mittleren Schwanzfedern, namentlich deren Innenfahnen, sind in der Farbe scharf von den Innenfahnen der übrigen Schwanzfedern verschieden, die mittleren sind schwärzlich, die anderen braunrot. a) Die Flügel sind verhältnismäßig kurz, anliegend nicht $7 \mathrm{~cm}$ lang; die verkürzte erste Schwinge ist verhältnismäßig lang; die Entfernung ihrer Spitze von der Beuge des anliegenden Flügels ist $4 \mathrm{~cm}$; beim Männchen ist das Kinn und die Kehle braunrot wie die Brust (Bd. I, S. 123)

Pratincola moussieri, Diadem-Wiesenschmätzer.

b) Der anliegende Flügel ist wenigstens $8 \mathrm{~cm}$ lang; aber die Entfernung der Spitze der ersten Schwinge von der vordern Flügelbeuge ist doch nur $4 \mathrm{~cm}$; beim Männchen ist das Kinn und die Kehle schwarz.

a) Die Brust, $4 \mathrm{~cm}$ unter der Schnabelwurzel, ist beim Männchen schwarz, beim Weibchen grau; bei letzterem sind die Ränder der Brustfedern nicht heller als die der oberen Flügeldeckfedern; die (dem Körper anliegenden) untern Flügeldeckfedern sind an der vorderen Beuge nicht rostgelblich oder rostrot (Bd. I, S. 50, Tafel 6, Fig. 1-5); besonders in Berggegenden . . . . . Ruticilla titys, Haus-Rötling.

ß) Die Brust, $4 \mathrm{~cm}$ unter der Schnabelwurzel, ist beim Männchen braunrot, beim Weibchen gelblich; beim Weibchen sind die Ränder der Brustfedern viel heller als die der oberen Flügeldeckfedern; die unteren Flügeldeckfedern sind gelblich oder rostrot.

* Beim Männchen befindet sich auf den Flügeln ein weißer Fleck, indem die Außenfahne von der dritten Schwinge an schmal weiß gesäumt, von der siebenten Schwinge an über die Hälfte weiß ist(Bd. I. S.61) Ruticilla phoenicurus mesolevea, Weißflugeliger Rotschwanz. 
** Beim Männchen ist die Außenfahne aller Schwingen nur schmal hell gerandet, sonst nicht vom vorigen verschieden (Bd. I, S. 59, Tafel 6, Fig. 6-8) . . . Ruticilla phoenicume, Garten-Rötling. BB) Die beiden mittleren Schwanzfedern sind nicht in Farbe von den benachbarten verschieden, nur bisweilen etwas dunkler.

a) Die Brust ist entweder rostrot gefärbt oder die Farbe zeigt eine rostgelbliche Mischung: in letzteren Falle sind die Ränder der Brustfedern immer z. T. dunkel.

a) Der Flügel zeigt keine weißen Teile, er ist anliegend $7-71 / 2 \mathrm{~cm}$ lang (Bd. I, S. 22, Tafel 4) . Erithacus rubeculus, Rotkehlchen.

ק) Die Flügeldeckferlern sind z. T. an der Spitze mit großem weißlichen Fleck versehen.

* Der anliegende Flügel ist nicht $7 \mathrm{~cm}$ lang; die 17. und 18. Schwinge sind nur mit graubräunlichem Außenrande versehen (Bd. I, S. 115, Tafel 12, Fig. 3-5); mehr in Berggegenden

Pratimala mubcolø, Schwarkehliger Wiesenschmitzer.

** Der anliegende Flügel ist über $8 \mathrm{~cm}$ lang; die Außenfahne der 17. und 18. Schwinge ist in der Außenhälfte weiß (vergl. Bd. IV, S. 168); südliche Art; das Jugendkleid von

Muscicapr collaris, Weißhalsiger Fliegenfänger.

b) Die Brust zeigt nicht die geringste rostrote oder rostgelbliche Farbe oder Mischung.

a) Auf den Flïgeln befinden sich reinweiße oder weißliche Federn bezw. Federteile.

* Die Außenfahne schon der vierten und fünften Schwinge ist an der Basis breit weiß, so daß die weiße Farbe unter den Flügeldeckfedern vorragt; das Männchen ist am Hinterhalse querüber mit weißem Halsband versehen (Bd. IV, S. 168, Tafel 20, Fig. 6); suidliche Art

Huscicrpa colluris, Weifhalsiger Fliegenfïnger.

** Erst die Außenfahne der sechsten Schwinge ist hart an der Basis weiß; der Hals des Männchens ist hinten schwarz (Bd. IV, S. 163, Tafel 19, Fig. 3 und Tafel 20, Fig. 1-4)

Musciccpa rtricapill, Schwarzgrauer Fliegentänger.

ß) Auf den Flügeln befinden sich keine weißen Federteile, die Ründer der Federn sind lediglich etwas heller grau.

$\dagger$ Es sind weder über dem Schwanze schön blaue noch an den Körperseiten schön gelbbraune Federn vorhanden.

* Die unteren (dem Körper anliegenden) Flügeldeckfedern an der vorderen Beuge sind schwefelgelb gefärbt (Bd. II, Tafel 6-7); vergl. die Gattung Phylloscopus weitel unten S. 42. 
** Die untern Flügeldeckfedern zeigen kein Gelb (Bd. IV, S. 158, Tafel 19, Fig. 1 und 2)

Muscicapa grisola, Gefleckter Fliegenfïnger.

† Die F'edern über den Schwanzfedern sind schön blau gefårbt, die Federn an den Körperseiten unter den Flügeln schön braungelb

Nemura cyanura

\section{Accentor.}

I. Der anliegende Flügel ist nicht $8 \mathrm{~cm}$ lang; die Schwanzfedern sind bis zum Ende dunkelgrau.

A) Die Federn der Kehle und der Kropfgegend und ebenso die Federn über den Augen sind beim reifen Tiere aschgrau, beim Jugendkleide ist die Kropfgegend rostgelb mit schwärzlichen Längsflecken versehen, ein Längsstreif über den Augen graugelblich (Bd. I, S. 76, Tafel 9, Fig. 1)

Accentor moduluris, Hecken-Braunelle.

B) Die Federn der Kehle und der Kropfgegend und ebenso ein Streif von der Schnabelwurzel über das Auge bis zurn Hals sind gelblichweiß bis blaß ockergelb (Bd. I, S. 82, Taf. 9, Fig. 2)

Accentor montanellus, Berg-Braunelle.

II. Der anliegende Flügel ist über 9,5 cm lang; die Schwanzfedern sind an der Spitze mit weißlichem oder gelblichem Fleck versehen; die Federn der Kehle sind beim ausgefärbten Kleide weißlich, vor der Spitze mit schwärzlichem Querfleck versehen (Bd. I, S. 68, Tafel 8, Fig. 1 und 2); im Gebirge

Accentor collaris, Alpen-Brannelle.

\section{Saxicola.}

I. Das Kinn und die Kehle sind weiß bezw. gelblichweiß oder rötlichweiß, bei jungen Tieren sind die einzelnen Federn bisweilen vor dem Rande mit einer grauen Bogenbinde versehen.

A) Der schwarze Teil auf der Innenfahne der zweitäußersten Schwanzfeder erstreckt sich über halb so weit nach der Basis hin als der schwarze Teil auf den beiden mittleren Schwanzfedern (Bd. I, S. 105)

Saxicola isabellina, Isabellfarbiger Steinschmätzer.

B) Der schwarze Teil auf der Innenfahne der zweitäußersten Schwanzfeder reicht nicht halb so weit nach der Basis hin wie der auf den beiden mittleren Schwanzfedern.

a) Der Rücken ist beim reifen Tier entweder weißlich und dabei rotbräunlich angeflogen oder er ist fast rotbraun; die Außenfahne der fünften Schwinge (der vierten längeren) ist vor dem Ende plötzlich verengt wie die der vierten (vergl. Fig. 25 S.9), der verengte Teil derselben ist nicht 
breiter als die Außenfahne der zweiten Schwinge an der breitesten Stelle (Bd. I, S. 96, Tafel 10, Fig. 2 und 3 und Tafel 11, Fig. 2)

Saxicola aurita, Ohren-Steinschmätzer.

b) Der Rücken ist beim Männchen rein aschgrau, beim Weibchen grau mit rötlichem, beim Jugendkleide mit bräunlichem Anfluge; die Außenfahne der fünften Schwinge ist bis zum Ende der Feder weit breiter als die der zweiten Schwinge an der breitesten Stelle (Bd. I, S. 84, Tafel 10, Fig. + und 5) . . Saxicola oenanthe, Grauer Steinschwitzer.

II. Das Kinn und die Kehle sind entweder schwarz oder grau, oder die einzelnen Federn sind an der Wurzel schwarz bezw. grau.

A) Die Unterseite des Körpers ist bis zum Bauche einschließlich braunschwarz, ebenso der Kopf und der Rücken, nur die Wurzel der Schwanzfedern und die dem Schwanze benachbarten Teile des Gefieders sind weiß, bei jungen Tieren sind außerdem einige Federspitzen weiß.

a) Die äußern Schwanzfedern sind am Ende stets weiß, oft ganz weiß; der Kopf des alten Männchens ist oben weiß; der anliegende Flügel ist uiber $9,6 \mathrm{~cm}$ lang . . . . . . . . . Saxicola leucopygia.

b) Die äußeren Schwanzfedern sind am Ende schwarz, nur der Saum ist in einer Ausdehnung von nicht ganz $1 \mathrm{~mm}$ hell; der Kopf ist oben immer schwarz; der anliegende Flügel wird bis 9,6 cm lang (Bd. I, S. 104)

Saxicola leucura, Trauer-Steinschmätzer.

B) Die Interseite des Körpers ist von der Hinterbrust an immer hell gefärbt.

a) Die schwarze Farbe ist auf den beiden mittleren Schwanzfedern kaum ausgedehnter als auf den andern; der Rücken des Männchens ist mehr oder weniger rötlich aschgrau (Bd. I, S. 102)

Saxicola deserti, Wiisten-Steinschmätzer.

b) Der schwarze Endteil auf der Innenfahne der zweitäußersten Schwanzfeder reicht nicht halb so iveit nach der Basis hinauf wie der schwarze Teil auf den beiden mittelsten Schwanzfedern.

، ) Das schwarze oder dunkle Feld unter dem Schnabel ist, von den ersten Federn am Kinn an gemessen, höchstens $2 \mathrm{~cm}$ lang, es reicht bei weitem nicht bis zur Schulterbeuge der anliegenden Flïgel (Bd. I, S. 92, Tafel 10, Fig. 1 und Tafel 11, Fig. 1)

Saxicola stapazina, Weißlicher Steinschmätzer.

§) Das schwarze Feld unter dem Schnabel ist über $2 \frac{1}{2} \mathrm{~cm}$ lang und reicht bis zur Schulterbeuge der Flügel.

* Der Rücken des Männchens ist beim Hochzeitskleide querüber schwarz, der Kopf oben weißlich, beim Weibchen und Herbstkleid ist die Oberseite braun (Bd. I, S. 100)

Saxicola pleschanka, Scheckiger Steinschmätzer. 
** Der Rủcken ist beim Hochzeitskleide des Männchens hell, mit rostfarbigem Anflug, ebenso der Kopf, aber heller; die andern Kleider gleichen denen der vorhergehenden Art. . Sasicola melanoleuca.

\section{Monticolu, Geocichla, Turdus und Mimus.}

I. Die Federn des Rückens sind gelblich, unmittelbar am Rande mit schwarzen halbmondförmigen Flecken versehen; die Flecke der Unterseite sind ebenfalls alle halhmondförmig quergestellt; der anliegende Flügel ist $14 \mathrm{~cm}$ lang oder länger.

A) Der Schwanz besteht aus 14 Federn (Bd. I, S. 145, Tafel 17, Fig. 1 und 2) Geocichla varia, Bunte Drossel.

B) Der Schwanz besteht aus 12 Federn (Bd. I, S. 150, Tafel 17, Fig. 3)

Geocichla dauma, Himalaya-Drossel.

II. Die Federn des Rückens sind unmittelbar an Rande nicht dunkler, meist heller gefärbt, oder die Grundfarbe ist nicht gelblich sondern grau.

A) Beim Männchen ist die Kehle schön blau; beim Weibchen sind die Brustfedern alle mit einer $1-1^{1} / 4 \mathrm{~mm}$ breiten, entweder zusammenhängenden oder auf dem Schaft unterbrochenen Querbinde vor dem Außenrande versehen, die Ränder selbst sind hell aber bisweilen teilweise abgenutzt, die Kehle und die Brust erscheinen deshalb fein marmoriert; in den Weichen befinden sich ebensolche aber $2 \mathrm{~mm}$ breite Federbinden.

2) Die Schwanzfedern sind, mit Ausnahme der beiden mittelsten, rostrot; beim Männchen ist der Kopf ganz blau, der Bauch aber rostrot (Bd. I, S. 124, Tafel 13, Fig. 1-3); in Berggegenden

Monticola saxutilis, Stein-Merle.

B) Die Schwanzfedern sind alle schwarz; beim Männchen ist der Kopf und auch der Bauch blau (Bd, I, S. 130, Tafel 14, Fig. 1-3)

Monticola cyanus, Blau-Merle.

B) Die Kehle ist nie schön blau und nie fein marmoriert; sind Binden auf den Brustfedern vorhanden, so befinden sich diese an den Federenden oder sie sind in der Mitte stark verbreitert.

AA) Kleinere Arten; der anliegende Flügel wird bis $10 \mathrm{~cm}$ lang.

a) Die unteren Schwanzdeckfedern sind rotbraun (Bd. I, S. 241, Tafel :30, Fig. 1) . . . . . . Mimus carolinensis, Katzenvogel.

b) Die unteren Schwanzfedern sind weiß.

๙ ) Die Außenfahne der sechsten Schwinge (der fünften längeren) ist vor dem Ende plötzlich verengt (vergl. Fig. 25 S. 9), $1 \mathrm{~cm}$ vom Ende der Feder entfernt ist sie nicht breiter als die Außenfahne der zweiten Schwinge an der breitesten Stelle; die Flecke an den Brustseiten sind dunkler als die Farbe des Rückens; der anliegende Flügel ist nicht $9 \mathrm{~cm}$ lang (Bd. I, S. 234, Tafel 29, Fig. 2) Tudus pallasii, Einsame Drossel. 
B) Die Außenfahne der sechsten Schwinge ist vor dem Ende nicht verengt, $1 \mathrm{~cm}$ vor dem Ende deshalb weit breiter als die Außenfahne der zweiten Schwinge an der breitesten Stelle; die Flecke auf der Brust sind nicht dunkler als die Farbe des Rückens; der anliegende Flügel ist itber $9 \mathrm{~cm}$ lang.

* Die Oberseite des Körpers, namentlich die oberen Schwanzdeckfedern sind rostrot (Bd. I, S. 232, Tafel 29, Fig. 1)

Turdus fuscescens, Wilsons Drossel.

** Die oberen Schwanzdeckfedern sind, wie die ganze Oberseite des Körpers, olivenbraun (Bd. I, S. 239, Tafel 29, Fig. 3)

Turdus swainsoni, Swainsons Drossel.

BB) Größere Arten; der anliegende Flügel ist über $11 \mathrm{~cm}$ lang.

a) An der (dem Körper anliegenden) Unterseite der Flügel befinden sich, besonders nach hinten hin, stets Federn, die größtenteils rostgelb oder rostrot gefärbt sind.

a) Die äußerste Schwanzfeder besitzt immer in größerer oder geringerer Ausdehnung einen rostgelben oder rostroten Ton, und unterscheidet sich dadurch, namentlich nach dem Innenrande hin, immer von der Farbe der Schwingen.

* Die Federn, welche sich an den Seiten des Körpers unter den anliegenden Flügeln und in den Weichen befinden, sind fast alle in größerer oder geringerer Ausdehnung rotbraun gefärbt (Bd. I, S. 189, Tafel 24, Fig. 1-4) . Turdus naumanni, Naumanns Drossel. ** Nur bisweilen besitzen die schwarzen Teile einzelner der an den Körperseiten befindlichen Federn einen rostbräunlichen Ton, diese Teile sind dann aber eher schwarzbraun als rostbraun zu nennen.

$\doteqdot$ An der Brust befinden sich nur scharf begrenzte längliche Flecke auf gelblichweißem Grunde; die unteren Flügeldeckfedern sind braungelb; der anliegende Flügel ist kaum über, meist unter $12 \mathrm{~cm}$ lang (Bd. I, S. 202, Tafel 26, Fig 1)

vergl. unten Tüllus musicus, Singdrossel.

$\therefore$ An der Brust befinden sich entweder keine scharfbegrenzten länglichen Flecke oder, wenn einzelne vorhanden sind, dann ist die Grundfarbe vieler Brustfedern grau.

$\times$ Die Federn der Kropfgegend sind nie rotbraun, nach dem Flügelbug hin sind immer einzelne Federn fast ganz schwarz, d. h. nur mit hellem Saum versehen.

Die Bürzelfedern sind entweder größtenteils rotbraun oder doch mit rotbraunen Rändern versehen (Bd. I, S. 175, Tafel 21, Fig. 1-2) vergl. Turdus fuscatus, Rotflügelige Drossel.

O) Die Bürzelfedern sind immer dunkelaschgrau (Bd, I, S. 184, Tafel 23, Fig. 1-2) vergl. Turdus atrigularis, Blasse Drossel. 
$\times X$ Die Federn der Kropfgegend sind entweder in größerer oder geringerer Ausdehnung heller oder dunkler rotbraun, oder sie sind z. T'. mit schwärzlichen, vorn spitzen Schaftflecken versehen (Bd. I, S. 170, Tafel 20, Fig. 1-3) Turdus ruficollis, Rothalsige Drossel.

ß) Die äußerste Schwanzfeder ist den Schwingen gleich gefärbt.

* Auf der Kropfgegend sind alle Federn mit schwärzlichen, vorn spitzen Schaftflecken versehen; der anliegende Flügel ist nur etwa $12 \mathrm{~cm}$ lang. $\uparrow$ Die unteren Flügeldeckfedern sind rostrot; auch die Seiten des Körpers sind unter den anliegenden Flügeln und in den Weichen mit rostroten Federn versehen (Bd. I, S. 218, Tafel 27, Fig. 1-4); nordische Art, in Deutschland fast nur auf dem Zuge

\section{Turlus ilicues, Rothrossel, Weindrossel.}

$\doteqdot$ Die unteren Flügeldeckfedern sind rostgelb; die Federn an den Körperseiten besitzen alle eine gelblichweiße Grundfarbe (Bd. I, S. 202, Tafel 26, Fig. 1) . . Turdus musicus, Sing-Drossel.

** Die Federn auf der Kropfgegend sind nicht mit vorn spitzen Schaftflecken versehen; der anliegende Fliigel ist meist $13 \mathrm{~cm}$ lang oder länger, stets länger als $12 \mathrm{~cm}$.

† Die Federn der Rückenseite (Rïcken, Bürzel, Flügelfedern) sind teilweise am Rande oder in der Endhälfte rotbraun oder braunrot, gefärbt (Bd. I, S. 175, Tafel 21, Fig. 1 und 2)

Turdus fuscatus, Rotflügelige Drossel.

$\dagger$ Die Federn der Rückenseite besitzen alle keine rotbraunen Ränder, allenfalls sind sie an der Basis oder am Schaft heller.

$\times$ Die Brust zeigt eine rostgelbliche oder roströtliche Grundfarbe. - Die unteren Schwanzdeckfedern sind schwärzlichgrau gefärbt, sie sind entweder einfarbig oder mit hellen Teilen von geringer Ausdehnung versehen (Bd. I, S. 153, Tafel 18, Fig. 3) das Jugendkleid von Turdus merula, Schwarz-Drossel, Amsel.

O Die unteren Schwanzdeckfedern sind wenigstens im mittleren Teil der Endhälfte breit weiß.

$\odot$ Die Federn der Kropfgegend sind entweder braunrot, oft grau berandet oder gelblich und mit schwärzlichem Fleck versehen (Bd. I, S. 196, Tafel 25, Fig. 1-3)

Turdus migratorius, Wander-Drossel.

$\odot \odot$ Die Federn der Kropfgegend sind entweder grau oder rostgelblich, oder z. T. olivenbraun (Bd. I, S. 180, Tafel 22, Fig. 1-2)

vergl. Turdus obscurus, Blasse Drossel.

$\times \times$ Die Brust und die Kropfgegend zeigen keine rostgelblichen oder roströtlichen Federn (Bd. I, S. 184, Tafel 23, Fig. 1-2)

Turdus atrigularis, Schwarzkehlige Drossel. 
b) Die Federn an der Unterseite der Flügel sind entweder grau oder weiß oder gelblichweiß oder olivenbräunlich, nur hart am Ende besitzen sie bisweilen einen rostbräunlichen oder rostgelblichen Anflug:

a) die großen unteren Schwanzdeckfedern sind ganz oder größtenteils dunkel gefärbt, allenfalls ist eine mittlere Längsbinde und der Rand weiß; die Federn am Bauch zwischen den Beinen sind entweder ganz schwarz bezw. graubraun oder doch mit einer gebogenen dunklen Querbinde versehen, die nicht den Rand berührt.

* Die Außenfahne der sechsten Schwinge ist vor dem Ende verengt (vergl. Fig. 32 S. 7) und deshalb $1 \mathrm{~cm}$ vom Ende entfernt nicht breiter als die der zweiten Schwinge an der breitesten Stelle; das Gefieder ist beim ausgefärbten Tier fast einfarbig schwarz oder schwarzbraun (Bd. I, S. 153, Tafel 18, Fig. 1-3) Turdus merulr, Schwarz-Drossel, Amsel.

Die Außenfahme der sechsten Schwinge ist vor dem Ende nicht verengt (vergl. Fig. 25 S.9) und deshalb $1 \mathrm{~cm}$ vor dem Encle doppelt so breit wie die Außenfahne der zweiten Schwinge an der breitesten Stelle; der ausgefärbte Vogel besitzt eine weiße Binde quer über die Oberbrust (Bd. I, S. 161, Tafel 19, Fig. 1-4); in Berggegenden

Turdus torquatus, Ring-Drossel.

ק) Die großen unteren Schwanzdeckfedern sind stets am Ende querüber weiß oder gelblich; in der Mitte des Bauches (zwischen den Beinen) sind die Federn in ihrem sichtbaren Teil entweder ganz weiß oder gelblichweiß; sind dunkle Teile vorhanden, so berihren dieselhen den Rand der Federn.

* Der anliegende Flügel ist 14-17 cm lang; die Brust ist stets mit scharf begrenzten dunklen Flecken versehen.

$\doteqdot$ Die Flecke auf den Seiten des Bauches sind halbmondförmig, vorn konkav; die Rückenseite des Körpers ist olivenbraun gefärbt, die Ränder der Flügeldeckfedern und Schwingen sind nicht aschgrau (Bd. I, S. 142, Tafel 16, Fig. 1-2)

Geocichla mollissima, Weichfederige Drossel.

$\because$ Die Flecke an den Seiten des Bauches sind vorn konvex; die Farbe des Rückens zieht ins Grüne; die Flügelfedern zeigen aschgrane Ränder (Bd. I, S. 226, Tafel 28, Fig. 1-2); im Norden und im Gebirge, sonst nur auf dem Zuge. T'urdus riscivorus, Mistel-Drossel.

Der anliegende Flügel ist höchstens $13,5 \mathrm{~cm}$ lang.

$\uparrow$ Die Oberbrust ist mit scharf begrenzten schwärzlichen, vorn spitzen Längsflecken versehen; der Hinterrücken und der Hals ist oben grau, der dazwischen liegende Teil des Rückens ist dunkelrotbraun (Bd, I. S. 209, Tafel 26, Fig. 2); in Deutschland nur auf dem Zuge

Turdus pilaris, Wacholder-Drossel, Krammetsvogel. 
it Die Oberbrust ist entweder einfarbig oder mit Flecken versehen, die vorne gerundet oder konkav sind, nur an der Kehle sind bisweilen Flecke vorhanden, die vorn spitz sind; die Rückenseite des Vogels ist von vorn bis hinten gleich gefärbt.

$\times$ Die unteren Schwanzdeckfedern sind nur am Ende querüber weiß, die weiße Farbe geht vom Ende nicht $2 \mathrm{~cm}$ weit nach der Wurzel hin; beim ausgefärbten Vogel ist der Rücken schieferschwarz (Bd. I, S. 135, Tafel 15, Fig. 1-5)

Geocichla sibirica, Sibirische Drossel.

$X \times$ Die großen unteren Schwanzdeckfedern sind am Schaft mindestens $3 \mathrm{~cm}$ nach der Wurzel hin weiß, nur am Rande des sichtbaren Teils sind sie dunkel gefärbt; der Ruicken ist olivenbraun gefärbt (Bd. I, S. 180, Tafel 22, Fig. 1 und 2)

Turdus obscurus, Blasse Drossel.

\section{Havporhynchus.}

(Naumann, Bd. I, S. 243, Tafel 30, Fig. 2)

Harporhynchus rufus, Rote Spottdrossel.

\section{Cettia.}

(Nadmann, Bd. I, S. 1, Tafel 1, Fig. 3) Cettia cetti, Cetti's Rohr'sänger.

\section{Lusciniolr.}

I. Die Federn an der Oberseite des Kopfes und am Oberhals sind in der Mitte fast schwarz, am Rande hell olivenbräunlich; die Federn des Rückens sind mit breiten olivenbräunlichen Rändern versehen (Bd. I, S. 8, Tafel $1 \mathrm{a}$, Fig. 2) . . . Lusciniola melanopogon, Tamarisken-Rohrsänger.

II. Die Federn des Oberkopfes, des Oberhalses und des Rückens sind querüber einfarbig olivenbraungrau (Bd. II, S. 5, Tafel 1 a, Fig. 1)

Lusciniola fuscata, Brauner Laubvogel.

\section{Locustella.}

I. Die Federn am Oberkopfe und Rücken sind queriber olivenbraungrau gefärbt, am Rande nicht heller.

A) In der Kropfgegend ist die Mitte der Federn viel dunkler gefärbt als der breite Randteil; die untern Schwanzdeckfedern sind olivenbräunlichgrau gefärbt, ihr Endteil ist weiß (Bd. II, S. 21, Tafel 1a, Fig. 3); östliche Art

\section{Locustella fluviatilis, Fluf-Rohrsänger.}

B) Die Federn in der Kropfgegend sind im sichtbaren Endteil querüber weißlich gefärbt, rotbräunlich angehaucht, ein dunkler Mittelteil ist nicht vorhanden; die untern Schwanzdeckfedern sind mehr ockerbräunlich gefärbt, 
der weißliche Endteil ist meist weniger scharf abgegrenzt (Bd. II, S. 26, Tafel 1 a, Fig. 6) . . Locustella luscinioides, Weiden-Rohrsänger.

II. Die Federn am Oberkopfe und Rücken sind in der Mitte schwärzlich, am Rande olivenbraungrau.

A) Die äußerste Schwanzfeder ist am Ende (etwa $3 \mathrm{~mm}$ ) breit weißlich gesäumt (Bd. II, S. 31, Tafel 1a, Fig. 7)

Locustella certhiola, Gestreifter Rohrsänger.

B) Die äußerste Schwanzfeder ist am Ende nicht weißlich gesäumt.

a) Die Federn der Vorderbrust sind mit dunklen Schaftflecken, die untern Schwanzdeckfedern ockerbräunlich, mit langem schmalen Schaftstrich versehen (Bd. II, S. 11, Tafel 1, Fig. 2 und 4)

Locustella lanceolata, Gestrichelter Heuschreckenrohrsänger.

b) Nur an der Unterkehle sind meist einige schwärzliche Fleckchen vorhanden; die untern Schwanzdeckfedern sind am Rande breit weißlich, der Schaftteil ist schwärzlich, der dunkle Teil verbreitert sich nach der Basis der Federn hin (Bd. II, S. 14, Tafel 1a, Fig. 4 und 5)

Locustella naevia (locustella), Heusehreckensinger.

\section{Calamodus und Acrocephalus.}

I. 'Die zweite Schwinge ist kuirzer als die sechste (Bd. II, S. 77, Tafel 1, Fig. 1) Acrocephalus agricola, Feld-Rohrsänger.

II. Die zweite Schwinge ist länger als die vierte.

A) Die Federn auf dem Oberkopf und Rücken sind am Rande oder auf der einen Hälfte viel heller als auf der Mitte bezw. auf der andern Hälfte. a) Auf der Mitte des Kopfes ist eine dunkel begrenzte, gelbliche Längsbinde vorhanden, die dadurch zustande kommt, daß von einigen Federn die Innenfahne fast ganz gelblich, die Außenfahne fast ganz schwarz ist (Bd. II, S. 40, Tafel 2, Fig. 2-5)

Calamodus arucuticus, Binsen-Rohrsäinger.

b) Auf der Mitte des Kopfes sind die Federn nur am Rande hell.

a) Die äußersten Schwanzfedern sind dunkelolivengraubraun gefärbt, am Rande ringsherum etwas heller gesäumt (Bd. II, S. 33, Tafel 2, Fig. 1)

Calcmodus schoenobaenus, Schilf-Rohrsiinger.

ק) Die äußerste Schwanzfeder ist schwärzlich, am Ende breit weißlich gesäumt (Bd. II, S. 31, Tafel 1 a, Fig. 7)

vergl. oben Locustella certhiola, Gestreifter Rohrsïnger.

B) Die Federn auf dem Oberkopf und dem Riicken sind queriber gleich dunkel gefärbt.

a) Der anliegende Flügel ist über $9 \mathrm{~cm}$ lang, die nackte Schnabelfirste mindestens $16 \mathrm{~mm}$ (Bd. II, S. 49, Tafel 2, Fig. 6)

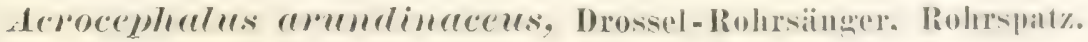


b) Der anliegende Flügel ist nicht über $8 \mathrm{~cm}$ lang, die nackte Schnabelfirste höchstens $13 \mathrm{~mm}$.

«) Die äußerste Schwanzfeder ist ungefähr ebenso lang wie die mittelste; die nackte Schnabelfirste ist höchstens $10 \mathrm{~mm}$ lang (Bd. II, S. 162, Tafel 11, Fig. 5) vergl. unten Syluia simplex, Garten-Grasmiicke.

$\beta)$ Die äußerste Schwanzfeder ist mindestens $3 \mathrm{~mm}$ kürzer als die mittelste; die nackte Schnabelfirste ist mindestens $11 \mathrm{~mm}$ lang.

Die längeren untern Schwanzdeckfedern sind grau, am Ende breit und scharf abgesetzt, weißlich gefärbt (Bd. II, S. 21, Tafel 1 a, Fig. 3)

vergl. oben Locustella fhuirtilis, Fluf-Rohrsïnger.

** Die längeren untern Schwanzdeckfedern sind ganz weiflich gefärbt.

† Die oberen Schwanzdeckfedern sind dunkel rostbräunlich; die untern Flïgeldeckfedern an der vorderen Beuge ebenfalls rostbräunlich gefärbt (Bd. II, S. 64, Tafel 3, Fig. 1 und 2)

Acrocephalus streperus, 'Teich-Rohrsänger.

$\doteqdot$ Die obern Schwanzdeckfedern sind olivenbräunlich; die untern Flügeldeckfedern weißlich gefärbt (Bd. II, S. 56, Tafel 3, Fig. 4)

Arocephalus palustris, Sumpf-Rohrsänger.

\section{H!ypolais und Phylloscopms [Phyllopneuste].}

I. Die erste Schwinge ragt nicht oder kaum über das Ende der den folgenden Schwingen aufliegenden längeren oberen Flügeldeckfedern hinaus.

A) Der anliegende Flügel ist nicht $7 \mathrm{~cm}$ lang; die Kehle zeigt fast gar keinen gelblichen Farbenton (Bd. II, S. 134, Tafel 7, Fig. 3)

Phylloscopus boreatis. Nordischer Laubvogel.

B) Der anliegende Flügel ist über $7 \mathrm{~cm}$ lang.

(1) Die Kehle ist weiß, die Oberseite des Körpers dunkelaschgrau gefärbt; die nackte Schnabelfirste ist mindestens $13 \mathrm{~mm}$ lang; der anliegende Flitgel ist über $8 \mathrm{~cm}$ lang (Bd. II, S. 90, Tafel 4, Fig. 4)

Hypolais olivetorum, Olivenspötter.

B) Die Kehle ist mehr oder weniger gelblich angeflogen, die Oberseite des Körpers grünlich oder olivenbräunlich gemischt; die nackte Schnabelfirste wird bis $12 \mathrm{~mm}$, der anliegende Fluigel bis $8 \mathrm{~cm}$ lang.

a) Der Bauch ist in der Mitte weiß; die Außenfahne der Schwingen ist lebhaft griinlich gelb berandet (Bd. I, S. 123, Tafel 6, Fig.4)

Phylloscopus sibilator, Wald-Laubvogel.

b) Der Bauch ist in der Mitte ebenso gelb gefärbt wie die Seiten der Kehle; die Außenfahne der Schwingen ist grau berandet (Bd. II, S. 82, Tafel 4, Fig. 2) . Hypolais philomeln (hypolciis), Gartenspötter. 
II. Die erste Schwinge ragt wenigstens $3 \mathrm{~mm}$ über das Ende der oberen Flügeldeckfedern hinaus.

A) Die zweite Schwinge ist nicht oder kaum (etwa $1 \mathrm{~mm}$ ) kürzer als die sechste Schwinge; die oberen Flügeldeckfedern sind stets alle schmal und gleichmäßig hell berandet.

2). Die nackte Schnabelfirste ist über $10 \mathrm{~mm}$ lang und an der vorderen Federgrenze über $4 \mathrm{~mm}$ breit.

a) Die unteren Schwanzdeckfedern sind leicht kanarienvogelgelb angehaucht (Bd. II, S. 92, Tafel 4, Fig. 3)

$$
\text { Hypolais polyglotta, Sänger-Laubvogel. }
$$

b) Die unteren Schwanzdeckfedern sind weiß (Bd. I, S. 88, Tafel 4, Fig. 1)

$$
\text { Hypolais pallida, Blasser Sänger. }
$$

2) Die nackte Schnabelfirste ist höchstens $9 \mathrm{~mm}$ lang und an der vorderen Federgrenze unter $4 \mathrm{~mm}$ breit.

a) Die Federn in der Kropfgegend zeigen keinen gelben Anflug; die unteren Flügeldeckfedern dagegen sind ziemlich lebhaft gelb (Bd. II, S. 113, Tafel 6, Fig. 1); suidlichere Art

\section{Phylloscopus bonelli, Berg-Laubvogel.}

b) Das Gefieder in der Kropfgegend besitzt einen deutlichen gelben Anflug (Bd. II, S. 117, Tafel 6, Fig. 3)

\section{Phylloscopus trochilus, Fitis-Iaubvogel.}

B) Die zweite Schwinge ist mindestens $2 \mathrm{~mm}$ kürzer als die sechste Schwinge (bei $P h$. nitidus $2 \mathrm{~mm}$, bei den andern Arten $3 \mathrm{~mm}$ und mehr kürzer), die größeren oberen Flügeldeckfedern sind oft (aber nicht immer) zum Teil am Ende breit hell gefärbt.

AA) Die oberen Flügeldeckfedern sind schmal und verwaschen hell gerandet, am Ende nicht breiter hell gerandet als vorn.

a) Die äußerste Schwanzfeder ist sehr hell, fast weißlich gefärbt, über $2 \mathrm{~mm}$ kürzer als die mittleren (Bd. II, S. 79, Tafel 10, Fig. 5)

Hypolais salicaria, Zwerg-Sänger.

b) Die äußerste Schwanzfeder ist kaum heller und kaum kürzer als die andern.

a) Die Rückenseite des Körpers, namentlich in der Bürzelgegend, ist mit einem entschieden grünlichen Ton versehen; die zweite Schwinge ist länger als die achte, die dritte, vierte und fünfte sind länger als die sechste (Bd. II, S. 103, Tafel 5, Fig. 3)

Phylloscopus mfis, Weiden-laubvogel.

B) Die Rückenseite des Körpers ist olivenbräunlich gefärbt; die zweite Schwinge ist kürzer als die achte, die dritte, vierte und fünfte sind nicht länger als die sechste (Bd. II, S. 100, 'T'afel 5, Fig. 4)

Phylloscopus tristis, Sibirischer Laubvogel. 
BB) Die größeren Flügeldeckfedern sind zum Teil am Ende breit und schräg abgeschnitten hellgelb gefärbt und zwar scharf abgegrenzt heller, so daß dadurch auf der Oberseite der Flügel eine oder zwei helle Querbinden bezw. Fleckenbinden entstehen.

a) Der Hinterrücken ist querüber mit einer gelblichweißen Binde versehen; der über die Augen ziehende helle Streif ist zwischen der Schnabelwurzel und dem Auge lebhaft gelb (Bd. II, S. 94, Tafel 5, Fig. 1)

Phylloscopus proregulus, Goldhähnchen-Laubvogel.

b) Der Hinterricken zeigt keine helle Querbinde; der iiber die Augen ziehende Streif ist meist weißlich (nur bei $P$. nitidus gelb).

a) Die 17. und namentlich die 18. Schwinge ist auf der Außenfahne sehr breit hell gerandet, deshalb zeigen die Flügel hinter den hellen Querbinden immer noch helle Längsstreifen (Bd. II, S. 96, Tafel 5, Fig. 2) Phylloscopus superciliosus, Gelbbrauiger Laubvogel.

$\beta$ ) Die letzten Schwingen sind nicht heller gerandet als die andern.

* Der Oberkopf ist in der Mitte mit hellem Längsstreif versehen (Bd. II, S. 128, Tafel 6, Fig. 2)

Phylloscopus coronatus, Gehäubter. Laubvogel.

** Der Kopf ist oben einfarbig.

† Die Kehle ist weiflich; der Streif, der von der Schnabelwurzel iiber die Augen zieht, ist zwischen der Schnabelwurzel und dem Auge gelblichweiß (Bd. II, S. 130, Tafel 7, Fig. 1)

Phylloscopus viridanus, Grüner Laubvogel

$\because$ Die Kehle ist gelblich, der Streif über den Augen ist zwischen Schnabelwurzel und Auge lebhaft gelb (Bd. II, S. 132, Tafel 7, Fig. 2) Phylloscopus nitidus, Gelber Laubvogel.

\section{Sylvia.}

I. Die erste Schwinge reicht mit ihrer Spitze nicht iber das Ende der den folgenden Schwingen aufliegenden oberen Filügeldeckfedern hinaus.

A) Die Außenfahne der äußersten Schwanzfeder ist fast bis zur IVurzel queriber weiß.

a) Die letzten Schwingen sind auf der Außenfahne nach der Basis hin in der Außenhälfte rostbräunlich; die Kehle ist stets weiß gefärbt, der Oberkopf wie der Riicken olivenbräunlichgrau (Bd. II, S. 174, Tafel 11, Fig. 3 u. 4)

Sylvire sylvia (cinerea), Dorn-Grasmiicke.

b) Die letzten Schwingen sind am Außenrande der Außenfahne weißlich oder gelblichgrau gefärbt; die Kehle und die vordere Kopfplatte sind beim ausgefärbten Gefieder schwarz . . . . . . Sylyia rïppelli.

B) Die Außenfahne der äußersten Schwanzfeder ist größtenteils dunkel gefärbt. 
a) Die äuferste Schwanzfeder zeigt am Ende der Innenfahne einen grofjen weißen oder weißlichen Fleck; die unteren Schwanzdeckfedern sind mit dunklen Winkelzeichnungen versehen (Bd. II, S. 138, Tafel 8, Fig. 1 u. 2)

\section{Sylvir misoria, Sperber-Grasmicke.}

b) Die äußerste Schwanzfeder ist entweder ganz grau oder rings schmal hell gerandet, der helle Rand ist am Ende der Innenfahne höchstens $2 \mathrm{~mm}$ breit, niemals zu einem weißlichen Fleck erweitert; die unteren Schwanzdeckfedern sind in dem sichtbaren Teil einfarbig hell, nach der Wurzel hin geht ihre Farbe allmählich in grau über.

a) Die nackte Schnabelfirste ist höchstens $10 \mathrm{~mm}$ lang; die äußerste Schwanzfeder ist ganz grau (Bd. II, S. 162, Tafel 11, Fig. 5)

\section{Sylvia simplex, Garten-Grasmiicke.}

ß) Die nackte Schnabelfirste ist mindestens $13 \mathrm{~mm}$ lang; die äußerste Schwanzferler ist am Ende $1^{1 / 2} \mathrm{~mm}$ breit weißlich gerandet (Bd. II, S. 90, Tafel 4, Fig. 4) s. oben Hypolais olivetorum, Olivenspötter.

II. Die erste Schwinge reicht über das Ende der den folgenden Schwingen aufliegenden oberen Flügeldeckfedern hinaus.

A) Die Außenfahne der äußersten Schwanzfeder ist bis zum Rande grau, ebenso wie die andern Teile der Feder.

a) Der Oberkopf ist dunkler als der Rücken, schwarz oder olivenbräunlich gefärbt; der Hals und die Brust zeigen keine dunklen Längsflecke; der anliegende Flügel ist nicht ganz $8 \mathrm{~cm}$ lang (Bd. II, S. 152, Tafel 9, Fig. 1-4)

\section{Sylvia atricapilla, Mönch-Grasmicke, Mönch.}

b) Der Kopt, der Hals und die Brust zeigen dunkle Schaftflecke; der anliegende Flügel ist über $8 \mathrm{~cm}$ lang (Bd. IV, S. 158, Tafel 19)

\section{vergl. oben Muscicapa grisola, Gelleckter Fliegenfïinger.}

B) Die Außenfahne der äußersten Schwanzfeder ist wenigstens zum Teil weiß bezw. weißlich.

AA) Die Außenfahne der äußersten Schwanzfeder ist auf einem 'Teil ihrer Länge bis zum Schaft hin rein weiß, entweder im Endteil, bis $5 \mathrm{~cm}$ weit vom Ende entfernt, oder weiter nach der Wurzel hin.

a) Die beiden mittleren Schwanzfedern sind rostgelblichgrau wie der Bürzel; die übrigen Schwanzfedern sind wenigstens auf der Innenfahne entweder schwärzlich oder weiß; der anliegende Flügel ist $6-6^{1} / 2 \mathrm{~mm}$ lang . . . . . . . . . . . . Sylvia nana.

b) Die beiden mittleren Schwanzfedern zeigen keinen andern Farbenton als die ubrigen Schwanzfedern, sie sind höchstens etwas heller.

( ) Der anliegende Flügel ist $6,5-8 \mathrm{~cm}$ lang, der Flügel ist spitzer, das Ende der siebenten Schwinge ist deshalb bei zusammengelegtem Flügel mindestens $6 \mathrm{~mm}$ vom Ende der längsten Schwinge entfernt. 
Der anliegende Flügel ist $7,5-8 \mathrm{~cm}$ lang (Bd. II, S. 144, Tafel 8, Fig. 3 und 4) . . . . Sylvia orphea, Sänger-Grasmücke. ** Der anliegende Flügel ist nicht über $7 \mathrm{~cm}$ lang (Bd. II, S. 168, Tafel 11. Fig. 1 und 2)

\section{Sylvia curruca, Zaun-Grasmiicke, Miillerchen.}

ß) Der anliegende Flügel ist nicht oder kaum ïber $6 \mathrm{~cm}$ lang; der Fliigel ist stumpfer, das Ende der siebenten Schwinge deshalb höchstens $5 \mathrm{~mm}$ vom Ende der längsten Schwinge entfernt.

* Die Außenränder der letzten Schwingen sind breit hell rostrot gefärbt und ebenso die diesen Schwingen an der Wurzel aufliegenden längeren Flügeldeckfedern, so daß der obere Teil der anliegenden Flügel rostrot erscheint; die Brust zeigt einen rötlichen Hauch, die Kehle aber ist weib . . . . . . . . . Sylvia conspicillata.

** Die Federränder am oberen Teil des anliegenden Flügels sind olivenbräunlich oder grau.

Auf dem mittleren Teil der äußersten Schwanzfeder bildet der Schaft eine scharfe Grenze zwischen dem hellsten (weißen) und dem dunkelsten Teil der Feder; der Oberkopf ist entweder schwärzer oder mehr grau als der Rücken (Bd. II, S. 148, Tafel 10, Fig. 1 u. 2) Sylvia melanocephala, Schwarzköpfige Grasmücke.

$\bigcirc$ Auf der äußersten Schwanzfeder sind die 'Teile neben dem Schaft nicht die dunkelsten; der Oberkopf zeigt dieselbe Farbe wie der Rücken: die Kehle und die Brust sind oft rostrot.

$\doteqdot$ Die unteren Schwanzdeckfedern sind größtențeils weiß (Bd. II, S. 181, Tafel 11a, Fig. 1 und 2)

Sylvia subalpina, Weißbärtiger Strauchsänger.

† Die unteren Schwanzdeckfedern sind größtenteils grau (Bd. II, S. 184, Tafel 10, Fig. 3 und 4) Sylvia undata, Provence-Grasmücke.

BB) Die Außenfahne der äußersten Schwanzfeder ist nirgends queriber reinweiß.

a) Die unteren Schwanzdeckfedern sind entweder weiß oder kanarienvogelgelblich.

«) Die unteren Schwanzdeckfedern sind gelblich angehaucht (Bd. II, S. 92, Tafel 4, Fig. 3)

vergl. oben S. 43 Hypolais polyglotta, Sänger-Laubvogel.

ß) Die unteren Schwanzdeckfedern sind weiß.

* Die zweite Schwinge ist ein wenig oder viel länger als die siebente; der Flügel ist spitzer, das Ende der siebenten Schwinge ist deshalb bei anliegendem Flügel $4 \mathrm{~mm}$ und dariiber vom Ende der längsten Schwinge entfernt (Bd. II, S. 88, Tafel 4, Fig. 1)

vergl. oben S. 43 Hypolais pallida, Blasser Sänger. 
** Die zweite Schwinge ist kürzer als die siebente; der Flïgel ist stumpfer und deshalb das Ende der siebenten Schwinge nicht $4 \mathrm{~mm}$ vom Ende der längsten Schwinge entfernt (Bd. II, S. 79, Tafel 10, Fig. 5)

vergl. oben S. 43 Hypolais salicaria, Zwerg-Sänger.

b) Die unteren Schwanzdeckfedern sind größtenteils grau.

«) Die Kehle und die Brust sind weißlichgrau bis schiefergrau

Sylvia sarda.

в) An der Kehle und an der Brust sind die Federn zum Teil rostrot (Bd. II, S. 184, 'Tafel 10, Fig. 3 und 4)

s. oben Sylvia undata, Provence-Grasmücke,

\section{Agrobutes.}

I. Der Rücken hat einen viel rötlicheren Farbenton als die Schwingen und ist zugleich heller; die mittleren Schwanzfedern sind queruber ebenso rotbraun wie die benachbarten (Bd. II, S. 187 und 191, Tafel 12, Fig. 2 und 3) Agrobates galactodes, Spanischer Heckensänger.

II. Der Rücken ist zwar heller als die Schwingen, aber kaum rötlicher; die beiden mittleren Schwanzfedern sind, namentlich auf der Innenfahne, stets viel dunkler als die andern Schwanzfedern (Bd. II, S. 187 und 193, Tafel 12, Fig. 1). . Agrobates familiaris, Griechischer Heckensänger.

\section{Anorthura [Troglodytes].}

(N.)NANx, Bd. II, S. 197. Tafel 1:3) Amorthmer troglodytes, Zamkönig.

\section{Cinclus.}

I. Die ganze Unterseite des Körpers besitzt eine schwarze Farbe mit rotbraunem Ton (Bd. II, S. 214, Tafel 14, Fig. 5)

Cinclus pallasi, Brauner Wasserstar.

II. Die Kehle und die Oberbrust sind weiß, beim Jugendkleide etwas dunkel gefleckt.

A) Der vordere Teil der dunklen Unterseite des Körpers, der beim ausgefärbten Gefieder unmittelbar an die weiße Oberbrust stößt, zeigt einen kaum merklichen rotbraunen Ton, die Farbe ist an der Brust etwa dieselbe wie am Oberhals (Bd. II, S. 214, Tafel 14, Fig. 4 und 5); nördliche Form

Cinclus cinclus, Nordischer Wasserstar.

B) Der vordere Teil der dunklen Unterseite des Körpers zeigt einen lebhaft rostroten Ton, er ist stets in größerer Ausdehnung lebhafter rostrot als der Oberhals (Bd. II, S. 208, Tafel 14, Fig. 1 und 3)

cinclus reinclus agurtirus, fiemeiner Wasserstar. Wasseramsel. 
Cisticola.

(Naumanx, Bd.II, S.217, Tafel 11 a, Fig.3) Cisticola cisticola, Cistensänger.

\section{Regrilus.}

I. Von der Schnabelwurzel geht durch das Auge ein dunkler Streif; über dem Auge befindet sich beim ausgefärbten Gefieder eine reinweiße Bogenbinde; vor der Schulterbeuge der Flügel sind die Federenden lebhaft gelb (Bd. II, S. 230, Tafel 15, Fig. 1-3); besonders im Suidwesten.

Regulus ignicapillus, Fenerkippliges Goldhïhnchen.

II. Der dunkle Streif durch das Auge fehlt; über dem Auge befinden sich nie reinweiße Federn: die Federn vor der Schulterbeuge der Flügel besitzen höchstens einen grünlichen Ton (Bd. II, S. 224, Tafel 15, Fig. 4-6)

Regulus regulus (cristatus), Gelbkïpliges Goldhïhnchen.

Panums [Calamophilus].

(Naumaxt, Bd. II, S. 234, Tafel 16, Fig. 1-4); besonders im Suidosten heimisch Prmomes birmmicus, Bart-Rohrmeise.

\section{Remiars [Aegithalus].}

(Naumaxx, Bd.II, S. 240, Tafel 17, Fig. 1-4); besonders im Südosten heimisch Remisus pendulinus, Beutelmeise.

,

(Naumann, Bd. II, S. 246, Tafel 18, Fig. 3-6)

\section{Aegithalus [Acredula].}

Aegithalus caudatus, Schwanzmeise.

I. Der Oberkopf ist nur bei den jungen Tieren an den Seiten dunkel gefärbt, beim ausgefärbten Vogel dagegen ganz weißlich (Bd. II, S. 246, Tafel 18, Fig. 3). . Jegithrtus roudutus, Woilkijpfigo Sohwanzmeise.

II. Der Oberkopf ist beim ausgefärbten Vogel nur in der Mitte weißlich, an den Seiten dagegen mit einer schwärzlichen Längsbinde versehen.

A) Der Rücken ist in der Mitte schwarz (Bd. II, S. 252, Tafel 18, Fig. 4 und 5); westliche Form

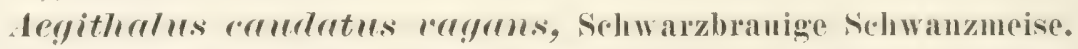

B) Die Mitte des Rückens ist querüber grau (Bd. II, S. 253, Tafel 18, Fig. 6) Aegithalus caudatus irbyi, Sïdliche Schwanzmeise.

\section{Proms.}

I. Die Unterseite des Körpers ist bis zum Bauche hin schwefel- oder goldgelb, nur die Federn unter dem Schwanze sind bisweilen weiß. 
A) Die äußerste Schwanzfeder ist der Länge nach bis zum Schafte oder dariuber hinaus weiß oder weißlich; der dunkle Teil an der Kehle ist in der Mitte stets nach hinten ausgezogen; der Oberkopf ist beim reifen Vogel glänzend schwarz; die nackte Schnabelfirste ist mindestens $8 \mathrm{~mm}$ lang (Bd. II, S. 254, Tafel 20, Fig. 3) . . Parus major, KohImeise.

B) Die Außenfahne der äußersten Schwanzfeder ist nur mit sehr schmalem hellen Außenrande versehen; die Kehle ist beim Jugendkleide ganz weiß, beim reifen Vogel ist der dunkle Teil nicht in der Mitte nach hinten ausgezogen; der Oberkopf ist beim reifen Vogel schön hellblau; der nackte Schnabel ist nicht $8 \mathrm{~mm}$ lang (Bd. II, S. 272, Tafel 18, Fig. 1 und 2)

Parus coemuleus, Blaumeise.

II. Der Bauch ist stets weiß oder schwach rostrot angehaucht, allenfalls besitzt die Brust einen gelblichen Ton (P.pleskiei).

A) Der Kopf trägt eine Haube; die schwärzlichen Haubenfedern zeigen wenigstens z. T. breite lichtgraue Endränder, beim Gefieder des reifen Vogels sind auch die Außenränder dieser Federn grö́tenteils licht (Bd. II, S. 268, Tafel 19, Fig. 1 und 2 und Tafel 20, Fig. 1)

Parus cristatus, Haubenmeise.

B) Der Kopf trägt keine Haube; die Federn des Oberkopfes sind entweder schwarz oder dunkel braungrau oder weißlich bezw. bläulich gefärbt.

AA) Am Kinn sind die Federchen entweder ganz weißlich oder nur an der Wurzel schmal dunkel; auch der Oberkopf ist weiß oder himmelblau. a) Die äußerste Schwanzfeder ist auf der Endhälfte querüber weiß; der Oberkopf ist meist kaum merklich blau angehaucht (Bd. II, S, 280, Tafel 18, Fig. 7) . . . . . . Parus cyanus, Lasurmeise.

b) Die äußerste Schwanzfeder ist nur auf der Außenfahne und am Endrande weiß; der Oberkopf ist in der Mitte ziemlich scharf abgegrenzt himmelblau (Bd.II, S. 278, Tafel 18, Fig. 8) Parus pleskei, Russische Blaumeise.

BB) Am Kinn sind stets einige der kleinen Federchen ganz oder fast ganz schwärzlich oder dunkelbraungrau; der Oberkopf ist aschgrau bis schwarzbraun oder schwarz gefärbt.

a) Die oberen Flügeldeclifedern sind teilweise mit breitem, scharf abgegrenztem weißen Endfleck versehen; in dem dunklen Teil des Hinterkopfes befinden sich stets weiße Federn (Bd. II, S. 264, Tafel 20, Fig. 2)

Parus ater, Tannenmeise.

b) Die oberen Flügeldeckfedern sind nur mit verwaschenen hellen Rändern versehen; am Nacken befinden sich keine weißen Federn

Parus palustris, Sumpfmeise.

a) Die mäusegraue Farbe des Oberkopfes reicht bis zum Rücken; dieser ist querüber roströtlich (Bd. II, S. 297, Tafel 22, Fig. 1)

Parus palustris cinctus, Lappländische Sumpfmeise. 
$\beta$ ) Der Oberkopf ist entweder schwarz oder dunkelgraubraun; im letzteren Falle von der Farbe des Rückens nicht verschieden.

Der anliegende Flügel ist über 6,5 cm lang; die Kehle ist (vom Kinn ab gemessen) über $2 \mathrm{~cm}$ weit nach unten dunkel gefärbt; der Oberkopf ist braunschwarz bis dunkelbraungrau (juv.); im letzteren Falle von der Farbe des Rückens kaum verschieden (Bd. II, S. 395, Tafel 21, Fig. 2) . . . . Parus palustris lugubris, Trauermeise.

** Der anliegende Flügel ist höchstens $6,5 \mathrm{~cm}$ lang; die Kehle ist weniger weit dunkel; wenn etwas weiter hinab dunkel, dann sind unten wenigstens die Federränder breit reinweiß.

Der Rücken ist entweder aschgrau mit kaum merklichem bräunlichen Ton oder fast weiß; die Seiten des Kopfes unter den Augen und des Halses sind rein weiß.

† Die weiße Farbe der Halsseiten geht unmerklich in die grauweiße Farbe des Rückens über; die Außenfahne der äußersten Schwanzfeder ist fast ganz reinweiß (Bd. II, S. 294, Anm.)

Parus palustris kamtschatkensis.

$\pitchfork$ Der Rücken ist aschgrau; die Farbe desselben ist von der weißen Farbe der Halsseiten scharf abgesetzt; die Außenfahne der äußersten Schwanzfeder ist fast querüber hellgrau.

X Im Norden und Nordosten (Bd. II, S. 292, Tafel 21, Fig. 3)

Parus palustris borealis, Nordische Meise. $X X$ In den Alpen (Bd. II, S. 291, Tafel 21, Fig. 2)

Parus palustris montamus, Alpenmeise.

O Der Rücken ist mehr bräunlich und die hellen Teile an den Seiten des Kopfes und Halses sind etwas gelblich oder grau angehaucht.

$\leftarrow$ Der dunkle Kinnfleck ist etwas ausgedehnter; die Federn des Oberkopfes besitzen beim reifen Gefieder keinen Metallglanz (Bd. II, S. 291, Tafel 21, Fig. 1); im Südwesten

Parus palustris salicarius, Weidenmeise.

† Der dunkle Kinnfleck ist weniger ausgedehnt; die Federn des Oberkopfes besitzen einen metallischen Glanz (Bd. II, S. 285, Tafel 21, Fig. 4 und 5); in Deutschland die häufigste Form

Parus palustris meridionalis, Nonnenmeise.

\section{Sitte.}

I. Die äußerste Schwanzfeder ist auf der Außen- und Innenfahne vor dem Ende z. T. reinweiß; diese weißen Teile sind oft nur durch den dunklen Schaft getrennt; die untern Schwanzdeckfedern sind in der Mitte stets viel 
heller als am Seitenrande, am Seitenrande rostgelb (juv.) oder rostrot: der anliegende Flügel ist über $8 \mathrm{~cm}$ lang.

A) Die Brust ist rein weiß (Bd. II, S. 302, Tafel 23, Fig. 4); nördliche Form

Sitta enroprea, Europaiischer Kleiber, Spechtmeise.

B) Die Brust ist rostgelblich (Bd. II, S. 302, Tafel 23, Fig. 1 und 2); süd-

lichere Form . Sitta europaea caesia, Westdeutscher Kleiber.

II. Die äußerste Schwanzfeder zeigt keine weißen Teile, auf der Innenfahne befindet sich ein dreieckiges gelblichweißes Feld; die Außenfahne ist nach der Wurzel hin wenig heller; die unteren Schwanzdeckfedern sind querüber rostgelblich; der anliegende Flügel ist nicht $8 \mathrm{~cm}$ lang (Bd. II, S. 309, Tafel 11a, Fig. 4) . . . Sitta neumayeri, Felsenspechtmeise.

\section{Tichodroma.}

(Naumaxx, Bd. II, S. 312, Tafel 24, Fig. 1 und 2); im Gebirge

Tichodroma muraria, Alpenmauerlïufer.

\section{Certhix.}

I. Die nackte Schnabelfirste ist beim reifen Vogel, in gerader Linie gemessen, über $15 \mathrm{~mm}$ lang; die stark gebogene Hinterkralle ist, ebenfalls in gerader Linie gemessen, kaum über halb so lang; beim jungen Vogel ist der Schnabel viel kürzer, aber immer noch um die Hälfte länger als die Hinterkxalle (Bd. II, S. 320, Tafel 25, Fig. 2); nordöstliche Form

Certhia familiaris marhyractyla, Kurzzehiger Bambaufer.

II. Die nackte Schnabelfirste ist beim reifen Vogel, in gerader Linie gemessen, nicht $15 \mathrm{~mm}$ lang; die weniger gebogene Hinterkralle ist etwa $3 / 4$ so lang; beim jungen Vogel ist die Hinterkralle fast ebenso lang wie der Schnabel (Bd. II, S. 320, Tafel 25, Fig. 1); westliche Form

Certhia familiaris, Grauer Baumläufer.

\section{Otocorys, Welruocorypha, Calandrella, Lullula, Galerida und Chersophilus.}

I. Die kürzeren Schwingen sind mindestens im Enddrittel (bis über $2 \mathrm{~cm}$ vor dem Ende) querüber reinweiß (Bd. III, S. 12, Tafel 1, Fig. 3)

Melanocorypha sibirica, Weißflügelige Lerche.

II. Die kürzeren Schwingen sind niemals vom Ende $1 \frac{1}{2} \mathrm{~cm}$ weit nach der Wurzel hin weiß gefärbt.

A) Der Schnabel ist sehr dick und die Firste stark gebogen (Fig. 52); der anliegende Flügel ist 12-13 cm, sehr selten etwas unter $12 \mathrm{~cm}$ lang.

a) Die äußerste Schwanzfeder ist höchstens auf der Außenfahne bis zum Schaft weiß; das reife Männchen

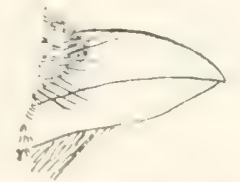

Fig. 52. Schnabel der Kialanderlerche.

$4^{*}$ 
ist fast ganz schwarz, namentlich an der Unterseite (Bd. III, S. 10, Tafel 3, Fig. 1 und 2) . . Melanocorypha yeltoniensis, Mohren-Lerche.

b) Die äußerste Schwanzfeder ist stets auch auf der Innenfahne in großer Ausdehnung weiß; der Körper ist nur am Hals vorn jederseits mit schwarzen bezw. schmal hell gerandeten Federn und über diesen mit fast ganz weißen Federn versehen (Bd. III, S. 6, Tafel 2, Fig. 1)

Melanocorypha calandra, Kalander-Lerche.

B) Der Schmabel ist weniger dick und die Firste weniger gebogen (Fig. 5:3); der anliegende Flügel ist stets unter $12 \mathrm{~cm}$ lang, meist viel kürzer.

20) Schwarze, am Rande z. T. schmal hell gesäumte Federn bilden an der Kehle und unter den Augen schwarze Zeichnungen; das Kinn, der obere Teil der Fig. 33. Schmabel dor Kehle und eine Binde über dem Auge sind beim aus-

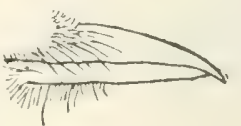
gefärbten Gefieder entweder gelblich oder rein weiß (Bd. III, S. 2, Tafel 1, Fig. 1 und 2) . . . . . Otocorys alpestris, Alpen-Lerche.

B) Das Gefieder zeigt keine schwarzen oder schwärzlichen Teile; alle Federn sind wenigstens am Seitenrande breit hell gesäumt.

a) Der anliegende Fliigel ist nicht $10 \mathrm{~cm}$ lang.

a) Die zweitäußerste Schwanzfeder ist auf der Innenfahne neben dem Schaft mit einer ziemlich ausgedehnten weißen Zeichnung versehen; der Schnabel ist sehr dünn; unter dem Schaft der ersten großen Schwinge liegt eine kurze, nicht bis an das Ende der den ersten Schwingen aufliegenden Flügeldeckfedern reichende Schwinge (Bd. III, S. 31, Tafel 2, Fig. 2) . . Lullula arborea, Heide-Lerehe, Baum-Iserche.

ß) Die zweitäußerste Schwanzfeder ist auf der Innenfahne nur hart am Endrande hell; der Schnabel ist dicker; unter der ersten größeren Schwinge liegt an der Basis keine kurze erste Schwinge.

* Auf der Kropfgegend befinden sich querüber Federn mit dunklen Schaftflecken; das Ende der vorragenden langen Schulterschwingen ist über $1 \mathrm{~cm}$ weit vom Ende des anliegenden Flügels entfernt (Bd. III, S. 16, Tafel 4, Fig. 4)

Calandrella pispoletta, Stummel-Lerche.

** Auf der Kropfgegend befinden sich nur an den Seiten Federn, die z. T. dunkel sind; das Ende der vorragenden langen Schulterschwingen ist bei unverletztem Gefieder nicht $1 \mathrm{~cm}$ vom Ende des anliegenden Flügels entfernt (Bd. III, S. 13, Tafel 4, Fig. 1)

Calandrella brachydactyla, Kurzzehige Lerche.

b) Der anliegende Flügel ist über $10 \mathrm{~cm}$ lang. 
a) Auf dem Kopfe ragen beim reifen Vogel die mittleren Federn haubenartig weit vor; auch beim Jugendkleide stehen einzelne Federn vor; bei diesem zeigen die Federn der Rückenseite des Vogels z. T. am Ende rundliche, weißliche Flecke; beim reifen Vogel geht die Farbe der Innenfahne der Rückenfedern am Ende ins Rostbraune über (Bd. III, S. 38, Tafel 5, Fig 1 und 2) . . Galevida cristata, Hauben-Lerche.

ß) Auf dem Kopfe ragen keine Federn vor; die äußerste Schwanzfeder ist stets in größerer Ausdehnung entweder weiß oder gelblichweiß; die Federn des Rückens sind entweder rings am Rande schmal hell gesäumt oder an der Innenseite breit hell gerandet.

* Der Schnabel ist lang und gebogen, mindestens $17 \mathrm{~mm}$ lang; der Sporn der Hinterzehe ist weit kürzer als der Schnabel, nicht $3 / 4$ so lang: wie dieser

Chersophilus duponti.

* Der Schnabel ist kürzer, die nackte Schnabelfirste nicht über $12 \mathrm{~mm}$ lang; der Sporn ist etwa ebenso lang oder länger als der Schnabel (Bd. III, S. 19, Tafel 4, Fig. 1 und 2)

Alauda arvensis, Feld-Terche.

\section{Anthes.}

I. Der Schaft der äußersten Schwanzfeder ist auf der Rückenseite $2 \mathrm{~cm}$ vom Ende entfernt immer leicht bräunlich und von hier nach der Wurzel hin überall gebräunt.

A) Die Schaftflecke am Kropf sind scharf begrenzt und ebenso dunkel wie die dunklen Teile der Schwanzfedern.

2) Die Kralle der Hinterzehe ist kürzer als die Zehe und ziemlich stark gebogen (Bd. III, S. 46. Tafel 6, Fig. 1)

Anthus trivialis, Baum-Pieper.

3) Die Kralle der Hinterzehe ist länger als die Zehe, wenigstens so lang wie diese und weniger stark gebogen (vergl. Fig. 55, S. 55).

a) Die hellen Teile der äußersten Schwanzfeder sind auf der Ruickenseite rauchbräunlich; die Außenfahne der vierten Schwinge ist $1 \mathrm{~cm}$ vor dem Ende weit breiter als die dritte; die Seitenränder der Federn des Oberrückens sind sehr hell (Bd. III, S. 54, Tafel 8, Fig. 2)

Anthus gustavi, Petschora-Pieper.

b) Die hellen Teile der äußersten Schwanzfeder sind ziemlich rein weiß; die Außenfahne der vierten Schwinge ist $1 \mathrm{~cm}$ vor dem Ende nicht breiter als die der dritten: die Seitenränder der Rückenfedern sind weniger hell.

a) Manche der Rückenfedern sind bis an den Endrand fast querüber ebenso dunkel gefärbt wie die sehr dunklen Schwanzfedern; beim 
Hochzeitskleide ist die Kehle oder auch die Brust rostrot (Bd. III, S. 64, Tafel 6, Fig. 4 u. 5 und Tafel 7, Fig. 2)

Anthus cervinus, Rotkehliger Wiesen-Pieper.

в) Die Rückenfedern sind in ihrem dunkelsten Teil, ebenso wie die Schwanzfedern, etwas heller braun, und die dunklen Flecke berühren den Endrand der Feder entweder gar nicht oder nur schmal in der Mitte; die Brust ist immer sehr hell rostgelblich gefärbt (Bd. II, S. 56, Tafel 6, Fig. 2 und Tafel 7, Fig. 1).

Anthus protensis, Wiesen-Pieper.

B) Die Schaftflecke in der Kropfgegend sind am Rande verwaschen und stets heller als die dunklen Schwanzfedern.

a) Die hellen Teile auf der Rückenseite der äußersten Schwanzfeder sind ziemlich rein weiß (Bd. III, S. 83, Tafel 7, Fig. 3 und Tafel 8, Fig.4); auf höheren Bergen . . . Anthus spipoletta, Wasser-Pieper.

b) Die hellen Teile auf der äußersten Schwanzfeder sind trübgrauweiß, höchstens in der Nitte heller (Bd. III, S. 80, Tafel 7, Fig. $t$ und Tafel 8, Fig. 1): in Deutschland nur auf dem Zuge Anthus obscums, Strand-Pieper.

II. Der Schaft der äußersten Schwanzfeder ist stets in grölierer Ausdehnung weiß, entweder vom Ende über $2 \mathrm{~cm}$ weit nach der Wurzel hin oder in der Mitte seiner Länge oder er besitzt in seiner ganzen Länge nicht den geringsten bräunlichen Ton.

A) Die Kralle der Hinterzehe ist mindestens $14 \mathrm{~mm}$ lang (Bd. II, S. 69, Tafel 6, Fig. 3 und Tafel 8, Fig. 5) Anthus richardi, Sporn-Pieper.

B) Die Kralle der Hinterzehe ist höchstens $11 \mathrm{~mm}$ lang.

2) Die ganze Rückenseite des Vogels ist fast lehmfarbig, die Mitten der Federn sind wenig dunkler; der Schaft der äußersten Schwanzfeder ist fast bis zur Wurzel weiß (Bd. III, S. 72, Tafel 8, Fig. 3); besonders im Westen . . . . . . Anthus campestivis, Brach-Pieper.

R) Die Rückenseite des Vogels ist dunkelolivenbraun, höchstens sind die Federränder heller: der Schaft der äußersten Schwanzfeder ist fast immer in größerer Ausdehnung braun.

a) Die Bürzelfedern sind in der Mitte viel dunkler als am Rande und in ihrem dunkelsten Teil fast ebenso dunkel wie die dunklen Schwanzfedern (Bd. II, S. 64, Tafel 6, Fig. 4 u. 5 und Tafel 7, Fig. 2)

vergl. Anthus cervinus, Rotkehliger Wiesen-Pieper.

b) Die Bürzelfedern sind in der Mitte kaum dunkler als am Rande, olivenbraun oder olivenbraungrau, heller als die Schwanzfedern (Bd. ШI, S. 94, Tafel 6, Fig. 6)

Anthus pensilvanicus, Amerikanischer Wasser-Pieper. 


\section{Motreilla und Budytes.}

I. Die Kralle der Hinterzehe ist kurz und stärker gebogen (Fig. 54); der Schwanz des erwachsenen Vogels (von der Einlenkung der Federn an, die man durch die oberen und unteren Deckfedern hindurch fiihlt, gemessen) ist $8 \mathrm{~cm}$ und darüber lang; die Kehle ist entweder weiß oder schwarz gefärbt. A) Die unteren Schwanzdeckfedern sind weiß; die Rückenseite des Vogels ist bis zum Schwanz grau oder schwarz.

a) Der Rücken des Vogels ist bis zum Schwanz grau, heller als die Schwanzfedern (Bd. II, S. 98, Tafel 9, Fig. 1-3 und Tafel 10, Fig. 1-3)

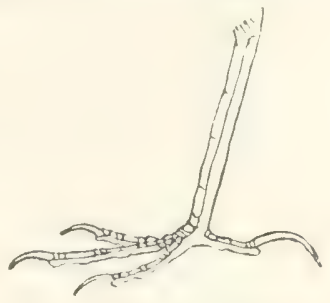

Fig. 54. Fuß der Bachstelze.

\section{Hotacilla alba, Weiße Bachstelze.}

b) Der Rücken des Vogels ist bis zum Schwanze schwarz, nicht oder kaum heller als die Schwanzfedern (Bd. III, S. 116, Tafel 11, Fig. 1-3); nur im Nordwesten

Motrcilla Iugubris, Schwarze Bachstelze.

B) Die unteren Schwanzdeckfedern sind mehr oder weniger gelb; die oberen Schwanzdeckfedern grünlichgelb (Bd. III, S. 118, Tafel 10, Fig. 4 und Tafel 12, Fig. 1-3); in Berggegenden

\section{Motacilla boarula, Graue Bachstelze, Gebirgsstelze.}

II. Die Kralle der Hinterzehe ist wenig gebogen und länger (Fig. 55); der Schwanz ist nicht $8 \mathrm{~cm}$ lang; die Kehle ist oft gelb gefärbt, oft aber auch weiß.

A) Die längeren unteren Schwanzdeckfedern sind immer weiß, die Seiten des Kopfes sind entweder lebhaft gelb wie der Bauch oder nebst dem Bauch ebenfalls weißlich.

AA) Die Oberseite des Kopfes ist beim reifen Männchen gelb; dann folgt ein schwarzer Halsring und dann der graue Rücken (Bd. II, S. 124, Tafel 13, Fig. 1, 2 und 5)

Budytes citreolus, Gelbköpfige Bachstelze.

BB) Die ganze Rückenseite des Vogels bis zum Kopf einschließlich ist beim männlichen und weiblichen Fig.55. Fuß der Schatstelze. Sommerkleide schwarz, beim Winterkleide grau (Bd. II, S. 126).

Budytes citreolus citreoloides, Hodgsons Schafstelze.

B) Die längeren unteren Schwanzdeckfedern sind meist mehr oder weniger gelb gefärbt; sind sie ziemlich rein weiß, so sind die Seiten des Kopfes mehr oder weniger grau gefärbt.

AA) Die Oberseite des Kopfes zeigt einen grünlichen oder gelben Farbenton oder sie ist lebhaft grünlichgelb. 
a) Die Oberseite des Kopfes ist ziemlich dunkel olivengrün, die gelbe Binde, welche sich von der Schnabelwurzel über das Auge zieht, ist scharf abgegrenzt (Bd. III, S. 129, Tafel 15, Fig. 1)

Budytes taivanus, Chinesische Schafstelze.

b) Die Oberseite des Kopfes ist lebhaft grüngelb.

a) Der Kopf ist lebhafter gelb, namentlich bei alten Vögeln; die über die Augen ziehende helle Binde ist dann kaum erkennbar ( $\mathrm{Bd}$. III, S. 128, Tafel 13, Fig. 4)

Budytes campestris campestris, Gelbstirnige Schafstelze.

$\beta)$ Die Oberseite des Kopfes und das Gefieder hinter dem Auge ist mehr grüngelb und deshalb die gelbe Binde über dem Auge deutlicher (Bd. II, S. 127, Tafel 13, Fig. 3) . Budytes campestris flavissimus.

BB) Die Oberseite des Kopfes zeigt keinen oder doch nur éinen äußerst schwachen grünlichen Ton.

a) Die Oberseite des Kopfes ist schwarz.

a) Der Kopf ist oben ganz schwarz; iiber den Augen befinden sich keine weißen oder gelben Federn (Bd. III, S. 143, Tafel 16, Fig. 2)

Budytes melanocephalus, Schwarzköpfige Schafstelze.

ß) Über dem Auge befindet sich eine gelbe oder weiße Binde.

* Die Binde über dem Auge ist weiß (Bd. III, S. 144, Tafel 16, Fig. 3).

Budytes melanocephalus paradoxus, Weißzügelige Bachstelze.

** Die Binde über dem Auge ist gelb (Bd. II, S. 145, Tafel 16, Fig. 4)

Budytes melanocephalus xanthophrys.

b) Die Oberseite des Kopfes ist weiß bis dunkelgrau.

a) Die Oberseite des Kopfes ist weiß (Bd. III, S. 129)

Budytes leucocephalus, Weißköpfige Schafstelze.

$\beta)$ Die Oberseite des Kopfes ist hellgrau oder dunkelgrau.

*) Die Kehle ist beim ausgefärbten Vogel immer gelb, nur das Kinn ist oft weißlich gefärbt; beim Jugendkleide ist die Kehle und die Unterseite mehr oder weniger weiß, erstere aber im unteren Teile immer etwas dunkel gefleckt.

† Eine helle Binde über dem Auge ist stets vorhanden.

$\bigcirc$ Die T'eile der Kopfseiten hinter dem Auge aber etwas tiefer (die Ohrdecken) sind stets grau gefärbt (Bd. III, S. 130, Tafel 14, Fig. 1-4)

Budyte's flovus, Gelbe Bachstelze, Schafstelze.

OO Die Ohrdecken sind beim reifen Vogel z. T. weiß (Bd. UI, S. 139, Tafel 15, Fig. 2) . . . . Budytes flavus beema.

$\pitchfork$ Von der hellen Binde über dem Auge ist beim reifen Vogel keine Spur vorhanden; die Oberseite des Kopfes ist dunkelgrau; die Ohr- 
decken sind schieferschwarz (Bd. III, S. 141, 'Tafel 15, F'ig. 3); in Deutschland nur auf dem Zuge

Budytes flavus borealis, Nordische Schat'stelze.

Die Kehle ist beim ausgefärbten Vogel weiß; die Brust schön gelb; in der Kropfgegend befinden sich damn keine dunklen Flecke; ron der hellen Binde über dem Auge ist oft keine Spur vorhanden (Bd. III, S. 140, Tafel 16, Fig. 1)

Budytes flavus cinereocapillus, Grauköpfige Schafstelze.

\section{Dendroecu.}

(Natmand, Bd. III, S. 146, Tafel 16, Fig. 5)

Dendroeca virens, Grüner Waldsänger.

Calcarims, Plectrophenax, Miliaria,

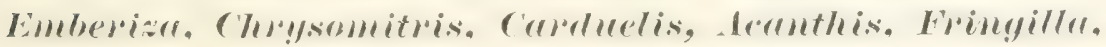
Chloris, Passer und Molothrus.

I. Die zweitäußerste Schwanzfeder ist auf der Innenfahne entweder im Enddrittel vom Schaft bis zum Innenrande weiß oder zwischen Schaft und Innenrand mit weißlicher Zeichnung (Streif oder Fleck) versehen; verschwindet diese Zeichnung (in seltenen Fällen), so ist die äußerste Schwanzfeder in größerer Ausdehnung neben dem Schaft auf der Innenfahne rein weiß.

A) Von der zweitäußersten Schwanzfeder ist der Wurzelteil des Schaftes (wenigstens $1 / 3$ der Länge) weiß; die äußerste Schwanzfeder ist zum großen Teil, mit Einschluß des Schaftes, rein weiß.

a) Die beiden äußersten Schwanzfedern zeigen vor dem Ende auf der Innenfahne neben dem Schaft einen dunklen Längsstreif (Bd. III, S. 157, Tafel 17, Fig. 1-4 und Tafel 18, Fig. 3 und 4); in Deutschland Wintervogel . . . . . Plectrophenax nivalis, Schuce-Ammer.

b) Die beiden äußersten Schwanzfedern sind entweder im Endteil ganz weiß oder nur am Endrande dunkel (Bd. III, S. 327, Tafel 41, Fig. 1 und 2); im höheren Gebirge . . . . Fringill Mivalis, Schnee-Fink.

B) Von der zweitäußersten Schwanzfeder ist der Schaft ganz dunkel und auch die äußerste Schwanzfeder ist in geringerer Ausdehnung weiß.

AA) Die Außenfahne der zweiten Schwinge und der folgenden Schwingen ist an der Wurzel querüber schön goldgelb (Bd. III, S. 291, Tafel 39, Fig. 4 und 5) . . Carduelis carduelis, Distel-Zeisig, Stieglitz.

BB) Der Flügel zeigt keine goldgelben Teile.

a) Der Bürzel ist schön gelbgrün gefärbt. 
a) Der Rücken ist fast ebenso grün wie der Bürzel; die drittäußerste Schwanzfeder ist ebenso wie die ziveitäußerste auf der Innenfahne mit einer ausgedehnten weifen Zeichnung versehen

Fringilla spodiogenys.

B) Der Riicken ist beim Weibchen olivengrün, beim Männchen rotbraun gefärbt: die drittäußerste Schwanzfeder ist ganz dunkel (Bd. III, S. 331, Tafel 39, Fig. 2. und 3) . . . Frimgill, roelehs, Buch-Fink.

b) Der Bürzel ist nicht schön gelbgrün gefärbt.

a) Die Außenfahne der fünften Schwinge ist $1 \mathrm{~cm}$ vor dem Ende immer sehr viel schmäler. meist nicht halb so breit wie $2 \mathrm{~cm}$ weiter nach der Wurzel hin.

S Die Schnabelfirste ist stark gebogen (Fig. 19 S. 6).

Die Federn an der Rückenseite des Körpers sind z. T. an den Rändern weißlich oder sehr hellgrau (Bd. III, S. 218, Tafel 26, Fig. 3)

Emberiza pyrrhuloides, Gimpel-Ammer.

: Die Federn an der Rückenseite des Körpers zeigen alle bräunliche oder gelblichgraue Ränder (Bd. III, S. 218, Tafel 26, Fig. 1 und 2)

Emberiza intermedia.

SS Die Schnabelfirste ist fast gerade.

Die Federn am Bauche zwischen den Beinen zeigen einen deutlichen gold- oder schwefelgelben Ton.

$\rightarrow$ Die Federn des Rückens, namentlich die an den Seiten des Rückens zeigen, besonders an den Rändern, einen rötlicheren Ton als die Bürzelfedern; beim reifen Männchen ist das Kinn in größerer Ausdehnung schwarz; dann folgt nach unten ein gelbliches Halsband, dann die graue Kropfgegend, damn die roströtliche Oberbrust und endlich die gelbliche Unterseite (Bd. III, S. 188, Tafel 21, Fig. 3 und 4)

Emberiza cirlus. Zaun-Ammer.

$\dagger$ Der Bürzel ist viel rostroter gefärbt als der Rücken; beim reifen Männchen ist das Kinn und die Kehle schön gelb, nur über die Kropfgegend zieht ein dunkler Schatten (Bd. III, S. 182, Tafel 21, Fig. 1 und 2) . . Emberiza citrinella, Gold-Ammer.

* Die Bauchfedern haben entweder einen rostbräunlichen oder einen rostgelblichen Ton, oder sie besitzen eine weiße Grundfarbe, oft sind sie mit dunklen Schaftflecken versehen.

$\div$ Die Federn des Bauches zwischen den Beinen und die unteren Schwanzdeckfedern sind immer mehr oder weniger rostfarbig, entweder roströtlich oder rostgelblich; der Rand der einzelnen Federn ist oft heller, besitzt aber immer noch einen deutlichen rostgelblichen Ton; in der Mitte des Kropfes und der Brust sind niemals dunkle Schaftflecken vorhanden; der Kopf des reifen Männchens 
ist grau, mit dunklen Zeichnungen versehen (Bd. III, S. 199, Tafel 23, Fig. 2 und 3); südliche Art . . Emberial cia, Zip-Ammer. $\because$ Die Federn mitten am Bauche sind stets am Rande weib und ebenso die unteren Schwanzdeckfedern größtenteils weiß, nicht gerade schneeweiß, aber olme deutlichen rostfarbigen Ton; am Kropf und an der Brust befinden sich oft auch in der Mitte dunkle Schaftflecke.

$\bigcirc$ Der anliegende Flügel ist $\left.8^{1} / 2-9\right)^{1} /, \mathrm{cm}$ lang; beim Männchen ist die Kehle rostrot (Bd. III, S. 209, Tafel 23, Fig. 1)

Emberiza leucocephala, Fichten-Ammer.

() Der anliegende Flügel ist $7-8 \mathrm{~cm}$ lang.

$X$ Auf der Kropfgegend sind die einzelnen Federn vor dem Endrand fast querüber rostrot ( $\mathrm{B}$ l. III, S, 205, Tafel 24, Fig. 1 und 2)

Emberiza rustica, Wald-Ammer.

$\times \times$ Die Federn in der Kropfgegend sind entweder querüber schwarz oder sie sind mit einem schmäleren dunkelbraunen Schaftfleck versehen.

$\odot$ Die Federn der Ohrgegend (vom Auge schräg nach hinten und unten) sind rotbraun, immer rotbrauner als die Ränder der mittleren Flügeldeckfedern; beim reifen Männchen ist eine mittlere Längsbinde auf dem Kopfe ebenfalls rotbraun (Bd. III, S. 207, Tafel 24, Fig. 3 und 4)

Emberiza pusilla, Zwerg-Ammer.

$\odot \odot$ Die Ohrdecken sind schwärzlich oder rötlichgrau, stets weniger rotbraun als die Ränder der mittleren Flügeldeckfedern.

! Über dem Auge befindet sich eine zitronengelbe Längsbinde, beim reifen Männchen außerdem mitten auf dem Kopfe eine weißliche Längsbinde (Bd. II, S. 202, Tafel 22, Fig. 4)

Emberiza chrysophrys, Gelbbrauige Ammer.

!! Über dem Auge befindet sich eine weißliche Längsbinde; beim Männchen ist der Kopf oben ganz schwarz (Bd. III, S. 212, Tafel 25, Fig. 1-4)

Emberian schoeniclus, Rohr-Ammer.

B) Die Außenfahne der fuinften Schwinge ist $1 \mathrm{~cm}$ vor dem Ende kaum schmäler als $3 \mathrm{~cm}$ vor dem Ende.

ur Wie auf der zweitäußersten Schwanzfeder, so befindet sich auch auf der Innenfahne der drittäußersten Feder am Ende ein großer, rundlicher, weißlicher Fleck; beim reifen Vogel befinden sich an der Kehle immer einige gelbe Federn (Bd. III, S. 377, Tafel 43, Fig. 2 und 3): südliche Art . . . . Pussur petronius, Stein-Sperling. 
$\left.\beta \beta^{\prime}\right)$ Auf der drittäußersten Schwanzfeder befindet sich niemals eine weiße Zeichnung.

Die Kralle der Hinterzehe ist wenig gebogen und viel länger als die Zehe: die Grundfarbe der Unterseite ist von der Hinterbrust an ziemlich rein weiß; im Nacken befinden sich immer Federn, die teilweise rostrot gefärbt sind, doch ist der rostrote Teil dieser Federn bisweilen verdeckt (Bd. III, S. 151, Tafel 17, Fig. 5) und Tafel 18, Fig. 1 und 2); in Deutschland Wintervogel

\section{Calcarius lapponicus, Lerchen-Spornammer.}

* Die Kralle der Hinterzehe ist stärker gebogen und nicht länger als die Zehe; die Grundfarbe der Hinterbrust ist mehr oder weniger gelbbräunlich oder grau.

$\div$ Auf der Innenfahne der zweitäußersten Schwanzfeder befindet sich neben dem Schaft ein weißer Längsstreif; selten ist die Feder ganz dunkel; die Hinterbrust ist beim reifen Tier ebenso grell gefärbt wie die Kehle oder noch schöner gelb; der Kopf des reifen Männchens ist oben dunkelbraunrot, die Umgebung des Schnabels schwarz, die Kehle schön gelb und über der Kropfgegend befinden sich ein dunkelrotbraunes Querband (Bd. III, S. 176, Tafel 20, Fig. 1 und 2)

$$
\text { Emberiza aureola, Weiden-Ammer. }
$$

$\div$ Die Innenfahne der zweitäußersten Schwanzfeder ist am Ende stets in größerer Ausdehnung weiß, meist im Endviertel vom Schaft bis zum Innenrand; die Hinterbrust besitzt selten einen gelblichen Ton; dann ist die Kehle noch schöner gelb; der Oberkopf ist niemals dunkelbraunrot und die Umgebung des Schnabels niemals schwarz. $\times$ Die Federn am hinteren Teil des Bauches sind ziemlich lebhaft rostbraun oder rostrot, und bisweilen mit dunklen Schaftflecken versehen.

(.) Die Federn der Kehle sind entweder rostbraun oder rostgelblich und im letzteren Falle oft mit dunklem Schaftfleck versehen (Bd. III, S. 197, Tafel 20, Fig. 3 und 4)

$$
\text { Emberiza caesia, Grauer Ortolan. }
$$

Die Federn der Kehle sind entweder schwefelgelb oder weißlich und im letzteren Falle oft mit dunklen Schaftflecken versehen (Bत̄. III, S. 191, Tafel 22, Fig. 1 und 2)

\section{Emberial hortulana, Garten-Ammer.}

$\times \times$ Die Federn am hinteren Teil des Bauches sind weißlich bis grau, im letzteren Falle besitzen sie oft einen undeutlichen braunen Ton (Bd. III, S. 180, Tafel 23, Fig. 4)

Emberiza cinerea, Grane Ammer.

II. Die zweitäußerste Schwanzfeder zeigt niemals eine weife Zeichnung und die äußerste niemals reinweiße Teile. 
A) Es sind entweder die Bürzelfedern z. T', gelb bezw. grüngelb oder die Schwanzfedern sind z. T. an der Wurzel schwefelgelb bis goldgelb.

AA) Die Außenfahne wenigstens der zweitäußersten Schwanzfeder ist im Wurzeldrittel querüber schwefelgelb bis goldgelb.

a) Die Außenfahne der zweiten Schwinge ist nahe der Wurzel querüber gelb; der anliegende Flügel ist über $8 \mathrm{~cm}$ lang.

a) Die Außenfahne der Schwingen bis zur zwölften ist queriber orler fast querüber gelb (Bd. III, S. 357, Tafel 43, Fig. 1)

Chloris sinica, Sibirischer Griinling.

ß) Die Außenfahne der Schwingen ist von der achten an nur noch am Rande grünlich (Bd. III, S. 349, Tafel 41, Fig. 3-5)

\section{Chloris chloris, Griin-Hänfling, Griinling.}

b) Die Außenfahne der zweiten Schwinge ist an der Wurzel nicht gelb: der anliegende Flügel ist nicht $8 \mathrm{~cm}$ lang (Bd. III, S. 280, Tafel 35, Fig. 1-3)

Chrysomitris spinus, Erlen-Zeisig.

BB) Die Außenfahne der zweitäußersten Schwanzfeder ist an der Wurzel höchstens in der Außenhälfte gelb.

a) Die äußerste Schwanzfeder ist entweder ganz oder doch z. 'I. viel heller als die andern Schwanzfedern; die nackte Schnabelfirste ist über $10 \mathrm{~mm}$ lang; der anliegende Flügel ist $8-9 \mathrm{~cm}$ lang.

1،) Die gelbe Farbe auf dem Bürzel zeigt immer eine rotbraune Mischung: in der Kropfgegend sind keine dunklen Schaftflecke vorhanden; der Kopf des reifen Männchens ist an der Oberseite schwarz (Bd. III, S. 171, Tafel 19, Fig. 3 und 4) Emberiza melanocephala, Kappen-Ammer.

§) Die gelbe Farbe auf dem Bürzel zeigt keine rote Mischung; die Federn der Kropfgegend sind beim Jugendkleide mit dunklen Schaftflecken versehen; der Kopf des Männchens ist ganz orangebraun (Bd. III, S. 204, Tafel 22, Fig. 3) Emberiza luteola, Braunkehlige Ammer.

b) Die äußerste Schwanzfeder ist nicht heller als die andern; die nackte Schnabelfirste ist nicht $8 \mathrm{~mm}$ lang; der anliegende Flügel mißt meist weniger als $8 \mathrm{~cm}$.

a) Die Außenfahne der zweiten bis vierten Schwinge ist in der Wurzelhälfte am Rande ebenso lebhaft orangegelb wie die Bürzelfedern; die Stirn ist orangerot, die Kehle schwarz (Bd. III, S. 278, Tafel 34, Fig.4) Serinus pusillus, Rotköpfiger Girlitz.

ॐ) Der Außenrand der Schwingen ist nie so lebhaft gelb wie die Bürzelfedern.

Der Schnabel ist kurz und dick; die längeren unteren Schwanzdeckfedern zeigen keinen gelben Ton, die Federn des Rückens sind stets mit dunklen Schaftflecken versehen (Bd. III, S. 273, Tafel 34, Fig. 1-3); im Süden häufiger . . Serinus serinus, Girlitz。 
** Der Schnabel ist weniger kurz und dick (etwa wie bei Fig. 17 S. 6); die längeren unteren Schwanzdeckfedern zeigen immer einen gelben Ton; der Rücken des reifen Männchens zeigt keine dunklen Schaftflecke.

† Der Rücken zeigt einen grünlichen Ton (Bd. III, S. 287, Tafel 35 Fig. 4) . . . Chryysomitris citrinella, Zitronen-Zeisig. $\uparrow$ Der Rücken ist bräunlich, die Unterseite lebhafter gelb (Bd. III, S. 290, Tafel 35, Fig. 5) Chrysomitris corsicana, Königs-Zeisig.

B) Weder der Bürzel noch die Schwanzfedern zeigen einen gelben oder grüngelben Farbenton.

AA) Die Außenfahne der vierten Schwinge (und oft auch der benachbarten) ist an der Wurzel mit einem 4-6 mm langen weißen Fleck versehen; die längeren unteren Flügeldeckfedern sind z. T. goldgelb (Bd. III, S. 343, Tafel 39, Fig. 1 und Tafel 40, Fig. 2 und 3); in Deutschland Wintervogel . . . . Hoingilla montifingilla, Berg-Fink.

BB) Die Außenfahne der vierten Schwinge zeigt keinen weißen Fleck an der Wurzel; an der Unterseite der Flïgel befinden sich keine goldgelb gefärbten Federn.

a) Die Außenfahne der fünften bis siebenten Schwinge ist stets breit weiß gerandet; der weiße Rand ist mindestens doppelt so breit wie der der ersten bis dritten Schwinge.

a) Auf der Innenfahne der äußersten Schwanzfeder ist der weiße Innenteil scharf von dem fast schwarzen Außenteil abgegrenzt und der weiße Teil fast ebenso breit wie der schwarze, oft sogar breiter; der anliegende Fliagel ist über $7,5 \mathrm{~cm}$ lang (Bd. III, S. 314, Tafel 38, Fig. 1-3 und Tafel 40, Fig. 1) . . . Acanthis cannubina, Blut-Hänfling.

ß) Auf der Innenfahne der äußersten Schwanzfeder ist der helle innere Teil mehr grau und weniger scharf von dem stets breiteren dunklen Teil der Innenfahne abgegrenzt; der anliegende Flügel ist meist nicht uiber $7,5 \mathrm{~cm}$ lang (Bd. III, S. 323, Tafel 38, Fig. 5-7); in Westdeutschland; Wintervogel . Acanthis Harirostris, Berg-Hainfling.

b) Die Außenfahne der fünften bis siebenten Schwinge ist nicht weißlich gerandet, nicht breiter hell gerandet als die vorhergehenden.

a) Die Federn am Bürzel und Hinterrücken sind z. T. mit weißlichen Rändern versehen oder ganz weiß; die Schnabelfirste ist bis zur Spitze fast schnurgerade; die Nasenlöcher sind unter dichten nach vorn gerichteten Borsten versteckt; der Kopf ist oben meist mit schön roten Federn versehen (Bd. III, S. 301, Tafel 36, Fig. 1-3 und Tafel 37, Fig. 1-4); in Deutschland Wintervogel .Arrmthis linurr, Birken-Zeisig.

ß) Am Rücken und Bürzel befinden sich nie Federn mit weißlichen Rändern; die Schnabelfirste ist nach der Spitze hin deutlich gebogen; 
die Nasenlöcher sind nicht unter dichten nach vorn vorragenden Borsten versteckt; der Kopf ist oben grau oder braun, oft dunkel gefleckt.

* Die außerste Schwanzfeder ist entweder in ihrer ganzen Ausdeh. nung viel heller als die andern oder sie zeigt doch einen hellen Querwisch; die Federn an der Oberseite des Kopfes sind stets in der Mitte dunkler.

† Die Federn der Kropfgegend sind am Ende mit dunklen Schaftflecken versehen; die unteren Schwanzdeckfedern sind entweder weiß oder bräunlichgrau (Bd. III, S. 165, Tafel 19, Fig. 1 und 2)

\section{Mitirria calandur (miliaria), Grau-Ammer.}

$\uparrow$ Die Kropfgegend zeigt keine dunklen Schaftflecke; die unteren Schwanzdeckfedern besitzen einen gelben Farbenton (Bd. II, S. 171, Tafel 19, Fig. 4)

vergl. oben Emberiza melanocephala, Kappen-Ammer.

** Die äußerste Schwanzfeder ist nicht heller als die andern: die Federn auf dem Kopfe sind meist ganz einfarbig.

† Die roströtlichgrauen Bürzelfedern zeigen schwarze Schaftflecke (Bd. III, S. 287)

vergl. oben Chrysomitris citrinella, Zitronen-Zeisig.

$\dagger$ Die Bürzelfedern sind entweder ganz schwarz oder ganz grau.

$\times$ Die oberen Flïgeldeckfedern sind stets z. T. mit scharf abgesetzten hellen (weißen, grauweißen oder bräunlichen) Endrändern versehen: die Außenfahne der dritten bis fünften Schwinge (meist auch die der benachbarten Schwingen) ist an der Wurzel heller gefärbt (rostgelblich bis rostbräunlich).

Der Kopf ist oben querüber rostbraun gefärbt; der anliegende Flügel ist etwa $7 \mathrm{~cm}$ lang (Bd. III, S. 371, Tafel 42, Fig. 3 und 4 )

Preser montumus, Feld-Sperling.

Der Kopf ist oben aschgrau, beim Männchen an den Seiten rotbraun gefärbt; der anliegende Fliigel ist etwa $8 \mathrm{~cm}$ lang (Bd. III, S. 35), Tafel 42, Fig. 1 und 2)

\section{Proser domestirns, Haus-Sperling, Spatz.}

$\times$ Die Flügeldeckfedern zeigen nur undeutlich verwaschene Ränder: die Außenfahne der dritten bis füften Schwinge ist nicht nach der Wurzel hin heller (Bd. IV, S. 4, Tafel 1, Fig. 3)

Molothrus cabanisii, Cassins Kuhvogel.

\section{Loxirl.}

I. Einige der Flügeldeckfedern besitzen einen mindestens $2 \mathrm{~mm}$ breiten weiben Endrand; dadurch entstehen auf den Flügeh weibe Querbinden. 
A) Der Oberschnabel ist etwas dicker (vergl. die Fig. 8 S. 2), die rote Farbe des Männchens ist etwas leuchtender (Bd. III, S. 238, Tafel 29. Fig. 2-4); die Art kommt aus dem Nordosten öfter nach Deutschland

Loxia bifasciata, Weißbindiger Krewzschmabel.

B) der Oberschnabel ist etwas schlanker, die rote Farbe des Männchens etwas dunkler (Bd. III, S. 238, Tafel 29, Fig. 1) . . Loxia Teucoptera.

1I. Die Flügeldeckfedern besitzen nur einen schmalen verwaschen hellen Rand; die Flügel zeigen deshalb keine weiße Binde.

A) Der anliegende Flïgel ist höchstens $10 \mathrm{~cm}$ lang (Bd. III, S. 222, Tafel 27, Fig. 1-3) . . . . Loxia curvirostra, Fichten-Kreuzschnabel.

B) Der anliegende Flügel ist uiber $10 \mathrm{~cm}$ lang (Bd. III, S. 232, Tafel 28, Fig. 1-3); nördliche, in Deutschland seltenere Art

Loxia pityopsittrcus, Kiefern-Krenzschmabel.

\section{Pinicola.}

(Naumann, Bd. III, S. 241, Tafel 30, Fig. 1 und 2); in Deutschland Wintervogel Pinicola enucleutor, Fichten - Gimpel.

\section{Serinus, Carpodacus und Erythrospisa.}

I. Die beiden äußersten Schwanzfedern zeigen auf der Innenfahne weiße Teile in größerer Ausdehnung.

A) An der Rückenseite des Körpers besitzen die Federn z. T. weißliche oder sehr hellgraue Ränder (Bd. III, S. 218, Tafel 26, Fig 3)

vergl. oben Emberiza pyrrhuloides, Gimpelammer.

B) An der Rückenseite des Körpers sind die Federn alle am Rande dunkler, bräunlich oder gelblichgrau gefärbt (Bd. III, S. 218, Tafel 26, Fig. 1 und 2) . . . . . . vergl, oben Emberiza intermedia.

II. Alle Schwanzfedern sind einfarbig dunkel, nur hart am Rande verwaschen heller.

A) Der Schnabel ist sehr kurz und dick, die nackte Firste deshalb in gerader Linie gemessen nicht $7 \mathrm{~mm}$ lang; das Gefieder zeigt meist, namentlich am Bürzel und auf der Brust, orangegelbe bis grüngelbe Farben (vergl. Bd. III, Tafel 34).

a) Die Bürzelfedern sind stets größtenteils oder ganz grüngelb gefärbt; ebenso sind die Federn auf der Brust, am Halse und auf dem Kopfe meist stellenweise hellgelb gefärbt (Bd. III, S. 273, Tafel 34, Fig. 1-3)

Serinus serinus, Girlitz.

1) Die Bürzelfedern sind beim reifen V'ogel dunkelgelb, beim jungen Togel bräunlich; der Kopf ist beim reifen Vogel schwarz, ein Stirnfleck orangerot (Bd. III, S. 278, Tafel 34, Fig. 4)

Serinus pusillus, Rotköpfiger Girlitz. 
B) Der Schnabel ist größer; die nackte Firste über $8 \mathrm{~mm}$ lang; das Gefieder zeigt oft auf dem Bürzel, an der Brust usw. rote T'eile.

a) Die Federn der Kropfgegend sind entweder lebhaft rot oder sie sind mit dunklen Schaftflecken versehen (vergl. N. Bd. III, Tafel 21).

a) An den Rückenfedern ist der dunkle, fast schwarze Mittelteil scharf von dem hellgrauen oder rötlichen Seitenteil abgesetzt; der anliegende Flügel ist über $8,5 \mathrm{~cm}$ lang (Bd. III, S. 253, Tafel 31, Fig. 4)

$$
\text { Carpodacus roseus, Rosen-Gimpel. }
$$

ß) An den Rückenfedern ist der mittlere Teil wenig und verwaschen begrenzt dunkler als die Ränder; der anliegende Flügel mißt meist weniger als $8 \mathrm{~cm}$ (Bd. III, S. 247, Tafel 31, Fig. 1-3); nordöstliche Art

Carpodacus evythrinus, Karmin-Gimpel.

b) Die Federn der Kropfgegend sind einfarbig grau, rosafarbig angehaucht (der Schnabel ist viel dicker als bei Carpodacus)

Erythrospiza githoginea.

\section{Pyrrhula.}

I. Die Unterseite des Männchens ist leuchtender rot gefärbt, die Oberseite heller grau; der anliegende Flïgel ist mindestens $9 \mathrm{~cm}$ lang ( $\mathrm{Bd}$. III, S. 257, Tafel 32, Fig. 1 und 2); nordöstliche Form

Pymorta pyrrhula, Nordischer Gimpel.

II. Die Unterseite des Männchens ist etwas dumpfer rot, der Rücken etwas dunkler grau gefärbt; der anliegende Flügel ist nicht $9 \mathrm{~cm}$ lang (Bd. III, S. 257, Tafel 32, Fig. 3 und 4); westliche Form

Pym\%ula mym\%ula (vulgaris) enropaea, Gemeiner Gimpel.

\section{Coccothraustes.}

(Naumann, Bd. III, S. 266, Tafel 33, Fig. 1-3)

Cocrothrumstes roccothroustes (nulyaris), Kirsch-Kernbeiber.

\section{Dolichonyx.}

(Naumann, Bd. IV, S. 1, Tafel 1, Fig. 1 und 2)

Dolichonyx oryzivorus, Bobolink, Reisvogel.

\section{Pristor。}

(Naumann, Bd. IV, S. 19, Tafel 4, Fig. 1-4) . Pastor roseus, Rosenstar.

\section{Sturmus.}

I. Die dunklen Teile am Halse und in der Kropfgegend zeigen stets einen deutlichen Purpurschiller, mehr als die Oberseite der Fligel, deren cichiller stets blau und grün gemischt ist; die Enden der Federn sind beim Jugendund Frühlingskleide in größerer Ausdehnung hell gefärbt. 
A) Der obere Teil der Kehle und das Kinn zeigen kleinen Purpurschiller (Bd. IV, S. 7, Tafel 2, Fig. 1 und 2 und Tafel 3, Fig. 1)

Sturnus vulyaris, Gemeiner Star.

B) Das Kinn, die Kehle und fast der ganze Kopf zeigen Purpurglanz (Bd. IV, S. 9, Tafel 3, Fig. 2)

Sturnus vulgaris menzbieri, Sibirischer Star.

II. Der Hals und die Kropfgegend zeigen keinen Purpurschiller, sondern einen Bleischimmer; ein schwacher Purpurschiller zeigt sich nur auf den Flügeln; die Federn sind schmäler und-spitzer; an den Enden der Federn sind höchstens ganz kleine helle Flecke vorhanden (Bd. IV, S. 15, Tafel 3, Fig. 3) . . . . . Sturnus unicolor, Einfarbiger Star.

\section{Oriolus.}

(Naumann, Bd. IV, S. 29, Tafel 5, Fig. 1-3)

Oriolus oriolus (galbula), Kirsch-Pirol.

\section{Pyrrhocorax, Lycus und Corvus.}

I. Die Schnabelfirste ist, rom Grunde der nach vorn gerichteten Federborsten über den Bogen bis zur Spitze gemessen, höchstens $35 \mathrm{~mm}$ lang.

A) Der Hals ist, wie das ganze Gefieder, schwarz, der Schnabel ist beim reifen.Vogel gelb, beim jungen Vogel schwärzlich, nur in der Wurzelhälfte des Unterschnabels gelb; die Füße sind beim reifen Vogel rot, beim jungen braunschwarz (Bd. IV, S. 40, Tafel 6, Fig. 1); in den Alpen

Pyrrhocorax pyrrhocorax (alpinus), Alpen-Dohle.

B) Der Hals ist, besonders an den Seiten, grau; der Schnabel und die Füße sind stets schwarz (Bd. IV, S. 80, Tafel 10, Fig. 2)

Lycus monedula, Dohlen-Rabe, Dohle.

II. Die Schnabelfirste ist, von der Wurzel der nach vorn gerichteten Federborsten bis zum Ende gemessen, über $45 \mathrm{~mm}$ lang.

A) Die Schnabelfirste ist, in der angegebenen Weise remessen, mindestens $7 \mathrm{~cm}$ lang; der anliegende Flügel mindestens $40 \mathrm{~cm}$ lang (Bd. IV, S. 85, Tafel 11, Fig. 1 und 2); in Deutschland spärlich

Corvus corax, Kolk-Rabe.

B) Die Schnabelfirste ist, in der angegebenen Weise gemessen, nicht $6 \mathrm{~cm}$ lang; der anliegende Flügel höchstens $35 \mathrm{~cm}$ lang.

a) Der Schnabel und die Füße sind rot; der anliegende Flügel ist nicht $28 \mathrm{~cm}$ lang; das die Nasenlöcher deckende Polster kleiner nach vorn vorstehender Federborsten ist nur $1 \mathrm{~cm}$ lang (Bd. IV, S. 48, Tafel 6, Fig. 2) Pyrrhocorax graculus, Steinkrähe.

b) Der Schnabel und die Füße sind schwarz; der anliegende Flügel ist mindestens $30 \mathrm{~cm}$ lang; das meist die Nasenlöcher deckende Polster nach 
vorn gerichteter Federborsten ist, wenn vorhanden, mindestens $2 \mathrm{~cm}$ lang. a) Die Schnabelfirste ist weniger stark gebogen (Fig. 23b, S. 7); die zweite Schwinge ist bedeutend länger als die sechste; das Gefieder hat am Halse einen schönen violetten Schiller (Bd. IV, S. 109, Tafel14, Fig.1 u. 2)

Corvus firugileyus, Saat-Rabe, Saatkrihe.

bb) Die Schnabelfirste ist stärker gebogen (Fig. $23 a$ ); die sechste Schwinge ist immer etwas länger als die zweite; das Gefieder hat am Halse einen schwach bläulichen Schiller.

a) Das Gefieder ist ganz schwarz bezw. blauschwarz (Bd. IV. S. 93, Tafel 12, Fig. 1); westliche Art

Corvus corone, Krïhen-Rabe, Rabenkrïhe.

B) Das Gefieder ist am Rücken und am Bauche aschgrau (Bd. IV, S. 100, Tafel 12, Fig. 2 und Tafel 13); östliche Art

Corvus cormix, Nebel-Rabe, Nebelkrähe.

\section{Nucifiaga.}

(Nauman, Bd. IV, S. 55, Tafel 7, Fig. 1-3); im Osten und in Berggegenden Tucifinaga caryocatactes, Tammen-Hïher.

\section{Perisoreus.}

(Naumanx, Bd. IV, S. 63, Tafel 8, Fig. 1-3)

Perisoreus infaustus, Unglücks-Häher.

\section{Garrulus.}

(Natmann, Bd. IV, S. 69, Tafel 9, Fig. 1-2)

Garrulus glandarins, Eichel-Hïher.

\section{Pica.}

(Naumann, Bd. IV, S. 75, Tafel 10, Fig. 1) Pica pice (caudata), Elster.

\section{Lanius.}

I. Die erste Schwinge ragt mit ihrer Spitze höchstens $1 \mathrm{~mm}$ über das Ende der längeren, den ersten langen Schwingen aufliegenden Flïgeldeckfedern hinaus; die Rückenseite des Vogels ist ganz grau, beim jungen Vogel mit feinen dunklen Querwellen versehen, beim reifen Vogel die Stirn immer schwarz (Bd. IV, S. 121, Tafel 15, Fig. 1 und 2); mehr südöstliche Art

\section{Lamius minos, Grauer Wiirger.}

II. Die erste Schwinge ragt mit ihrem Ende mindestens $2 \mathrm{~mm}$, meist aber viel mehr ïber das Ende der den nächsten schwingen aufliegenden Fliigeldeckfedern hinaus; die Rückenseite des Vogels ist entweder am Hals oder 
am Rücken oder an den oberen Schwanzdeckfedern oft (aber nicht immer) mehr oder weniger rotbraun gefärbt oder gemischt.

A) Der anliegende Flügel ist höchstens etwa 10,5 cm lang; der Schwanz ist von der durch das Gefieder hindurch fühlbaren Wurzel bis zum Ende gemessen höchstens 9,5 cm lang; die Oberseite des Körpers ist vom Hals bis zu den oberen Schwanzdeckfedern wenigstens zum Teil rostrot gefärbt oder rostrot gemischt; beim jungen Vogel sind wenigstens auf dem Kopfe und dem Halse sehr deutliche dunkle Querwellen vorhanden.

a) Der Grundteil der dritten bis sechsten Schwinge ist auf der Außenfahne von der Wurzel an wenigstens $1 \mathrm{~cm}$ weit weiß oder gelblichweiß. aa) Von der äußersten Schwanzfeder ist die Außenfahne und der Endteil weiß oder weißlich gefärbt; der Oberkopf ist beim alten Vogel rotbraun, die Stirn und der Rücken schwarz (Bd. IV, S. 139, Tafel 17, Fig. 1-2); südlichere Art . . . . Lanius senctor, Rotköpfiger Wirger.

bb) Die Außenfahne der äußersten Schwanzfeder ist ganz rotbraun; beim alten Vogel ist der Oberkopf und der Rücken bräunlichgrau (Bd. IV, S. 152, Tafel 18, Fig. 4)

Lanius isabellinus, Isabellfarbiger Würger.

b) Die Schwingen sind höchstens hart an der Wurzel weiß, die Außenfahne der dritten Schwinge von der Wurzel an keinen $\mathrm{cm}$ weit weiß; bei alten Vögeln ist der Mittelriicken einfarbig rostrot, der Kopf oben einfarbig grau, beim Männchen scharf abgesetzt aschgrau (Bd. IV, S. 145, Tafel 18, Fig. 1-3) Lanius collurio, Rotrickiger Wiirger.

B) Der anliegende Flügel ist über 10,5, meist über $11 \mathrm{~cm}$ lang; der Schwanz ist uiber $10 \mathrm{~cm}$ lang; die Oberseite des Vogels ist stets fast einfarbig grau, nur beim jungen Vogel zeigt sie bisweilen einen rostfarbigen Ton.

a) An den Flügeln ist die Wurzel der Außenfahne nur bei den langen Schwingen bis zur neunten oder zehnten weiß, deshalb zeigt sich auf dem anliegenden Flügel nur ein kleiner weißer Spiegel.

aa) Der Körper ist an der Rückenseite dunkelgrau, nach hinten hin heller, aber auch die Schwanzdeckfedern sind noch grau, nicht weiß (Bd. IV, S. 137, Tafel 16, Fig. 3)

Lanius meridionalis, Südlicher Würger.

bb) Die Rückenseite des Vogels ist heller grau, bei jungen Vögeln etwas bräunlich; die oberen Schwanzdeckfedern sind fast weiß (Bd. IV, S. 135, Tafel 16, Fig. 1 und 2); in Deutschland nur Wintervogel

Lanius excubitor borealis, Einspiegeliger Wiirger.

b) Die Wurzel der Außenfahne ist auch an den kleinen Schwingen weiß; deshalb zeigen sich auf dem anliegenden Flügel zwei oft mehr oder weniger miteinander verschmelzende Spiegel (Bd. IV, S. 127, Tafel 15, Fig. 1-3 und Tafel 16, Fig. 4) Lamius exrubitor, Großer Wirger. 
Ampelis [Bombycilla].

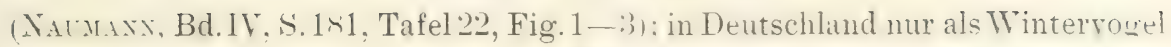

Ampelis garmulus, Seidenselıwanz.

\section{Hirundo, Chelidonaria, Biblis und Clivicola.}

I. Die zweitäußerste Schwanzfeder (oft auch die folgenden) ist auf der Innenfahne mit einem großen weißen oder hellbräunlichen Fleck versehen.

A) Die Federn der Rückenseite sind schwarz und zeigen einen bläulichen Schiller; die äußerste Schwanzfeder ist mindestens $1 \mathrm{~cm}$ länger als die beiden mittelsten und zeigt, ebenso wie die zweitäußerste, auf der Innenfahne einen großen hellen Fleck: das Kinn und die Kehle sind beim ausgefärbten Vogel rotbraun, beim jungen Vogel bräunlich.

a) Die ganze Unterseite ist ebenso tief braunrot wie die Kehle; die hellen Flecke auf der Innenfahne der Schwanzfedern sind nach außen hin stets rotbråunlich gefärbt (Bd. IV, S. 193, Tafel 23, Fig. 4?)

Hirundo rustica savignii, Ägyptische Rauchschwalbe.

b) Die oft ziemlich stark gebräunte Unterseite des Körpers ist stets viel heller als die Kehle; die Flecke auf -der Innenfahne der Schwanzfedern sind stets rein weiß (Bd. IV, S. 191, Tafel 23, Fig. 1-3 und ? 4)

Hivundo rustica, Rauch-Sehwalbe.

B) Die Rückenfedern sind dunkelbräunlichgrau gefärbt und besitzen niemals einen blauen Schiller: die äußerste Schwanzfeder ist stets ganz dunkel gefärbt und nur etwa $1 / 2 \mathrm{~cm}$ länger als die beiden mittelsten; das Gefieder zeigt niemals rein rotbraune Teile (Pd. IV, S. 211, Tafel 24, Fig. 2)

Biblis rupestris, Felsen-Schwalbe.

II. Die zweitäußerste Schwanzfeder ist stets ganz dunkel gefärbt; die äußerste bisweilen am Innenrande mit schmalem weißen Fleck versehen.

A) Der Lauf ist im unteren Teil ganz nackt; die Brustfedern zeigen schmale dunkle Schaftstriche; die äußerste Schwanzfeder ist beim reifen Vogel mindestens $5 \mathrm{~cm}$ länger als die beiden mittelsten; das Gefieder zeigt am Hals und am Hinterrücken rotbraune Teile (Bd. IV, S. 202, Tafel 24, Fig. 1)

Hirundo rufula, Gestrichelte Felsen-Schwalbe.

B) Der Lauf trägt in seinem unteren Teil, wenigstens über der Hinterzehe stets einige Federchen; die Brustfedern zeigen niemals schmale dunkle Schaftlinien, sind aber bisweilen zum Teil ganz dunkel; die äułerste Schwanzfeder ist höchstens $2 \mathrm{~cm}$ länger als die beiden mittelsten; das Gefieder zeigt niemals rein rostbraune Teile.

a) Die Rückenfedern besitzen stets einen blauen Schiller; die Bürzelfedern sind stets weißlich; die Füße sind bis zu den Krallen befiedert ( $\mathrm{Bd}$. IV, S. 204, Tafel 25, Fig. 1 und 2)

Chelidonaria [Chelidon] urbica, IIaus-Schwalbe. 
b) Die Riickenseite des Körpers ist ganz dunkelbraungrau. nach hinten hin zeigen die Federn oft hellere Ränder; der Lauf ist nur hinten über der Hinterzehe mit einigen Federchen versehen (Bd. IV, S. 216, Tafel 26, Fig. 1 und 2) . . . Clivicola [Cotyle] riparia, Ufer-Schwalbe.

\section{Arten der Segler.}

\section{Apus [Cypselus] und Chaetura.}

I. Der Lauf ist bis zu den Zehen mit kleinen Federchen besetzt; die Flügel sind ganz dunkel: die Schäfte der Schwanzfedern ragen nicht deutlich über die Fahnen vor.

A) Der Bürzel und die Kehle sind weißlich; sonst ist das Gefieder dunkel; der anliegende Flügel ist $12-14 \mathrm{~cm}$ lang . . . . . Apus affinis. B) Der Bürzel ist nicht heller als der Rücken; der anliegende Flügel ist $14-22 \mathrm{~cm}$ lang.

a) Die Hinterbrust nnd der Bauch sind größtenteils weiß; der anliegende Fliigel ist 20-22 cm lang; der Oberkopf und der Rücken sind dunkelgraubraun (Bd. IV, S. 226, Tafel 27, Fig. 2)

Apus melba, Alpen-Segler.

b) Nur das Kinn und der obere Teil der Kehle sind mehr oder weniger weißlich; sonst ist das ganze Gefieder schwärzlich; der anliegende Flügel ist 14-18 cm lang (Bd. IV, S. 232, Tafel 27, Fig. 1)

\section{Apus apus, Mauer-Segler, T'urmschwalbe.}

II. Der Lauf ist nackt; die Innenfahne der letzten Schwinge ist weiß und bildet jederseits auf dem Rücken des Togels einen weißen Fleck; die Flügel zeigen einen sehr lebhaften blaugrinen Metallglanz: die unteren Schwanzdeckfedern sind weiß; die nackten Schaftenden der Schwanzfedern ragen $3 \mathrm{~mm}$ und weiter vor (Bd. IV, S. 239)

Chaetura caudacuta, Nadelschwänziger Segler.

\section{Arten der Nachtschwalben. Caprimulgus.}

I. Die langen Schwingen sind am Innenrande der Innenfahne immer in größerer Ausdehnung weiß; die weiße Farbe erstreckt sich in mehreren runden Zacken fast bis zum Schaft; die Schwanzfedern, auch die äußersten sind am Ende nie querüber rein weiß; die Farbe der Rückenseite ist heller (Bd. IV, S. 254, Tafel 25, Fig. 1)

Caprimulgus aegyptius, Ägyptischer Tagschläfer. II. Die langen Schwingen zeigen entweder keine weißen Teile oder sie besitzen auf der Innenfahne einen großen weißen Fleck, der fast bis zum 
Schaft reicht; die Enden der beiden äußersten Schwanzfedern sind oft, aber nicht immer, rein weiß.

A) Die Grundfarbe der Federn ist vom Oberkopf bis zum Rücken grau gewässert; ein braunes Halsband ist nicht vorhanden; an der Kehle befinden sich niemals Federn, die weif und nur am Endrande schwarz sind; der weiße Fleck auf der Innenfahne der großen Schwingen ist nur beim Hochzeitskleide des AIännchens vorhanden (Bd. IV, S. 244, Tafel 28, Fig. 1-3)

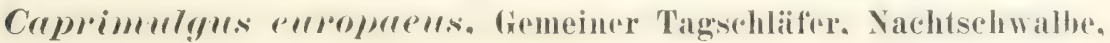
Ziegenmelker.

B) Die Grundfarbe der Federn ist nur am Oberkopf und am Rücken grau gewässert; zwischen Oberkopf und Rücken befindet sich querüber ein Halsband mit gelb- bis rotbrauner Grundfarbe; an der Kehle befinden sich jederseits einige weiße, nur an der Spitze querüber schwarz gerandete Federn (Bd. IV, S. 253) . . Caprimulgus ruficollis, Rothals-Ziegenmelker.

\section{Arten der Klettervögel.}

\section{Picus, Dendrocopms Picoides und Dryocopus.}

I. Der anliegende Flugel ist über $18 \mathrm{~cm}$ lang; das Gefieder ist schwarz, nur der Oberkopf ist mehr oder weniger rot (Bd. IV, S. 304, Tafel 35, Fig. 1 u. 2); .besonders in Berggegenden. IM.yocopms martils, schwarz-spereht.

II. Der anliegende Flügel ist höchstens $17 \mathrm{~cm}$ lang; das Gefieder ist nicht schwarz.

A) Die Oberseite des Körpers ist grau oder grün, hinten gelbgrün; die äulierste Schwanzfeder ist entweder einfarbig oder heller und dunkler grau gebändert.

a) Die Stirn und der Scheitel sind beim Männchen und Weibchen bis zum Nacken hin in einer Ausdehnung von mehr als $6 \mathrm{~cm}$ entweder einfarbig rot oder rot gefleckt; der anliegende Flügel ist über $15 \mathrm{~cm}$ lang (Bd. IV, S. 265, Tafel 29, Fig. 1-3) . . . Picus viridis, Griin-Specht.

b) Nur die Stirn des Männchens ist, von vorn gemessen, $3 \mathrm{~cm}$ weit rot; der anliegende Flügel bleibt stets etwas unter $15 \mathrm{~cm}$ (Bd. IV, S. 272, Tafel 30, Fig. 1-3); besonders im Norden

Picus canus, Grau-Specht.

B Die Oberseite des Körjers ist schwarz und weiß gefleckt ofler gebaindert, oft auch z. T. reinweiß; auch die äußerste Schwanzfeder ist in der Endhälfte weiß und schwarz gefleckt oder gebändert.

a) Es sind nur drei Zehen vorhanden, von denen zwei nach vorn und eine nach hinten gerichtet ist; die Federn der Stirn sind weißlich und schwärzlich gefleckt, beim Männchen am Ende zitronengelb (Bd. IV, S. 300, Tafel 34, Fig. 1 und 2) . Picoides tridactylus, Dreizehen-Specht. 
b) Es sind vier Zehen vorhanden, von denen zwei nach hinten gerichtet sind; die Federn der Stirn sind nicht weißlich und dunkel gefleckt.

a) Die Unterseite des Körpers zeigt keine rote Farbe; der anliegende Flügel ist $8-10 \mathrm{~cm}$, die Schnabelfirste, von der Wurzel der nach vorn gerichteten Federn bis zur Spitze gemessen, höchstens $16 \mathrm{~mm}$ lang.

* Die Seiten der Brust zeigen stets schmale dunkle Schaftflecke; die schwarzen Querbinden auf dem Rücken sind breit (Bd. IV, S. 295, Tafel 33, Fig. 3 und 4) . . Dendrocopus minor, Klein-Specht. ** Die Seiten der Brust zeigen nur einige undeutliche und breite Flecke: die dunklen Querbinden des Rückens sind sehr schmal und fehlen bisweilen gänzlich (Bd. IV, S. 296, Tafel 33, Fig. 5)

Dendrocopus minor pipra, Sibirischer Klein-Specht.

ß) Die Federn unter dem Schwanze sind stets mehr oder weniger rot gefärbt: der anliegende Flügel ist über $12 \mathrm{~cm}$, die Schnabelfirste über $20 \mathrm{~mm}$ lang. * Die dunklen Federn der Kropfgegend sind am Ende schön rot (Bd. IV, S. 284) . . . . Dendrocopus numidicus, Mauren-Specht. ** Die Kehle, der Kopf und die Brust zeigen niemals rote Teile.

Ein schwarzes oder dunkles Band verläuft vom unteren Mundwinkel nach hinten; der anliegende Flügel ist über $13 \mathrm{~cm}$ lang.

$\doteqdot$ Die Mitte des Rückens ist der Länge nach bis zu den Schwanzdeckfedern schwarz; die Schnabelfirste ist höchstens $27 \mathrm{~mm}$ lang (Bd. IV, S. 277, Tafel 31, Fig. 1-3)

Dendrocopus major, Rot-Specht, Bunt-Specht.

† Der Hinterriicken ist weiß; die Schnabelfirste ist meist über $30 \mathrm{~mm}$ lang (Bd. IV, S. 286, Tafel 32, Fig. 1 und 2); nordöstliche Art

Dendrocopus leuconotus, Weil-Specht.

$\bigcirc \bigcirc$ Unter dem Auge befindet sich keine dunkle Längsbinde; der anliegende Flügel ist nicht $13 \mathrm{~cm}$ lang (Bd. IV, S. 290, Tafel 33, Fig. 1 u. 2)

Dendrocopus medius, Mittel-Specht.

\section{Jymx.}

(NAumann, Bd. IV, S. 324, Tafel 36, Fig. 1 und 2)

Jymx torquilla, Grauer Wendelials.

\section{Arten der Eisvögel und Bienenfresser.}

\section{Merops.}

I. Die Federn auf dem Hinterkopfe besitzen stets eine mehr oder weniger dunkle, rotbraune Grundfarbe; die schön gelbe Kehle ist stets durch einen dunklen Querschatten von der blaugrünen Unterseite getrennt ( $\mathrm{Bd} I V$, S. 332, Tafel 37, Fig. 1 und 2); südlicher Vogel

Merops apiaster, Europiiischer Bienenfresser. 
II. Die Federn auf dem Hinterkopfe zeigen niemals eine rotbraune Grundfarbe; die rotbraune Kehle ist hinten nicht durch einen dunklen Querschatten begrenzt Merops persicus.

\section{Alecto, Halcyon und Ceryle.}

I. Der anliegende Flügel ist höchstens $12 \mathrm{~cm}$ lang; der Bürzel zeigt einen schönen blauen oder blaugriinen Schiller; ebenso besitzen die Schwanzfedern z. T. einen blauen Schiller und keine weißen Flecke.

A) Der anliegende Flügel ist 11-12 $\mathrm{mm}$ lang; die Firste des roten oder rotbraunen Schnabels ist 5-6 cm lang; der Kopf und der Hals sind oben dunkelrotbraun (Bd. IV, S. 360, Tafel 39, Fig. 1 und 2)

Haleyon smyrnensis, Braun-Liest.

B) Der anliegende Flügel ist 6-8 cm lang; die Firste des schwarzen Oberschnabels ist $2^{1} / 2-3^{1} / 2 \mathrm{~cm}$ lang; die Federn an der Oberseite des Kopfes und Halses zeigen blauschillernde Querflecke (Bd. IV, S. 346, Tafel 38, Fig. 1 und 2) . . . . . Alcedo ispida, Gemeiner Eisvogel.

II. Der anliegende Flügel ist $15-17 \mathrm{~cm}$ lang; der Bürzel ist dunkelblaugrau; die Schwanzfedern zeigen weiße Querflecke; die Firste des schwarzen Schnabels ist etwa $5 \mathrm{~cm}$ lang (Bd. IV, S. 419)

Ceryle alcyon, Gürtelfischer.

\section{Art der Racken.}

Coracias.

(Natanis, Bd. IV, S. 364, Tafel 40, Fig. 1 und 2)

Coracias g(t)mula, Blau-Racke.

\section{Art der Hopfe.}

Uрири.

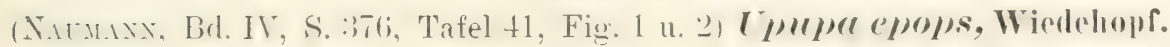

\section{Arten der Kuckucke.}

\section{Cuculus, Coccystes und Coccyius.}

I. Die äußeren Schwanzfedern zeigen auf dem Schaft eine Reihe mehr oder weniger ausgedelnter, weißer Flecke, die sich mitunter als Binden quer iiler die Feder fortsetzen: die Interseite des Körpers zeigt immer dunkle (purerwellen (Bd. IV, S. 393, Tafel 42, Fig. 1-3 und Tafel 43, Fig. 1 und 2)

Cuculus canomis, Gemeiner Kuckuck.

II. Die äußere Schwanzfeder ist nur am Ende weiß; die Unterseite des Körpers ist größtenteils weißlich und zeigt niemals dunkle Querwellen. 
A) Der anliegende Fliigel ist $14-15 \mathrm{~cm}$ lang; die Fliigel zeigen auf der Oberseite niemals weiße Flecke...... Coccyzus americanus. B) Der anliegende Flïgel ist 19-23 cm lang, nur bei unausgefiederten Vögeln kürzer; auf der Oberseite der Flügel entstehen durch weiße Federenden stets zahlreiche weiße Flecke (Bd. IV, S. 411, Tafel 44, Fig. 1 u. 2) Coccystes glandarius, Häher-Kuckuck.

\section{Die Arten der Raubvögel. strix.}

(Niumaxx, Bd. V, S. 5, Tafel 1, Fig. 1 und 2): in Häusern

strix flammer, Schleiereule.

\section{Glancidimm, Sumia, Nyctea und Syrmimm.}

I. Der anliegende Flügel ist 10-17 cm lang, der Schwanz von der durch das Gefieder fuihlbaren Wurzel bis zum Ende der Schwanzfedern ist höchstens $9 \mathrm{~cm}$ lang.

A) Die Zehen sind zerstreut beborstet; der anliegende Flügel ist $15-17 \mathrm{~cm}$ lang; die Außenfahne der fünften Schwinge ist am Ende meist verengt, aber der enge Endteil undeutlich abgesetzt (Bd. V, S. 10, Tafel 2, Fig. 1)

Glaucidium [Athene] noctur, Steinkauz, Käuzchen.

B) Die Zehen sind dicht befiedert oder beborstet; der anliegende Flügel ist 10-11 cm lang; die Außenfahne der fünften Schwinge ist vor dem Ende deutlich abgesetzt verengt (Bd. V, S. 14, Tafel 3, Fig. 3); nordöstlicher Vogel . . . Glaurdium prssevinum, Sperlings-Eule.

II. Der anliegende Flügel ist über $22 \mathrm{~cm}$ lang, der Schwanz über $14 \mathrm{~cm}$ lang. A) Die äußerste Schwanzfeder ist entweder ganz weiß bezw. auf weißem Grunde dunkel gefleckt oder sie zeigt auf der Innenfahne große, ziemlich rein weiße, scharf abgesetzte Flecke; die Federn der Brust zeigen bis unten hin dunkle Querwellen, niemals Längsflecke.

a) Die äußerste Schwanzfeder ist entweder ganz weiß oder sie trägt ausgedehnte dunkle Flecke; die mittelsten Schwanzfedern sind $23-25 \mathrm{~cm}$ lang, der anliegende Flügel ist $t 1-t t \mathrm{~cm}$ lang (Bd. V, S. 28, Tafel 5 , Fig. 1 und 2) . . . . . Nyctea scandiaca, Schnee-Eule.

b) Die äußerste Schwanzfeder ist neben dem Schaft stets dunkel gefärbt und zeigt nur auf der Innenfahne große weiße Flecke, auf der Außenfahne kleine Randflecke; die mittleren Schwanzfedern sind $14-18 \mathrm{~cm}$ lang, der anliegende Fluigel 22-26 cm lang (Bd. V, S. 24, Tafel 4, Fig. 1 u. 2); nordöstliche Art . . . . . . . . Sumir Ulula, Sperbcr-Eule.

B) Die äußerste Schwanzfeder zeigt entweder keine reinweißen Teile oder die weißen Teile der Innenfahne werden nach dem Schaft hin ganz all- 
mählich schmutziggelblich: die Federn der Brust zeigen höchstens oben dunkle Querwellen, nach den Beinen hin aber stets dunkle Längsflecke.

91) Der anliegende Flügel ist $27-29 \mathrm{~cm}$ lang (Bd. V, S. 34, Tafel 6, Fig.1 u. 2)

\section{symium, rluro, Waldkauz.}

B) Der anliegende Fliigel ist iiber $34 \mathrm{~cm}$ lang.

a) Die Federn des Hinterhalses zeigen breite dunkle Schaftflecke, welche gegen den hellen Außenrand in einfacher Linie abgegrenzt sind; die Federn um die Augen zeigen keine Spur ron konzentrischen dunklen Wellenlinien (Bd. V, S. 41, Tafel 7, Fig. 1 und 2); östliche Art

Syminm uralense, Habichts-Eule.

b) Die Federn des Hinterhalses sind entweder bunt oder sie tragen eine helle Querbinde; die Strahlenfedern um die Augen zeigen stets deutliche konzentrische Wellenlinien.

«) Die Federn am Hinterhals sind mit weißer Querbinde gezeichnet; die hellen Querbinden auf den Schwanzfedern sind nicht marmoriert; der anliegende Flügel ist $35-36 \mathrm{~cm}$ lang . S Syrnium nebulosum.

ß) Die Federn am Hinterhals und die hellen Querbinden auf den Schwanzfedern sind marmoriert: der anliegende Flügel ist $42-45 \mathrm{~cm}$ lang (Bd.V, S. 46, Tafel 8, Fig. 1) Syrnium lapponicum, Lapplands-Eule.

\section{Nyctala.}

(Naumaxx, Bd. V, S. 17, Tafel 2, Fig. 2); häufiger im Norden

Nyctale tengmalmi, Tengmalms-Kauz.

\section{Pisorhina.}

(Natmaxx. Bd. V, S. 50, Tafel 3, Fig: 1 und 2)

Pisorhina scops, Zwergohreule.

Isio [Otus].

I. Der Kopf ist jederseits mit einem mindestens $3 \mathrm{~cm}$ langen, abstehenden Ohrfederbüschel versehen (Bd. V, S. 54, Tafel 9, Fig. 1)

Asio otus, Wald-0hreule.

II. Der Kopf ist mit kaum merklich abstehenden Ohrfedern versehen (Bd. V, S. 58, Tafel 9, Fig. 2) . . .Asio arcipituims, Sumpf-0hreule.

\section{Bullo.}

(Nacmaxx, Bd. V, S. 62, Tafel 10, Fig. 1) Bubo mbo (muximus), Ihu.

\section{Fralco und Timmunceluss.}

I. Der anliegende Flügel ist höchstens etwa $28 \mathrm{~cm}$ lang:

A) Die Mittelzehe ist mit Kralle uber doppelt so lang wie die Schnabelfirste ïber den Bogen gemessen. 
a) Die Schwanzfedern sind auf der Unterseite der Innenfahne bis zu der von Federn verdeckten Wurzel mit 10-12 dunklen Querbinden versehen; von einer dunklen Binde unter dem Auge läuft vorn ein Streif neben der Kehle herab (Bd. V, S. 102, Tafel 17, Fig. 1 und 2)

Falco subbuteo, Lerchenfalke.

b) Die Schwanzfedern sind auf der Unterseite der Innenfahne bis zur verdeckten Wurzel entweder mit 7-8 dunklen Querbinden oder nur mit einer breiten Endbinde versehen; unter den Augen befindet sich keine scharfe schwarze Zeichnung (Bd. V, S. 111, Tafel 19, Fig. 1-4)

Falco aesalon, Merlinfalke.

B) Die Mittelzehe ist mit Kralle nicht doppelt so lang wie die Schnabelfirste.

a) Die Krallen sind schwarz, der Schwanz ist, von der durch die Federn fühlbaren Wurzel bis zum Ende gemessen, $16^{1} / 2-18 \mathrm{~cm}$ lang; der Rücken des Vogels ist rostfarbig, dunkel gefleckt oder quer gebändert (Bd. V, S. 116, Tafel 20, Fig. 1 und 2)

Tinnunculats timunculus, Turuflalke.

b) Die Krallen sind gelblichweiß; der Schwanz ist $12-16 \mathrm{~cm}$ lang.

a) Die Wachshaut des Schnabels und die Füße sind rot oder rötlichgelb gefärbt; der Rücken des Vogels ist entweder einfarbig blaugrau oder die Grundfarbe zeigt doch einen blaugrauen Ton (Bd. V, S. 128, Tafel 22, Fig. 1-3); östliche Art

Timmuculus vespertinus, Rotfudfalke.

ß) Die Wachshaut des Schnabels ist gelb; die Füße zeigen einen kaum merklichen rötlichen Ton; der Rücken des Vogels ist entweder einfarbig rostrot oder auf roströtlicher Grundfarbe dunkel gefleckt oder gebändert (Bd. V, S. 122, Tafel 21, Fig. 1 und 2); südliche Art

Tinnunculus naumanni, Rötelfalke.

II. Der anliegende Flügel ist über $28 \mathrm{~cm}$ lang.

A) Das Ende der kurzen Federchen an der Innenseite des Laufes ist höchstens $18 \mathrm{~mm}$ von den obersten Schuppen der Fufsohle, die sich zwischen Hinter- und Innenzehe befinden, entfernt (Nauxaxx, Bd. 5, S. 82, Fig.); der anliegende Flügel ist $35-42 \mathrm{~cm}$ lang.

a) Die längsten unteren Schwanzdeckfedern sind beim ausgefärbten Vogel entweder ganz weiß oder mit sehr schmalen, an der breitesten Stelle kaum über $1 \mathrm{~mm}$ breiten Schaftstreifen versehen; beim Jugendkleide zeigen diese Federn am Ende eine schräg nach außen verlaufende Querbinde, die einen kaum $5 \mathrm{~mm}$ breiten Endteil frei läßt (Bd. V, S. 83, Tafèl 12, Fig. 1-5)

Falco gyrfalco islandus, Isländischer Gerfalke. 
b) Die längeren unteren Schwanzdeckfedern sind am Ende stets mit dunklen Schaftflecken versehen, die an der breitesten Stelle mindestens etwa $2 \mathrm{~mm}$ breit sind (Bd. V, S. 81, Tafel 11, Fig. 1-3)

Falco gyrfalco, Kleiner Gerfalke.

B) Das Ende der kurzen Federchen an der Innenseite des Laufes ist stets über $2 \mathrm{~cm}$ von den nächsten Sohlenhöckerchen entfernt (NALMAx, Bd. V, S. 82, Fig.).

a) Die unteren Schwanzdeckfedern sind stets mit sehr deutlichen dunklen Querbinden oder Winkelflecken gezeichnet; an den Beinen sind bei alten Vögeln stets sehr deutliche dunkle Querwellen vorhanden; unter den Augen befindet sich stets eine zusammenhängende dunkle Zeichuung. von welcher ein breiter dunkler Bartstreif abwärts verläuft (Bd. V, S. 95, Tafel 15, Fig. 1 und 2 und Tafel 16, Fig. 1 und 2)

Falco peregrimus, Wanderfalke.

b) Die unteren Schwanzdeckfedern sind entweder einfarbig hell oder mit sehr undeutlichen bezw. unregelmäßigen dunklen Zeichnungen versehen: an den Beinen sind nie scharfe dunkle Querwellen vorhanden; die dunkle Zeichnung unter dem Auge ist oft undeutlich und der Bartstreif ist stets schmal oder fehlt ganz.

a) Die längeren Federn am oberen Teil der Beine sind am Ende größtenteils dunkel (Bd. V, S. 87, Tafel 13, Fig. 1 und 2)

Falco sacer, Würgfalke.

$\beta$ ) Die längeren Federn am oberen Teil der Beine sind am Ende größtenteils hell.

Der Scheitel zeigt querïber eine heller oder dunkler rostbräunliche Grundfarbe (Bd. V, S. 92, Tafel 14, Fig. 1 und 2)

Falco feldeggi, Feldeggsfalke.

$\therefore$ Der Scheitel ist ebenso wie der Hals in der Mitte stets dunkel gefärbt

Falco punicus.

\section{Hilvus.}

I. Die mittleren Schwanzfedern sind $6-9 \mathrm{~cm}$ kürzer als die äußersten, die mittelsten auf der Rückenseite hell rostrot, höchstens auf dem schaft sellıst mit dunklen Flecken und vor dem Ende mit Andeutung einer Querbinde versehen; auf der Unterseite der zweitäußersten Schwanzfeder sind die hellen Zwischenräume zwischen den nicht bis zum Innenrande der Feder reichenden dunklen Querhinden mindestens dreimal so loreit wie die Bänder (Bd. V, S. 134, Tafel 23, Fig. 1 und '2)

Milvus milvus (regalis), Roter Milan.

II. Die mittleren Sichwanzfedtern sind höchstens is ('m kürzer als die äufjersten. die mittelsten auf der Rückenseite dunkelgraubrau bis schwiirzlich wefarht und stets wenigstens mit schattenartigen, undeutlichen Querbinden ver- 
sehen; auf der Unterseite der zweitäußersten Schwanzfeder sind die hellen Zwischenräume zwischen den dunklen Querbinden höchstens doppelt so breit wie die Binden (Bd. V, S. 139, Tafel 23, Fig. 3)

Milves korschun (migrans), Schwarzbramer Milau.

Elanus.

(Naumanx, Bd. V, S. 144, Tafel 24, Fig. 1 und 2)

Elanus coeruleus, Schwarzflügeliger Gleitaar.

\section{Penis.}

(Naumann, Bd. V, S. 149, Tafel 25, Fig. 1 und 2 und Tafel 26, Fig. 1 und 2)

Pernis apivorus, Wespen-Bussarl.

\section{Pandion.}

(Naumann, Bd. V. S. 157, Tafel 16) . Pamdion haliä̈tus, Flußadler.

\section{Hriliciètus.}

I. Sind die Schwanzfedern in der Endhälfte querüber weiß (ad.), so ist oft auch der Kopf bis zur Kropfgegend hell, aber nicht weiß, die hellen Federn auf der Kropfgegend aber sind stets mit dunklen Schaftstreifen versehen; sind die Schwanzfedern am Ende teilweise dunkel (juv.), so ist die Innenfahne neben dem Schaft immer sehr hell gefärbt, oft ganz weiß (Bd. V, S. 162, Tafel 28, Tafel 29 und Tafel 30)

Haliaëtus rubicillı. Seeadler.

II. Sind die Schwanzfedern in der Endhälfte queriber weif (ad.), so ist auch der Kopf weif, aber nicht bis zur Kropfgegend: die Federn der Kropfgegend sind stets ganz dunkel; sind die Sichwanzfedern am Ende teilweise oder ganz. dunkel, so ist die Innenfahne unmittelbar neben dem Schafte stets verdunkelt (Bd. V, S. 171, Tafel 31)

Haliaëtus leucocephalus, Weißköpfiger Seeadler.

\section{Circuëtus.}

(Naumann, Bd. V, S. 176, Tafel 32, Fig. 1 und 2)

Circcëtus gallicus, Natternadler, Schlangenadler.

\section{Buteo.}

I. Die Federn in der Kropfgegend sind wenigstens z. T. neben dem dunklen Schaft oder Schaftstreif sehr hell und nach dem Rande hin wieder dunkler gefärbt; die Schwanzfedern sind auf der Oberseite sehr dunkel, mit undeutlicher bräunlicher Bänderung versehen (Bd. V, S. 139, Tafel 23, Fig. 3)

vergl. oben Hilvus horsthum, Schwarzer Milau. 
II. Die Federn in der Kropfgegend sind alle entweder vom Schaft bis zum Rande gleichmälig dunkel oder nur neben dem Schaft dunkel und dann bis zum Rande hin gleichmätig hell: die Schwanzfedern sind entweder rostbram oder dunkelbraun, ohne Bänderung, auf der Innenfahne bisweilen weiß oder auf der Oberseite sehr deutlich hell und dunkel gebändert.

A) Die mittelsten Schwanzfedern sind entweder hell und dunkel gebändert und dann unten z. T. fast ebenso scharf gebändert wie oben, freilich im Grundton unten etwas heller als oben; verliert sich die Bänderung, so tritt nie eine rostbraune Farbe auf; der anliegende Flügel ist $37-43 \mathrm{~cm}$ lang (Bd. V, S. 180, Tafel 33, Fig. 1 und 2 und Tafel 34, Fig. 1-3)

Buteo buteo (vulgaris), Mäusebussard.

B) Die mittelsten Schwanzfedern sind entweder hell und dunkel gebändert und dann unten stets viel undeutlicher gebändert als oben; verliert sich die Bänderung, indem die dunklen Querbänder schmäler werden und schliełslich ganz schwinden, so tritt wenigstens in der Endhälfte stets eine hellere oder dunklere Rostfarbe auf; der anliegende Flügel ist $34-49 \mathrm{~cm}$ lang. a) Der anliegende Flügel ist $34-40 \mathrm{~cm}$ lang (Bd. V, S. 189 und 192, Tafel 35, Fig. 1-3 und Tafel 36, Fig. 1 und 2); östliche Art

Buteo aimumemannae, Falkenbussarl und Buteo desertorum, Steppenbussard.

Die beiden Formen sind nicht scharf vom Mäusebussard und voneinander zu unterscheiden.

b) Der anliegende Flügel ist $40^{1} / 2-49 \mathrm{~cm}$ lang (Bd. V, S. 194, Tafel 37 , Fig. 1 und 2) ....... Buteo ferox, Adlerbussard.

\section{Archibutco, Aquila und Nisciëtus.}

I. Die Schnahelfirste ist vom Rande der Befiederung bis zur Spitze über den Bogen gemessen nicht $4 \frac{1}{2} \mathrm{~cm}$ lang.

A) Die zweite Schwinge ist viel länger als die sechste (Bd. V, S. 197, Tafel 38, Fig. 1 und 2); in Deutschland besonders im Winter

Archibuteo layopus, Rauhfub-Bussari.

B) Die zweite Schwinge ist viel kürzer als die sechste (Bd. V, S. 245), Tafel 50, Fig. 1 und 2) . . . . Nisaëtus pennatus, Zwergadler.

II. Die Schnabelfirste ist ïber $4 \frac{1}{2} \mathrm{~cm}$ lang.

A) Der anliegende Flügel $57-70 \mathrm{~cm}$ lang.

a) Die Schwanzfedern sind in der Wurzelhälfte wenigstens auf der Innenfahne weiß (Bd. V, S. 202, Tafel 39, Tafel 40, Fig. 1 und '2 und Tafel $t 1$, Fig. 1 und 2) . . Aquila chrysä̈tus, Steinaller, Goldadler.

b) Die Schwanzfedern sind an der Wurzel der Innenfahne nie reinweib.

a) Die Federn am Scheitel sind größtenteils sehr hell gefärbt (Bd. V, S. 218, Tafel 42, Tafel 43, Fig. 1 und 2 und Tafel 44, Fig. 1 und 2)

Aquila melanaëtus, Kaiserader. 
ß) Die Federn am Scheitel sind größtenteils dunkelbraun gefärbt (Bd. V, S. 238, Tafel 48, Fig. 1 und 2)

vergl. unten Aquila nipalensis, Steppenadler.

B) Der anliegende Flügel ist nicht $57 \mathrm{~cm}$ lang.

a) Die Federn der Kropfgegend sind weiß bis rostgelb gefärbt, entweder einfarbig oder mit dunklem Schaftstreifen versehen.

aa) Die Federn der Kropfgegend sind mit einem scharfen dunklen Schaftstreifen versehen; der anliegende Flügel ist $49-52 \mathrm{~cm}$ lang (Bd. V, S. 240, Tafel 49, Fig. 1 und 2) Nisaëtus fasciatus, Habichtsadler.

bb) Die Federn der Kropfgegend zeigen keine scharfen dunklen Schaftstreifen; der anliegende Flügel ist $53-55 \mathrm{~cm}$ lang (Bd. V, S. 236, Tafel 47, Fig. 1 und 2) . . . . . Aquila fulvescens, Prachtadler.

b) Die Federn der Kropfgegend sind entweder dunkelbraun oder sie hathen einen dunkelrostbraunen Ton.

a) Der anliegende Flügel ist mindestens $50 \mathrm{~cm}$ lang.

๔) Die meisten Schwanzfedern sind auf der Innenfahne vom Ende bis zur Wurzel mit gewässerten Querwellen versehen (Bd. V, S. 238, Tafel 48, Fig. 1 und 2) . . . . Aquila nipalensis, Steppenadler.

ß) Die Schwanzfedern sind höchstens am Ende der Innenfahne mit gewässerten Querbinden versehen (Bd. V, S. 225, Tafel 45, Fig. 1 und 2); östliche Art . . . . Aquilı maculata, Grober Schreiadler.

b) Der anliegende Flügel ist nicht $50 \mathrm{~cm}$ lang (Bd. V, S. 230, Tafel 46, Fig. 1 und 2); im Osten håufiger

Arruila pomarina (naevia), Kleiner Sehreiadler.

\section{Accipiter und Astur.}

I. Der anliegende Flügel ist $28-38 \mathrm{~cm}$ lang.

A) Die erste Schwinge ragt mit ihrem Ende weit über das Ende der siebenten Schwinge hinaus; die Außenfahne der fünften Schwinge wird gegen das Ende nur ganz allmählich etwas schmäler (Bd. V, S. 284, Tafel 59, Fig. 1--3). vergl. unten Circus macrurus, Steppenweihe.

B) Die erste Schwinge reicht nicht oder kaum bis ans Ende der achten Schwinge; die Außenfahne der fünften Schwinge verengt sich in der Mitte plötzlich von etwa $9 \mathrm{~mm}$ Breite auf etwa $2 \mathrm{~mm}$ (Bd. V, S. 261, Tafel 54 und 55)

Astur palumbarius, Hiihnerhabicht.

II. Der anliegende Flügel ist $18-27 \mathrm{~cm}$ lang.

A) Die Außenfahne der sechsten Schwinge ist vor der Mitte plötzlich auf etwa $1 / 3$ ihrer Breite verengt; die sechste Schwinge ragt mit ihrem Ende stets uber das Ende der zweiten Schwinge hinaus; die Mittelzehe ist sehr lang und diinn (Bd. V, S. 252, Tafel 51, Fig. 1 und 2 und Tafel 51, Fig. 1 und 2)

Accipiter misus, Finkenhabicht, Sperber. 
B) Die Außenfahne der sechsten Schwinge ist gegen das Ende, etwas aber nicht bis auf die Hiilfte ihrer Breite rerengt; die zweite Schwinge ist stets länger als die sechste; die Mittelzehe ist kurz und dick (Bd. V, S. 258, Tafel 53, Fig. 1 und 2) . . . . . Astus brevipes, Zwerghabicht.

\section{Circris.}

I. Die Außenfahne der fünften Schwinge ist in der Mitte plötzlich auf mindestens die Hälfte ihrer Breite verengt.

A) Die zweitiußerste Schwanzfeder zeigt niemals deutliche Querbinden, allenfalls neben dem Schaft unregelmäBige dunkle Flecke; der Rücken des Vogels ist stets dunkelbraun (Bd. V, S. 267, Tafel 56, Fig. 1-3)

Circus aeruginosus, Rohrweihe.

B) Die zweitiuuferste Schwanzfeder ist stets mit regelmä13igen. entweder vollständigen oder abgekürten dunklen Querbinden versehen; der Riicken des Vogels ist entweder in der Grundfarbe dunkelbraun. und damn tragen die äußeren Schwanzfedern auf der Rückseite :3-4 breite, durchlaufende, dunkle Querbinden oder der Rücken ist blaugrau, und dann tragen die äußeren Schwanzfedern 5-6 außen abgebrochene schmale schwarze Binden auf weißem Grunde (Bd. V, S. 274, Tafel 57, Fig. 1-3)

Civeus cyaneus, Kornweihe.

II. Die Außenfahne der fünften Schwinge ist vor dem Ende ganz allmählich und nicht bis auf die Hälfte ihrer Breite verengt.

A) Die V'erengung der breiten Innenfahne der ersten Schwinge liegt melnr als $2 \mathrm{~cm}$ hinter dem Ende der den ersten Schwingen aufliegenden oberen Flïgeldeckfedern (Bd. V, S. 279, Fig., Tafel 58, Fig. 1-3)

Circus pygargus, Wiesenweihe.

B) Die Verengung der Innenfahne der ersten Schwinge liegt nicht $1 \frac{1}{2} \mathrm{~cm}$ hinter dem Ende der oberen Flügeldeckfedern (vergl. die Fig., Naumann, Bd. V, S. 284) (Bd. V, S. 284, Tafel 59, Fig. 1-3); östliche Art

Circus macrums, Steppenweihe.

\section{Gypcëtus.}

(Naumanx, Bd. V, S. 292, Tafel 60 und Tafel 61, Fig. 1-3)

Gypaëtus barbatus, Bartgeier, Lämmergeier.

\section{Neophron.}

(Nautanx, Bd. V, S. 303, Tafel 62, Fig. 1 und 2)

Neophron percnopterus, Schmutziger Aasvogel.

\section{Gyps.}

(Naumanx, Bd. V, S. 309, Tafel 63 und Tafel 64); südeuropåische Art

Gyps fulvus, Giinsegeier. 


\section{Vultus.}

(Naumany, Bd. V, S. 317, Tafel 67)

Vultur monachus, Kuttengeier, Mönchsgeier.

\section{Arten der Tauben.}

\section{Columba.}

I. Die Außenfahne der äußersten Schwanzfeder ist nach der Wurzel hin querüber grau; die oberen Flügeldeckfedern zeigen keine schwarzen Teile; beim ausgefärbten Vogel sind am Halse die Federenden teilweise weiß; der anliegende Flügel ist beim ausgewachsenen Vogel $24-26 \mathrm{~cm}$ lang (Bd. VI, S. 18, Tafel 2, Fig. 1 und 2) . Columba palumbus, Ringeltaube.

II. Die Außenfahne der äußersten Schwanzfeder ist in der Wurzelhälfte fast querüber rein weiß; die größeren Flïgeldeckfedern sind zum Teil mit schwarzen Querbinden oder Flecken versehen; am Hals zeigen sich niemals weiße Federränder; der anliegende Flügel ist $20-23 \mathrm{~cm}$ lang.

A) Die Oberseite der Flügel zeigt zwei querüber verlaufende schwarze Binden; der Hinterricken ist stets rein weiß (Bd. VI. S. 5, Tafel 1, Fig. 1 u. 2)

Columba livia, Felstaube.

B) Die Oberseite der Flügel ist nur mit schwarzen Flecken oder mit einer verkürten Querbinde versehen; der Hinterriicken ist blaugrau, wie der Vorderricken (Bd. VI, S. 26, Tafel 3, Fig. 1 und 2)

Columba oences, Hohltaube.

\section{Turtur.}

I. Die Außenfahne der äußersten Schwanzfeder ist der Länge nach querüber rein weiß (Bd. VI, S. 36, Tafel 4, Fig. 1 und 2); im Süden zahlreicher

Turus turur, T'urteltaube.

II. Die Außenfahne der äußersten Schwanzfeder ist nicht rein weiß, sondern bläulichgrau bis schwärzlich gefärbt, namentlich an der Grenze des hellen Endteils greift die dunkle Farbe immer auf die Außenfabne uiber.

A) Der anliegende Flügel ist $181 / 2-21 \mathrm{~cm}$ lang, das dunkle Halsband beim ausgefärbten Vogel ist hinten unterbrochen; an den Seiten ist es breit und durch weißliche Federränder fleckig geteilt; die großen oberen Flïgeldeckfedern sind zum Teil rostfarbig gerandet . . . Turtur orientalis.

B) Der anliegende Flügel ist kaum uiber $17 \mathrm{~cm}$ lang; das schwarze Halsband beim ausgefärbten Vogel ist hinten nicht unterbrochen; es ist schmal und höchstens durch sehr schrnale weiße Federränder zerteilt; die oberen Flïgeldeckfedern sind dunkelaschgrau, der Rand etwas verwaschen heller; gezähmt gehaltene Art . . . . Turtur risorius, Lachtaube. 


\section{Ectopistes.}

In Nordamerika . . . . Ectopistes migratorius, Wandertaube,

\section{Arten der Hühner.}

\section{Lagopus.}

I. Größere Art; die Kralle der Mittelzehe ist, in gerader Linie von der Wurzel bis zur Spitze gemessen, mindestens $15 \mathrm{~mm}$ lang (Bd. VI, S. 50, Tafel 5, Fig. 1 und 2); vom Norden bis Ostpreußen verbreitet

Lagopus lagopus (albus), Moorschneehuhn.

II. Kleinere Art; die Kralle der Mittelzehe ist, in der angebenen Weise gemessen, nur 8-12 mm lang (Bd. VI, S. 58, Tafel 6, Fig. 1 und 2); im Norden und in den Alpen

Lagopus mutus (alpinus), Alpenschneehuhn.

\section{Bonasa.}

(Naumann, Bd. VI, S. 67, Tafel 8, Fig.1 und 2); besonders in Bergwäldern Bonasa bonasia, Europaiisches Haselhuhn.

\section{Tetrao.}

I. Der anliegende Flügel ist $23-27 \mathrm{~cm}$ lang; die mittleren Schwanzfedern sind über $1 \mathrm{~cm}$ kürzer als die äußeren (Bd. VI, S. 76, Tafel 9, Fig. 1 u. 2)

Tetrao tetrix, Birkhuhm.

II. Der anliegende Flügel ist $30-43 \mathrm{~cm}$ lang; die mittleren Schwanzfedern sind über $1 \mathrm{~cm}$ länger als die äußeren (Bd. VI, S. 89, Tafel 11 und 12); besonders in Bergwäldern . . . Tetrao mogallus, Auerhuhm.

\section{Coturnix.}

(Naumann, Bd. VI, S. 112, Tafel 14, Fig. 1-3)

Cotmix cotumix (commenis), Wachtel.

\section{Perdix.}

(Naumann, Bd. VI, S. 126, Tafel 15, Fig. 1 und 2)

Perdix perdix (cinerea), Reblıun, Rephuhn.

\section{Caccrbis.}

I. Beim ausgefärbten Vogel geht durch das Auge eine schwarze Binde und das dunkle Querband unter der weißen Kehle ist tiefschwarz gefärbt.

A) Das schwarze Querband unter der Kehle ist nicht nur oben sondern auch unten scharf abgegrenzt; auf den Federn der Weichen ist die gelb- 
liche Querbinde jederseits von einer. schwärzlichen Querbinde eingefaßt (Bd. VI, S. 150, Tafel 16, Fig. 1 und 2); in den Alpen

Caccabis saxatilis, Steinhuhn.

B) Das schwarze Querband unter der weißen Kehle löst sich nach unten in schwarze Flecke auf: auf den Weichenfedern ist die weißliche Mittelbinde nur nach dem Ende hin von einer schwärzlichen Querbinde eingefaßt (Bd. VI, S. 157, Tafel 17, Fig. 1 und 2) . . Caccabis rufa, Rothuhn.

II. Durch das Auge geht auch beim ausgefärbten Vogel niemals eine schwarze Binde; das dunkle Querband, welches die weiße Kehle unten begrenzt, ist dunkel rotbraun; die Enden der Federn sind hier mit rundlichen weißen Flecken versehen . . . . . . . . . Caccabis petrosa.

\section{Froncolinus.}

In Siidleuropa . . . . . . Francolinus francolinus (vulgaris).

\section{Phasianus.}

(Naumann, Bd. VI. S. 170, Tafel 18, Fig. 1 und 2); eingeführt

Phosicnus colchicus, Edelfasan.

\section{Meleagris.}

(Naumann, Bd. VI, S. 187, Tafel 19b)

Meleagris gallopavo, Wilder Truthahn.

\section{THmix.}

In Siideuropa . . . . . . Turnix silvatica, Laufhühnchen.

\section{Arten der Stelzvögel. \\ Arder, Herodius, Ardeola, Ardetta, Botrums, Nycticorax und Bubulcus.}

I. Die Schwingen, wenigstens von der sechsten an, und die Schwanzfedern, bisweilen mit Ausnahme der beiden mittleren, sind rein weiß.

A) Das Gefieder ist ganz weiß, die nackte Schnabelfirste ist $71 / 2-9 \mathrm{~cm}$ lang.

a) Der Lauf ist bis $11 \mathrm{~cm}$ lang, der anliegende Flügel 25-29 (bezw. bis 31) $\mathrm{cm}$ lang, die nackte Schnabelfirste $7^{1} / 2-10^{1} / 2 \mathrm{~cm}$ lang; der Schnabe] ist aschblaugrau bis schwarz; die Ruickenseite der Zehen ist grüngelb (Bd. VI, S. 233, Tafel 23, Fig. 1 u. 2) Herodias garzetta, Seidenreiher.

b) Der Lauf ist über $14 \mathrm{~cm}$ lang, der anliegende Flügel $35-42 \mathrm{~cm}$ lang, die nackte Schnabelfirste 11-13 $\mathrm{cm}$ lang; der Schnabel ist wenigstens an der Wurzel des Unterschnabels gelb; der Zehenrïcken ist braun bis braunschwarz (Bd. VI, S. 226, Tafel 22, Fig. 1 und 2); im Siidosten

Herodias alba, Silberreiher. 
B) Die Rückenseite des Vogels ist mehr oder weniger dunkel gefärbt, wenigstens ist die Oberseite des Kopfes vorn gelbrötlich und nicht rein weiß; die nackte Schnabelfirste ist $5^{1 / 2}-7 \mathrm{~cm}$ lang.

a) Auf der Oberseite des Kopfes sind die Federn vor ihrem Rande immel' breit schwarzbraun gezeichnet (Bd. VI, S. 240, Tafel 24, Fig. 1 und 2)

Ardeola ralloides, Schopfreiher.

b) Die Federn auf der Oberseite des Kopfes, oft auch die des Halses bis zum Kropfe und die des Hinterrückens sind hell rostgelb oder hell rostrot gefärbt . . . . . . Bubulcus coromandus, Kuhreiher.

II. Die Schwingen und Schwanzfedern sind dunkel gefärbt.

A) Die nackte Schnabelfirste ist $3^{1} / 2-6 \mathrm{~cm}$ lang, der anliegende Flügel $12^{1} / 2$ bis $16 \mathrm{~cm}$ lang (Bd. VI, S. 247, Tafel 25, Fig. 1-3); mehr im Osten

\section{Arretta minata, Kleine Rohrlommel.}

B) Die nackte Schnabelfirste ist über $6 \mathrm{~cm}$ lang, der anliegende Flügel iiber $24 \mathrm{~cm}$ lang.

a) Die nackte Schnabelfirste ist $9^{1} / 2-15 \mathrm{~cm}$ lang.

a) Der anliegende Flügel ist $41-49 \mathrm{~cm}$ lang; im Gefieder fehlt die rostbraune Farbe vollkommen (Bd. VI, S. 203, Tafel 20, Fig. 1 und 2)

Arden cineren, Hischreiher.

B) Der anliegende Flïgel ist $33-40 \mathrm{~cm}$ lang; es sind stets rostbraune Federn vorhanden, besonders am Halse (Bd. VI, S. 218, Tafel 21, Fig. 1 und 2); im Südosten . . Avdea purpurea, Purpurreiher.

b) Die nackte Schnabelfirste ist $61 / 4-71 / 2 \mathrm{~cm}$ lang.

«) Die Schwingen sind einfarbig, entweder dunkelgrau oder schwarzbraun, nur die Spitzen sind hell; die Mittelzehe mißt mit Kralle 6 bis $81 / 2$ cm (Bd. VI, S. 272, Tafel 28, Fig. 1-3)

Nycticonax mycticorax (griseus), Nachtreiher.

B) Die Schwingen sind hell rostbraun und schwarz, entweder quer gebändert oder gefleckt; die Mittelzehe mißt mit Kralle $10-11 \mathrm{~cm}$ (Bd. VI, S. 257, Tafel 26, Fig. 1 und 2)

Botanus stellaris, Große Rohrdommel.

\section{Ciconir.}

I. Das Gefieder ist weib, nur die Fligel sind ganz oder z. T. schwarz.

A) Die nackten Teile am Auge sind beim alten Vogel rot, beim jungen braun aber nicht dunkler als der Schnabel: beim anliegenden Fliigel sind die schwarzen Federn fast volliommen von weiben Federn verdecki (Bd. VII. S. 95, Tafel 8, Fig. 2) vergl. unten Grus leucogeranus, Mönchskranich.

B) Die nackten Teile vor und hinter dem Auge sind beim alten Vogel schwarz, auch beim jungen schwärzlich, viel dunkler als der graurötliche 
Schnabel: hei anliegendem Flügel sind die schwarzen Federn größtenteils sichtbar (Bd. VI, S. 301, Tafel 30, Fig. 1 und 2)

Ciconia ciconia (alba), Weiler storch.

II. Das Gefieder ist, mit Ausnahme der Unterseite vom Kropfe ab, schwarz oder schwärzlich (Bd. VI, S. 320, Tafel 1, Fig. 1 und 2)

Ciconia nigra, Schwarzer Storch.

\section{Platalea.}

(Naumann, Bd. VII, S. 4, Tafel 1, Fig. 1 u. 2)

Platalea leucorodia, Weißer Löffler, Löffelreiher.

\section{Plegadis und Geronticus.}

I. Die Hornschilder verlaufen vorn quer über den Lauf; der Kopf ist nur vor den Augen nackt (Bd. VII, S. 16, Tafel 2, Fig. 1-3)

Plegadis falcinellus, Dunkelfarbiger Sichler.

II. Der Lauf ist vorn dicht netzartig getäfelt; der Kopf ist ganz nackt (Bd. VII, S. 199, Tafel 20, Fig. 1 und 2) . Geronticus eremita, Waldrapp.

\section{Syrroptes.}

(N.1lmaxi, Bd. VII, S. 29, Tafel 3, Fig. 1 und 2); kam wiederholt in Flügen nach Deutschland . . . . Syrrhaptes paradoxus, Steppenhuhn.

\section{Pterocles.}

I. Der Bauch ist weißlich, die Brust zeigt 2-3 dunkle Querbänder; beim Männchen ist außerdem das Kinn und die Kehle schwärzlich (Bd. VII, S. 47, Tafel 4, Fig. 3) . . . . . . Pterocles alchata, Spießflughuhn.

II. Der Bauch ist wenigstens in der Nitte entweder dunkel rotbraun bis schwarz oder schwärzlich gebändert: hinter der Brust befindet sich eine dunkle Binde und allenfalls noch eine an der Kehle, beim Weibchen sind zwischen beiden schwarze Flecke vorhanden.

A) Der anliegende Flügel mißt $17-19 \mathrm{~cm}$; die Federn am Bauch sind heim Männchen rotbraun, beim Weibchen z. T. einfarbig schwärzlich, z. T. schwärzlich gebändert; unter der Kehle befindet sich keine schwarze Querbinde (Bd. VII, S. 50, Tafel 4, Fig. 4)

Pterocles exustus, Wüstenflughuhn.

B. Der anliegende Flügel mißt 22-25 cm; Die Federn am Bauche sind schwarz, alle stets ohne Bänderung; an der Kehle befindet sich beim Männchen eine schwarze Winkelbinde, beim Weibchen eine schmale, nicht winkelige Binde (Bd. VII, S. 40, Tafel 4, Fig. 1 und 2)

Pterocles arenarius, Sandflughuhn. 


\section{Otis und Houbara.}

I. Die Schwingen sind, namentlich auf der Innenfahne, an der Wurzel immer scharf abgeschnitten weif gefärbt; an der fünften Schwinge ist die Innenfahne nicht bis $10 \mathrm{~cm}$ vor dem Ende querüber dunkel; der anliegende Flügel ist höchstens $40 \mathrm{~cm}$ lang; die Federn vorn an der Seite des Halses sind immer schwarzbraun gezeichnet.

A) Der anliegende Flügel mißt $25-27 \mathrm{~cm}$; die füfte Schwinge ist, im Gegensatz zur vierten, plötzlich viel weiter nach dem Ende hin wei13; die dunkle Farbe geht auf der vierten Schwinge wenigstens $2 \mathrm{~cm}$ weiter nach der Wurzel hin als auf der fünften (Bd. VII, S. 73, Tafel 6, Fig. 1 und 2); siidlichere Art

Otis tetrux, Zwergtrappe.

B) Der anliegende Flügel ist $: 36$ - 40 cm lang: die dunkle Farbe greht aul? der fünften Schwinge ebensoweit oder noch weiter nach der Wurzel hin als auf der vierten (Bd. VII, S. 82, Tafel 7)

Houbara macqueni, Kragentrappe.

II. Die Schwingen werden nach der Wurzel hin allmählich heller; die fünfte Schwinge ist $20 \mathrm{~cm}$ vor dem Ende noch querüber grau; der anliegende Flügel ist 50-65 cm lang; der Hals ist vorn an den Seiten einfarbig blaugrau, bei jungen Tieren sind die Federenden gelblich (Bd. VII, S. 57, Tafel 5, Fig. 1 und 2)

Otis terda Grobtrappe.

\section{Gins.}

I. Der Torderteil des Kopfes mit Einschluti der Augen ist scharf abgeschnitten nackt, nur mit weißlichen Wollhaaren besetzt; die nackte Schnabelfirste ist beim ausgewachsenen Vogel 16-20 cm lang; das Gefieder ist bei alten Vögeln weif, bei jungen rötlichweiß (Bd. VII, S. 95, Tafel 8, Fig. 2)

Grus leucogeranus, Mönchskranich.

II. Der Kopf ist vorn entweder befiedert oder mit anliegenden schwarzen Borstenhaaren dicht besetzt; die nackte Schnabelfirste ist höchstens $12 \mathrm{~cm}$ lang; das Gefieder ist größtenteils grau.

A) Die nackte Schnabelfirste ist $7-11 \mathrm{~cm} \mathrm{lang,} \mathrm{die} \mathrm{Mittelzehe} \mathrm{ist} \mathrm{mit}$ Kralle $9^{1} / 2-11 \mathrm{~cm}$, der anliegende Fliggel, bis zum Ende der Schwingen, uiber $50 \mathrm{~cm}$ lang; der Hals ist vorn nicht bis zur Kropfgegend hinunter schwarz, beim Jugendlkleide ganz grau (Bd. VШ, S. 97, Tafel 9)

Grus !)us (cinerea), Gemeiner Kranich.

B) Die nackte Schnabelfirste ist $6-6 \frac{1}{2} \mathrm{~cm}$ lang, die Mittelzehe mit Kralle $71 / 2-8^{3} / 4 \mathrm{~cm}$, der anliegende Flitgel $43-50 \mathrm{~cm}$ lang; der Hals ist vorn bis zur Kropfgegend hinab schwarz und zwar unten mit langen schwarzen Federn versehen (Bd. VII, S. 90, Tafel 8, Fig. 1)

Grus virgo, Jungfernkranich. 
Fulica.

(Nadmann, Bd. VII, S. 122, Tafel 10, Fig. 1-3)

Fulica atra, Gemeines Wasserhuhn, Bläßhuhn.

\section{Porphyrio.}

In Südeuropa . . . . . . Porphyrio veterum, Purpurhuhn.

\section{Gallinula.}

(Naumann, Bd. VII, S. 142, Tafel 11, Fig. 1-3)

Gallinula chloropus, Gemeines Teichhuhn.

\section{Ortygometra und Crex.}

I. Die Ruickenseite des Körpers zeigt niemals weißliche Flecke; der anliegende Flügel ist $13-1 t^{1 / 2} \mathrm{~cm}$ lang; die Nittelzehe mit Kralle ist etwas kiuzer als der Lauf, von der Oberseite der Zehenwurzel bis zur Mitte des Fersengelenkes gemessen (Bd. VII, S. 180, Tafel 15, Fig. 1-3)

Crex crex (pratensis), Wiesen-Sumpflumn, Wachtelkinig.

II. Die Rückenseite des Körpers zeigt weißliche Flecke: der anliegende Flïgel mißt $81 / 2-12^{1} / 2 \mathrm{~cm}$; die Nittelzehe mit Kralle ist bedeutend länger als der Lauf.

A) Die Federn, welche von unten den Schwanzfedern anliegen, sind hell rostbrïunlich, ungebändert und ungefleckt; der anliegende Fliigel ist $11-12 \frac{1}{2} \mathrm{~cm}$ lang (Bd. VII, S. 156, Tafel 12, Fig. 1 u. 2)

Ortygometra poriana, Gesprenkeltes Sumpt'huhn.

B) Die dem Schwanze von unten anliegenden Federn sind wenigstens am Ende schwarz und weib gebändert oder gefleckt; der anliegende Flügel mißt $8 \frac{1}{2}-10^{1 / 2} \mathrm{~cm}$.

a) Der anliegende Flügel ist $81 / 2-9 \mathrm{~cm}$ lang; die Außenfahne der ersten Schwinge ist am Außenrande scharf abgesetzt weißlich (Bd. VII, S. 17t, Tafel 14, Fig. 1 u. 2); südlichere Art

Ortygometra pusilla, Zwerg-Sumpf'hulu.

b) Der anliegende Flïgel mißt $10-10^{1 / 2} \mathrm{~cm}$. Die Außenfahne der ersten Schwinge ist am Rande nicht oder kaum heller (Bd. VII, S. 166, Tafel 13, Fig. 1-3) . . . . Ortygometra parva, Kleines Sumpfhuhn.

Rallus.

(Naumann, Bd. VII, S. 191, Tafel 16, Fig. 1 u. 2)

Rallus aquaticus, Wasserralle.

\section{Vanellus.}

I. Die mittleren Schwanzfedern sind im Basaldrittel oder fast bis zur Mitte weiß, dann bis vor den weißlichen Endrand schwarz; der Lauf ist vorn mit 
z. T. fast querüber laufenden Tafeln versehen; der Schaft der zweiten und dritten Schwinge ist nicht heller als die Fahne, wenigstens auf den dunkelsten Stellen der Schwinge nicht heller.

A) Die drei ersten Schwingen sind vor dem Ende breit hellgefärbt; die Riickenfedern sind dunkel und besitzen einen metallischen Glanz, nur der Saum ist bisweilen bräunlich; die Unterseite des Körpers ist auf der Kropfgegend schwärzlich, der Bauch ist reinweif, die unteren Schwanzdeckfedern sind rotbräunlich (Bd. VIII, S. 3, Tafel 1, Fig. 1-3)

Vanellus vanellus (cristalus), Gemeiner Kiebitz.

B) Die ersten Schwingen sind ganz schwarz; der Rücken des Körpers ist einfarbig dunkelgrau und zeigt keinen Metallschimmer; die Kropfgegend ist grau; die unteren Schwanzdeckfedern sind weiß; die mittleren Teile des Bauches sind stets z. T. dunkler als der Kropf (Bd. VIII, S. 15, Tafel 3, Fig. 1) . . . . . Vanellus gregarius, Herden-Kiebitz.

11. Die mittleren Schwanzfedern sind mit zahlreichen dunklen Querbändern gezeichnet; der Lauf ist vorn dicht schuppig getäfelt; der Schaft der fuinf ersten Schwingen ist viel heller als die fast schwarze Fahne neben ihm (Bd. VIII, S. 35, Tafel 2, Fig. 3 u. 4); vergl. unten

Charadrius squaturola, Kiebitz-Regenpfeifter.

\section{Charadrins.}

I. Es ist eine deutliche Hinterzehe vorhanden; der anliegende Fliggel ist $191 / 4-21 \mathrm{~cm}$ lang (Bd. VIII, S. 35, Tafel 2, Fig. 3 u. 4); in Deutschland Durchzugsvogel, besonders am Meere

Chavadrias squatarola, Kiebitz-Regenpleifer.

II. Die Hinterzehe fehlt gänzlich; der anliegende Flügel ist höchstens $19 \mathrm{~cm}$ lang.

A. Die mittleren Schwanzfedern sind entweder querüber hell und dunkel gebändert oder doch an den Seitenrändern mit mehreren hintereinander liegenden hellen Flecken versehen; der anliegende Flügel ist $16-19 \mathrm{~cm}$ lang; der Körperriicken ist schwärzlich, mit hellgelblichen Flecken versehen, indem die hellen Federränder in der Mitte schmal dunkel unterbrochen sind.

a) Der anliegende Fluigel ist 16-17 $\mathrm{cm}$ lang; die Schwanzfedern sind mit .) -6 hellen Binden bezw. Randflecken hintereinander versehen (Bd. V'II, S. 31, Tafel 3, Fig. 2-4)

Charadrius dominicus, Kleiner Gold-Regenpfeifer.

b) Der anliegende Flügel ist $18-19 \mathrm{~cm}$ lang; die S(hwanzfedern sind mit 7-8 hellen Binden bezw. hellen Fleckenpaaren hintereinander versehen (Bd. VIII, S. 21, Tafel 2, Fig. 1 u. 2); nördlicher Zugvogel

Charadrius pluvialis, Gold-Regenufeif'er. 
B) Die mittleren Schwanzfedern sind allenfalls am Ende mit einer weißen Querbinde versehen; die Rückenseite des Körpers ist graubraun; nur die Seitenränder oder die ganzen Ränder der Federn sind hell, dann aber nicht fleckig, d. h. der Rand ist nicht schmal dunkel unterbrochen.

a) Die Außenfahne der äußersten Schwanzfeder ist größtenteils dunkel; der anliegende Flügel ist uiber $14 \mathrm{~cm}$ lang.

( ) Der Schaft der zweiten Schwinge ist der Länge nach braun; die weiße Endpartie auf der Innenfahne der äußersten Schwanzfeder ragt zwischen Schaft und Innenrand gerundet nach der Basis hin vor; der Bauch ist beim ausgefärbten Vogel vorn zwischen den Beinen schwärzlich oder rötlich gefärbt (Bd. VII, S. 43, Tafel 4, Fig. 2 u. 3 und Taf. 5, Fig. 1); in Deutschland nur Durchzugsvogel

\section{Charadrius morinellus, Mornell-Regenpfeiler.}

$\beta)$ Der Schaft der zweiten Schwinge ist in größerer Ausdehnung weiß; die Innenfahne der äußersten Schwanzfeder ist lediglich etwas breiter weißlich gerandet als die Außenfahne; die Bauchseite des Körpers ist von der Kropfgegend an fast reinweiß (Bd. VIII, S. 77, Tafel 8, Fig. 1 u. 2)

Charadrius asiaticus, Asiatischer Regenpfeifer.

b) Die Außenfahne der äußersten Schwanzfeder ist ganz weiß, oft auch die Innenfahne; der anliegende Flügel ist nicht $14 \mathrm{~cm}$ lang.

a) Nur auf der ersten Schwinge ist der Schaft zum Teil weiß, auf den folgenden ist er ganz braun; die Außenfahne der fünften und sechsten Schwinge ist ganz dunkel gefärbt (Bd. VIII, S. 67, Tafel 7, Fig. 1-3); südlichere Art . Charadrius aubias, Fluk-Regenpleifer.

$\beta$ ) Auch auf der zweiten und dritten Schwinge ist der Schaft zum Teil weiß; die Außenfahne der fünften und sechsten Schwinge zeigt, wenigstens neben dem Schafte, weiße Teile.

Die beiden äußersten Schwanzfedern sind ganz weiß; die weiße Zeichnung auf der Außenfahne der sechsten Schwinge reicht bis zum Rande (Bd. VIII, S. 53, Tafel t, Fig. 1 und Tafel 5, Fig. 3); besonders am Heere. . Chatalvims alexandrimus, See-Regenpfeifer.

**) Die zweitäußerste Schwanzfeder ist auf der Innenfahne vor dem weißen Ende scharf abgesetzt schwarz; die weiße Zeichnung auf der Außenfahne der sechsten Schwinge reicht nicht bis zum Rande (Bd. VIII, S. 59, Tafel 6, Fig. 1-3); im Sommer fast nur am Meere

Charalrius hiaticula, Sand-Regenpleiler.

Arenaria [Strepsilas].

(Naumann, Bd. VIII, S. 82, Tafel 5, Fig. 2 und Tafel 8, Fig. 3 u. 4); fast nur am Neere . . . Arencria interpres, Halsband-Steinwålzer. 


\section{Haematopus.}

(Naumann, Bd. VIII, S.91, Tafel 9, Fig. 1-3); am Mleere

Haematopus ostrilegus, Instern-Fischer.

\section{Cutsorius.}

(Naumand, Bd. VIII, S. 102, Tafel 10, Fig. 1 u. 2)

Cursorius gallicus, Rennvogel.

\section{Glareole.}

I. Unter den Flügeln befinden sich wenigstens einige, oft viele, schön rotbraune Federn; die kurzen Schwingen sind zum Teil rein weiß gerandet (Bd. VII, S. 109, Tafel 11, Fig. 1-3)

Glareola pratincola, Halsband-Giarol.

II. Unter den Flïgeln sind alle Federn, auch die größeren, schwarz; von den kleinen Schwingen ist keine rein weiß gerandet (Bd. VIII, S. 119, Tafel 11, Fig. 4) . Glarcola melanoptera, Schwarzfligeliger Giarol.

\section{Oedicnemus.}

(Naumanx, Bd. VIII, S. 124, Tafel 12, Fig. 1 u. 2)

Oedicnemus oedicnemus (crepitans), Europäischer Triel.

\section{Rerumirostur.}

(Naumaxi, Bd. VIII, S. 140, Tafel 13, Fig. 4 u. 5); am Meere

Recurvirostra avosetta (avocetta), Irosett-Sibler.

\section{Himcontopus.}

(NAundxi, Bd. VIII, S. 150, Tafel 13, Fig. 1-3); siidlicher Vogel

Himantopms himantopus (candidus), stelzenlainfere, strandreuter.

\section{Phraluropus.}

I. Der Schnabel ist im Enddrittel, von oben gesehen, nicht $2 \mathrm{~mm}$ breit; der anliegende Flügel ist $10^{1} / 2-11^{1} / 2 \mathrm{~cm}$ lang (Bd. VIII, S. 161, Tafel 14, Fig. 3, 4 u. 6 und Tafel 15, Fig. 2); am Meere, in Deutschland nur auf dem Zuge

Phalaropus lobatus, Schmalschnibeliger Wassertreter.

II. Der Schnabel ist im Enddrittel über $3 \mathrm{~mm}$ breit; der anliegende Hlügel ist $12 \frac{1}{2}-13 \mathrm{~cm}$ lang (Bd. VIII, S. 167, Tafel 14, Fig. 1, 2 u. 5 und 'Tafel 15, Fig. 1 - Phalaroms fulicarius, Plattschnäbeliger Wassertreter.

\section{Calidris.}

(Naumann, Bd. VIII, S. 174, Tafel 15, Fig. 3 und Tafel 16, Fig. 1 u. 2); auf

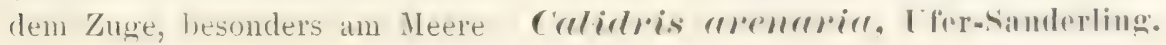




\section{Limicola.}

(NAumaxi, Bd. VIII, S. 182, 'Tafel 16, Fig. 3 u. 4); auf dem Zuge, nahe der'

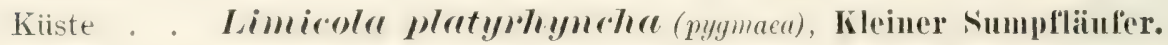

\section{Tringa und Tryngites.}

I. Der anliegende Fluigel ist $15-17 \frac{1}{2} \mathrm{~cm}$ lang; der Oberschnabel ist vor dem Ende. von oben gesehen, fast :3 mm breit; die beiden mittleren Schwanzfedern sind nicht merklich länger als die äußerste Schwanzfeder und vor dem hellen Rande nicht merklich dunkler als jene in der dunklen Partie vor ihrem hellen Rande (Bd. VII, S. 239, Tafel 20, Fig. 1 und Tafel 21, Fig. 1-3); auf dem Zuge an den Meereskïsten

\section{Tringa canuta, Isländischer Strandlïufer.}

II. Der anliegende Flügel ist sehr selten $14 \frac{1}{2} \mathrm{~cm}$ lang, meist kuirzer; der Oberschnabel ist im Enddrittel höchstens $2 \mathrm{~mm}$ breit; die beiden mittleren Schwanzfedern sind meist in großer Ausdehnung schwarz oder schwärzlich, während die äußeren Schwanzfedern immer grau oder weiß sind (nur bei $T$. subarcuuta sind auch die mittleren Schwanzfedern größtenteils grau).

A) Die änßerste Schwanzfeder und die erste Schwinge sind auf der Innenfahne scharf hell und dunkel marmoriert (Bd. IX, S. 25, Tafel 2, Fig. 4)

Tryngites rufescens, Rötlicher Uferläufer.

B) Die Innenfahne der äußersten Schwanzfeder und der ersten Schwinge ist nach dem Innenrande hin ganz allmählich etwas heller.

a) Die nackte Schnabelfirste ist höchstens '2 $\mathrm{cm}$ lang; der anliegende Fliigel höchstens $10 \mathrm{~cm}$ lang.

a) Die äußerste Schwanzfeder ist wenigstens auf der Außenfahne grau; der Lauf ist, von der Oberseite der Zehenwurzel bis zur Mitte des Fersengelenkes gemessen, über $18 \mathrm{~mm}$ lang (Bd. VIII, S. 197, Tafel 17, Fig. 3 und Tafel 19, Fig. 4-6); in Deutschland Durchzugsvogel

Tringre minuta, Kleiner Strandläufer.

ß) Die äußerste Schwanzfeder ist rein weiß; der Lauf ist nicht $18 \mathrm{~mm}$ lang (Bd. VIII, S. 191, Tafel 17, Fig. 4 und Tafel 18, Fig. 1, 2 u. 7); in Deutschland Durchzugsvogel

Tringa temminckii, Temminck's Strandlaiufer.

b) Die nackte Schnabelfirst ist stets über $21 \mathrm{~mm}$ lang; der anliegende Flügel ist stets über $10^{1} / 2 \mathrm{~cm}$ lang (bei Tringa schinzi etwa $11 \mathrm{~cm}$ lang, sonst noch länger).

a) Die Mittelzehe mit Kralle ist länger als der Lauf, von der Oberseite der Zehenwurzel bis zur Mitte des Fersengelenks gemessen; die Beine sind gelb (Bd. VIII, S. 230, Tafel 20, Fig. 3 und Tafel 21, Fig. 4 u. 5); am Meere auf dem Zuge . Tringa maritima, See-Strandliuler. 
ß) Die Mittelzehe mit Kralle ist kürzer als der Lauf.

aa) Die beiden mittleren Schwanzfedern zeigen fast auf der ganzen Fläche einen deutlichen grauen Schimmer, nur neben dem hellen Rande verläuft meist ein schwacher dunkler Schatten; die oberen Schwanzdeckfedern sind weiß, oft mit dunklen Querbändern oder Querflecken versehen; der Schnabel ist in der Endhälfte immer etwas abwärts gebogen, die nackte Firste desselben ist $31-42 \mathrm{~mm}$ lang (Bd. VIII, S. 223 , Tafel 18, Fig. 5 u. 6); in Deutschland Durchzugsvogel

Trumgre subarenerta (suburquata), Bogenschnäbliger Strandläufer.

bb) Die beiden etwas zugespitzten mittleren Schwanzfedern sind stets in größerer Ausdehnung schwarzbraun bis schwarz, ohne grauen Hauch; die mittleren oberen Schwanzdeckfedern sind meist dunkel (nur bei Tringa fuscicollis weiß); der Schnabel ist niemals abwärts gebogen, die nackte Firste selten bis $35 \mathrm{~mm}$ lang.

$u \kappa)$ Die Nittelzehe ist mit Kralle höchstens $22 \mathrm{~mm}$ lang; die Beine sind schwarz oder schwärzlich.

* Die mittleren oberen Schwanzdeckfedern sind weiß, so daß über dem Schwanz das Gefieder querüber weiß ist (Bd. VII, S. 237)

Tringa fuscicollis, Bonapartes Strandläufer.

** Die mittleren oberen Schwanzdeckfedern sind größtenteils dunkel.

$\doteqdot$ Die nackte Schnabelfirste ist beim ausgewachsenen Vogel über $30 \mathrm{~mm}$ lang; der anliegende Flügel ist mindestens $11^{1} / 2 \mathrm{~cm} \mathrm{lang}$ (Bd. VII, S. 205, Tafel 17, Fig. 1 und Tafel 18, Fig. 3 u. 4); vom Norden bis Norddeutschland Brutvogel, auch auf dem Zuge besonders am Meere . . Tringa alpina, Alpen-Strandläufer. $\$$ Die nackte Schnabelfirste ist höchstens $30 \mathrm{~mm}$ lang; der anliegende Flügel ist etwa $11 \mathrm{~cm}$ lang (Bd. VIII, S. 217, Tafel 17, Fig. 2 und Tafel 19, Fig. 1-3); an den südlicheren Teilen unserer Küsten Brutvogel

Tringa alpina schinsi, Schinz' Alpen-Strandlaiufer.

$\beta \beta)$ Die Mittelzehe ist mit Kralle mindestens $25 \mathrm{~mm}$ lang; die Beine sind mehr oder weniger rein gelb.

* Die äußersten Schwanzfedern sind auf der Innenfahne etwa von $1 \mathrm{~cm}$ vor dem Ende an abgeschrägt, fast zugespitzt; vor dem weißlichen Rande sind diese Federn sehr dunkel gefärbt; die nackite Schnabelfirste ist $22-27 \mathrm{~mm}$ lang (Bd. VIII, S. 238)

Tringa acuminata, Sibirischer Strandläufer.

** Die äußersten Schwanzfedern sind weit kürzer abgeschrigt und deshalb am Ende gerundet; vor dem hellen verwaschenen Rande sind sie grau; die nackte Schnabelfirste ist 27 - 31 mm lang (Bd. VIII, S. 237)

Tringa maculata, Gefleckter Strandliufer. 


\section{Phitomachus [Machetes] und Bartramia.}

I. Die äußerste Schwanzfeder und die erste Schwinge sind auf der Innenfahne scharf hell und dunkel gefleckt oder gebändert (Bd. IX, S. 19, Tafel 2, Fig. 1 u. 2 und Tafel 3, Fig. 1)

Bartramia longicauda, Bartrams Uferläufer.

II. Die Innenfahne der äußersten Schwanzfeder und der ersten Schwinge sind nicht gefleckt (Bd. VIII, S. 250, Tafel 22, 23 und 24)

Philomrehus purgmax, Vielfarbiger Kampflïufer, Kampflıahn.

\section{Tringoides [Actitis].}

I. Der Schnabel ist von der Nitte an deutlich aufwärts gebogen; die nackte Schnabelfirste ist über $35 \mathrm{~mm}$ lang (Bd. IX, S. 105, Tafel 9, Fig. 1 u. 2)

vergl. unten Terekia cinerea, Graue Uferschnepfe.

II. Der Schnabel ist nicht aufwärts gebogen; seine nackte Firste ist nicht $30 \mathrm{~mm}$ lang.

A) Die Innenfahme einiger der kurzen Schwingen ist größtenteils weiß, vor dem Ende mit dunklen Flecken oder Zeichnungen versehen; die Unterseite des Körpers zeigt niemals scharf begrenzte dunkle Flecke (Bd. IX, S. 3, Tafel 1, Fig. 5 u. 6 und Tafel 4, Fig. 3)

\section{Tringoides hypoleucus, Fluß-U terliuter.}

B) Die Innenfahne aller kurzen Schwingen ist nur am Ende schmal und an der Wurzel breiter weiß gefärbt; die Unterseite des Körpers zeigt oft, aber nicht immer, runde schwarze Flecke (Bd. IX, S. 13, Tafel 2, Fig. 3 und Tafel 3, Fig. 2) . . Tringoides macularius, Drossel-Uferläufer.

\section{Totell11.s.}

I. Der Lauf, von der Oberseite der Zehenwurzel bis zur Mitte des Fersengelenkes gemessen, ist nicht $4 \mathrm{~cm}$ lang und höchstens um ${ }^{1} / 3$ länger als die Mittelzehe mit Kralle; die Farbe der Füße ist grüngelb bis blaugrün.

A) Der Schaft der ersten Schwinge ist wenigstens zum Teil weiß; die mittleren Schwanzfedern sind bis zur Wurzel hell und dunkel quer gebändert; der anliegende Flügel ist $11^{1} / 2-13^{1} / 4 \mathrm{~cm}$ lang $(\mathrm{Bd}$. IX, S. 32, Tafel 1, Fig. 3 und 4 und Tafel 4, Fig. 2); Brutvogel besonders in Norddeutschland . . . . Totanus glareola, Bruch-Wasserläufer.

B) Der Schaft der ersten Schwinge ist der Länge nach braun: die Wurzelhïlfte der Schwanzfedern ist fast ganz weiß; der anliegende Flügel ist ist $13^{1} / 2-16 \mathrm{~cm}$ lang (Bd, IX, S. 43, Tafel 1, Fig. 1 u. 2 und Tafel 4, Fig. 1)

Totanus ochropus, Punktierter Wasserliufer.

II. Der Lauf ist über $4,5 \mathrm{~cm}$ lang und etwa um die Hülfte länger als die Nittelzehe mit Kralle. 
A) Die Innenfahne der ersten Schwinge ist bis zum Schaft schwarz und weiß quer gebändert; die hellen Teile der äußeren Schwanzfedem sind z. T. braungelblich (Bd. IX, S. 19, Tafel 2, Fig. 1 u. 2 und Tafel 3, Fig. 1) vergl. oben Bartramia longicauda, Bartrams Uferläufer.

B) Die Innenfalne der ersten Schwinge ist neben dem Schaft einfarbig dunkel; die hellen Teile der åußeren Schwanzfedern sind alle rein weiß.

a) Die Farbe der Beine ist blaugrünlich; die Federn, welche den Schwanzfedern von unten anliegen, sind weiß, selten mit einzelnen dunklen Fleckchen versehen.

a) Die nackte Schnabelfirste ist über $4,5 \mathrm{~cm}$ lang; der anliegende Flügel ist $17 \frac{1}{2}-19 \mathrm{~cm}$ lang (Bd. IX, S. 81, Tafel 7, Fig. 3 u. 4 und Tafel 8 , Fig. 2); in Deutschland nur auf dem Zuge

Totanus Tittorens (glottis), Hellfarbiger Wasserlïufer.

B) Die nackte Schnabelfirste ist nicht 4,5 cm lang; der anliegende Flügel ist 13-14 cm lang (Bd. IX, S. 96, Tafel 5, Fig. 3 u. 4 und Tafel 6, Fig. 2)

Totanus stagnatilis, Teich-Wasserläufer.

b) Die Farbe der Beine ist rot, in der Jugend heller oder dunkler gelblich; die unteren Schwanzdeckfedern sind stets z. T. am Ende quer gebändert.

i) Die nackte Schnabelfirste ist $5^{1 / 2}-6 \mathrm{~cm}$ lang, der anliegende Flïgel $16^{1 / 2}-20 \mathrm{~cm}$ lang; alle Schwingen sind dunkel, höchstens z. T. weiß gefleckt oder gebändert; der Oberschnabel ist an der Rückenseite bis zur Wurzel dunkel (Bd. IX, S. 70, Tafel 7, Fig. 1 u. 2 und 'Tafel 8, Fig. 1); nordöstliche Art, in Deutschland nur auf dem Zuge

Totumus fuscus, Dunkelfarbiger Wasserlïuler.

ק) Die nackte Schnabelfirste ist $3^{1 / 2}-4^{1} / 2 \mathrm{~cm}$ lang; der anliegende Fliigel mißt $15-16^{1} / 3 \mathrm{~cm}$; die mittleren Schwingen sind vorherrschend, oft ganz weiß; der Oberschnabel ist an der Wurzel, ebenso wie der Unterschnabel, rot gefärbt (Bd. IX, S. 55, Tafel 5, Fig. 1 u. 2 und Tafel 6, Fig. 1)

Totamus totanus (gambetta, culidris) Cambett-Wasserlïuler.

\section{Terelsir, Limosa und Macromhamphus.}

I. Der anliegende Fliigel ist $12-1: 3 \mathrm{~cm}$ lang, die nackte Schnabelfirste $36-52 \mathrm{~mm}$ lang, die Mittelzehe mit Kralle $22-25 \mathrm{~mm}$ lang; die Schwanzfedern sind grau, am Rande etwas dunkel gefleckt (Bd. IX, S. 105, Tafel 9, Fig. 1 u. 2) . . . . . Terelia cinerea, Grane Uferschnepfe.

II. Der anliegende Fliigel ist mindestens $14 \mathrm{~cm}$ lang, die nackte Schnabelfirste mindestens $55 \mathrm{~mm}$ lang, die Mittelzehe mit Kralle 28-48 mm lang: die Schwanzfedern sind entweder hell und dunkel gebaindert oder in der Endhälfte schwar\%. 
A) Die mittleren Schwanzfedern sind dicht hell und dunkel quer gebändert; die Mittelzehe mit Kralle ist 28-37 mm lang.

a) Der anliegende Flügel ist $14-16 \mathrm{~cm}$ lang, die Mittelzehe mit Kralle 28-32 mm lang (Bd. IX, S. 135)

Macrorhamphus griseus, Strandläufer-Schnepfe.

b) Der anliegende Flügel ist mindestens $20 \mathrm{~cm}$ lang, die Nittelzehe mit Kralle 31-37 mm lang (Bd. IX, S. 120, Tafel 10, Fig. 3 u. 4 und Tafel 11, Fig. 2); in Deutschland Durchzugsvogel, besonders an den Küsten

Limosa lapponica (rufa), Rostrote Uferschnepfe.

B) Die mittleren Schwanzfedern sind wenigstens in der Endhälfte schwarz: die Mittelzehe mit Kralle ist 37-48 mm lang (Bd. IX, S. 111, Tafel 10, Fig. 1 u. 2 und Tafel 11, Fig. 1); in Norddeutschland Brutvogel

Limosa limosa (aegocephala, melanura), Schwarzschwainzige Uferschnepfe, Pfuhlschnepfe.

\section{Numenius.}

I. Die nackte Schnabelfirste ist $12-16 \mathrm{~cm}$ lang, der anliegende Flügel 28-31 cm lang (Bd. IX, S. 140, Tafel. 12, Fig. 1 und 2)

Numenius arcuatus (arquatus), Grober Brachvogel.

II. Die nackte Schnabelfirste ist $6 \frac{1}{2}-91 / 2 \mathrm{~cm}$ lang, der anliegende Fligel $23-27 \mathrm{~cm}$ lang.

A) Der Oberkopf ist, wie bei der vorhergehenden Art ïberall grau, dunkel gefleckt, indem alle Federn in der Mitte dunkel, am Rande hell sind (Bd. IX, S. 159, Tafel 13, Fig. 2)

Numenius tenuirostris, Dünnschnäbliger Brachvogel.

B) Der Kopf ist oben dunkelbraun, in der Mitte mit einem hellen Längsstreif versehen (Bd, IX, S. 151, Tafel 13, Fig. 1 und 3); vom Norden bis Norddeutschland Brutvogel

Numenius phreopus, Regen-Brachyogel.

\section{Gallinago.}

T. Der Kopf zeigt oben einen dunklen Mittelstreif: die nackte Schmabelfirste ist höchstens $45 \mathrm{~mm}$ lang; der Schwanz besteht aus 12 Federn (Bd. IX, S. 194, Tafel 16, Fig. 1 und 2); vom Norden bis Norddeutschland Brutvogel

Gallina!go grallinula Kleine Sumpf-Sohnepfe oder Bekassine.

II. Am Kopfe ist oben der Mittelstreif hell, jederseits schwarz eingefaßt; die nackte Schnabelfirste ist iber $5 \mathrm{~cm}$ lang; der Schwanz besteht aus 14 oder 16 Federn.

A) Die oberen Flügeldeckfedern zeigen einen weißen, am Schaft nicht unterbrochenen Rand; die erste Schwinge zeigt einen sehr schmalen hellen Aufiemrand; die äufieren Schwanzfedern sind in der Endhïlfte weiß; der 
Schwanz besteht aus 16 Federn (Bd. IX, S. 167, Tafel 14, Fig. 1 und 3); vom Nordosten bis Norddeutschland Brutvogel

Gallinayo mor,jos. Große Sumpt-schnepfe, Doppelbekassine.

B) Die oberen Fliigeldeckfedern zeigen einen gelblichen, am schafte unterbrochenen Rand; die Außenfahne der ersten Schwinge ist bis über die Mitte hinaus ganz weiß; an den äußersten Schwanzfedern ist nur der Rand weiß; der Schwanz besteht aus 14 Federn (Bd. IX, S. 177, Tafel 15, Fig. 1 und 2)

Grullinr!go yollinr,go, Gemeine Sumpt-Schneple oder Bekassine.

Scolopax.

(Naumann, Bd. IX, S. 201 Tafel 17, Fig. 1-3)

Sroloprax rusticula, Gemeine Wald-Schmepfe.

\section{Art der Flamingos.}

\section{Phoenicopterus.}

(Naumann, Bd. VI, S. 284, Tafel 29, Fig. 1-3)

Phoenicopterus roseus, Rosenfarbiger Flamingo.

\section{Arten der Schwimmvögel.}

\section{Cygnus.}

I. Die Haut vor dem Auge ist schwarz; bei alten Vögeln befindet sich auf der Wurzel des Schnabels ein Höcker (Bd. IX, S. 230, Tafel 18, Fig. 1-3); in Norddeutschland Brutvogel . . C Cygmus olor, Höcker-Schwan. II. Die Haut vor dem Auge ist fleischfarbig oder gelb; auf der Wurzel des Schnabels befindet sich nie ein Höcker.

A) Die Mittelzehe ist mit Kralle mindestens $15 \mathrm{~cm}$ lang: beim alten Togel ist der Schnabel vom Ende bis an die Nasenlöcher schwarz (Bd. TX, S. 251, Tafel 19, Fig. 1 und 2); in Deutschland nur auf dem Zuge

Cy!nuts cygmus (musicus), Sing-Schwan.

B) Die Mittelzehe ist mit Kralle $12-14 \mathrm{~cm}$ lang; beim alten Vogel ist der Schnabel vom Ende bis über die Nasenlöcher hinweg schwarz (Bd. IX, S. 260, Tafel 20, Fig. 1-4); nordöstliche, auf dem Zuge an unsere Küsten kommende Art . . Cygmus bewickii, Schwarznasiger Schwan.

\section{Chen, Anser, Branta und Chencilopex.}

I. Der Schaft der ersten Schwinge ist last bis zum Ende weifj oder grelblichweiß; die Füße sind gelb oder rötlich.

Dahl, Buch zum Bestimmen der Vögel 
A) Das Gefieder ist ganz weiß, nur die Schwingen sind am Ende schwarz (Bd. IX, S. 270, Tafel 21, Fig. 1-3) Chen hyperboreus, Schnee-Gans.

B) Das Gefieder ist namentlich an der Rückenseite des Körpers größtenteils grau.

a) Der Nagel des Schnabels ist entweder schwarz oder dunkelbraun.

18) Der Oberschnabel ist an der Wurzel mehr oder weniger schwarz gefärbt; die Ränder desselben sind deutlich gezähnt; der Kopf ist stets grau gefärbt.

Die nackte Schnabelfirste ist, in gerader Linie gemessen, uiber $5 \mathrm{~cm}$ lang, nur bei ganz jungen Tieren etwas darunter (Bd. IX, S. 322, Tafel 25, Fig. 1); in Deutschland Wintervogel

Anser fobalis (segetum), Saat-Gans.

** Die nackte Schnabelfirste ist, in gerader Linie gemessen, $4-5 \mathrm{~cm}$ lang (Bd. IX, S. 354, Tafel 25, Fig. 2)

Anser brachyrhynchus, Rotfuß-Gans.

ß) Der Oberschnabel ist, mit Ausnahme des Nagels, ganz gelblich; die Ränder sind nicht gezähnelt; der Kopf des alten Vogels ist weiß, oben mit schwarzen Zeichnungen versehen (Bd. IX, S. 282)

Anser indicus, Indische Gans.

b) Der Nagel des Schnabels ist weiß oder gelblich gefärbt.

(九) Die Mittelzehe mit Kralle ist $8-10 \mathrm{~cm}$ lang; die nackte Schnabelfirste ist in gerader Linie gemessen, $5^{1} / 2-7^{1} / 2 \mathrm{~cm}$ lang; (ler anliegende Flügel ist 42,5-52 cm lang; das Gefieder der Stirn ist stets grau (Bd. IX, S. 284, Tafel 22, Fig. 1 und 2)

Anser anser (cinereus, ferus), (xrau-(Yans.

ß) Die Nittelzehe mit Kralle ist höchstens $71 / 2 \mathrm{~cm}$ lang; die nackte Schnabelfirste ist $4-5 \mathrm{~cm}$, der anliegende Flügel $36-42,5 \mathrm{~cm}$ lang; bei alten Vögeln ist das Gefieder der Stirn immer mehr oder weniger weiß. * Der anliegende Flïgel wird beim alten Vogel bis $40 \mathrm{~cm}$ lang; die weiße Stirnbefiederung erstreckt sich dann bis zwischen die Augen (Bd. IX, S. 300, Tafel 23, Fig. 1-3) Anser erythropus, Zwerg-Gans.

**: Der anliegende Flïgel ist $39-42,5 \mathrm{~cm}$ lang; die weiße Stimbefiederung ist von der Schnabelwurzel nach oben gemessen nur $22 \mathrm{~cm}$ breit (Bd. IX, S. 309, Tafel 24, Fig. 1-3); erscheint bei uns als Zugvogel, besonders an den Küsten Anser albifrons, Bläissen-(Kans.

II. Der Schaft der ersten Schwinge ist fast bis zur Wurzel, wenigstens in der Endhälfte braun oder schwarz gefärbt.

A) Die Füße sind rot; die Farbe des Flügel ist teilweise rotbraun (Bd. IX. S. 376, Tafel 28 Fig. 1 und 2)

Chenalopex aegyptiacus, Ägyptische Enten-Gans. 
B) Die Füße sind schwarz; die Flügel zeigen keine rotbraunen Farbentöne. a) Der Vorderhals ist his zur Kropfgegend rotbraun gefärbt (Bd. IX. S. 373, Tafel 27, Fig. 3) . . . . . Branta ruficollis, Rothals-Gans.

b) Der Vorderhals ist braunschwarz bis schwarz gefärbt.

a) Der Kopf ist ganz schwarz; die Halsseiten zeigen bei alten Tieren einen weißen Fleck; der anliegende Flügel ist $32-36 \mathrm{~cm}$ lang (Bd. IX, S. 360, Tafel 26, Fig. 1-3); an den deutschen Küsten Wintervogel . . . . . . Branta bernicla (brenta), Ringel-Gans.

ß) Die Stirn und die Wangen sind weiß oder weiß gefleckt; der anliegende Flügel ist 40-43 cm lang (Bd. IX, S. 367, Tafel 27, Fig. 1 u. 2); an den deutschen Küsten auf dem Zuge

Branta leucopsis, Weißwangen-Gaus.

\section{Aix.}

I. Die kleineren Federn an der in der Ruhelage dem Körper anliegenden Unterseite der Fluigel sind größtenteils weiß, mit scharf abgegrenzten dunklen Flecken und Binden versehen: beim Prachtkleide des Mïnnchens sind die Teile des Gefieders unter den Augen schwarz, metallisch glänzend und von den längeren Flügeldeckfedern ist keine in größerer Ausdehnung rotbraun (Bd. X, S. 11, Tafel 1, Fig. 5) . . Aix sponsa, Braut-Ente.

II. Die unteren Flügeldeckfedern sind fast ganz dunkel graubraun, nur der Rand ist verwaschen heller; am Prachtkleide des Männchens sind die Wangen gröbtenteils rotbraun und ebenso sind einige der gröłeren den Flïgeln aufliegenden Federn rotbraun (Bd. X S. 13, Tafel 1, Fig. 4)

Aix galericulata, Mandarinen-Ente.

\section{Tadorna [Vulpanser], Anas und Dafila.}

I. Der anliegende Flügel ist über $22,5 \mathrm{~cm}$ lang.

A) Von einigen der dem anliegenden Flïgel aufliegenden lïngeren Federn ist die Außenfahne fast ganz rotbraun; der anliegende Flügel ist $30^{1} / 2$ bis $38 \mathrm{~cm}$ lang.

a) Die Unterseite des Körpers ist fast ganz rotbraun; die seitlichen Schwanzfedern siod entweder ganz schwarz oder doch nur am Endrande etwas hell; dasselbe gilt von den oberen Schwanzdeckfedern (Bd. IX, S. 394, Tafel 30, Fig. 1-3) . . Tudorna casarca (rutila), Rost-Ente.

b) Die Unterseite des Körpers ist ganz oder in ausgedehntem Maße weiß oder schwarzbraun gefärbt; die seitlichen Schwanzfedern sind entweder ganz weiß oder nur am Endrande dunkel gefärbt und ebenso die oberen Schwanzdeckfedern (Bd. IX, S. 382, Tafel 29, Fig. 1-4); in der Nihhe der Meereskuisten

'Tadorna tadorna (vulpanser, comuta), Brand-Gans, Fuchsente. 
B) Keine der dem Flügel aufliegenden gröberen Federn ist auf der Außenfahne gro̊ßtenteils rotbraun; der anliegende Flügel ist $17-30 \mathrm{~cm}$ lang.

a) Der Schnabel ist im Enddrittel mindestens $19 \mathrm{~mm}$ breit; der stets grołe blau oder blauviolett schillernde Spiegel auf den Flügeln ist nach der Flügelwurzel hin (vorn) zunächst schwarz begrenzt; an den genannten schwarzen Querstreifen der Fliigel legt sich wurzelwärts ein weißes oder bräunlichweißes Querband an; die Füße sind rot; beim Prachtkleide des Männchens ist der Köpf ganz grünschillernd schwarz und einige der oberen Schwanzdeckfedern sind nach oben gebogen (Bd. X, S. 16 Tafel 1, Fig. 1, Tafel 2, Fig. 1 u. 2 und Tafel 3, Fig. 1)

Anas boschas (boscas), Mårz-Ente, Stockente.

b) Der Schnabel ist im Enddrittel höchstens $18 \mathrm{~mm}$ breit; der Spiegel auf den Flügeln, wenn er überhaupt vorhanden ist, schillert stets grün und ist vorn braun oder weißlich begrenzt.

a) Die nackte Schnabelfirste ist, in gerader Linie von der Federgrenze mitten auf dem Schnabel bis zum Ende gemessen, 2,9-3;5 cm lang, der Nagel ist 5-6 mm breit; die Farbe des Schnabels ist, mit Aus nahme des schwarzen Endteils, grau; der Schwanz besteht aus 14 Federn beim Prachtkleide des Männchens ist der Hals größtenteils rotbraun (Bd. X, S. 55, Tafel 1, Fig. 2 u. Tafel 3, Fig. 2 u. 3); in Norddeutschland Brutvogel (Subg. Mareca) . . . . Anas penelope, Pfeif-Ente.

$\beta)$ Die nackte Schnabelfirste ist stets mindestens $3,6 \mathrm{~cm}$ lang, der Nagel immer schmäler: der Schwanz besteht oft aus 16 Federn: der Hals ist beim Prachtkleide des Männchens nie rotbraun.

aa) An den Federn, welche auf den anliegenden Flügeln einen weißen Streifen erzeugen, ist der weiße Randteil immer scharf gegen den angrenzenden schwarzen Teil abgegrenzt; beim Prachtkleide des Männchens ragen die beiden mittleren Schwanzfedern $5-7 \mathrm{~cm}$ ïber die benachbarten vor und die Unterseite des Körpers ist vom Vorderhalse an weiß oder rötlich $(\mathrm{Bd}$. $\mathrm{X}$, S. 109, Tafel 6, Fig. 1, Tafel 7, Fig. 1 und Tafel 8, Fig. 2 u. 3); als Brutvogel mehr in Norddeutschland

Dafila acuta, Spitz-Ente, Spieß-Ente.

bb) An den Federn, welche das weiße Feld auf den anliegenden Flügeln bilden, wird der helle Randteil nach dem Schafte hin allmählich dunkler oder die ganze Außenfahne ist weiß bezw. weißgrau.

$u(x)$ Die Fußße sind rot, in der Jugend gelblich. Die Federn, welche auf dem anliegenden Flügel ein weißliches Feld hervorbringen, sind fast bis zum Schaft weißlich: beim Prachtkleide des Männchens sind der Kopf und der Hals fein hell und dunkel gewellt (Bd. X, S. 69, Tafel 1, Fig. 3 und Tafel 2, Fig. 4 und 5); in Norddeutschland einzeln brititend (Subg. Chaulelasmus)

Anrs strepera, Mittel-Ente, Schmatter-Ente. 
$\beta \beta)$ Die Füße sind schwarz, in der Jugend heller; die Federn, welche auf dem anliegenden Flügel eine helle Zeichnung erzeugen, sind nur am Rande weiß; beim Prachtkleide des Männchens ist der Kopf oben schwarz metallisch schillernd, das Kinn und die Kehle sind weiß (Bd. X, S. 78, Tafel 4, Fig. 3) Anas falcata, Sichelflügelige Ente.

II. Der anliegende Flügel ist nicht $22,5 \mathrm{~cm}$ lang.

A) Der anliegende Flügel zeigt auf der Fläche weder metallisch glänzende noch schwarze Federn (Bd. X, S. 66, Tafel 6, Fig. 5)

Anas angustirostris, Marmel-Ente.

B) Auf dem anliegenden Flügel zeigen sich stets ausgedehnte schwarze, meist metallisch glänzende Federteile.

a) Die hellen Federränder, welche den metallisch glänzenden Spieguel atuf dem anliegenden Flügel vorn begrenzen, sind bis unten hin rotbraun; beim Prachtkleide des Männchens werden die hellgelblichen Kopfseiten durch eine vom Auge abwärts ziehende schwarze Bogenbinde geteilt (Bd. X, S. 80, Tafel 6, Fig. 3) . . . Anas formosa, Pracht-Ente.

b) Die hellen Federränder, welche die metallischen oder schwarzen Teile auf dem anliegenden Flügel vorn begrenzen, sind wenigstens neben dem (stets schwarzen) unteren Teil weißlich; die besser sichtbaren oberen Federränder ziehen oft sehr stark ins Rotbraune (Subg. Querquedula).

a) Die Federn, welche den stets schöngrünen Metallspiegel auf dem anliegenden Flügel bilden, besitzen meist bis fast zum Rande hin die metallischgrüe Farbe; ist an ihrem Ende ein 1-2 mm breiter weiber Rand vorhanden, so ist die weiße Farbe von der metallgrimen F'arbe stets durch schwarze oder graue Teile getrennt.

aa) Der Grundteil des Flügels ist schön himmelblau; die Füße sind gelbbräunlich; beim Prachtkleide des Männchens verläuft vorn um das Auge ein weißer Mondfleck (Bd. X, S. 92, Tafel 6, Fig. 4)

Anas discors, Blauflügel-Ente.

bb) Der Grundteil des Flügels ist grau; die Füße sind grau bis schwärzlich; beim Prachtkleide des Männchens befindet sich an den rotbraunen Koptseiten hinter dem Auge ein metallisch glänzendes dunkles feld, diti als Binde am Halse herabläuft (Bd. X, S.96, Tafel 4, Fig. 2 und Tafel 5, Fig. 3 u. 4) . . . . . . . Anas recece, Krick-Ente.

в) Auf den Flügeln fehlt oft der Metallglanz gänzlich; sind metallglänzende Federn vorhanden, so stoßen die metallglänzenden 'Teile einzelner Federn unmittelbar an einen $2-3 \mathrm{~mm}$ breiten rein weißen Randteil derselben; beim Prachtkleide des Münnchens verlüuft oberhalb der Augen eine weiße Bogenbinde (Bd. X, S. 83, Tafel 4, Fig 1 und 'Tafel 5, Fig. 1 u. 2) . . . . Anas querguedula (ciria), Knäk-Ente. 


\section{Spatula.}

(Naumani, Bd. X, S. 122, Tafel 6, Fig. 2, Tafel 7, Fig. 2 und Tafel 8, Fig. 1)

Spatula clypeata, Lölfel-Ente.

\section{Fuligula.}

I. Der Schwanz besteht aus 16 Federn; die Zehen und der Lauf sind immer gelb bis rot gefärbt; der anliegende Flügel ist nicht über $25 \mathrm{~cm}$ lang (Subg. Clangula).

A) Der anliegende Fligel ist 15-181/2 $\mathrm{cm}$ lang; unter und hinter dem Auge ist die Befiederung des Kopfes mehr oder weniger weiß; die weiße Farbe kann sich nach hinten soweit ausdehnen, daß sie von beiden Seiten des Kopfes hinten zusammenschließt (Bd. X, S. 172, Tafel 13, Fig. 3)

Fuligula albeola, Büffel-Ente.

B) Der anliegende Fliigel ist 20-25 $\mathrm{cm}$ lang; ein weißer Fleck fehlt am Kopfe entweder gänzlich $(q)$ oder er befindet sich zwischen dem Auge und der Schnabelwurzel (ठ).

a) Der weiße Fleck an der Schnabelwurzel des Männchens ist hinten gerundet, nicht gestutzt oder ausgerandet; die dunklen Teile des Kopfes schillern beim Prachtkleide des Männchens nur gegen das Licht gesehen violett, sonst grün (Bd. X, S. 156, Tafel 12, Fig. 1 u. 2 und Tafel 16, Fig. 1); vom Norden bis Norddeutschland Brutvogel

Fuligula clangula (glaucion), Schell-Ente.

b) Der weiße Fleck an der Schnabelwurzel des Männchens ist hinten breit gestutzt oder etwas ausgerandet; die dunklen Teile des Kopfes besitzen einen violetten oder blauen Glanz; das Weibchen ist durchschnittlich etwas größer als das der bei uns häufigen vornergehenden Art; eine scharfe Unterscheidung aber diirfte kaum möglich sein (Bd. X, S. 168, Tafel 13, Fig. 1 und 2) . . . Fuligula islandica, Spatel-Ente.

II. Der Schwanz besteht aus 14, nur ausnahmsweise einmal aus 16 Federn; im letzteren Falle sind die Füße, namentlich der Lauf schwärzlich oder bleigrau; die Fïße sind überhaupt nur selten rot oder rötlich (nie gelblich) gefärbt, sind sie rot oder rötlich, so ist der anliegende Flügel über $25 \mathrm{~cm}$ lang.

A) Der Schnabel ist beim Männchen schön rot; nur beim Weibchen und namentlich beim Jugendkleide ist die Farbe mehr oder weniger verdunkelt; der anliegende Flügel ist $26-28 \mathrm{~cm}$ lang, beim Weibchen und beim Jugendkleide kaum kiirzer (Bd. X, S. 193, Tafel 10, Fig. 5 und Tafel 15, Fig. 1): suidlichere Art (Subg. Nctta) . . Fuligula Mufina, Kolben-Ente.

B) Der Schnabel ist wie die Füije blaugrau bis schwarz gefärbt, auch beim Jugendkleide niemals rötlich; der anliegende Flügel ist $17-23 \mathrm{~cm}$ lang, die höheren Maße kommen aber nur beim ausgefärbten Männchen vor. 
a) Auf den Flügeln sind allenfalls einzelne Federränder von $3 \mathrm{~mm}$ Breite weißlich; der anliegende Flügel ist 20-22 cm lang; beim Prachtkleide des Männchens ist der Kopf schön rotbraun und der Rücken ist fein hell und dunkel quergewellt (Bd. X, S. 174, Tafel 10, Fig. 3 und Tafel 14, Fig. 2 und 3) (Subg. Nyroca) .

Fuligula ferina, 'Tafel-Ente.

b) Auf den Flügeln ist stets ein weißer Spiegel von größjerer Ausdehnung vorhanden, indem einige Federn ror dem dunklen Endrande queriber weits sind.

a) Der Schaft der vierten Schwinge ist vor dem Ende immer in größerer Ausdehnung sehr hell, heller als der Außenteil der schmalen Außenfahne auf gleicher Höhe; der Kopf ist nie metallisch schwarz, beim Männchen im Hochzeitskleide rotbraun; der anliegende Flügel ist $17-19^{1} / 2 \mathrm{~cm}$ lang (Bd. X, S. 182, Tafel 10, Fig. 4, Tafel 14, Fig. 1 und Tafel 15, Fig 2 u. 3) (Subg. Nyroca).

Fuligula myroca, Moor Ente.

B) Der Schaft der vierten Schwinge ist immer der Länge nach dunkelbraun bis schwarz, niemals vor dem Ende heller als der Außenteil der Außenfahne in gleicher Höhe; beim Hochzeitskleide des Männchens ist der Kopf metallisch glänzend schwarz; der anliegende Flügel ist 191/2 bis $23 \mathrm{~cm}$ lang.

Auf der Rüickenseite des Körpers, auch auf den anliegenden Flügeln, fehlen feine weiße Zeichnungen entweder gänzlich oder sie sind so fein, daß die einzelnen Strichelchen, aus denen sie bestehen, kaum 1/2 mm lang sind; auf dem Kopfe ragen einige Federn schopfartig vor, namentlich beim Prachtkleide des Männchens (Bd. X, S. 136, Tafel 10, Fig. 1 und Tafel 11, Fig. 1-4)

\section{Fuligula fuligula (cristata), Reiher-Ente.}

Auf der Rückenseite des Körpers, namentlich auf den anliegenden Flïgeln sind die weißen Zeichnungen immer deutlicher; die feinen weißen Strichelchen, aus denen sie bestehen, sind stellenweise immer etwa $1 \mathrm{~mm}$ lang oder länger; beim Prachtkleide des Männchens ist der ganze Rücken fein weiß und dunkel quergewellt; auf dem Kopfe stehen keine Federn schopfartig vor (Bd. X, S. 147, Tafel 10, Fig. 2 und Tafel 12, Fig. 3); besonders als Wintervogel an den norddeutschen Kiisten

Fuligula mavila, Berg-Ente.

\section{Hriveldre.}

(Naumann, Bd. X, S. 199, Tafel 16, Fig. 2 und Tafel 17, Fig. 1- t): an den norddeutschen Kiisten gemeiner Wintervogel

Hrovelda Hyemalis (glacialis), Eis-Ente.

\section{Histriomicus.}

(Naumans, Bd. X, S. 212, Tafel 18, Fig. 1 und 2)

Histrionicus histrionicus, Kragen-Ente. 


\section{Eniconetta.}

(Naumann, Bd. X, S. 218, Tafel 19, Fig. 1 und 2)

Eniconetta stclleri, Scheckente.

\section{Somatevia.}

I. Die Befiederung tritt an den Seiten des Oberschnabels bis unter den Hinterrand des Nasenlochs und damit mindestens $10 \mathrm{~mm}$ weiter vor als auf der Mitte des Oberschnabels; der Schnabel und die Fiuße sind olivengrünlich (Bd. X, S. 223, Tafel 20, Fig. 3 und Tafel 21, Fig. 2 und 3); an der Nordseekïste Brutvogel, im Winter auch auf der Ostsee

Somateria mollissima, Eider-Ente.

II. Die Befiederung tritt an den Seiten des Schnabels nicht bis unter das Nasenloch und deshalb weniger weit vor als auf der Mitte; der Schnabel und die Füße sind rotbraun bis rot gefärbt, nur in der ersten Jugend schwärzlich (Bd. X, S. 236, Tafel 20, Fig. 1 u. 2, Tafel 21, Fig. 1 und Tafel 22, Fig. 1-2) . . . . . . . Somateria spectabilis, Pracht-Ente.

\section{Oidemia [Oedemia].}

I. Die Befiederung tritt auf der Mitte des Oherschnabels mindestens $10 \mathrm{~mm}$ weit schmal vor; beim Prachtkleide des Männchen sind die Stirn und die hinteren Kopf- und Halsseiten mit einem weißen Fleck versehen (Bd. X, S. 258, Tafel 25, Fig. 1 u. 2) . . Oidemia perspicillata, Brillen-Ente.

II. Die Befiederung tritt auf der Nitte des Oberschnabels nicht schmal vor; auf der Stirn und am Hinterkopfe befinden sich niemals weißbefiederte Teile. A) Auf dem anliegenden Flügel ist ein großer weifier Spiegel vorhanden: beim Prachtkleide des Männchen befindet sich unter dem Auge ein weiber Fleck (Bd. X, S. 251, Tafel 23, Fig. 3 und Tafel 24, Fig. 1 u. 2); in Deutschland Wintervogel, besonders an den Kïsten

Oidemia fusca, Sammet-Ente.

B) Das Gefieder zeigt am Kopfe und auf den Fligeln niemals weiße Teile (Bd. X, S. 244, Tafel 23, Fig. 1 u. 2 und Tafel 24, Fig. 3); an den deutschen Küsten Wintervogel . . . . Oidemia nigra, Trauer-Ente.

\section{Erismatura.}

(Naumann, Bd. X, S. 263, Tafel 26, Fig. 1 und 3)

Erismatura leucocephala Ruder-Ente.

\section{Meryus.}

I. Die nackte Schnabelfirste ist 26-32 $\mathrm{mm}$ lang; der Schnabel und die Füße sind blaugrau (Bd. X, S. 273, Tafel. 27, Fig. 3, Tafel 28, Fig. 3 und Tafel 29, Fig. 3); in Deutschland Wintervogel, besonders im Osten

ITergus albellus Kleiner Såger. 
II. Die nackte Schnabelfirste ist selten unter . 0 , niemals unter $40 \mathrm{~mm}$ lang: der Schnabel und die Füße sind meist rot, selten schwarz.

A) Der anliegende Flügel ist $19.21 \mathrm{~cm}$ lang; die nackte Schmabelfirste ist 40-45 mm lang; der Schnabel ist schwarz; der Kopf ist, namentlich beim MÏ̈nnchen mit einer hohen, zusammengedrückten, halbkreisförmigen Haube versehen (Bd. X, S. 280) . . . . Mcrgus cucullatus, Hauben-Säger.

B) Der anliegende Flugel ist $22.20 \mathrm{~cm}$ lang, die nackite Schnabelfirste iiber $45 \mathrm{~mm}$ lang; der Schnabel und die Füße sind rot; der Kopf ist allenfalls mit haubenartig verlängerten schmalen Federn versehen.

a) Das weiße Feld auf den Flügeln ist entweder ununterbrochen oder nur mit schmalen, dunklen, aus dunklen Federrändern gebildeten Längsstreifen versehen; die Federn unter dem vorderen Teil des anliegenden Flügels sind entweder weiß oder rötlich bezw. gelblich $\left(\sigma^{\top}\right)$ oder endlich aschgrau: im lezteren Falle selten undeutlich quer gewellt: der anliegende Fliigel ist 24-30 cm lang (Bd. X, S. 290; Tafel 27, Fig. 1, Tafel 28, Fig. 1 und Tafel 29, Fig. 1); Brutvogel, besonders im Nordosten Deutschlands

Mergus merganser, Großer Säger.

b) Das weiße Feld auf den Flügeln ist, abgesehen von den durch dunkle Federränder gebildeten Längstreifen, stets auch von einem dunklen Querbande unterbrochen; die Federn unter dem vorderen Teil des anliegenden Flïgels sind beim Männchen scharf (aber fein) schwarz und hell quergewellt, beim Weibchen z. T. dunkelbraun gefärbt; der anliegende Flügel ist 22-25 cm lang (Bd. X, S. 281, Tafel 27, Fig. 2, Tafel 28, Fig. 2 und Tafel 29, Fig. 2); vom Norden bis Nordostdeutschland Brutvogel

Mergus serrator, Mittlerer Säger.

\section{Pelecunus.}

I. Der befiederte Teil vorn auf dem Schnabelrücken ist grestutzt, in der Mitte sogar etwas eingezogen: die Schäfte der großen Schwingen sind so dunkel wie die Fahnen (Bd. XI, S. 21, Tafel 2, Fig. 1)

Pelecanus crispus, Krausköpfiger Pelikan.

II. Die Befiederung ragt oben auf der Mitte des Oberschnabels im spitzen Winkel oder schmal gerundet vor; die Schäfte der grofen Schwingen sind weißlich, im Gegensatz zu den schwärzlichen Fahnen, nur gegen das Ende dunkler.

A) Die Schnabelfirste ist, von dem mittelsten Teil der vorderen Federgrenze über den vorderen Bogen bis zur Spitze gemessen, 31-34 cm lang (Bd. XI, S. 20) . . . . . Pelecanus roseus, Rosenfarbiger Pelikan.

B) Die nackte Schnabelfirste ist iiber den Bogen bis zur Spitze gemessen 38-42 cm lang (Bd. XI, S. 8, Tafel 1, Fig. 1)

Pelecanus onocrotalus, Gemeiner Pelikan. 
Fregatu [Tachypetes, Attagen].

(Naumaxi, Bd. XI, S. 27, Tafel 3, Fig. 2 u. 3)

Fregata aquila, Fregattvogel.

Sula [Dysporus].

(Naumaxx, Bd. XI, S. 35, Tafel 4, Fig. 1-3); nur an den Nordseeküsten Deutschlands öfter vorkommend . . . Sula bassana, Baß-Tölpel.

Phalaciocorax [Carbo].

I. Die nackte Schmahelfirste ist, über den gebogenen Endteil bis zur Spitze gemessen, $31-36 \mathrm{~mm}$ lang, der anliegende Flügel ist $20-21 \mathrm{~cm}$ lang (Bd. XI, S. 77, Tafel 5, Fig. 3, Tafel 6, Fig. 3 und Tafel 7, Fig. 3 u. 4)

Phalacrocorax pygmaeus, Zwerg-Scharbe.

II. Die nackte Schnabelfirste ist $50-80 \mathrm{~mm}$ lang, der anliegende Flügel $25-38 \mathrm{~cm}$ lang.

A) Die dunklen Federränder auf der Rückenseite des Vogels sind z. T. weit über $2 \mathrm{~mm}$ breit, die Federn sind am Ende gerundet, selten hier und da etwas winkelig zugespitzt; der anliegende Flügel ist $31-36 \mathrm{~cm} \mathrm{lang}$ (Bd. XI, S. 51, Tafel 5, Fig. 1, Tafel 6, Fig. 1 u. 4 und Tafel 7, Fig. 1); in Deutschland nur noch sehr zerstreut kolonieweise britend

Phalacrocorax carbo (cormoranus), Kormoran-Scharbe.

B) Die dunklen Federrånder auf der Rückenseite des Vogels sind niemals iiber $2 \mathrm{~mm}$ breit; der Endrand der Federn ist in der Mitte meist winklig gebrochen; der anliegende Flügel ist $25-29 \mathrm{~cm}$ lang (Bd. XI, S. 67, Tafel 5, Fig. 2, Tafel 6, Fig. 2 und Tafel 7, Fig. 2)

Phalacrocorax graculus, Krähen-Scharbe.

\section{Phaëton.}

(Naumaxs, Bd. XI, S. 88, Tafel 3, Fig. 1) Phaëton acthereus, Tropikvogel.

\section{Hydrochelidom.}

I. Der Kopf ist entweder oben bis zur Schnabelwurzel schwarz, unten weil3 (Sommerkleid) oder die Federn auf dem Kopfe sind mit dunklen Schaftflecken versehen, die vorn nicht über $^{1}{ }_{3}$ der Federbreite einnehmen (Winterkleid) oder die Federn des Rückens sind mit breiter, scharf abgegrenzter, heller Randbinde von mindestens 22 mm Breite versehen (.Jugendkleid); der anliegende Fliigel ist $21-25 \mathrm{~cm}$ lang, beim Jugendkleide bisweilen nur $20 \frac{1}{2} \mathrm{~cm}$ lang (Bd. XI, S. 97, Tafel 8, Fig. 2 und Tafel 10, Fig. 1 u. 2); nur im Südosten

Hydlochelidon hybridl, Weibbiirtige Seeschwalbe, Trauerseeschwalbe. 
II. Der Kopf ist entweder oben und unten bis zur Schnabelwurzel schwarz bezw. unten grau (Sommerkleid) oder die Federn sind auf dem Kopfe vorn weiß bis hellgrau, hinten dunkel mit lichterem Rande, der nicht $1 / 3$ der Federbreite einnimmt (Winterkleid); die Rückenfedern sind nie scharf abgesetzt, hell gerandet oder gebändert, höchstens mit verwaschenem hellen Rande versehen (.Jugendkleid): der anliegende Fliigel ist $20 \ldots 21 \frac{1}{2} \mathrm{~cm}$ lang.

A) Die Füße sind rot bis rotgelb; der Rücken ist beim Sommerkleide schwärzlich, viel dunkler als die Oberseite der Flügel; beim Winter- und Jugendkleide sind die Federn hinten auf dem Kopfe alle schmal weifilich gerandet (Bd. XI, S. 114, Tafel 8, Fig. 1, Tafel 9, Fig. 1 u. 3 und Tafel 10, Fig. 3); ebenfalls südöstliche Art

Hydrochetidon fissipes (leuroptera), Weißnigelige Seeschwalbe.

B) Die Fïße sind dunkelrotbram: der Rücken ist beim schwarzköpfigen Sommerkleide wie die Oberseite der Flïgel schiefergrau, beim hellstirnigen Winter- und Jugendkleide sind die Federn hinten auf dem Kopfe entweder einfarbig dunkel oder gelbgrau gerandet (Bd. XI, S. 105, Tafel 8, Fig. 3, Tafel 9, Fig. 4 und Tafel 10, Fig. 4)

\section{Hydrochelidon migra, Schwarze Seeschwalbe.}

\section{Sterna.}

1. Der Schaft der 2. Schwinge ist gröbtenteils hraunschwarz: der anliegrende Flügel ist $14-30 \mathrm{~cm}$ lang.

A) Der anliegende Flügel ist $14-18 \mathrm{~cm}$ lang; der Schnabel und die Füß̉e sind beim alten Vogel orangerot, heim jungen Vogel fleischfarbig, nur die Schnabelspitze ist dunkel; die Schwingen sind, von der 2. oder 3. an, mehr oder weniger grau und ebenso die Rückenfedern ganz oder teilweise grau oder weißlich gefärbt (Bd. XI, S. 119, Tafel 11, Fig. 4 u. 5, Tafel 12, Fig. 1 u. 2 und Tafel 13, Fig. 1) . . Sterna mimuta, Zwerg-Meerschwalbe.

B) Der anliegende Flìgel ist $26-30 \mathrm{~cm}$ lang; der Schnabel und die Füße sind schwärzlich; die Schwingen sind von der 2. an alle gleich dunkel und die Rückenfedern sind alle schwarz oder schwarzbraun, höchstens der Endrand der letzteren hell.

a) Die Schwanzfedern werden nach der Mitte des Schwanzes hin länger, nur die beiden mittelsten sind wieder etwas kiurzer; die Mittelzehe ist mit Kralle über $3 \mathrm{~cm}$ lang; die Befiederung ragt auf der Mitte des Schnabels am weitesten vor (Bd. XI, S. 180)

vergl. unten Anous stolidus, Gemeiner Noddi.

b) Die Schwanzfedern werden nach der Mitte des Schwanzes hin immer kürzer; die Mittelzehe ist mit Kralle nicht $3 \mathrm{~cm}$ lang; die Befiederung tritt mitten auf dem Oberschnabel etwas zuriick (Bd. XI, S. 178, Tafel 14, Fig. 3) . . . . Sterna fuliginosa, Nußbraune Seeschwalbe. 
II. Der Schaft der zweiten Schwinge ist weiß oder weißlich, höchstens gegen das Ende dunkler; der anliegende Flügel ist. $19^{1 / 2}-42 \mathrm{~cm}$ lang.

A) Der Oberschnabel ist vor dem Nasenloch, genau im Profil gemessen, $10-13 \mathrm{~mm}$ hoch, der anliegende Flügel mindestens $37 \mathrm{~cm}$ lang; die Innenfahne der Schwingen wird nach dem Innenrande hin nicht heller (Bd. XI, S. 170, Tafel 13, Fig. 2 u. 3, Tafel 16, Fig. 1 und Tafel 17, Fig. 2); bisher in Deutschland nur noch auf Sylt brütende Art

Sterna tschegrava (caspia), Raub-Seeschwalbe.

B) Der Oberschnabel ist am Vorderrande des Nasenloches nicht 9 $\mathrm{mm}$ hoch; der anliegende Flügel jst nicht $37 \mathrm{~cm}$ lang: die Innenfahne der Schwingen wird nach dem Innenrande hin heller.

a) Die Füße sind beim alten Vogel, der sich durch seinen grauen Rücken auszeichnet, schwarz, beim jungen Vogel, der sich durch gebänderte Rückenfedern auszeichnet, rötlichgrau; der Oberschnabel ist, am Vorderrande des Nasenloches, genau im Profil gemessen, $4^{1 / 2}-6 \frac{1}{2} \mathrm{~mm}$ hoch, der anliegende Flügel beim ausgefärbten Vogel über $28 \mathrm{~cm}$ lang.

a) Der Schnabel ist gelb oder gelblich, höchstens nach dem Ende hin dunkler.

Der anliegende Flügel ist $31-37 \mathrm{~cm}$ lang; der Oberschnabel ist, an Vorderrande des Nasenloches, genau im Profil gemessen, 7-81/2 $\mathrm{mm}$ hoch (Bd. XI, S. 169).

Sterna bergii, Eil-Seeschwalbe.

Der anliegende Flügel ist $27-30 \mathrm{~cm}$ lang; der Oberschnabel ist am Vorderrande des Nasenloches $5 \frac{1}{2}-6 \mathrm{~mm}$ hoch (Bd. XI, S. 169)

Sterna media, Rüppelsche Seeschwalbe.

B) Der Schnabel ist schwarz, höchstens am Ende gelblich.

Der Schnabel ist kürzer und dicker, ganz schwarz nur beim jungen Vogel (mit gebänderten Rückenfedern) am Ende etwas heller; der Oberschnabel ist am Vorderrande des Nasenloches, genau im Profil gemessen, $6 \mathrm{~mm}$ hoch; die nackte Schnabelfirste ist $3 \frac{1}{2}-4 \mathrm{~cm}$ lang (Bd. XI, S. 148; Tafel 14, Fig. 1, Tafel 16, Fig. 3 und Tafel 17, Fig. 1); südliche, in Deutschland nur noch sehr zerstreut vorkommende Art

Sterna nilotice (anglica), Lach-Seeschwalbe.

** Der Schnabel ist länger und dünner, das Ende stets über $1 \mathrm{~cm}$ weit heller; der Oberschnabel ist am Vorderrande des Nasenloches $4^{1 / 2}$ bis höchstens $51 \%, \mathrm{~mm}$ hoch; die nackte Schnabelfirste ist beim ausgefärbten Tier (mit grauem Rücken) 5-6 cm lang; beim jungen Vogel kürzer; dann ist aber der Oberschnabel an der genannten Stelle nur $4 \frac{1}{2} \mathrm{~mm}$ hoch (Bd.XI, S. 153, Tafel 14, Fig. 2, Tafel 16, Fig. 2 und Tafel 17, Fig. 3); bisher noch zerstreut an den Nordseekuisten brütende Art

Sterna cantiaca, Brand-Seescliwalbe. 
b) Die Füße sind beim alten Vogel (mit grauem Rücken) schön rot bis orange, beim jungen Vogel fleischfarbig: der anliegende Flügel ist (beim ausgefärbten Vogel) höchstens $28 \mathrm{~cm}$ lang; der Oberschnabel ist am Vorderrande des Nasenloches nicht $4 \frac{1}{2} \mathrm{~mm}$ hoch.

a) Der Schnabel ist ganz schwarz; die zweite Schwinge ist am Hinterrande bis zur Spitze weißlich gefärbt; der anliegende Flügel ist $19 \frac{1}{2}-24 \mathrm{~cm}$ lang (Bd. XI, S. 164, Tafel 11, Fig. 2); vielleicht noch einzeln an den Nordseeküsten brütend

Sterna dougalli (paradisea), Dougalls Seeschwalbe.

ß) Der Schnabel ist größtenteils rot, beim jungen Vogel (mit gebänderten Rückenfedern) fleischfarbig; die weißen Teile auf der breiten, hinteren Fahne der zweiten Schwinge sind gegen das Ende der Feder auch am Hinterrande dunkel begrenzt; der anliegende Flügel ist $21-28 \mathrm{~cm}$ lang. * Der dunkle Längsstreif auf der breiten Fahne der ersten Schwinge neben dem Schaft ist $8 \mathrm{~cm}$ vor dem Ende etwa doppelt so breit wie die dunkle, schmale Fahne an derselben Stelle; der Oberschnabel ist beim ausgefärbten Vogel am Ende 6-12 mm weit schwarz (Bd. XI, S. 128, Tafel 11, Fig. 1, Tafel 12, Fig. 4 und Tafel 13, Fig. 2 u. 3)

Stema himundo, Fluk-Seeschwalbe.

** Der dunkle Streif neben dem Schaft auf der breiten Fahne der ersten Schwinge ist $8 \mathrm{~cm}$ vor dem Ende nicht $11 / 2 \mathrm{mal}$ so breit wie die dunkle Außenfahne der Schwinge an derselben Stelle; der Oberschnabel ist beim ausgefärbten Vogel bis zur Spitze rot (Bd. XI, S. 137, Tafel 11. Fig. 2, Tafel 12, Fig. 3 und Tafel 13, Fig. 4); an den Meeresküsten

Stema macrura, Kiisten-Seeschwalbe.

(NAUMANN, Bd. XI, S. 180)

\section{Amous.}

Anous stolidus, Gemeiner Noddi, Tölpelseeschwalbe.

\section{Larms und Pagophila.}

I. Der anliegende Flügel ist $39-52 \mathrm{~cm}$ lang.

A) Die Schwingen sind entweder ganz weiß bezw. grauweib (ausgefärbter Vogel) oder sie sind grau marmoriert (Jugendkleid); die Schäfte derselben sind entweder weils oder gegen das Ende sehr hellgrau bezw. hellbriunlich.

a) Die nackte Schnabelfirste ist, uiber den Bogen gemessen, über $5 \frac{1}{2} \mathrm{~cm}$ lang, der Oberschnabel am Vorderrande des Nasenloches genau im Profil gemessen $10 \mathrm{~mm}$ und darüber hoch (Bd. XI, S. 267, Tafel 24, Fig. 33, Tafel 25, Fig. 3 und Tafel 26, Fig. 3); aus dem Norden im Winter öfter an unsere Nordseekiisten kommende Art

Lame glaucers, Eis-Möve. 
b) Die nackte Schnabelfirste ist nicht $5 \mathrm{~cm}$ lang, der Oberschnabel am Vorderrande des Nasenloches nur $9 \mathrm{~mm}$ hoch (Bd. XI, S. 275, Tafel 27, Fig. 4 u. 5 und Tafel 29, Fig. 4) . . Larus leucopterus, Polar-Möve.

B) Die Schwingen sind teilweise schwarz oder dunkelbraun; auch die Schäfte sind z. T. dunkelbraun.

a) Der geschlossene Schnabel ist, über der höckerartigen Erweiterung des Unterschnabels genau im Profil gemessen, über $2 \mathrm{~cm}$ hoch; der anliegende Flügel ist 47-52 cm lang (Bd. XI, S. 258, Tafel 24, Fig. 2, Tafel 25, Fig. 2 und Tafel 26, Fig. 2 u. 4); im Winter an unsern Küsten

\section{Larus marinus, Mantel-Möve.}

b) Der geschlossene Schnabel ist über der Erweiterumg des Unterschmabels nicht $2 \mathrm{~cm}$ hoch; der anliegende Flügel ist $39-47 \mathrm{~cm}$ lang.

a) Die breite Innenfahne der ersten Schwinge ist beim ausgefärbten (graurückigen) Vogel größtenteils weiß, nur vor dem Ende befindet sich eine schwarze Binde; beim gefleckten Jugendkleid befinden sich auf der Innenfahne meist weiße Teile; im Sommer ist der Kopf beim ausgefärbten Tier schwarz (Bd. XI, S. 204)

Larus ichthyaëtus, Fisch-Möve.

ß) Die Innenfahne der ersten Schwinge ist neben dem Schaft wenigstens bis zur Mitte dunkel gefärbt; beim gefleckten. Jugendkleid befinden sich auf der Innenfahne nie weiße Flecke; der Kopf ist nie schwarz.

Der Rücken ist zwischen den Flïgeln beim ausgefärbten Vogel dunkelschiefergrau, so dunkel wie die Innenfahne im dunklen Endteil der ersten Schwinge vor dem Innenrande, nur nicht bräunlich angeflogen wie diese; der anliegende Flügel ist 39-44 cm lang (Bd. XI, S. 232, Tafel 24, Fig. 1, Tafel 25, Fig. 1 und Tafel 26, Fig. 1); nicht selten an die deutschen Küsten kommend . La Ho fuscus, Herings-Möve.

** Der Rücken ist beim ausgefärbten Vogel heller oder dunkler blaugrau, viel heller als der dunkle Teil der Innenfahne der ersten Schwinge in der Endhälfte; der anliegende Flügel ist $42-46{ }^{1} / 2 \mathrm{~cm}$ lang, selten kürzer.

$\dagger$ Die Füße sind beim ausgefärbten Vogel fleischrot gefärbt, der Schnabel größtenteils gelb (Bd. XI, S. 240, Tafel 21, Fig. 2, Tafel 22, Fig. 1 u. 3 und Tafel 23, Fig. 2 u. 3); an den Küsten der Nordsee brütend . . . . . . . Larus argentatus, Silber-Möve.

$\dagger$ Die Füße sind beim ausgefärbten Vogel gelb gefärbt, wie die Wurzel des Schnabels; die beiden folgenden Arten sind schwer unterscheidbar.

$\bigcirc$ Der Rücken ist beim ausgefärbten Vogel dunkelaschgrau, dunkler als bei der Silbermöve (Bd. XI, S. 239)

Larus affinis, Sibirische Möve.

O Der Rücken ist hellaschgrau, noch etwas heller als bei der Silbermöve (Bd. XI, S. 255) . Larus cachinnans, Graumantel-Möve. 
II. Der anliegende Flügel ist $18-39 \mathrm{~cm}$ lang.

A) Der anliegende Fligel ist 18-24 cm lang; die ersten Schwingen sind beim (graurückigen) alten Vogel hellgrau mit weißer Spitze, beim (buntriickigen) jungen Vogel am Vorderrande braunschwarz, am Hinterrande weiß (Bd. XI, S. 186, Tafel 18, Fig. 1, Tafel 19, Fig. 1 und Tafel 20, Fig. 1); in Deutschland nur auf dem Zuge. Larms mimutus, Zwerg-Möve.

B) Der anliegende Flügel ist über $25 \mathrm{~cm}$ lang.

a) Der Schaft der zweiten Schwinge ist weiß, nur am Ende oft dunkel gefärbt.

«) Die Schwingen sind entweder einfarbig weiß, wie das ganze Gefieder (ausgefärbter Vogel) oder, wie auch andere Federn des Gefieders, am Ende mit einem kleinen Fleck versehen (Jugendkleid); der anliegende Flïgel ist $31-35 \mathrm{~cm}$ lang (Bd. XI, S. 280, Tafel 27, Fig. 1-3)

Pagophila eburnea, Elfenbein-Möve.

ß) Die erste Schwinge ist stets am Vorderrande teilweise schwarz gefärbt. « $\alpha)$ Die zweite Schwinge ist stets am Hinterrande 2-10 $\mathrm{mm}$ breit dunkel gerandet; der anliegende Flügel ist $28-32 \mathrm{~cm}$ lang.

Die nackte Schnabelfirste ist, vorn über den Bogen bis zur Spitze gemessen, stets über $40 \mathrm{~mm}$ lang; der Kopf und der Hals sind stets weiß (Bd. XI, S. 222) . Larus gelastes, Dünnschnäbelige Möve.

: Die Schnabelfirste ist, von der mittleren Federgrenze vorn iiber den Bogen gemessen, höchstens $39 \mathrm{~cm}$ lang; der Kopf ist entweder ganz braunschwarz (Sommerkleid) oder es befindet sich nur an den oberen Halsseiten ein dunkler Fleck (Winterkleid) (Bd. XI, S. 206, Tafel 18, Fig. 2 u. 3, Tafel 19, Fig. 3 u. 4 und Tafel 20, Fig. 2 u. 3)

Larus ridibundus, Lach-Ḧ̈ve.

$\beta \beta)$ Die zweite Schwinge ist höchstens in der Endhälfte schmal (nicht $2 \mathrm{~mm}$ breit) dunkel gerandet.

* Das Ende der Schwingen ist stets schwarz und von diesem schwarzen Endteil läuft am Hinterrande ein schmaler Saum aus, der sich nach der Mitte der Feder hin verliert; der anliegende Flügel ist $2427 \mathrm{~cm}$ lang; der Kopf ist, wie bei der folgenden, im Sommer schwarz (Bd. XI, S. 197, Tafel 19, Fig. 5) Larus philadelphia, Bonapartes Möve.

* Das Ende der Schwingen ist niemals schwarz; der anliegende Flügel ist 28-30 cm lang (Bd. XI, S. 199, Tafel 18, Fig. 4, Tafel 19, Fig. 2 und Tafel 20, Fig. 4) Larus melanocephalus, Schwarzkopf-Möve.

b) Der Schaft der zweiten Schwinge ist größtenteils dunkelbraum bis schwarz gefärbt.

a) Der anliegende Fligel ist :5. :34 cm lang: die beiden ersten Schwingen sind, wenn beim ausgefärbten Vogel der Kopf weiß ist, schwarz, vor dem Ende weib. beim Jugendkleide (mit schaftflectigen Kopffedern) 
ganz dunkel (Bd. XI, S. 223, Tafel 21, Fig. 1, Tafel 22, Fig. 2 und Tafel 23, Fig. 1); vom Norden bis an unsere Küsten Brutvogel

Larus canus, Sturm-Möe.

(3) Der anliegende Flügel ist bis $34 \mathrm{~cm}$ lang; beim Vogel im Sommerkleide ist der Kopf schwarz bis grauschwarz.

* Die Schnabelfirste ist, von der Federgrenze über den Bogen bis zur Spitze gemessen, $50-53 \mathrm{~mm}$ lang, der anliegende Flügel $32-34 \mathrm{~cm}$ lang; beim Sommerkleide breitet sich die schwarze Farbe des Kopfes bis auf die Oberbrust aus und der Schnabel ist an der Spitze schwarz; beim Jugendkleide ist der Hals und die Oberseite des Kopfes, wie der Vorderrücken, dunkelbraun (Bd. XI, S. 221)

Larus leucophthalmus, Weißaugen-Möve.

** Die nackte Schnabelfirste ist $36 \mathrm{~mm}$ lang, der anliegende Flügel $30^{1} / 2 \mathrm{~cm}$ lang; der Schnabel ist beim ausgefärbten Vogel ganz rot, nicht vorn schwarz (Bd. XI, S. 221)

Larus atricilla, Bleigrauköpfige Möve.

\section{Rissa.}

(Naumann, Bd. XI, S. 286, Tafel 28, Fig. 4 u. 5 und Tafel 29, Fig. 3); vom Norden oft an unsere Küsten kommend

Rissa tridactyla, Dreizehen-Möve.

\section{Xem.r.}

(Naumann, Bd. XI, S. 295, Tafel 28, Fig. 2 u. 3 und Tafel 29, Fig. 2)

Xema sabinii, Gabelschwänzige Möve.

\section{Rhodostethia.}

(Navianx, Bd. XI, S. 297, Tafel 28, Fig. 1 und Tafel 29, Fig. 1)

Rhodostethia rosea, Rosenfarbige Möve.

Stercorarius [Lestris].

I. Der anliegende Flïgel ist über $39 \mathrm{~cm}$ lang; die Wurzel der Schwingen ist weiß (beim anliegenden Flügel ist die weiße Farbe als Fleck sichtbar); die mittleren Schwanzfedern ragen auch beim ausgefärbten Vogel nicht. $2 \mathrm{~cm}$ vor (Bd. XI, S. 303, Tafel 30, Fig. 2)

Stercorarius skua (catarhactes), Große Raubmöve.

II. Der anliegende Flügel ist $27-36 \mathrm{~cm}$ lang und zeigt keinen weißen Basalfleck; die beiden mittleren Schwanzfedern ragen beim ausgefärbten Tier über $7 \mathrm{~cm}$ vor.

A) Die Mittelzehe ist mit Kralle mindestens $5 \mathrm{~cm}$ lang; der anliegende Flïgel :3t-36 cm lang; die vorragenden mittleren Schwanzfedern des aus- 
gefärbten Vogels sind am Ende breit gerundet (Bd. XI, S. 310, Tafel 30, Fig. 3 und Tafel 31, Fig. 2)

Stercorarius pomarinus (pomatorhinus), Mittlere Raubmöve.

B) Die Nittelzehe ist mit Kralle nicht $45 \mathrm{~mm}$ lang; der anliegende Flügel ist 27-33 cm lang; die mittleren Schwanzfedern laufen beim ausgefärbten Federkleid schmal und spitz aus.

a) Die beiden mittleren Schwanzfedern ragen beim ausgefärbten Vogel etwa $20 \mathrm{~cm}$ ïber die benachbarten hinaus: nur die Schäfte der beiden ersten Schwingen sind rein weif, der Schaft der dritten Schwinge und namentlich der der vierten und folgenden ist erheblich dunkler (Bd. XI, S. 329, Tafel 31, Fig. 3 und Tafel 32, Fig. 1, 2 u. 3)

Stercorarius longicauda, Kleine Rauböve.

b) Die beiden mittleren Schwanzfedern ragen auch beim ausgefärbten Vogel nicht $10 \mathrm{~cm}$ vor; der Schaft der dritten Schwinge ist wie der der beiden ersten rein weif, auch der der vierten ist kaum dunkler, erst der Schaft der fünften Schwinge ist deutlich verdunkelt (Bd. XI, S. 317, Tafel 31, Fig. 1, Tafel 32, Fig. 1 und Tafel 33, Fig. 4 u. 5); aus dem Norden oft an die deutschen Nordseekuisten kommend

Stercorarius parasiticus (cepphus crepidatus), Schmarotzer-Raubmöve.

\section{Diomedea und Thalassogerom.}

1. Der Oberschnabel ist an den Seiten bis fast zum Ende dunkel, fast schwarz gefärbt, nur die Firste ist der Länge nach hell.

A) Der Unterschnabel ist ganz schwarz gefärbt; die Oberseite des Kopfes zeigt von der Schnabelwurzel bis zu den Augen keinen grauen Ton (Bd. XII, S. 7)

Thalassogeron chlororhynchos, Buntschnäbeliger Albatros.

B) Der Unterschnabel ist an der Unterseite bis zum Endteil heller gefärbt; die Oberseite des Kopfes zeigt bis zur Schnabelwurzel einen grauen Ton (Bd. XII, S. 7)

Thalassogeron culminalus, Gelbfirstiger Albatros.

II. Der Oberschnabel ist ganz hell gefärbt.

A) Das Rïckengefieder zwischen den Flïgeln ist weiß und mit sehr feinen dunklen Querwellen gezeichnet (Bd. XII, S. 3)

Diomedea exulans, Wandernder Albatros.

B) Die Rïckenfedern zwischen den Flügehn sind entweder einfarbig dunkel. grau oder mit noch etwas dunkleren Rändern versehen (Bd. XI, S. 6, Tafel 1) . Diomedea melanophrys, Schwarzzügeliger Albatros. Dahl, Buch zum Bestimmen der Vügel 


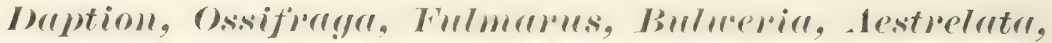

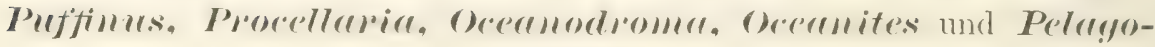 Aromer.}

I. Die nackte Schnabelfirste ist, uiber den Endbogen bis zur Spitze gemessen, höchstens 221 cm lang; die ganze Unterseite des Körpers ist meist viel dunkler als die Federn über dem Schwanze; letztere sind weißlich.

A) Der anliegende Flügel ist nicht $13 \mathrm{~cm}$ lang; die mittleren Schwanzfedern sind nicht kürzer als die seitlichen (Bd. XII, S. 39, Tafel 5, Fig. 1 und 2); häufig an die deutschen Nordseeküsten sich verfliegender: Vogel

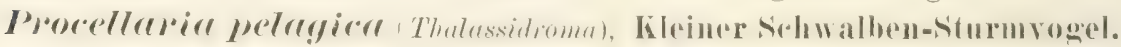

B) Der anliegende Fliigel ist mindestens $15 \mathrm{~cm}$ lang; die mittleren Schwanzfedern sind immer etwas kiirzer als die seitlichen.

a) Die Beine sind sehr lang, der Lauf ist mindestens $3 \mathrm{~cm}$ lang: die Schwimmhaut ist zwischen den Zehen hell (gelb) gefärbt.

a) Die Unterseite des Körpers ist schwarz, die Federn über dem Schwanz sind weiß gefärbt; die nackte Schnabelfirste ist, iiber den Bogen gemessen, nicht $15 \mathrm{~mm}$ lang (Bd. XII, S. 52, Tafel 5, Fig. 3)

Oceanites oceanicus, Buntfüßige Sturmschwalbe.

ß) Die Unterseite des Körpers ist weiß; die Federn über dem Schwanz sind grau; die nackte Schnabelfirste ist, über den Bogen gemessen, iiber $15 \mathrm{~mm}$ lang (Bd. XII, S. 53)

Pelagodroma marina, Fregatten-Sturmvogel.

b) Die Beine sind kurz; der Lauf ist nicht $2,5 \mathrm{~cm}$ lang; die Schwimmhaut der Füße ist ganz dunkel, schwärzlich gefärbt (Bd. XII, S. 47, Tafel 6, Fig. 1 u. 2) . Oceanodroma leuenrhoa, Gabelschwänziger Schwalben-Sturmvogel.

II. Die nackte Schnabelfirste ist, über den Endbogen bis zur Spitze gemessen, mindestens $24 \mathrm{~cm}$ lang; die Unterseite des Körpers ist nicht dunkler als die Federn ïber dem Schwanze.

A) Die Scheidewand zwischen den Nasenlöchern ist an der dünnsten Stelle nicht halb so dick wie der Querdurchmesser des Nasenloches.

a) Die nackte mittlere Firste der Nasenröhre ist $4-6 \mathrm{~cm}$ lang, der anliegende Flügel $45-55 \mathrm{~cm}$ lang (Bd. XII, S. 8, Tafel 2)

Ossifraga gigantea, Riesen-Sturmvogel.

b) Die nackte obere Mittellinie der Nasenröhre ist höchstens 1,5 cm lang, der anliegende Flügel höchstens $35 \mathrm{~cm}$ lang.

aa) Die Nasenröhre ist verhältnismäßig kurz, an ihrer Seitenabgrenzung gemessen ist sie nicht halb so lang (nur etwa drittel so lang) wie die in gerader Linie gemessene Entfernung ihres Vorderrandes von der Spitze des Oberschnabels; die Oberseite der Flïgel ist stets schwärzlich oder schiefergrau gefärbt. 
a) Das ganze Gefieder, anch die Unterseite ist schwarz gefärbt; der anliegende Fliigel ist etwa $20 \mathrm{~cm}$ lang (Bd. XII, S. 19)

\section{Bulweria anjinho, Bulwers Sturmvogel.}

ß) Die Unterseite des Körpers ist wenigstens z. T. weiß gefärbt; der anliegende Flïgel ist $21-32 \mathrm{~cm}$ lang.

$a(x)$ Die Stirn ist rorn weiß gefärbt; der anliegende Fliigel ist 21 bis $30 \mathrm{~cm}$ lang.

* Der anliegende Flügel ist 221 cm lang; die Brust ist an beiden Seiten schiefergrau (Bd. XII, S. 21)

Aestrelata brevipes, KurzfüBiger Sturmvogel.

* Der anliegende Fliigel ist $27-30 \mathrm{~cm}$ lang; die Brust ist ganz weil) (Bd. XII, S. 20)

Aestrelala hasitata, Teufels-Sturmvogel.

$\beta \beta)$ Die Stirn ist bis zur Schnabelwurzel dunkel gefärbt; der anliegende Flügel ist ïber $30 \mathrm{~cm}$ lang (Bd. XII, S. 21)

Aestrelata incerta, Unsicherer Sturmvogel.

bb) Die Nasenröhre ist verhältnismäßig lang: an Seitenrande gemessen ist sie halb so lang wie die Entfernumg ihres Vorderendes von der Spitze des Oberschnabels in gerader Linie gemessen; die Oberseite der Flügel ist entweder weiß gefleckt oder hellgrau gefärbt.

a) Die Oberseite der Flïgel ist hellgrau gefärbt; der Seitenrand der Nasenröhre ist mindestens dreimal so lang wie die Entfernung ihres Vorderrandes ron dem hell gefärbten festen Endteil des Schnabels; der anliegende Fluigel ist $32-34 \mathrm{~cm}$ lang (Bd. XII, S. 12, Tafel 3)

Fulmarus glacialis, Eis-Mövensturmvogel.

$\beta$ ) Die Oberseite der Fliigel ist schwärzlich und weiß gefleckt; die Seitennaht der Nasenröhre ist nicht doppelt so lang wie die Entfernung ihres Endrandes rom schwarzen festen Endteil des Schnabels; der anliegende Flügel ist $26-28 \mathrm{~cm} \operatorname{lang}(\mathrm{Bd}$. XII, S. 7)

Daption capensis, Kaptaube.

B) Die Scheidewand zwischen den Nasenlöchern ist an der dünnsten Stelle fast so breit oder breiter als der Durchmesser des Nasenloches.

a) Der anliegende Fligel ist $28-37 \mathrm{~cm}$ lang; die nackte Schnabelfirste ist, über den Endbogen bis zur Spitze gemessen, $\overline{7}-7 \mathrm{~cm}$ lang.

a) Der Schnabel ist größtenteils dunkel gefärbt; der anliegende Flügel ist 28-31 cm lang; die Bauchseite des Körpers ist mehr oder weniger dunkel gefärbt.

(r) Die Bauchseite des Körpers ist ganz dunkel gefïrbt (Bd. XII, S. 32, 'Tafel 4, Fig. 2) Puffinus griseus, Dunkler 'Taucher-Sturmvogel.

$(\beta)$ Bie Bauchseite des Körpers ist mehr oder weniger weiß gefärbt (Bd. XII, S. 34) . . . Puffinus gravis, Grober Sturmtaucher. 
§) Der Schnabel ist größtenteils gelblich gefürbt: der anliegende Flügel ist $33-37 \mathrm{~cm}$ lang; die Bauchseite des Körpers ist ganz weiß (Bd. XII, S. 35) . . . . . . Puffinus kuhli, Kuhls Sturmtaucher.

b) Der anliegende Flügel ist $18-25 \mathrm{~cm}$ lang; die Schnabelfirste ist, uiber den Endbogen bis zur Spitze gemessen, höchstens $4 \mathrm{~cm}$ lang.

a) Der anliegende Flügel ist 18-21 cm lang, die Schnabelfirste, uiber den Bogen gemessen, nicht $3^{1} / 2 \mathrm{~cm}$ lang (Bd. XII, S. 33)

Puffinus obscurus bailloni, Kleiner Sturmtaucher.

ק) Der anliegende Flïgel ist 22-24 cm lang; die Schnabelfirste ist, über den Bogen gemessen, etwa $4 \mathrm{~cm}$ lang (Bd. XII, S. 26, Tafel 4, Fig. 1); trüher auf der Nordsee nicht selten

Puffinus puffinus (anglorum areticus), Norlischer 'Taucher-Sturmyogel.

\section{Colymbus: [Podiceps].}

I. Die nackte Schnabelfirste ist $18-25 \mathrm{~mm}$ lang; der anliegende Flügel ist höchstens $16 \mathrm{~cm}$ lang; die Außenzehe ist mit Kralle nicht $6 \mathrm{~cm}$ lang.

A) Keine Schwinge ist ganz weiß, wenigstens auf der Außenfahne sind alle grau; der anliegende Flügel ist höchstens $12 \mathrm{~cm}$ lang; der Lauf ist hinten mit spitzen Sägezähnen versehen (Bd. XII, S. 105, Tafel 8, Fig. 2) und Tafel 12, Fig. 1-4)

Colymbus fluciatilis (minor), Keiner Iappentaucher oder SteibfuB.

B) Die Schwingen sind etwa von der 17. an ganz weiß; der anliegende Flügel ist über $12 \mathrm{~cm}$ lang; die Zähne hinten am Lauf sind oben gerundet. a) Der Hals ist beim Sommerkleide fast ganz schwarz; die 14. Schwinge ist auf und neben dem Schaft an der Wurzel dunkel gefleckt (Bd. XII, S. 98, Tafel 8, Fig. 4 und Tafel 11, Fig. 1-4); mehr im Osten

\section{Colymble nigloirollis, Schwarzhalsiger Lappentaucher.}

b) Der Hals ist beim Sommerkleide fast ganz rotbraun; die 14. Schwinge ist ganz weiß, auch der Schaft (Bd. XII, S. 85, Tafel 8, Fig. 5 und Tafel 10, Fig. 1-4); in Deutschland nur auf dem Zuge

Colymbus amritus (cornutus), Gehörnter Lappentaucher.

II. Die nackte Schnabelfirste ist uiber $30 \mathrm{~mm}$ lang; der anliegende Flügel ist wenigstens $16 \mathrm{~cm}$ lang; die Außenzehe ist mit Kralle über $6 \mathrm{~cm}$ lang. A) Die ganze Länge des Vogels, von der Schnabelspitze bis zur Schwanzspitze über den Rücken gemessen, ist höchstens $51 \mathrm{~cm}$; beim Hochzeitskleide sind die Seiten des Kopfes nach dem Halse hin weißgrau und der Hals ist vorn rot (Bd. XII, S. 78, Tafel 8, Fig. 2 und Tafel 9, Fig. 1-4)

Colymbus guiseiffend (ndricollis), Rothalsiger Lappentaucher.

B) Die ganze Länge des Vogels ist mindestens $53 \mathrm{~cm}$; heim Hochzeitskleide ist der Hals vorn weiß; auch die Kopfseiten sind hinter dem Auge weiß; 
der Kopf ist mit rotbraunem, dunkel gerandetem Kragen und mit schwarzen Hörnerbuischeln versehen (Bd. XII, S. 63, Tafel 7, Fig. 1-t und Tafel 8, Fig. 1)

Colymbus cristutus, Grober Lappentaucher.

\section{Gavia [Colymbus Urinator].}

1. Die nackte Schnabelfirste ist in der Nitte über $6 \frac{1}{2} \mathrm{~mm}$ lang; beim Prachtkeide ist der Vorrücken querüber mit großen, rundlichen, weißen Flecken versehen, je zwei auf einer Feder, etwa um ihre eigene Breite voneinander entfernt; der Kopf ist beim Prachtkleide schwarz und besitzt einen grünlichen oder bläulichen Schiller.

A) Der Schnabel ist größtenteils schwarz; beim Prachtkleide zeigt der Hals unter dem weißgefleckten Halsbande einen grünlichen Schiller (Bd. XII, S. 122, Tafel 13, Fig. 2 und Tafel 14, Fig. 2); im Winter an unsere Kïsten kommende, auch die Flüsse hinaufgehende Art

Gavia torquata (glacialis), Westlicher Eis-Seetaucher.

B) Der Schnabel ist größtenteils gelb; beim Prachtkleide zeigt der Hals unter dem Halsbande einen blauen Schiller (Bd. XII, S. 130, Tafel 13, Fig. 3) . . . . Gavia adamsi, Östlicher Eis-Seetaucher.

II. Die nackte Schnabelfirste ist nicht $6^{1} / 2 \mathrm{~cm}$ lang; die Federn des Rückens zeigen niemals zwei große rundliche weiße Flecke, die etwa um ihre eigene Breite voneinander getrennt sind; der Kopf ist beim Prachtkleide z. T. aschgrau gefärbt.

A) Die Federn des ganzen Rückens sind entweder mit je zwei kleinen weißen Schrägflecken versehen, die um weit mehr als ihre Breite getrennt sind oder sie sind einfarbig, dann ist aber der Hals vorn braunrot, hinten weiß gestreift, an den Seiten grau (Bd. XII, S. 139, Tafel 13, Fig. 4 und Tafel 14, Fig. 3); im Winter an unsere Küsten und in unsere Flüsse kommende Art . . . Gavia lumme (septentrionalis), Norl-Seetaucher.

B) Die Federn des Rückens sind entweder einfarbig, bezw. hell berandet. dann ist der Hals aber immer vorn weiß oder grau; oder die Rückenfedern sind $z$. T. weiß quergebändert und dann ist der Hals vorn größtenteils schwarz und mit einem violetten Schiller versehen, beim Übergangskleide schwärzlich gefleckt (Bd. XII, S. 132, Tafel 13, Fig. 1 und Tafel 14, Fig. 1); vom Norden bis Nordostdeutschland Brutvogel

Gavia aretica, Polar-Sectaucher.

\section{Mergulus.}

(Naumanx, Bd. XII, S. 149, Tafel 15, Fig. 3 und Tafel 16, Fig. 3); im Winter vom Norden bis in die Nordsee kommender Vogel

Mergulus alle, Kleiner Krabbentacher. 


\section{Aler.}

I. Die Schnabelfirste ist, über den Bogen gemessen, 3-4 cm lang (Bd. XI, S. 160, Tafel 15. Fig. 1 u. 2 und Tafel 16, Fig. 1 u. 2); an unsern Kuisten Wintervogel, bisher auf Helgoland einzeln noch brütend

Alca torolu, 'Tord-Alk.

II. Die Schnabelfirste ist 8-10 cm lang (Bd. XII, S. 169, Tafel 17-17d); ausgestorbene nordische Art. ....Alea impennis, Riesen-Alk.

\section{Urirl.}

Die Formen dieser Gattung lassen sich nicht durch scharfe Merkmale voneinander trennen.

I. Die eingedrüickte Linie, welche sich im Gefieder des Kopfes vom Auge nach hinten zieht, ist weißlich gefärbt (Bd. XI, S. 223, Tafel 18, Fig. 3 und Tafel 19, Fig. 3); einzeln unter den Schmalschnabellummen brïtend

Uria vhingvia, Ringel-Lumme.

II. Die vom Auge nach hinten verlaufende eingedrückte Linie ist nicht weißlich gefärbt.

A) Der Vorderrand des Nasenloches ist der Spitze des Schnabels nicht näher als dem Auge (Bd. XII, S. 217, Tafel 18, Fig. 1 u. 4 und Tafel 19, Fig. 1); auf den Felsenküsten des Nordens, auch auf Helgoland brütend

Uria lomvia, Schmalsehnabel-Lumme.

B) Der Vorderrand des Nasenloches ist der Spitze des Schnabels viel näher als dem Auge (Bd. XII, S. 227, Tafel 18, Fig. 2 und Tafel 19, Fig. 2)

Uria brïnnichi, Dickschnabel-Lumme.

\section{Cepphus.}

(Naumann, Bd. XII, S. 234, Tafel 20); an den deutschen Küsten Wintervogel Cepphus grylle, Gryll-Teiste.

\section{Phaleris.}

(Naumanx, Bd. XII, S. 242) . . . Phaleris psittacula, Papagei-Alk.

\section{Frotericula.}

(Naumand, Bd. XII, S. 247, Tafel 21); auf Felsen am Neere britender, friiher auch auf Helgoland häufiger Vogel

Fratercula aretica, Arktischer Lund. 


\section{Übersicht der Nester der in Deutschland brütenden Vögel.}

In dieser Übersicht konnten sehr seltene Ausnahmen in Nestbau natïrlich nicht beriicksichtigt werden, wie denn überhaupt die sichere Bestimmung eines Nestes bis auf die Art in manchen Fällen sehr schwierig, in einigen sogar, wie die Übersicht zeigt, unmöglich ist. In den allermeisten Fällen aber wird die hier gegebene Übersicht den Anfänger, wenn er ein Nest mit vollem Gelege vor sich hat, mit einiger Sicherheit zum Ziele führen, zumal wenn er den Vogel flichtig beobachten konnte. Das Letztere ist in manchen Fällen auch für den Kenner unerläßlich. Die Zahlen verweisen, wie im vorhergenden Teil, auf die Abbildungen (der Eier) im "neuen Naumann".

I. Das Nest ist offen oder doch nicht eigentlich überdeckt; oft steht es allerdings unter einer Scholle oder unter dichtem Pflanzenwerk oder endlich an einer stark abschüssigen Böschung; der Oberrand des eigentlichen Nestes ist aber frei, das Nest nicht ïberbaut.

A) Das Nest steht unmittelbar auf dem Boden, oder im dichten Grase nicht merklich vom Boden getrennt oder auf dem Wasser bezw. auf geknicktem Schilf über dem Wasser oder auf einem Seggenbult über dem Wasser bezw. über sumpfigem Boden.

AA) Das auf dem Wasser schwimmende Nest besteht aus nassen Pflanzenteilen; die meist schmutzigen Eier sind nach beiden Enden hin gleichmäßig verjüngt. Das Gelege besteht aus $2-5$, selten aus 6 Eiern

Steibliilie, Taucher.

a) Die Eier sind $47-62 \mathrm{~mm}$ lang, also kein Ei des Geleges unter $47 \mathrm{~mm}$. a) Die Eier sind durchschnittlich 53-54, nicht über $56 \mathrm{~mm}$ lang $(50-56 \mathrm{~mm})$. (Bd. XII, Tafel 22, Fig. 17-19)

Colymbus griseigena.

ß) Die Eier sind durchschnittlich größer und werden oft uiber $56 \mathrm{~mm}$ lang. (Bd. XII, Tafel 22, Fig. 12-14) - Colymbus cristatus.

b) Die Eier sind $33-49 \mathrm{~mm}$ lang, stets einzelne Eier des Geleges unter $47 \mathrm{~mm}$.

«) Die Eier sind $40-49 \mathrm{~mm}$ lang. 
* Nördliche Art (Bd. XII, Tafel 22, Fig. 15-16); der Hals des Vogels ist braunrot .

Colymbus auritus.

** In Deutschland zahlreich brïtende Art (Bd. XII, Tafel 22, Fig. 222 -23); der Hals des Vogels ist, wie der Kopf, schwarz

Colymbus nigricollis.

B) Die Eier sind 32-40 mm lang (Bd. XII, Tafel 22, Fig. 22-23)

Colymbus fuviatilis.

BB) Das Nest besteht aus trockenen Pflanzenteilen oder die Eier liegen auf dem nackten Boden.

a) Die Eier sind einfarbig, weiß, grün, blau, gelblich oder bräunlich, selten einzelne Eier des Geleges zerstreut gefleckt:

aa) Die 5-19 Eier werden vor dem Brüten mit trockenen Nestteilen bedeckt, während des Brütens mit ausgerupften Federn dicht umgeben; sie sind 42-122 $\mathrm{mm}$ lang.

a) Von den Eiern des Geleges ist wenigstens die Mehrzahl über $63 \mathrm{~mm}$ lang.

aı) Die Eier sind 97-122 mm lang. . . Schwan, Cygmus olor.

$\beta \beta)$ Die Eier sind höchstens $95 \mathrm{~mm}$ lang.

$\odot$ Das Nest befindet sich auf trockenen Dünen an der Nordsee; die Eier sind $66-83 \mathrm{~mm}$ lang

Eiderente, Somateria mollissima.

$\odot$ Das Nest befindet sich nicht auf den Dünen der Nordsee, meist an Binnengewässern.

* Die Eier sind $75-95 \mathrm{~mm}$ lang.

Gans, Anser anser.

** Die Eier sind $60-73 \mathrm{~mm}$ lang:

Siiger.

$\doteqdot$ Die Eier sind $63-73 \mathrm{~mm}$ lang.

Meryus merganser.

$\dagger$ Die Eier sind $60-71 \mathrm{~mm}$ lang; der weibliche Vogel unterscheidet sich vom vorhergehenden dadurch, daß das weiße Feld auf dem Flügel dunkel quergeteilt ist .

Mergus serrator.

ß) Von den Eiern des Geleges ist wenigstens die Mehrzahl unter $63 \mathrm{~mm}$ lang; - - die Nester der Enten sind schwer unterscheidbar; man achte deshalb stets genau auf den Vogel.

$a \boldsymbol{a})$ Von den Eiern des Geleges ist keins unter $55 \mathrm{~mm}$ lang und höchstens die Hälfte unter $58 \mathrm{~mm}$.

$\odot$ Die Eier sind ziemlich rein blaugrünlich oder meergrün; das $\sigma$ zeichnet sich durch runden weißen Wangenfleck, das $q$ durch dunkel geteilten großen weißen Spiegel auf dem Flügel ąus.

Schellente, Fuligula clangula.

$\odot \odot$ Die Eier sind nicht rein blaugrünlich. 
* Die Eier sind fast weiß, nur mit schwachem olivenbräunlichen oder olivengrïnlichen Ton versehen; das o zeichnet sich durch schwarzen Kopf mit weißem Halsring, das braungraue $O$ durch blaten, hinten weiß begrenzten Spiegel auf dem Flïgel aus

Stockente, Anas boschas.

** Die Eier sind dunkler olirengrünlich oder -bräunlich.

$\doteqdot$ Das Nest befindet sich an Gewässern, die dicht mit Schilf usw. bewachsen sind, die Eier sind 55-62 mm lang; das $\sigma$ zeichnet sich durch ganz hellgraue Flügel, das $q$ durch völliges Fehlen des weißen Flügelfleckes aus. Tafelente, Fuligula ferima.

$\doteqdot$ Das Nest befindet sich besonders an großen offenen Gewässern.

$\times$ Die Eier sind nicht iiber $60 \mathrm{~mm}$ lang und besitzen einen braungelblichen Ton; das $\sigma^{7}$ zeichnet sich von folgendem durch schwarzen Rücken, das o durch fast ganz braunen Kopf aus

Reiherente, Fuligula fuligula.

$\times \times$ Von den Eiern des Geleges sind einzelne über $60 \mathrm{~mm}$ lang: sie sind olivengrïnlichgrau; das $\sigma^{7}$ zeichnet sich durch grauen Ruicken, das $\circ$ durch scharfen weißen Ring um die Schnabelwurzel aus . . . . . Bergente, Fuligula marila.

$\beta \beta)$ Von den Eiern des Geleges ist keins über $59 \mathrm{~mm}$ lang und mindestens einzelne sind unter $55 \mathrm{~mm}$ lang.

$\odot$ Die Eier sind $48-59 \mathrm{~mm}$ lang.

* Das Nest steht meist auf Seggenbulten oder im Schilf unmittelbar neben Wasser oder Morast.

$\frac{1}{\dagger}$ Die Eier sind gelblichweiß und besitzen keinen deutlichen griullichen 'Ton, sie sind $50-58 \mathrm{~mm}$ lang; am Vogel fällt der breite Schnabel auf . . . . Iöffelente, Spatula clyperta. $\uparrow$ Die Eier besitzen stets einen grülichen Ton.

$\times$ Die meisten Eier des Geleges sind iiber $52 \mathrm{~mm}$ lang; das of fällt durch roten Kopf und schwarze Unterseite, das $\underline{O}$ durch die helle braungraue Farbe des Gefieders auf

Kolbenente, Fuligula mima.

$\times \times$ Die Eier sind 49-53 mm lang, die meisten Eier des Geleges nicht $52 \mathrm{~mm}$; der Vogel fällt durch den braunen Vorderkörper auf . . . . . Moorente, Fuligula nyюoca.

: Das Nest befindet sich meist auf festem, oft auf steinigem Boden.

$\nmid$ Die Eier sind gelblichweiß, 53-58 mm lang; das $\sigma^{7}$ zeichnet sich durch roten Kopf mit weißer Stirn, das $q$ durch reinweiße Unterseite von den folgenden aus

Pleifente, Luas penelope. 
$\div$ Die Eier besitzen einen grinlichen Ton und sind $50-59 \mathrm{~mm}$ lang. $\times$ Der Vogel zeichnet sich von folgendem durch einen breiten weißen Spiegel auf dem Flügel aus

Mittelente, Inas strepera. $\times \times$ Der Vogel zeichmet sich durch schmalen weitien Spiegelrand, das of auch durch lange Schwanzfedern aus

$\odot \odot$ Die Eier sind $42-47 \mathrm{~mm}$ lang.

Spitzente, Dafila acuta.

Die Eier sind braungelblichweit3; das on zeichnet sich durch weißen Streif über dem Auge, das $q$ durch Fehlen des grünen Spiegels aus . . . . Kuäickente, Aurs quevomedula.

Die Eier besitzen keinen bräunlichen Ton; das $\sigma^{7}$ zeichnet sich durch dunklen Streif durch das Auge, das o durch grüen Spiegel auf dem Flügel aus . . . . . Krickente, Anas rrecca.

bb) Die Eier werden vor der Brutzeit nicht mit trockenen Pflanzenteilen bedeckt und während des Brütens nicht wit ausgerupften Fddern dicht umhüllt; sie sind 16-60 $\mathrm{mm}$ lang.

a) Das Gelege besteht aus 8-2: Eiern.

(иx) Die Eier sind $31-38 \mathrm{~mm}$ lang . Rephuhu, Perdix perdix. p $\beta$ ) Die Eier sind $40-48 \mathrm{~mm}$ lang

Fasan, Phasianus colchicus.

B) Das Gelege besteht aus 3-(i, selten aus mehr Eiern.

$\boldsymbol{\alpha} \boldsymbol{\alpha})$ Die Eier sind $33-58 \mathrm{~mm}$ lang, bisweilen fast kugelig.

$\odot$ Die Eier sind braungrau, $50-58 \mathrm{~mm}$ lang

Rohrdommel, Botaums stellaris.

$\odot \odot$ Die Eier sind wei13, bisweilen bläulich angeflogen.

* Die Nester stehen in Kolonien auf geknicktem Schilfrohr; die Eier sind 54-60 mm lang Purpurreiher, Ardea purpurea.

* Die Nester stehen nicht in Kolonien dicht nebeneinander.

$\doteqdot$ Die Eier sind (frisch) bläulich angeflogen $33-37 \mathrm{~mm}$ lang

Zwergreiher, Aviletu minutu.

$\nrightarrow$ Die Eier sind nie bläulich angeflogen.

$\times$ Das Nest steht im Schilf oder auf Wiesen.

Die 2-3 Eier sind 38-42 mm lang

Sumpfohreule, Otus accipitionus.

O Die 4-6 Eier sind $47-50 \mathrm{~mm}$ lang

Rohrweihe, Circus uevuginosus.

$X \times$ Das Nest steht an trockenen Orten, im Getreide usw.

Die 2-3 Eier des Geleges sind alle ungefleckt

Sumplohreule, Otus accipitrinus. 
OO Von den 4-6 Eiern des Geleges sind oft einzelne mit zerstreuten Flecken versehen, sie sind $36-49 \mathrm{~mm}$ lang (Bd. V, Tafel 70, Fig. 12-15) . . Kornweihe, Circus cyaneus und die seltenere Wiesenweihe, Cireus pygargms.

$\beta \beta)$ Die kier sind $16-28 \mathrm{~mm}$ lang.

$\odot$ Die Eier sind $16-20 \mathrm{~mm}$ lang.

* Die Farbe der Eier ist ein reines Blau. (Bd. I, Tafel 31, 34-35)

Wiesenschmitzer, P'atincolre rubetra.

** Die Eier haben eine schmutzig verwaschene Farbe (Bd. I, Tafel :31, Fig. 15-17) . . Blankehlchen, Erithacus cyaneculus. C. Die Eier sind 20 -28 $\mathrm{mm}$ lang, blaß blaugrün; man findet das Nest nur im Gebirge.

Die Eier sind länglicher, bei 20-25 mm Länge nur $15-17 \mathrm{~mm}$ breit Ilpenbramelle, Arecentor colluris.

* Die Eier sind rundlicher, bei 23-28 mm Länge 17-20 mm breit

Steinmerle, Honticolı saxcutilis.

b) Die Eier sind nicht einfarbig hell gefärbt, sondern gefleckt, mitunter aber durch dichte Flecke fast einfarbig dunkelbraun oder dunkelgrau. aa) Die Nester stehn in Kolonien kaum über $1-2 \mathrm{~m}$ voneinander entfernt.

a) Die Eier sind höchstens $46 \mathrm{~mm}$ lang.

r r $)$ Die Nester stehen in Sümpfen auf Seggenbulten, geknicktem Schilf usw. und sind meist gut gebaut . . . 'Trauerseeschwalben.

- Die Eier sind höchstens $36 \mathrm{~mm}$ lang (30-36 mm) (Bd. XI, Tafel 38, Hig. 7-14) . . . . die häufige Hydrochelidom nigra und die siidöstliche Hyclrochelidon fissipes.

$\odot$ Von den Eiern der Gelege ist wenigstens eins länger als $36 \mathrm{~mm}$ (35-42 mm) (Bd. XI, Tafel 38, Fig. 1-6)

Hydrochetidon hybridu.

$\beta$ Die Nester stehen auf festem Boden und bestehen meist aus einzelnen Halmen, sind aber bisweilen nux eine einfache Bodenvertiefung.

- Die Eier sind 30-36 mm lang (Bd. XI, Tafel 37, Fig. 16-24)

'Lwergseeschwalbe, sterna minuta.

$\odot \odot$ Die Eier sind 36 - $46 \mathrm{~mm}$ lang, wenigstens einzelne Eier eines jeden Geleges sind also über $36 \mathrm{~mm}$ lang.

* Es befinden sich im Neste fast immer 4 Eier; der Vogel ist sehr langbeinig, nicht gabelschwänzig; die Eier sind 40-4t mm lang (Bd. Vய, 'Tafel 27, Fig. 13-14)

Stelzenliouler, Fimantopus himentopus. 
** Das Gelege besteht aus 2-3 Eiern; der Vogel ist kurzbeinig, gabelschwänzig.

$\uparrow$ Die Nester werden nur an der Nordsee gefunden.

$X$ Die Nester stehen besonders auf Rasenflächen in der Nähe des Meeresstrandes (Bd. XI, Tafel 33, Fig. 19-30)

Kiistenseesehwalbe, Sterma macruru.

$X \times$ Die Nester stehen meist auf Sand und Kies (Bd. XI, Tafel 37, Fig. 7-10) . . . . Sterna dongalli.

$\doteqdot$ Die Nester werden an Binnengewässern und an der Ostsee gefunden.

$\times$ Von den Eiern ist keins iiber $45 \mathrm{~mm}$ lang $(36-45 \mathrm{~mm}$ ) (Bd. XI, Tafel 35, Fig. 1-12)

FIußseeschwalbe, sterna hirundo.

$X X$ Von den Eiern sind stets einzelne über $45 \mathrm{~mm}$ lang, keins ist unter $41 \mathrm{~mm}(41-54 \mathrm{~mm})(\mathrm{Bd}$. XI, Tafel 37, Fig. 1-6)

Lachseeschwalbe, Sterna nilotica.

B) Von den Eiern des Geleges sind stets einzelne über $46 \mathrm{~mm}$ lang. $\boldsymbol{\alpha} \boldsymbol{\alpha})$ Die Nester werden an Binnengewässern und an der Ostsee gefunden.

Häufige, meist in großen Kolonien nistende Art, ohne Gabelschwanz (Bd. XI, Tafel 36, Fig. 1-9) Lachmöve, Lames vidibundus. ** Seltene, in Kolonien zu wenigen Paaren nistende Art, mit Gabelschwanz (Bd. XI, Tafel 37, Fig. 1-6)

Lachseeschwabe, Sterma nilotica.

$\beta \beta)$ Die Nester werden nur an den Nordseeküsten gefunden.

* Die Eier sind nie über $55 \mathrm{~mm}$ lang ( $46-55 \mathrm{~mm}$ ).

- Der Vogel ist sehr langbeinig und besitzt keinen Gabelschwanz: die Eier besitzen eine meist rostgelbliche Grundfarbe (Bd. VIII, Tafel 28, Fig. 1-4) . . Säbler, Recurvirostra avosetta.

$\nrightarrow$ Der Vogel ist kurzbeinig und besitzt einen Gabelschwanz; die Grundfarbe der Eier ist meist fast weißlich (Bd. XI, Tafel 34, Fig. 8-21) . . . Brandseeschwalbe, Sterna cantiace.

** Von den Eiern des Geleges sind stets einzelne über $55 \mathrm{~mm}$ lang.

$\div$ Das Nest ist eine Vertiefung im Sande ohne Pflanzenteile; die Eier sind 55-65 mm lang; der Vogel besitzt einen Gabelschwanz (Bd. XI, Tafel 34, Fig. 22-24)

Raubseeschwalbe, Sterna tschegrove.

$\div$ Das Nest ist mit Pflanzenteilen ausgelegt; der Vogel besitzt keinen Gabelschwanz. 
$\times$ Von den Eiern des Geleges sind stets einzelne unter $60 \mathrm{~mm}$ lang (53-65 mm) (Bd. XI, Tafel 38, Fig. 20-27)

Sturmmöve, Larus camms.

$X \times$ Von den Eiern des Geleges ist keins unter $60 \mathrm{~mm}$ lang $(60-80 \mathrm{~mm}$ (Bd. XI, Tafel 39, Fig. 1-8)

Silbermöe, Lamus argentatus.

bb) Die Nester stelien nicht in Kolonien nebeneinander.

«) Die Eier sind $27-100 \mathrm{~mm}$ lang:

ar ) Die Eier besitzen eine reinweiße Grundfarbe.

Die 2 Eier des Geleges sind lang gestreckt $27-33 \mathrm{~mm}$ lang, selten eins bis $35 \mathrm{~mm}$; sie liegen ohne Unterlage im Walde, besonders im Nadelholzwalde (Bd. IV, 'Tafel 47, Fig. 23-32)

Nachtschwalbe, Camomulgus europaeus.

* Das Gelege besteht aus $4-10$ Eiern; die Eier sind $34-49 \mathrm{~mm}$ lang, stets einzelne Eier des Geleges über $35 \mathrm{~mm}$.

$\div$ Das Gelege besteht aus 6-10 Eiern; die Eier sind $34-37 \mathrm{~mm}$ lang; das Nest steht entweder über dem Wasser oder iiber sumpfigem Boden (Bd. VII, Tafel 19, Fig. 18-23)

Wasserralle, Rallus aruaticus.

$\because$ Das Gelege besteht aus 4-6 Eiern; die Eier sind $40-49 \mathrm{~mm}$ lang; das Nest steht selten an einem sumpfigen Ort, meist im Getreide oder im niederen Buschwerk.

$\times$ Die Eier sind $42-49 \mathrm{~mm}$ lang; häufigere Art

Kornweihe, Circus cyameus.

$\times \times$ Die Eier sind $40-48 \mathrm{~mm}$ lang; seltene Art

Steppenweihe, Circus macumus.

$\beta \beta)$ Die Eier besitzen keine reinweiße Grundfarbe.

Das volle Gelege besteht aus 5--18 Eiern.

$\doteqdot$ Das Nest befindet sich an nicht sumpfigen Stellen, allenfalls auf feuchten, aber nicht sumpfigen Wiesen.

$\times$ Die Eier sind 28-32 $\mathrm{mm}$ lang; das Nest befindet sich meist im Getreide (Bd. VI, 'Tafel 32, 1-7)

Wachtel, Cotumix cotumix.

$\times \times$ Die Eier sind mindestens $33 \mathrm{~mm}$ lang.

Die Eier sind nicht $47 \mathrm{~mm}$ lang.

$S$ Das Nest wird nur im Gebirge gefunden.

is Die Eier sind mit größeren dunkelbraunen Flecken versehen.

$\odot$ Das Nest befindet sich nur in Gebirgswåldern, meist unter Büschen versteckt; die Eier sind meist $39-41 \mathrm{~mm}$ lang: (Bd. VI, 'Tafel 32, lig. 30-32)

Haselhuhn, Bonasa bonasia. 
$\odot \odot$ Man findet das Nest nur oberhalb del Baumgrenze unter überhängenden Felsen, zwischen Alpenrosen usw.; die Eier sind meist $42-44 \mathrm{~mm}$ lang (Bd. VI, Tafel 32, Fig. 22-25)

Alpenschneehuhn, Lagopus mutus.

of Die Eier sind mit feinen rostroten oder rotgelben Flecken versehen; das Nest wird nur in den Alpen zwischen Felsen, Alpenrosen, Baumstümpfen usw. gefunden (Bd. VI, 'Tafel :22, Fig. 12)

Steinhuhn, Caccabis sraxatilis.

SS Das Nest wird nur in der Ebene gefunden.

is Die Eier sind $401 / 2-47 \mathrm{~mm}$ lang; das Nest wird nur im äußersten Nordosten Deutschlands gefunden (Bd. VI, Tafel 32, Fig. 26-29) . . Moorschneehuhn, Layopms lagopas. क Die Eier sind 33-391/2 mm lang; das Nest wird überall in Deutschland, besonders auf Tiesen, gefunden (Bd. VII, Tafel 1!), Fig. 11-16) . . . . Wiesenknarrer, Crex crex. O Die Eier sind $47-6: 3 \mathrm{~mm}$ lang:

s Von den Eiern des Geleges ist stets die Mehrzahl iiber $53 \mathrm{~mm}$ lang $(52-(i 2 \mathrm{~mm})$; das Nest findet man besonders in großen Wäldern der Gebirge usw. (Bd. VI, Tafel 32, Fig. 18-21)

Auerhuhn, Tetrco urogallus.

SS Von den Eiern des Geleges ist stets die Mehrzahl unter $52 \mathrm{~mm}$ lang $(48-53 \mathrm{~mm})$; das Nest wird besonders auf Heiden, aber auch in Gebirge gefunden (Bd. VI, Tafel 32, Fig. 8-11)

Birkhuhn, Tetroo tetrix.

$\mapsto$ Das Nest befindet sich an sumpfigen Orten oder im Schilf über dem Wasser.

× Von den Eiern des Geleges ist stets die Mehrzahl über $38 \mathrm{~mm}$ lang.

$\cap$ Die Eier sind t9-57 mm lang, hell gelblichgrau, fein grau und schwarz bespritzt (Bd. VII, Tafel 19, Fig. 2t-26)

B̈ißhuhn, Fulicr ator.

( ) Die Eier sind 36 - 45 mm lang; die Flecke sind rötlicher und oft etwas größ3er (Bd. VII, Tafel 19, Fig. 1-4)

Teichluhn. Gallimula chloropus.

$\times \times$ Von den Eiern des Geleges ist stets die Mehrzahl unter $36 \mathrm{~mm}$ lang $(2 \overline{7}-3 \overline{\mathrm{mm}})$.

$\cap$ Die Eier sind $27-32 \mathrm{~mm}$ lang, sehr dicht und verwaschen gefleckt (Bd. VII, Tafel 19, Fig. 8-10)

Zwergsumpthiilner, Ortygometra parer u. O. pusilla.

$\bigcirc$ Von den Eiern des Geleges sind stets einzelne über $320 \mathrm{~mm}$ lang (29-37 mm); die Flecke sind nicht sehr dicht und einige sehr scharf abgegrenzt. 
S Die Grundfarbe der Eier ist licht rötlich (Bd. VII, 'Tafel 19, Fig. 18-2:3) . . Wasserralle, Rallus agurticus. SS Die Grundfarbe del Eier ist stets mit Grau gemischt (Bd. VII,

Tafel 19, Fig. 5-7) Sumpfluhu, Ortygometre poraran. Das volle Gelege besteht aus $1-1$ Eiern.

Die 1-3 Eier des Geleges sind alle mindestens $73 \mathrm{~mm}$ lang.

$\times$ Die Eier sind 9.2-101 mm lang: das Nest findet man in Simpfen (Bd. VII, Tafel 18, Fig. 5-7) .

Kranich, Givs grus.

$\times \times$ Die Eier sind 73 - 12 mm lang, von den Eiern des Geleges erreicht aber höchstens eins die obere Grenze.

Das Nest befindet sich in der Nähe des Wassers: die Erer sind lang gestreckt, $7(;-92 \mathrm{~mm}$ lang, die Flecke sind fast schwarz (Bd. XII, Tafel 25, Fig. 1_-5); nur in Nordostdeutschland

Polartaucher. Gavia aretice.

O Das Nest befindet sich auf Äckern; die 2-3 Eier sind kurz oval, 7: - $8+\mathrm{mm}$ lang; die Flecke sind grau und braun (Bd. VII, Tafel 18, Fig. 1-4)

Trappe, Otis trodu.

1 Von den Eiern des Geleges ist wenigstens eins unter $7: 3 \mathrm{~mm}$ lang; das Gelege besteht aus :3-4 Eiern.

$\times$ Das Nest befindet sich im Walde oder im Weiden- bezw. Erlengebüsch.

Die Eier sind :3:3-38 mm lang; das Nest steht neben Flußufern im Weidengebiisch (Bd. IX, Tafel 31, Fig. 1-(j)

Uferläufer, l'inugoides hypolencos.

Die Eier sind $43-4$ ? $\mathrm{mm}$ lang; das Nest wird in Wäldern und Erlengebüschen gefunden.

$S$ Die Eier sind nach dem einen Ende hin viel stärker verjuingt als nach dem anderen hin, also birnförmig; die Flecke sind $z$. T. dunkelbramschwarz (Bd. IX, Tafel 31, Fig. 7-10)

Strandwasserläufer, Totomus littoreus.

sS Die Eier sind hiihnereierförmig und die Flecke sind weniger dunkel (Bd. LX, Tafel 34, Fig. 7-10)

Waldschnepfe, Scotoprex: ilsticula.

$X \times$ Das Nest befindet sich rveder im Walde noch im Gebiisch, selten neben einem einzelnen höheren Strauch.

O Das Nest steht entweder auf sumpfigem Boden oder allenfalls an einer trockenen Stelle nasser Wiesen.

$\odot$ Die Eier des Geleges sind alle nicht unter $48 \mathrm{~mm}$ lang:

$S$ Das Gelege besteht meist aus + Eiern; diese besitzen eine dunkelbraungrine Grundfarbe und sind 50 (i) $\mathrm{mm}$ lang (Bd. IX. Tafel 3:3, Fig. 12-19). Iterschnepte, Limosa limosa. 
SS Das Gelege besteht meist aus 3 Eiern; diese besitzen eine licht ockergelbbraune oder licht grünliche Grundfarbe und sind 48-55 mm lang (Bd. VIII, Tafel 25, Fig. 1-3)

Goldregenpfeifer, Charadrius pluvialis.

$\odot \odot$ Es sind stets einzelne Eier des Geleges unter $48 \mathrm{~mm}$ lang, meist sind alle kleiner.

S Die Eier des Geleges sind alle über $40 \mathrm{~mm}$ lang (nur abnormerweise kommt eins von $39 \mathrm{~mm}$ Länge vor) (die Eier und Nester der folgenden Arten sind schwer zu unterscheiden, der Anfänger muß deshalb auf den Vogel achten).

s Das Nest steht auf einem trockenen Wiesenfleck oder auf einem feuchten Acker neben einer Wiese; die 4 Eier besitzen eine verhältnismäßig dunkle olivenbraungrünliche Grundfarbe und sind 39-52 mm lang; man wird vom Vogel unter fortwährendem Rufen umflogen (Bd. VIII, Tafel 25, Fig. 5-9)

Kiebitz, Vanellas vanellus.

of Das Nest steht meist in einem Seggenbult; die Eier besitzen ebenfalls eine braungrünliche Grundfarbe und sind $41-46 \mathrm{~mm}$ lang; in einiger Entfernung vom Nest (100-1000 m) befindet sich der Kampfplatz der mit schönem Halskragen geschmückten Männchen (Bd. VIII, Tafel 26, Fig. 20--30)

Kamplihahn, Philomachus mugnax.

is Die Eier besitzen eine helle, meist gelbliche oder sehr hellgrünliche Grundfarbe; die Vögel fallen nicht besonders auf.

! Der Vogel ist schnepfenartig kurzbeinig; die Eier sind $42-48 \mathrm{~mm}$ lang (Bd. IX, Tafel 34, Fig. 19-21)

Doppelbekassine, Gallinago major.

!! Der Vogel ist sehr langbeinig; die Eier sind $41-47 \mathrm{~mm}$ lang (Bd. IX, Tafel 32, Fig. 13-24)

Gambettwasserläufer. Totanus totanus.

SS Die Eier des Geleges sind wenigstens z. T. unter $40 \mathrm{~mm}$, auch unter $39 \mathrm{~mm}$ lang.

is Von den Eiern des Geleges sind stets einzelne mindestens $37 \mathrm{~mm}$ lang, oft sind alle iiber $37 \mathrm{~mm}$; der Vogel ist nicht an die Meereskuiste gebunden.

! Die Eier sind durchweg dunkler gefärbt; der Vogel ist schnepfenartig kurzbeinig.

$\square$ Die Eier sind im Durchschnitt etwas größer, $37-42 \mathrm{~mm}$ lang; der Vogel brütet überall in Deutschland (Bd. IX, Tafel 34, Fig. 1-i) Bekassine, Gallinago yallinago. 
Die Eier sind etwas kleiner, 36-40 mm, der Vogel brütet selten in Norddeutschland (Bd. IX, Tafel 34, Fig. 8-12)

Kleine Bekassine, Gallinago gallimula.

!" Die Eier besitzen durchweg eine etwas hellere Grundfarbe; der Vogel ist sehr langbeinig.

$\square$ Der Vogel brütet überall in Deutschland; die Eier sind $36-42 \mathrm{~mm}$ lang (Bd. LX, Tafel 31, Fig. 17-25)

Bruchwasserliufer, Totanus glareola.

$\square \square$ Der Vogel bruitet in Ungarn häufig, selten in Deutschland; die Eier sind $38-41 \mathrm{~mm}$ lang

Teichwasserliufer, Totanus stagnatilis.

की Die Eier sind alle unter $37 \mathrm{~mm}$ lang, einzelne Eier des Geleges bleiben stets unter $36 \mathrm{~mm}$ (32-361/2 mm); der Vogel ist an die Meeresküiste gebunden, brütet aber oft auch in Sümpfen hinter der Düne (Bd. VHI, Tafel 28, Fig. 5-12)

Alpenstrandläufer, Tringa alpina.

Das Nest steht entweder auf festem Boden oder auf salzhaltigem Boden an der Meeresküiste.

- Die Eier des Geleges sind höchstens $38 \mathrm{~mm}$ lang.

$S$ Das Nest befindet sich an Flußufern.

en Das Nest steht im Sande; die Eier sind 29-32 mm lang (Bd. VIII, Tafel 27, Fig. 1-6)

Flubregenpleifer, Charadrius dubius.

क D Das Nest steht im Rasen; die Eier sind 33-38 mm lang (Bd. IX, Tafel 31, Fig. 1-6)

Uferliufer, Tringoides hypoleucos.

SS Das Nest wird nur an der Meeresküste gefunden.

(n) Das Nest steht auf humusreichem, mit Salzpflanzen bewachsenem Boden; die Eier sind 32 -36 mm lang (Bd. VШ, Tafel 28, Fig. 5-12)

Alpenstrandliufer, Trimga relpina.

of Das Nest steht im Sande und ist meist nur eine flache Vertiefung desselben; die Eier sind 28-37 mm lang.

: Die Eier sind 32-37 mm lang (Bd. VIII, Tafel 25, Fig. 16-21)

Sandregenpfeifer, Charadrius hireticula.

!! Die Eier sind 28 - 33 mm lang (Bd. VIII, Tafel 25, Fig. 11-15)

Seeregenpleilier, Charadrius alexandrinus.

$\odot \odot$ Von den Eiern des Geleges sind selten einzelne unter $38 \mathrm{~mm}$ lang. 
$\mathrm{S}$ Die Eier sind mindestens $60 \mathrm{~mm}$ lang und stets einzelne im Gelege über $61 \mathrm{~mm}(60-76 \mathrm{~mm})$ (Bd. IX, Tafel 33, Fig. 1-5)

Brachvogel, Numenius arcuatus.

SS Die Eier sind höchstens $61 \mathrm{~mm}$, stets aber einzelne des Geleges unter $59 \mathrm{~mm}$ lang.

in Die Eier sind 45-61 $\mathrm{mm}$ lang, stets einzelne des Geleges iiber $46 \mathrm{~mm}$.

$\square$ Die Grundfarbe der Eier ist dunkelolivengriin; die Flecke sind verwaschen und nicht viel dunkler als der Grund: die Eier sind $46-54 \mathrm{~mm}$ lang (Bd. VII, Tafel 17, Fig. 7-10)

Zwergtrappe, Otis tetrax.

Die Grundfarbe der Eier hebt sich scharf von den z. T. braunschwarzen Flecken ab und ist selten grünlich.

! Das Nest wird nur in der Nähe des Meeresstrandes, auf salzhaltigem Boden gefunden.

". Die Eier sind 52-61 mm lang, einzelne des Geleges stets iiber $5 \pm \mathrm{mm}$; das Gelege besteht meist aus 3 Eiern (Bd. VIII, Tafel 26, Fig. 1-7)

Austernfischer, Haematopus ostrilegus.

?" Die Eier sind $46-54 \mathrm{~mm}$ lang, einzelne des Geleges stets unter $52 \mathrm{~mm}$; das Gelege besteht meist aus 4 Eiern (Bd. VIII, Tafel 28, Fig. 1-4)

Sïbler, Recurvivostro rvosetta.

!! Das Nest steht nicht im Bereich des Meeresstrandes.

? Das Gelege besteht aus 2-3̈ Eiern; die Eier haben die Gestalt von Hühnereiern und sind 52-58 mm lang (Bd. VII, Tafel 26, Fig. 1-7)

T'riel. Oedicnemus oerlicnemus.

?? Das volle Gelege besteht aus 4 Eiern; die Eier sind an einem Ende viel spitzer als am anderen und $48-55 \mathrm{~mm}$ lang (Bd. VIII, Tafel 25, Fig. 1-3)

Goldregenpfeifer, Chavadrins pluvialis.

on Die Eier sind $36-16 \mathrm{~mm}$ lang, stets einzelne des Geleges unter $45 \mathrm{~mm}$.

! Das Nest findet man nur im Gebirge über der Baumgrenze, z. B. im Riesengebirge; die Eier sind $36-16 \mathrm{~mm}$ lang; das Gelege besteht aus 3 Eiern (Bd. VIII, Tafel 25, Fig. 10)

Mornellregenpfeifer, Charadrius morinellus.

!! Das Nest findet man nur am Meeresstande; es enthält 3-4 Eier von 38-44 mm Länge (Bd. VIII, Tafel 27, Fig. 7-12) . . Steinwïzer, Arenaria intermes. 
!.!. Man findet das Nest ganz vereinzelt im Binnenlande und zwar in der Ebene; die 3-4 Eier des Geleges sind an beiden Enden fast gleich gerundet (Bd. VII, Tafel 17, Fig. 6)

Steppenhuhn, Symhaptes paradoxus.

ß) Die Eier sind $16-26 \mathrm{~mm}$, selten eins im Gelege bis $28 \mathrm{~mm}$ lang; das Nest ist napförmig; der Napf ist am Rande bis $7 \mathrm{~cm}$ breit.

$\boldsymbol{\alpha} \boldsymbol{\alpha})$ Die Eier sind mit Schnörkeln und größeren Flecken von rötlichschwarzer Earbe versehen.

* Das Nest steht auf sumpfigem oder moorigem Boden zwischen Schilf, Weiden und Erlen; die Eiel sind 18-22 mm lang (Bd. IIT, Tafel 46, Fig. 28-32) . Rohrmmmer, Emberisa schoenichus. ** Das Nest steht an nicht sumpfigen und nicht moorigen Orten. $\uparrow$ Die Eier sind 18-24 mm lang, höchstens einzelne des Geleges über $22 \mathrm{~mm}$ lang; der Napf des Nestes ist am Oberrande $5^{1 / 2}$ bis $6 \frac{1}{2} \mathrm{~cm}$ breit.

Der Napf des Nestes ist am Oberrande $5 \frac{1}{1} \mathrm{~cm}$ breit; die Eier sind mit großen Flecken und wenigen Schnörkeln versehen (Bd. III, Tafel 46, Fig. 16-20)

Gartenammer, Emberisa hortulana.

$\bigcirc \bigcirc$ Der Napf des Nestes ist $6 \frac{1}{2} \mathrm{~cm}$ breit; die Eier sind meist mehr mit Schnörkeln als mit Flecken versehen (Bd. III, 'T'afel 46, Fig. 6-11) . . . . Goldammer, Emberisa citrinella. $\pitchfork$ Die Eier sind 21-28 mm lang, höchstens einzelne des Geleges unter $23 \mathrm{~mm}$; auch das Nest ist größer (Bd. III, Tafel 46, Fig. 1-5)

Grauammer, Hiliaria calumara.

$\beta \beta)$ Die Eier sind nicht mit großen rötlichschwarzen Flecken und nicht mit dicken Schnörkeln versehen.

* Das Nest besteht äußerlich immer aus trockenem Laub und ist tief napfförmig, der Napf bei $6 \mathrm{~cm}$ Breite $4^{1} / 2 \mathrm{~cm}$ tief. Die Eier sind so dicht gefleckt, daß sie einfarbig dunkelbraun zu sein scheinen.

$\div$ Das Nest steht meist im sumpfigen Weidengebüsch und besteht äußerlich aus Weidenlaub; der Napf wird am Rande bis $6 \mathrm{~cm}$ breit (Bd. I, Tafel 31, Fig. 15-17)

Blaukehlehen, Evithacus cyaneculus.

it Das Nest steht an trockeneren Orten und besteht äußerlich meist aus Eichenlaub; der Napf ist $6 \frac{1}{2} \mathrm{~cm}$ breit.

$\times$ Westliche Art (Bd. I 'Tafel 31, Fig. 1-4)

Nachtigall, Erithrense lascinir.

$\times \times$ Östliche Art . . Sprosser, Erithacus philomela. 
* Das Nest besteht äußerlich nicht aus trockenem Laub und der Napf ist meist weniger tief, bei $6 \mathrm{~cm}$ Breite $4 \mathrm{~cm}$ tief; die Eier sind oft dicht gefleckt, aber selten so dicht, daß sie fast einfarbig erscheinen.

$\uparrow$ Die Eier sind sehr licht gefärbt; auf weißem, bläulichem oder rötlichem Grunde entweder licht rostrot gefleckt oder sehr zerstreut mit feinen dunklen Flecken versehen, 15-19, sehr selten bis $20 \mathrm{~mm}$ lang.

$\times$ Die Eier sind auf weißem Grunde zerstreut fein schwärzlich gefleckt und bekritzelt; das Nest steht im Schilfrohr (Bd. II, Tafel 27, Fig. 46-49). . Bartmeise, Pamurus biarmicus. $\times \times$ Die Eier sind auf bläulichem oder rötlichem Grunde lichtrostrot gefleckt.

() Die Grundfarbe der Eier ist rötlichweiß (Bd. II, Tafel 26, Fig. 9-12) . . Henschreckensånger, Locmstella naevia.

O Die Grundfarbe der Eier ist ein mehr oder weniger reines Blaugrïn.

8 Die Grundfarbe der Eier ist ein schönes Blaugrün; die Flecke sind meist sehr spärlich oder fehlen ganz (Bd. I, Tafel 31, Fig. 34-35) . . Wiesenschmätzer, Protincola vubetra.

SS Die Grundfarbe der Eier ist graugrünlich und es sind stets roströtliche Flecken vorhanden (Bd. I, Tafel 31, Fig. 36-40)

Schwarkehlehen, Pratincola rubicola.

†े Die Eier sind dunkler gefärbt, indem die Flecke grau bis schwärzlichrotbraun werden und oft so dicht stehen, daß die Eier grau erscheinen; sie sind $16-26 \mathrm{~mm}$ lang.

5 Die Eier sind 16-20 mm lang, nur einzelne des Geleges über $18 \mathrm{~mm}$; sie sind sehr kurz eiförmig und durch dichte Flecke fast einfarbig grau, selten mit einigen feinen schwarzen Schnörkeln versehen.

in Das Nest steht an sehr sumpfigen Stellen (Bd. II, Tafel 26, Fig. $28-31$ )

Schilfrohrsänger, Calamodus schoenobrenus.

in Das Nest steht auf festerem Boden, allenfalls auf Wiesen und an Gräben (Bd. III, Tafel 45, Fig. 36-40)

Schafstelze, Budytes flaves.

SS Die Eier sind 18-26 mm lang, stets nur einzelne des Geleges unter $19 \mathrm{~mm}$; sie sind meist gestreckter und erscheinen niemals einfarbig dunkel.

in Das Nest ist flach und steht meist frei auf Getreidefeldern, an Wegen, seltener auf nassen Wiesen; die Eier sind 21 bis $26 \mathrm{~mm}$ lang. 
Das Nest steht in der Nähe der Dörfer und Straßen im Getreide; die Eier sind meist gröber gefleckt (Bd. III, Tafel 44, Fig. 11-15̄)

Haubenlerehe, Galeriala cristata.

O Das Nest ist weit von menschlichen Wohnungen und von Straßen entfernt im Getreide oder auf Wiesen: die Eier sind meist feiner gefleckt (Bd. II, Tafel 44, Fig. 1-5)

Feldlerche, Alauda arensis.

un Das Nest ist fester gebaut, tief napfförmig, meist sehr versteckt unter Pflanzen; die Eier sind 18-2+ $\mathrm{mm}$ lang und ihre Flecke besitzen oft einen rötlichen Ton.

Man findet das Nest in Gebirgen an der Baumgrenze (Bd. III, Tafel 44, Fig. 40-43). Wasserpieper, Anthus spipoletta.

O Man findet das Nest in der Ebene oder am Fuße der Gebirge.

๑ Das Nest steht auf sumpfigen Wiesen (Bd. III, Tafel 44, Fig. 50-54) . . Wiesenpieper, Anthus matensis. $\odot$ Das Nest steht in Wäldern oder an dürren Orten.

! Man findet das Nest an Waldrändern oder auf Waldlichtungen, an Orten, die weder diirr noch sumpfig sind (Bd. III, Tafel 45, Fig. 5-14) . Bammieper, Anthus trivialis.

!! Das Nest steht an dürren Orten mit Heidekraut und jungen Nadelholzpflänzlingen.

? Das Nest steht versteckt (Bd. III Tafel 45, Fig. 15-18)

Brachpieper, Authus compestris.

"? Das Nest steht ziemlich frei (Bd. III, Tafel 44, Fig. 6-10)

Heidelerche, Lullula arhorea.

B) Das Nest ist immer deutlich vom Boden getrennt, es steht: zwischen niederen Pflanzen, zwischen nicht gebrochenen Schilfhalmen, auf Sträuchern, Bäumen, Baumstümpfen, Zäunen oder auf der Firste eines Hauses.

AA) Das Nest ist entweder oben flach oder, wenn napfförmig; der Napf am Innenrande oben wenigstens $81 / 2 \mathrm{~cm}$ breit; die Eier sind mindestens $23 \mathrm{~mm}$ lang, stets einige des Geleges über $24 \mathrm{~mm}$.

a) Das Nest ist entweder oben flach oder, wenn napfförmig, der Napf am Innenrande oben $13 \mathrm{~cm}$ und daruber breit, die Eier sind 26-84 $\mathrm{mm}$ lang, wenn das Nest napfförmig ist, ist höchstens eins der Eier des Geleges unter $31 \mathrm{~mm}$ lang.

aa) Es sind stets mehrere Nester wenig voneinander entfernt und bilden eine Kolonie, entweder auf einem Baum oder auf Weidengesträuch.

a) Die Eier sind auf bräunlichem oder olivengrünlichem Grunde dunkel gefleckt, 29-42 mm lang; die Nester stehen in einem Sumpf auf 
Weidenbüschen oder auf niederen Pflanzen (Bd. XI, S. 38, Fig. 1-14). Man vergl. oben S. 123 die Arten der

Trauerseeschwalben, Hydrochelidon.

B) Die Eier sind auf weißem oder bläulichem Grunde oft mehr oder weniger gefleckt, doch oft auch einfarbig weiß bis blau; die Nester stehen auf Bäumen.

a bläulichem Grunde mit Kalküberzug versehen und dadurch fleckig; am Boden unter den Nestern liegen fast immer Fischreste.

Die Eier sind auf bläulichem Grunde mit Kalküberzug versehen, 58-67 mm lang (Bd. XI, Tafel 41, Fig. 1-3)

Scharbe, Phalacrocorax carbo.

** Die Eier sind rein blaugrünlich.

† Die Eier sind 56-69 mm lang Fischreiher, Ardea cineren.

t† Die Eier sind $46-55 \mathrm{~mm}$ lang

Nachtreiher, Nycticorax mycticorax.

$\beta \beta$ ) Die Eier sind $29-45 \mathrm{~mm}$ lang, auf mehr oder weniger bläulichem Grunde dunkel gefleckt; am Boden unter den Nestern liegen keine Fischreste.

* Die Eier sind 35-45 mm lang; die Flecke mehr verwaschen (Bd. IV, Tafel 47, Fig. 19-26) Saatkrïhe, Corvus frugilegus. ** Die Eier sind 29-38 mm lang; der Grund ist meist heller und die Flecke treten deshalb schärfer hervor (Bd. IV, Tafel 48, Fig. 7 bis 14); die Nester einzeln zwischen denen der Saatkrähen und von diesen gebaut. . . . . . Dohle, Lycus monedula.

bb) Die Nester stehen nicht in Kolonien nebeneinander.

a) Die Eier sind einfarbig, entweder weiß oder grünlich oder grau, selten einzelne Eier des Geleges mit sehr zerstreuten dunklen Flecken versehen. « $\iota$ ) Im Nest befinden sich 8-17 Eier von 56-73 mm Länge; während der Brutzeit sind dieselben mit Federn dicht umgeben.

* Die Eier sind 63-73 mm lang, also keins unter $63 \mathrm{~mm}$

Säiger, Mergus merganser.

: Die Eier sind 56-66 mm lang, stets einige im Gelege unter $63 \mathrm{~mm}$.

$\div$ Die Eier sind rein meergrün Schellente, Fuligula clangula.

$\div$ Die Eier besitzen einen olivenbräunlichen Ton

Stockente, Anas boschrs.

$\beta \beta)$ Das Gelege besteht aus $1-5$, selten aus $6-7$ Eiern.

* Die Eier sind 26-45 mm lang.

$\doteqdot$ Die 3-4 Eier des Geleges sind fast kugelig, 37-43 mm lang

Waldohreule, Asio otus. 
$\because$ Das Gelege besteht aus zwei länglichen Eiern; das Nest nur aus wenigen Zweigen.

$\times$ Die Eier sind $26-35 \mathrm{~mm}$ lang

'Turteltaube. Therer tortur.

$\times \times$ Die Eier sind $38-45 \mathrm{~mm}$ lang

Ringeltaube, Columba palumbus.

** Die Eier sind 48-90 $\mathrm{mm}$ lang.

$\div$ Das Gelege besteht aus einem Ei, das 65-80 mm lang ist

Schlangenadler, Circcëtus gallicus.

$\uparrow$ Das Gelege besteht aus 2-5 Eiern.

S Auf das Nest sind stets grine Zweige gelegt; die Eier sind 51-64 mm lang (Bd. V, Tafel 70, Fig. 5-6)

IIihnerhabicht, Astur pulumbarius.

SS Das Nest ist nicht mit grünen Zweigen belegt.

i Es sind wenigstens einzelne Eier des Geleges über $63 \mathrm{~mm}$ lang.

Das Nest steht auf der Firste eines Hauses, seltener auf einem Baum, dessen Stamm oben abgebrochen ist; die Eier sind $60-80$, meist $67-78 \mathrm{~mm}$ lang . Klapperstorch, Ciconia cicomia.

$\bigcirc$ Das Nest steht weder auf dem Dache eines Hauses noch auf einem oben abgebrochenen Baumstamm, sondern in der Krone eines Baumes oder auf einem Seitenast.

$\odot$ Von den Eiern des Geleges ist sehr selten eins unter $70 \mathrm{~mm}$ lang (69-90 mm) . . . Seeadler, Haliaëtus albicilla. $\odot \odot$ Von den Eiern des Geleges ist selten eins $69 \mathrm{~mm}$ lang, meist sind sie kleiner $(61-70 \mathrm{~mm})$

Schwarzer Storeh, Cicomia nigro.

is. Es ist keins der Eier des Geleges über $63 \mathrm{~mm}$ lang.

Die Eier sind $48-50 \mathrm{~mm}$ lang; man findet das Nest nur im äußersten Osten Deutschlands

IIabichtseule, Syrnium uralense.

Die Eier sind 53-63 mm lang; der Vogel war ursprünglich iiber ganz Deutschland verbreitet, ist aber an vielen Orten schon recht selten . . . . . Uhu, Bubo bubo.

ß) Die Eier des Geleges sind sämtlich gefleckt, oft so dicht, daß sie ganz gelbbraun aussehen.

rst Die Eier sind sehr kurz eiförmig, niemals an einem Ende viel spitzer, oft fast kugelig, auf weißem bis gelblichem, seltener bläulichem Grunde gelbbraun bis schwarz oder rotbraun gefleckt; das Nest ist flach, $d . h$. oben wenig eingesenkt.

Die Eier sind $34-45 \mathrm{~mm}$ lang. 
$\doteqdot$ Die Eier sind auf weißem Grunde mit nicht sehr dichten, gröferen, rotbraunen bis schwarzen Flecken versehen (Bd. V, Tafel 70, Fig. 7-11) . . . . Sperber, Acripiter nisus.

$\rightarrow$ Die Eier sind auf gelblichem Grunde sehr dicht gelbbraun bis dunkelrotbraun gefleckt.

$\mathrm{S}$ Die Eier sind etwas kleiner 34-44, aber meist 35-38 mm lang (Bd. V, Tafel 65, Fig. 17--21); meist besteht das Gelege aus 5-6 Eiern . Turmfalke, Timmunculus tinnunculus. SS Die Eier sind etwas größer, 39-44 mm lang (Bd. V, Tafel 65, Fig. 12-14); das Gelege besteht aus 3-4 Eiern

lerchenfalke, Falco subbuteo.

** Die Eier sind 46-81 mm lang:

$\rightarrow$ Die Eier sind $46-70 \mathrm{~mm}$ lang.

S Die Eier sind so dicht bräunlich gefleckt, daß der Grund bräunlich erscheint.

- Das Gelege besteht aus 2, selten 3 Eiern; die Eier sind $47-60 \mathrm{~mm}$ lang (Bd. V, Tafel 65, Fig. 10-11)

Wespenbussard, Permis apivoms.

in Das Gelege besteht aus 3, öfter aus 4 Eiern; die Eier sind 47 -56 mm lang (Bd. V, Tafel 65, Fig. 1-4)

Wanderfalke, Falco peregrinus.

SS Die weiße oder bläulichweiße Grundfarbe der Eier ist immer in größerer Ausdehnung sichtbar.

o Zum Nestbau werden unter anderm Lumpen, Papier usw. verwendet; der Schwanz des Vogels ist am Ende mehr oder weniger gabelförmig ausgeschnitten.

Der Schwanz des Vogels ist tief, rechtwinklig gegabelt (Bd. V, Tafel 66, Fig. 14-16) . . Gabelmilan, Hilvus milvus.

O Der Schwanz des Vogels ist weniger ausgerandet $(\mathrm{Bd} . \mathrm{V}$, Tafel 66, Fig. 18-20 . Schwarzmilan, Milvus korschun.

कo Zum Nestbau werden keine Lumpen verwendet; der Schwanz des Vogels ist nicht gegabelt.

Die 2-4 Eier des Geleges sind 50-59 mm lang, stets mindestens die Hälfte der Eier des Geleges unter $56 \mathrm{~mm}$.

$\odot$ der Schwanz des Vogels ist dicht quer gebändert; die Art ist überall in Deutschland häufig (Bd. V, Tafel 68, Fig. 1-4)

Maiusebussard, Buteo buteo.

$\odot$ Der Schwanz ist nur am Ende mit einem oder mit wenigen dunklen Bändern versehen; die Art dringt vom Norden her bis Norddeutschland vor (Bd. V, Tafel 68, Fig. 9-12)

Rauhfubussard, Archibuteo lagopus. 
Die Eier sind $50-69 \mathrm{~mm}$ lang, stets mindestens die Hälfte der Eier des Geleges über $56 \mathrm{~mm}$.

- Das Nest steht meist in den dünnen, höchsten Zweigen eines Baumes und enthält 3-4 Eier von 50-67 mm Länge (Bd. V, Tafel 68, Fig. 5-8) . . Fluliadler, Prudion hralirëtus. $\odot$ Das Nest steht meist nur $10-15 \mathrm{~m}$ hoch und enthält 1 -2 Eier von 58-69 mm Länge

Schreiadler, Aquila pomarina.

$\uparrow$ Die Eier sind $71-81 \mathrm{~mm}$ lang und das Gelege besteht aus nur 1--2 Eiern (Bd. V, Tafel 69, Fig. 1-3)

Steinadler, Aquila chryscëtus.

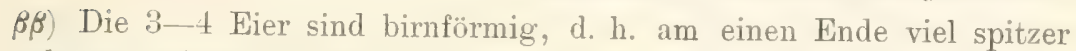
als am andern, 37-42 mm lang, auf hell olivengrïlich gelber Grundfarbe mit dunklen Flecken versehen; die Flecke haben teilweise einen violetten Ton; das Nest wird nicht vom Vogel selbst gebaut (Bd. IX, Tafel 31, Fig. 26-28) . Wasserläufer, Totanus ochropms. rr) Die Eier sind langeiförmig, am einen Ende nur wenig spitzer als am andern, 29-53 mm lang, auf bläulichweißem oder blauem Grunde grau bis schwärzlich, seltener bräunlich gefleckt.

* Die Eier sind 29-37 mm lang, die Mehrzahl der Eier des Geleges ist nicht $36 \mathrm{~mm}$ lang; das Nest steht meist $4-8 \mathrm{~m}$ hoch.

$\div$ Die 5-7 Eier des Geleges sind sehr dicht grau gefleckt; das Nest ist aus Zweigen, Halmen und feinen Wurzeln hergestellt (Bd. IV, Tafel 46, Fig. 18 -23)

Eichelhäher, Garmulus glandarius.

$\uparrow$ Die 3-4 Eier des Geleges sind zerstreut bräunlich gefleckt; das Nest enthält eine gemauerte Schicht und besteht z. T. aus Flechten und Moos (Bd. IV, Tafel 48, Fig. 1-6)

Tannenhiher, Nuciforngr caryocratutes.

Die Eier sind $36-53 \mathrm{~mm}$ lang, selten eins des Geleges nicht $38 \mathrm{~mm}$; das Nest steht meist höher.

$\uparrow$ Der Napf des Nestes ist an seinem Oberrande $21-24 \mathrm{~cm}$ breit; die Eier sind 42-.53 mm lang, höchstens einzelne des Geleges unter $44 \mathrm{~mm}$ (Bd. IV, Tafel 49, Fig. $1-8$ )

Kolkrabe, Corvus rolax.

$\because$ Der Napf des Nestes ist am oberen Innenrande $17-18 \mathrm{~cm}$ breit; die Eier sind $36-47 \mathrm{~mm}$ lang; höchstens einzelne des Geleges über t2 $\mathrm{mm}$.

$X$ Der Vogel ist z. T. grau gefïrbt, östliche Art (Bd. IV, Tafel 47, Fig. (j-13)

Nebelkrihe. Com:ls rom ix. 
$\times \times$ Der Vogel ist ganz schwarz, westliche Art (Bd. IV, Tafel 49, Fig. 9-18) . . . . Rabenkrïhe, Corvus corone.

b) Das stets napfförmige Nest ist kleiner, am oberen Innenrande höchstens $13 \mathrm{~cm}$ breit; die Eier sind 23-34 $\mathrm{mm}$ lang; mehrere Eier des Geleges sind stets unter $31 \mathrm{~mm}$ lang.

aa) Das Nest hängt zwischen zwei Zweigen, meist in einer Gabel; die Eier sind auf rötlichem Grunde mit scharfen, fast schwarzen Flecken versehen, 28-33 mm lang (Bd. IV, Tafel 46, Fig. 1-4)

Pirol, Oriolus oviolus.

bb) Das Nest hängt zwischen Schilfrohrhalmen iber dem Wasser oder über morastigem Boden; die Eier sind 20-26 mm lang, ziemlich dicht olivengrün bis schwarz gefleckt (Bd. II, Tafel 26, Fig. 19-23)

Drossehohrsånger, Acrocephatus ammdinceens.

cc) Das Nest hängt nicht frei zwischen Zweigen oder zwischen Schilfrohrhalmen.

a) Das Nest ist innen gemauert, nicht mit Halmen usw. ausgelegt; die Eier sind 23-32 mm lang.

« $\iota)$ Die Grundfarbe der Eier ist schön blau; die Flecke sind zerstreut und fast schwarz (Bd. I, Tafel 32, Fig. 14-21)

Singlrossel, Turdus musicus.

$\beta \beta)$ Die Grundfarbe der Eier ist weniger blau und die Flecke sind sehr dicht und meist heller (Bd. I, Tafel 32, Fig. 33-38)

Rotdrossel, Turdus iliacus.

B) Das Nest ist innen nicht ausgemauert.

ия) Die Eier sind mit rötlichen bis dunkelrotbraunen Flecken versehen.

* Die Eier sind auf hellgrünlichem bis grünlichem Grunde zerstreut groß gefleckt, 28-32 mm lang (Bd. I, Tafel 32, Fig. 39-47)

Misteldrossel, Turdus viscivorus.

** Die Eier sind auf grünblauem Grunde mit dichteren und kleineren, heller oder dunkler roten Flecken versehen.

$\div$ Der Napf des Nestes ist kleiner, 5-61/2 cm tief; das Nest steht meist in der Nähe menschlicher Wohnungen, ziemlich niedrig;' die Eier sind 24-32 mm lang (Bd. I, Tafel 32, Fig. 1-10)

Amsel, Thrdus memila.

$\pitchfork$ Der Napf des Nestes ist etwas größer, meist $7 \mathrm{~cm}$ tief; das Nest ist meist von menschlichen Wohnungen weit entfernt und steht meist höher über dem Boden; die Eier sind 26-34 mm lang. $\times$ Man findet das Nest in der Knieholzregion höherer Gebirge, besonders auf Krüppelfichten (Bd. I, Tafel 32, Fig. 11-13)

Ringdrossel, Turdus torquatus. 
$X X$ Man findet das Nest in der Ebene, besonders im Norden (Bd. I, Tafel 32, Fig. 22-32)

\section{Wacholderdrossel, Turdus pilaris.}

$\left.\beta \beta^{\circ}\right)$ Die Eier sind mit violettgrauen und dunkelbraunen Flecken versehen, 21-28 mm lang.

* Das Nest steht sehr niedrig, niemals $1 \mathrm{~m}$ hoch über den Boden und ist fast immer mit Pferdehaaren ausgelegt, fast immer ist der Innenrand des Napfes unter $8 \mathrm{~cm}$ breit (Bd. III, Tafel 46, Fig. 1-5)

Granammer, Miliaria calandra.

** Das Nest steht immer über $1 \mathrm{~m}$, ja, über $2 \mathrm{~m}$ hoch, oft hoch oben auf Bäumen.

$\div$ Das Nest besteht äußerlich stets ausschließlich aus trockenen Reisern und steht 2-11 m hoch; der Napf ist am oberen Innenrande $8-10 \mathrm{~cm}$ breit (Bd. III, Tafel 48, Fig. 18-22)

Kernbeiber, Coccothraustes coccothrumstes.

$\uparrow$ Das Nest besteht äußerlich stets vorwiegend aus Halmen, Queckenwurzeln, Stengeln usw. und ist oft mit Wolle, Haaren und Federn ausgelegt; es steht nie unter $3,5 \mathrm{~m}$.

$\times$ Der Napf des Nestes ist am oberen Innenrande $12-13 \mathrm{~cm}$ breit (Bd. IV, Tafel 49, Fig. 19-24)

Grober Wirger, Lanius excubitor.

$\times \times$ Der Napf des Nestes ist am oberen Innenrande $81 / 2-9^{1} / 2 \mathrm{~cm}$ breit (Bd. IV, Tafel 46, Fig. 5-12)

Graner Wiirger, Lanius minor.

BB) Das Nest ist kleiner und stets napfförmig; der obere Innenrand des Napfes ist höchstens $8 \mathrm{~cm}$ breit; die Eier sind höchstens $25 \mathrm{~mm}$ lang; stets einzelne Eier des Geleges unter $23 \mathrm{~mm}$.

a) Das Nest ist äußerlich a us trockenem Laub gebaut und steht kaum iiber dem Boden; die Eier sind fast einfarbig unrein blau bis kaffeebraun, selten deutlich gefleckt.

aa) Der Napf des Nestes ist am oberen Innenrande $6 \frac{1}{2} \mathrm{~cm}$ breit; das Nest besteht äußerlich aus Eichenlaub und steht an trockenen Orten.

a) Westliche Art (Bd. I, Tafel 31, Fig. 1-4)

Nachtigall, Erithreos luscinia. ß) Östliche Art. . . . . Sprosser, Erithacus philomela. bb) Der Napf des Nestes ist $5 \frac{1}{2} \mathrm{~cm}$ breit; das Nest steht meist im sumpfigen Weidengebüsch und besteht äußerlich aus Weidenlaub (Bd. I, Tafel 31, Fig. 15-17) . Batukhlehen, Erithrens ryaneculus.

b) Das Nest besteht äußerlich aus Halmen, Zweigen, Wurzeln oder Moos. aa) Das Nest steht entweder über dem Wasser, oder über morastigem Boden oder endlich im Weiden- und Erlengebüsch der Ufer. 
«) Die Eier sind auf reinweißem Grunde sehr fein schwärzlich bekritzelt, 15-19 mm lang (Bd. II, Tafel 27, Fig. 46_49)

\section{Bartmeise, Punums biamicus.}

ґ) Die Eier sind auf rötlich verwaschenem Grunde grob schwärzlich geflecht und geschnörkelt, 17-22 mm lang(Bd.II, Tafel46, Fig. 28-32)

Rohrammer, Emberiad schoeniclus.

$\gamma$ Die Eier sind dicht und fein gefleckt, höchstens mit einzelnen Kritzeln oder Schnörkèln versehen.

« $\alpha$ ) Das Nest hängt zwischen Halmen oder senkrechten Zweigen so daß der Boden frei ist. Die Nestbestandteile sind um die Halme und Zweige, welche das Nest tragen, gewickelt.

* Das Nest hängt über dem Wasser und ist an Schilfrohrhalmen befestigt.

$\div$ Der Napf des Nestes ist am oberen Innenrande $6 \frac{1}{2} \mathrm{~cm}$ breit, die Eier sind 20-26 mm lang, nur einzelne des Geleges unter $22 \mathrm{~mm}$ (Bd. II, Tafel 26, Fig. 19-23)

Drosselrohrsainger, Acrocephalus armandinaceus.

$\div$ Der Napf ist nicht über $5 \mathrm{~cm}$ breit; die Eier sind $16-20 \mathrm{~cm}$ lang (Bd. II, Tafel 26, Fig. 24 -27)

Teichohrsinger, Acrocephales streperus.

4. Das Nest steht nie iiber dem Wasser und ist seltener an Schilfrohr befestigt.

$\uparrow$ Die Eier sind auf blaugrünlichem Grunde mit z. T. großen dunklen Flecken versehen, $17-21 \mathrm{~mm}$ lang (Bd. II, Tafel 26, Fig. 15-18)

Sumpfrohrsåinger, Acrocephalus palustris.

$\rightarrow$ Die Eier sind sehr dicht und fein gefleckt, so daß die gelbliche Grundfarbe ganz verschwindet, 15-19 mm lang (Bd. II Tafel 26, Fig. 5-8) . Binsenrohrsinger, Calamodus aquaticus. $\because$ Die Eier sind auf rötlichweißem Grunde fein und weniger dicht gefleckt, so daß die Grundfarbe überall hervortritt, 18 -22 mm lang (Bd. II, Tafel 26, Fig. 13-14)

Flufrohrsiinger, Locustella fluviatilis.

$\beta \beta)$ Das Nest ist nicht hängend angebracht, der Boden ist immer gestützt; die Eier sind 16-20 mm lang.

* Das Nest besteht namentlich aus breiten Schilfblättern und steht meist auf umgebrochenem Schilf über dem Wasser (Bd. II, Tafel 26, Fig. 36-38) Weidenrohrsänger, Locustella luscinioides. * Das Nest besteht besonders aus feinerem Material (Bd. II, Tafel 26, Fig. 28-31)

Schilfrohrsiinger, Calnmorlus schoenobcrems. 
bb) Das Nest steht weder ïber dem Wasser noch äber morastigem Boden noch auch im Weiden- oder Erlengebüsch der Ufer.

๙ D) Die Eier sind einfarbig blau bis weißlich, selten mit einzelnen zerstreuten rötlichen Flecken versehen.

aus) Das Nest ist äußerlich besonders aus Moos, innerlich aus Haaren, Wolle und Federn gebaut: es steht in dichten Büschen; die Eier sind tiefblau 17-21 $\mathrm{mm}$ lang

Heckenbramelle, Accentor modularis.

$\beta \beta)$ Das Nest besteht äußerlich besonders aus Halmen und ist innen mit Haaren, selten mit Federn ausgelegt; es steht meist an und auf Baumästen; die Eier sind heller, selten blau, 15-19 mm lang

Schwargraner Fliegenfïinger, Muscicapa atricapilla.

$\beta$ ) Die Eier sind mehr oder weniger gefleckt oder beschnörkelt, die Flecke oft so dicht, daß die Eier grau erscheinen.

aı) Die Eier sind 12-14 mm lang, höchstens einzelne Eier des Geleges $14 \mathrm{~mm}$; das Nest ist fast kugelig, aber mit einem Eingang von oben versehen, äußerlich etwa $9-10 \mathrm{~cm}$ breit; es hängt an Nadelholzzweigen.

Die Eier sind mehr gelblich; häufige Art (Bd. II, Tafel 27, Fig. 39_42)

Goldhïhnchen, Regulus regulus.

** Die Eier sind mehr rötlich, südwestliche Art (Bd. II, Tafel 27, Fig. 35-38)

Fenerköpfiges Goldhihnchen, Reyntus ignicapillus.

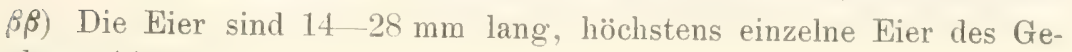
leges $14 \mathrm{~mm}$.

Das Nest steht meist auf einem dickeren Ast entweder in der Gabel eines Baumes oder auf einem starken Seitenaste nahe am Stamm oder auf dem Kopf einer Kopfiveide.

$\div$ Der Napf des Nestes ist am obern Innenrande über $7 \mathrm{~cm}$ breit und besteht oft äußerlich aus Reisern; die Eier sind $21-27 \mathrm{~mm}$ lang, höchstens einzelne Eier des Geleges unter 22 mm.

$\times$ Die Eier sind mit Schnörkeln und Flecken gezeichnet (Bd. III, Tafel 48, Fig. 18-22)

Kernbeilier, Coccothraustes coccothraustes.

$\times X$ Die Eier sind nur gefleckt, die Flecke oft zu einem Kranz vereinigt (Bd. IV, Tafel 48, Fig. 28--37)

\section{Rotköpfiger Wirger, Lanins senator.}

$\rightarrow$ Der Napf des Nestes ist $5-6^{1} / 2 \mathrm{~cm}$ breit; das Nest besteht nicht aus Reisern; die Eier sind $16-23 \mathrm{~mm}$ lang, aber höchstens einzelne des Geleges iiber $21 \mathrm{~mm}$. 
$\times$ Die Eier sind auf grünlichem Grunde verwaschen rot gefärbt oder mit verwaschen rötlichen Flecken versehen und außerdem dunkelbraun gefleckt, $17-23 \mathrm{~mm}$; das Nest ist äußerlich mit Flechten beklebt.

8 Überall häufige Art (Bd. III, Tafel 47, Fig- 1-8)

Buchfink, Foingillr coelebs.

S8 Nordische, bei uns selten brütende Art (Bd. III, Tafel 47, Fig.9-16) . . . Bergfink, Fringilla montifringilla. $\times \times$ Die Grundfarbe der Eier ist nicht verwaschen rötlich; die Eier sind nicht mit verwaschenrötlichen Flecken versehen.

8 Am spitzen Ende des Eies sind die Flecke sehr spärlich; die Flecke sind z. T. schwärzlich; die Eier sind $17-23 \mathrm{~mm}$ lang (Bd. III, Tafel 47, Fig. 17-21) Griuling, Chloris chloris. SS Die Eier sind überall dicht rötlich gefleckt, $16-21 \mathrm{~mm}$ lang. so Man findet das Nest in Buchenwäldern mit Unterholz; die Eier sind 16-17 mm lang (Bd. IV, Tafel 46, Fig. 35-36)

Kleiner Fliegenfänger, Muscicapa parva.

\& Man findet das Nest besonders in der Nähe menschlicher Wohnungen und neben Straßen; die Eier sind 16-21 mm lang; (Bd. IV, Tafel 46, Fig. 37-45)

\section{Gefleckter Fliegenfïinger, Muscicapa grisola.}

** Das Nest steht entweder im dichten Gezweig oder in einer dïnnen Gabel, nie auf dickeren Ästen.

$\dagger$ Das Nest steht nahe am Boden, selten bis $30 \mathrm{~cm}$ hoch im dichten Gezweig; die Eier sind 18-28 mm lang, auf rötlichweißem Grunde meist mit vielen Kritzeln oder Schnörkeln versehen.

$\times$ Die Eier sind 18-24 mm lang, höchstens einzelne Eier des Geleges über $22 \mathrm{~mm}$; der Napf des Nestes ist am obern Innenrande $5^{1} / 2-6^{1} / 2 \mathrm{~cm}$ breit.

Der Napf des Nestes ist oben $5 \frac{1}{2} \mathrm{~cm}$ breit; die Eier sind mit großen Flecken und wenig zahlreichen Schnörkeln versehen (Bd. III, Tafel 46, Fig. 16-20)

Gartenammer, Emberisa hortulana.

$\bigcirc \bigcirc$ Der Napf des Nestes ist $6^{1} / 2 \mathrm{~cm}$ breit; die Eier sind mehr mit Schnörkeln als mit großen Flecken versehen (Bd. III, Tafel 46, Fig. 6-11) . Goldammer, Emberisa citrinella. $\times \times$ Die Eier sind 21-28 mm lang, höchstens einzelne Eier des Geleges unter $23 \mathrm{~mm}$; auch das Nest ist größer (Bd. III, Tafel 46, Fig. 1-5) - Grauammer, Miliaria calandru. 
$\because$ Das Nest steht selten nur $30 \mathrm{~cm}$ hoch, meist viel höher; die Eier sind höchstens am einen Ende mit Schnörkeln versehen, dann aber auf bläulichweißer Grundfarbe.

$\times$ Die Eier sind auf dunkelrosafarbigem Grunde dunkelschwarzbraun gefleckt, 17-20 $\mathrm{mm}$ lang; das Nest steht $1-4 \mathrm{~m}$ hoch in der Gabel eines dornenlosen Strauches (Bd. II, Tafel 26, Fig. 32-35)

Spötter, Hypolais philomela.

$X \times$ Die Eier besitzen einen grünlichen, bläulichen, weißlichen oder sehr licht rötlichen Grund.

Die Eier sind zerstreut rötlich bis schwarzbraun gefleckt und zwar auf bläulichem oder schwach grünlichem, nie rötlichem Grunde.

S Die Eier sind 17-25 mm lang, höchstens einzelne Eier des Geleges unter $19 \mathrm{~mm}$.

(n) Die Grundfarbe der Eier ist ein lebhaftes Blaugriin; das stumpfere Ende ist mit kleinen schwärzlichen Flecken versehen; sie sind 19-22 mm lang (Bd. III, Tafel 48, Fig. 9-12)

Karmingimpel, Carpodacus erythrinus.

in Die Grundfarbe der Eier ist sehr hell.

! Das Nest steht, schon im Januar bis März, auf Nadelholzbäumen, meist $10 \mathrm{~m}$ hoch.

$\square$ Die Eier sind 20-24 mm lang (Bd. III, Tafel 48, Fig. 48-51)

Fichtenkreuzschmabel, Loxice curvirostro.

Die Eier sind $20-25 \mathrm{~mm}$ lang; das Nest dürfte kaum von dem der vorhergehenden Art zu unterscheiden sein (Bd. III, Tafel 48, Fig. 47 )

Kiefernkrenzschnabel, Loxir pityopsitturus.

!! Der Vogel brütet später im Jahr und das Nest steht entweder auf Sträuchern oder auf Laubholzbåumen, selten auf Nadelholzbäumen und dann meist weniger hoch.

$\square$ Die Grundfarbe der Eier ist kaum grünlich; man findet das Nest in der Ebene und zwar nicht in dichten Wäldern (Bd. II, Tafel 47, Fig. 17-21)

Grinling, Chloris chloris.

Die Grundfarbe der Eier ist deutlich grünlich; man findet das Nest in ausgedehnten Wäldern, namentlich im Gebirge (Bd. III, Tafel 48, Fig. 1-8)

Rotgimpel, Pym\%ula pym\%ula.

SS Die Eier sind 14-20 mm lang, höchstens einzelne Eier des Geleges über $18 \mathrm{~mm}$.

(n) Das Nest steht meist ïber $3 \mathrm{~m}$ hoch. 
: Das Nest steht gewöhnlich in Nadelholzwäldern auf Nadelholzbäumen, aber auch auf Erlen und enthält im Innern selten Pferdehaare (Bd. III, Tafel 47. Fig. 47-50)

Erlenzeisig, Chrysomitris spimus.

.. Das Nest steht meist auf Laubholzbäumen oder auf höheren Sträuchern in Laubholzwäldern, Obstgärten usw. und enthält im Innern fast immer Pferdehaare.

$\square$ Der Napf des Nestes ist am oberen Innenrande etwa $4^{1 / 2} \mathrm{~cm}$ breit (Bd. III, Tafel 47, Fig. 52-56)

Girlitz, Serinus serinus.

Der Napf des Nestes ist etwa $5^{1} / 2 \mathrm{~cm}$ breit (Bd. IU, Tafel 47, Fig. 42-46) Stieglitz, Carduelis carduelis.

of Das Nest steht meist in einem Strauch, selten bis $3 \mathrm{~m}$ hoch über dem Boden.

! Überall in Deutschland häufig (Bd. III, Tafel 47, Fig. 27-31)

Bluthänfling, Acanthis cannabina.

!! Nordische Art, die einzeln in Deutschland brüten soll (Bd. III,

Tafel 47, Fig. 37-41) Birkenzeisig, Acunthis linaria.

Die Eier sind entweder olivengriin bis olivenschwarz gefleckt oder rötlich gefleckt, dann aber auf rötlichem Grunde.

$S$ Die Eier sind so dicht matt gefleckt, daß sie einfarbig olivengrünlichgrau erscheinen; sie sind 19-23 mm lang; das Nest steht meist $1 / 2-1 \mathrm{~m}$ hoch in einem Dornbusch (Bd. II, Tafel 27, Fig. 1-4) . . . Sperbergrasmiicke, Sylvia nisoria.

SS Die Eier sind immer sehr deutlich gefleckt.

a D Der Napf des Nestes ist am oberen Innenrande $7-8 \mathrm{~cm}$ breit: die Eier sind $18-25 \mathrm{~mm}$ lang, immer nur einzelne Eier des Geleges unter $20 \mathrm{~mm}$; das Nest steht besonders in Dornbüschen.

! Das Nest steht meist tiefer, $2 / 3-21 / 2$ m über dem Boden; der Kopf des Vogels ist oben grau bis bräunlichgrau; die Flügel zeigen kein Weiß (Bd. IV, Tafel 48, Fig. 26-42)

Rotrickiger Wirger, Lanius collario.

!! Das Nest steht meist höher, 2-4 m über dem Boden; der Kopf des Vogels ist oben rot; die Flügel sind weiß gefleckt (Bd. IV, Tafel 49, Fig. 28-37)

Rotköpfiger Würger, Lamius senctor.

in Der Napf des Nestes ist $5-6 \frac{1}{2} \mathrm{~cm}$ breit; die Eier sind 16-22 mm lang, die Mehrzahl der Eier des Geleges ist unter $20 \mathrm{~mm}$ lang. 
: Die Eier sind, abgesehen von gröberen Flecken, sehr dicht mit feinen olivengrünen Spritzen bedeckt, $16-20 \mathrm{~mm}$ lang (Bd. II, Tafel 27, Fig. 25-29)

Dorngrasmiicke, Sylvia sylvia.

!! Die Eier sind nicht mit olivengrünen Spritzchen bedeckt.

Der Napf des Nestes ist am oberen Innenrande etwa $5 \mathrm{~cm}$ breit; das Nestmaterial ist mit vielen Gespinnstflocken verwebt; die Eier sind meist unter $17 \mathrm{~mm}$ lang (Bd. II, Tafel 27, Fig. 14-17)

Zaungrasmicke, Sylvia curveca.

Der Napf des Nestes ist etwa $6 \mathrm{~cm}$ breit, die Eier sind meist über $17 \mathrm{~mm}$ lang:

? Man findet das Nest im Walde und im Gebüsch (Bd. II, Tafel 27, Fig. 5-9)

Mönchgrasmicke, Sylvia rotricapilla.

?? Man findet das Nest besonders in Gärten und an Straßen (Bd. II, Tafel 27, Fig. 18-22)

tartengrasmiicke, Sylvia simplex.

II. Das Nest ist entweder mit einer künstlich hergestellten Decke versehen oder es befindet sich vollkommen in einer natürlichen oder künstlich hergestellten Höhle bezw. auf einem Vorsprung einer senkrechten Felswand oder endlich an einer steilen Böschung; als Standorte sind zu nennen: Häuser und andere Bauwerke, Felswände, Erdwälle, Steinmauern, Baumhöhlen, bisweilen auch der enge Spalt zwischen zwei Stämmen.

A) Die Eier sind einfarbig, weiß, blau, rötlichweiß oder hellgrau.

AA) Die 8-17 Eier des Geleges sind 57-73 mm lang.

a) Die Eier sind weiß, nur frisch mit einem schwach rötlichen Ton versehen, 64-69 mm lang; das Nest befindet sich fast immer in einer Erdhöhle, selten in einer Baumhöhle Fuchsente. Tadorna tadorma.

b) Die Eier sind gelblich bis graugrülich oder meergrün (vergl. oben S. 120).

aa) Die Eier sind schön meergrün, 57-66 mm lang; das Nest befindet sich (selten) in einem hohlen Baumstamm

Schellente, Fuligula clangula.

bb) Die Eier sind nicht rein meergrün, sondern gelblich oder graugrünlich mit gelblichem Ton.

a) Die Eier sind $63-73 \mathrm{~mm}$ lang, das Nest befindet sich (zuweilen) in einem hohlen Baumstamm

Gänsesïger, Meryus meryanser.

ß) Die Eier sind 60-71 mm lang; das Nest befindet sich (zuweilen) in einer kurzen Erdhöhle . . Mittlerer Säger, Mergus serrator. Dah 1, Buch zum Bestimmen der Vögel 
BB) Die Eier sind 15-52 $\mathrm{mm}$ lang.

a) Das Nest befindet sich in einer Erdhöhle von über $50 \mathrm{~cm}$ Länge; die Eier sind reinweiß.

aa) Die Eier sind länglich $15-20 \mathrm{~mm}$ lang, als Neststoffe werden Halme, Wurzeln und Haare in die Höhle getragen; die Nester stehen an Erdwänden kolonieweise nebeneinander

Uferschwalbe, Clivicola riparia.

bb) Die Eier sind fast kugelig, 21--27 mm lang, als Neststoffe sind nur Speisereste von Insekten oder Fischen vorhanden.

a) Der Vogel brütet in Kolonien; die Neststoffe sind Reste von Insekten; die Eier sind $24-27 \mathrm{~mm}$ lang

Bienenfresser, Herops apiaster.

ß) Der Vogel brütet einzeln; die Neststoffe sind Fischreste, die Eier sind 21-24 mm lang. . . . Eisvogel, Alcedo ispirla.

b) Das Nest ist ein kuinstlich geflochtener Beutel, der oben an der Seite seine Öffnung hat und an Schilf oder Bäumen, oft ïber dem Wasser, hängt; die Eier sind weiß, 15-18 mm lang

Beutelmeise, Remizus pendulinus.

c) Das Nest befindet sich in Baum- oder Mauerhöhlen, in Felsspalten, in Häusern oder in kurzen Erdhöhlen.

aa) Das Nest befindet sich in einer selbstgehauenen Baumhöhle und steht meistens über $4 \mathrm{~m}$ hoch; die Eier liegen auf Holzspänen und sind glänzend weiß.

a) Die Eier sind 27 - $35 \mathrm{~mm}$ lang.

a $x$ ) Das Gelege besteht aus 3-4 (selten aus 5) Eiern; die Eier sind $31-36 \mathrm{~mm}$ lang, stets sind einzelne Eier des Geleges über $33 \mathrm{~mm}$ lang. . . . . . Schwarzspecht, Dryocopus martius. $\beta \beta)$ Das Gelege besteht aus 5-8, selten bis 9 Eiern und die Eier sind $27-33 \mathrm{~mm}$ lang.

Das Gelege besteht aus 6-8, meist aus 7 Eiern und die Eier sind 29-33 mm lang . . . . . . Grinspecht, Picus viridis. ** Das Gelege besteht meistens aus 5-6 Eiern und die Eier sind 27-29 mm lang . . . . . Grauspecht, Picus cunus.

§) Die Eier sind 17-28 $\mathrm{mm}$ lang, stets einzelne Eier des Geleges unter $27 \mathrm{~mm}$.

$\boldsymbol{\alpha} \boldsymbol{\alpha})$ Die Eier sind 20-28 mm lang, stets einzelne Eier des Geleges über $22 \mathrm{~mm}$.

* Das Gelege besteht aus 3-5, selten aus 6 Eiern und die Eier sind 23-28 mm lang.

$\doteqdot$ Verbreitete Art, die besonders in Nadelholzwäldern brütet

Rotspecht, Dendrocopus majos. 
$\because$ Östliche Art, die in Laubholzbäumen nistet

Weilspecht, Dendrocopus lenconotus.

* Das Gelege besteht aus 5-6, selten aus 6-8 Eiern und die Eier sind 20-25 mm lang Mittelspecht, Dendrocopus medius. $\left.\beta \beta^{\prime}\right)$ Die Eier sind $17-20 \mathrm{~mm}$ lang

Kleinspecht, Dendrocopus minor.

bb) Die Nisthöhle ist nicht vom Vogel selbst ausgemeißelt; es liegen deshalb niemals Späne unter der Höhle am Boden und die Eier liegen nicht auf Spänen in der Höhle; oft steht das Nest in Häusern oder in Mauern. a) Die Eier sind $31-52 \mathrm{~mm}$ lang, stets einige im Nest über $32 \mathrm{~mm}$; das Nest besteht meist aus wenigen Neststoffen.

rerk) Das Gelege besteht aus 2 länglichen Eiern von 35-40 mm Länge; das Nest befindet sich in einer Baumhöhle und besteht aus wenigen dürren Zweigen . . . . . Hohltaube, Columba oenas.

$\beta \beta)$ Das Gelege besteht aus 3-6, selten aus 6-10 Eiern und das Nest besteht nicht aus Reisern.

* Die Eier sind 31-39 mm lang, höchstens einzelne Eier des Geleges iiber $36 \mathrm{~mm}$.

$\uparrow$ Das Nest besteht aus Halmen, Wurzeln, Haaren und Federn; die Eier sind $33-39 \mathrm{~mm}$ lang; das Nest steht in Baumhöhlen

Blauracke, Coracias garmula.

$\div$ Neststoffe fehlen fast gänzlich.

Das Nest steht besonders in Gebäuden und in Baumhöhlen der Feldhölzer; die Eier sind 33-36 mm lang

Steinkauz, Glaucidium noctur.

OC Das Nest steht besonders in Baumhöhlen der Nadelholzwälder, selten in Gebäuden; die Eier sind $31-37 \mathrm{~mm}$ lang

T'engmalmeule, Nyctala tengmalmi.

** Die Eier sind $37-52 \mathrm{~mm}$ lang, höchstens einzelne Eier des Geleges unter $38 \mathrm{~mm}$.

$\div$ Das Nest befindet sich stets in Gebäuden; die Eier sind $37-46 \mathrm{~mm}$ lang, höchstens einzelne Eier des Geleges über $43 \mathrm{~mm}$

Solnleiereule, Strix Hrmmer.

Das Nest steht selten in Gebäuden, fast immer in Baumhöhlen; die Eier sind 44-52 mm lang, höchstens einzelne Fier des Geleges unter $46 \mathrm{~mm}$.

Das Gelege besteht aus 3-5 Eiern

Waldkauz, Syrminm aluco.

$\bigcirc \bigcirc$ Das Gelege besteht meist aus 6-8 Eiern; das Nest wurde nur in Ostpreußen gefunden

sperbereule, Surnia ulula. 
§) Die Eier sind 16-32 $\mathrm{mm}$ lang, selten einzelne Eier des Geleges über $31 \mathrm{~mm}$; nur das langgestreckte Ei der Turmschwalbe wird bisweilen $36 \mathrm{~mm}$ lang.

arı) Die Eier sind mehr oder weniger blau gefärbt.

* Die Eier sind 20-32 mm lang, stets einige Eier des Geleges über $21 \mathrm{~mm}$.

$\uparrow$ Das Nest steht in einer Baumhöhle oder in Gebäuden; die Eier sind 27-32 mm lang . . . . Star, Sturnus vulgaris.

+ Das Nest findet man nur im Gebirge; es steht zwischen Steinen oder in Felshöhlen; die Eier sind $20-28 \mathrm{~mm}$ lang.

$\times$ Die Eier sind länglicher, bei $20-25 \mathrm{~mm}$ Länge nur $15-17 \mathrm{~mm}$ breit . . . . . Alpenbramelle, Accentor collaris.

$\times \times$ Die Eier sind rundlicher, bei 23-28 mm Länge 17-20 mm breit . . . . . . Steimmerle, Monticola saxatilis.

** Die Eier sind 15-22 $\mathrm{mm}$ lang; Eier von $22 \mathrm{~mm}$ sind aber äußerst selten.

† Die Eier sind 15-19 mm lang; das Nest steht in Baumhöhlen, oft iiber Hanneshöhe.

$\times$ Zum Nestbau werden nur Halme und andere Pflanzenteile verwendet; das Nest wird in Süddeutschland gefunden

Halsbandfliegentïinger, Muscicapa collaris.

$X \times$ Zum Nestbau werden außer Pflanzenteilen auch Federn, Wolle oder Haare verwendet; das Nest wird in ganz Deutschland gefunden

Schwarzoraner Fliegenfainger, Muscivapa atrircupilla.

$\doteqdot$ Die Eier sind 18-23 mm lang; das Nest steht in Steinmauern, Häusern, selten in sehr niedrigen Baumhöhlen.

$\times$ Die Eier sind schön blau gefärbt, 18-21 mm lang; das Nest ist stets mit vielen Federn getuittert

Gartenrotschwanz, Ruticilla phoenicums.

$\times \times$ Die Eier sind bläulich, $19-23 \mathrm{~mm}$ lang; das Nest enthält selten viele Federn; es wird oft auch im Gebirge gefunden.

Die Kehle des Vogels ist schwarz, der Schwanz rot

Hausrotschwanz, Ruticilla titys.

$\bigcirc$ Die Kehle des Vogel ist weiß, der Schwanz schwarz und weiß

Steinschmïtzer, Saxicolı oenanthe.

$\beta \beta)$ Die Eier sind gelblich oder graubräunlich gefärbt, 22-29 mm lang; das Nest steht in einer Baumhöhle (Bd. IV, Tafel 47, Fig. 33-36)

Wiedehopf', Upupa epops.

$\gamma \gamma)$ Die Eier sind rein weiß gefärbt. 
Das Nest ist aus Erde aufgemauert und bis auf ein kleines Flugloch rings geschlossen; die Eier sind 16-21 mm lang

Hansschwalbe, Chelidonarir urbica.

** Das Nest steht in vorgefundenen Höhlungen entweder in Häusern oder im Holzwerk oder in Steinmauern oder in Baumhöhlen.

$\uparrow$ Das Nest steht in einer Baumhöhle, es besteht aus wenigen Halmen; die 7-11 Eier des Geleges sind glänzend weiß, 18-22 mm lang . . . . . . . Wendehals, Jynx torquilla.

Das Nest steht selten in einer Baumhöhle, meist in Gebäuden, Steinmauern oder Holzwerk oder es ist mit künstlicher Decke versehen; das Gelege besteht aus 3-6, selten aus 7 Eiern.

$\times$ Die Eier sind $18-22 \mathrm{~mm}$ lang, das Nest steht meist in einem Mauerloch der Gebäude oder in einem Felsspalt

Hausrotschwanz, Ruticilla titys.

$\times \times$ Die Eier sind 24-28 mm lang; das Nest steht niedrig am Wasser, entweder in einer Mauer oder im Holzwerk oder zwischen Baumwurzeln und ist dann mit Neststoffen überdeckt

Wasseramsel, Cinclus cinclus.

$\times \times \times$ Die 3 Eier des Geleges sind lang gestreckt, 28-36 mm lang: das Nest steht hoch oben an Gebäuden, selten in einer Baumhöhle; es besteht aus wenigen, mit Speichel verkitteten, Stoffen

Turmselıwalbe, Apus cous.

B) Die Eier sind gefleckt, bisweilen so dicht, daß sie einfarbig dunkelgrau erscheinen, selten sind einzelne Eier des Geleges einfarbig weiß oder bläulich.

AA) Die Eier sind 57-90 mm lang; das Nest steht auf Felsen und entbehrt oft aller Neststoffe: das Gelege besteht aus 1-2 Eiern.

a) Das Nest steht auf einem Felsvorsprung der Gebirge und besteht aus Zweigen als Unterlage; das Gelege besteht aus 1-2 Eiern; diese sind rundlich, 71 -81 mm lang (Bd. V, Tafel 69, Fig 1-3)

Steinadler, Aquila chrysä̈tus.

b) Das Nest steht auf Felsvorsprüngen an der Meeresküste und entbehrt meist aller Neststoffe; wenigstens sind nie Zweige vorhanden; das Gelege besteht fast immer aus einem Ei.

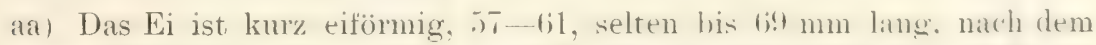
einen Ende him spitzer. mit blassen Flecken rersehen (Bd. MII. Tafel 2.2. Fig. 8-11

Iund, Fratercula arcica.

bb) Das Ei ist $69-80 \mathrm{~mm}$ lang, gestreckt, an einem Ende stark zugespitzt, mit dunklen Flecken und Schnörlkeln versehen (Bd. XII, Tafel 24, Fig. 1-11) . . . . . . Ismme. Livia Iomrir. 
BB) Die Eier sind 12-48 $\mathrm{mm}$ lang.

a) Die Eier sind $22-48 \mathrm{~mm}$ lang, höchstens einzelne Eier des Geleges unter $24 \mathrm{~mm}$.

aa) Die Eier sind fast kugelig, bei $36-44 \mathrm{~mm}$ Länge $26-30 \mathrm{~mm}$ breit, auf weißem Grunde dicht rostgelb bis schwarz gefleckt, selten ganz rostgelb (Bd. V, Tafel 65, Fig. 17--21)

Turmfalk, Tinmunculus timnunculus.

bb) Die Eier sind länglich, nicht rostgelb gefleckt.

a) Die Eier sind 30-42 mm lang, höchstens einzelne Eier des Geleges unter $32 \mathrm{~mm}$.

u $\iota$ ) Das Nest steht in Felshöhlen der Hochalpen; die Eier sind 36 bis $42 \mathrm{~mm}$ lang (Bd. IV, Tafel 47, Fig. 1-5)

Apendohle, Pymhocorax pyrhocorax.

$\beta \beta)$ Das Nest steht in hohen Gebäuden und in Baumhöhlen; die Eier sind 30-38 mm lang (Bd. IV, Tafel 48, Fig. 7-14)

Dohle, Lycus monedula.

$\gamma \gamma$ ) Das Nest steht frei im Gezweig eines Baumes oder eines sehr hohen Strauches, ist mit einem Dach von trockenen Zweigen überbaut und unten ausgemauert; die Eier sind $32-37 \mathrm{~mm}$ lang (Bd. IV, Tafel 48, Fig. 15-24) . . . . . . Elster, Pica pica.

ק) Die Eier sind 22-32 mm lang, höchstens einzelne Eier des Geleges sind über $31 \mathrm{~mm}$.

$\alpha(x)$ Die Eier liegen ohne Unterlage in einer Baumhöhle, sind grau oder graugelb gefärbt und 22-29 mm lang (Bd. IV, Tafel 47, Fig. 33 bis 36) . . . . . . . Wiedehopt, Upupr ерорs.

$\beta \beta)$ Das Nest steht an Erdwällen, Gartenzäunen usw.

* Die Eier sind dicht rötlich gefleckt, 24-32 mm lang (Bd. I, Tafel 32, Fig. 1-10) . . . . . . Ansel, Turdus memula. * Die Eier sind mit großen schwärzlichen Flecken und Schnörkeln versehen, 21-28 mm lang (Bd. III, Tafel 46, Fig. 1-5)

Grauammer, Miliaria calandra.

b) Die Eier sind 12-25 mm lang, höchstens einzelne Eier des Geleges über $23 \mathrm{~mm}$.

aa) Die Eier sind 12-18 mm lang.

a) Das Nest steht in einer Baumhöhle, seltener in einer Erdhöhle oder in einem Baumspalt und ist immer mit einer sehr engen Öffnung versehen.

$\boldsymbol{\alpha} \alpha)$ Als Neststoffe werden gewählt: äußerlich besonders Reiser, Halme und Baumbast, innen fast immer Federn, selten Haare; das Nest steht oft in Spalten der Gebäude, hinter abgespaltener Rinde usw.; 
die Eier sind 14-17 mm lang, fleischrot gefleckt (Bd. II, Tafel 28, Fig. 49-52) . . . . Baumliufer, Certhia fomiliaris. $\beta \beta)$ Als Neststoffe werden verwendet: äußerlich immer Halme und Moos, aber kein Bast, innen immer Tierhaare, seltener Federn; die Eier enthalten außer fleischroten Flecken graurötliche oder violette Flecke.

* Die Eier besitzen eine glänzende Schale; die Flecke sind fein.

* Man findet das Nest besonders in Nadelholzwäldern (Bd. II, Tafel 28, Fig. 57-60); der Kopf des Vogels ist oben schwarz

'Tannenmeise, Parus ater.

$\dagger$ Man findet das Nest mehr in Laubwäldern und Gärten (Bd. II, Tafel 28, Fig. 34-37); der Kopf des Vogels ist oben blau

Blaumeise, Parus roemuleus.

** Die Eier sind glanzlos.

$\div$ Man findet das Nest besonders in Nadelholzwäldern; die Eier sind gröber gefleckt (Bd. II, Tafel 27, Fig. 43-45); der Vogel ist mit einer Haube versehen. Haubenmeise, Pams cristatus.

$\rightarrow$ Man findet das Nest in Laubholzwäldern, Gärten usw.; die Eier sind weniger grob gefleckt; der Vogel besitzt keine Haube.

$\times$ Die Eier sind 16-20 mm lang (Bd. II, Tafel 28, Fig. 25-28); der Vogel ist an der Unterseite gelb

Kohlmeise, Parnes major.

$\times \times$ Die Eier sind 15-17 mm lang (Bd. II, Tafel 27, Fig. 54-57); der Vogel ist an der Bauchseite weißlich

Sumplimeise, Parus palustris.

ß) Das Nest steht entweder frei und ist dann mit künstlicher Decke versehen oder in einer sehr weiten Höhle.

$\boldsymbol{\alpha}(x)$ Das Nest befindet sich auf Bäumen oder Sträuchern wenigstens über $1 \mathrm{~m}$ hoch.

* Das Nest ist fast kugelig und im Durchmesser nur 9-10 cm breit; es hängt an Nadelholzzweigen, und der Eingang befindet sich oben; die Eier besitzen eine gelbliche oder rötliche Grundfarbe und sind $12-14 \mathrm{~mm}$ lang.

$\uparrow$ Die Eier sind mehr gelblich (Bd. II, Tafel 27, Fig. 39-42); häufige Art

Goldhïhnchen, Regulas regulus. $\multimap$ Die Eier sind mehr rötlich (Bd. II, Tafel 27, Fig. 35-38); südwestliche Art

Fenerköpliges Goldhĭhnchen, Regulus ignicapillus.

** Das Nest ist größer und oft höher als breit; die Lingangsöffnung befindet sich oben an der Seite: die Eier sind auf weißem Grunde rötlich gefleckt. 
$\uparrow$ Das Nest ist äußerlich mit Flechten beklebt, $16-19 \mathrm{~cm}$ hoch, $9-12 \mathrm{~cm}$ breit; die Eier sind 13-14 mm lang und meist sehr spärlich rot gefleckt (Bd. II, Tafel 28, Fig. 29-33)

Schwanzmeise, Aegithalus caudatus.

$\because$ Das Nest besteht äußerlich aus Zweigen und Halmen; es ist ein verlassenes Eichhörnchen- oder Elsternest: die Eier sind kleiner.

S Die Eier sind 16-20 mm lang (Bd. II, Tafel 28, Fig. 25-28); der Vogel besitzt keine Haube . Kohmeise, Pams major.

SS Die Eier sind durchschnittlich kaum über $16 \mathrm{~mm}$ lang, also kleiner (Bd. II, Tafel 27, Fig. 43-45); der Vogel besitzt eine Haube

Haubenmeise, Parus cristatus.

$\beta \beta)$ Das Nest steht entweder am Boden oder nahe iiber dem Boden, höchstens $1 \mathrm{~m}$ hoch.

* Das Nest besteht fast ausschließlich oder doch vorwiegend aus Moos und ist mit Haaren, Wolle und Federn gefüttert; die Eier sind 15-18 mm lang (Bd. II, Tafel 27, Fig. 30-34)

Zaunkinig, Anorthura troglodytes.

* Das Nest besteht nicht vorwiegend aus Moos.

$\doteqdot$ Das Nest ist nie mit Federn gefüttert.

$\times$ Die Eier sind 15-18 mm lang (Bd. II, Tafel 26, Fig. 44-47); häufige Art . Waldlaubvogel, Phylloscopus sibilator. $\times \times$ Die Eier sind 15-16 mm lang (Bd. II, Tafel 28, Fig. 9-11); suidliche Art . . Berglaubrogel, Phylloscopus bonelli.

$\pitchfork$ Das Nest ist stets mehr oder weniger mit Federn gefüttert; die Eier sind $14-16 \mathrm{~mm}$ lang.

$\times$ Die Eier sind rotgelb gefleckt (Bd. II, Tafel 26, Fig. 48-52)

Fitislaubyogel, Plylloscopms trochilus.

$\times \times$ Die Eier sind rotbraun und dunkelviolett gefleckt, namentlich am stumpfen Ende (Bd. II, Tafel 26, Fig. 39-43)

Weidenlaubvogel, Plylloscopus rufius.

bb) Die Eier sind 16-25 mm lang, stets mehrere Eier des Geleges iuber $18 \mathrm{~mm}$.

a) Das Nest steht in einer Baumhöhle mit enger Öffnung, in einem Mauerloch nur dann, wenn dieses eng von Bäumen umgeben ist, meist über Manneshöhe, steht es tiefer, so ist die Öffnung sehr eng; bisweilen ist dieselbe vom Vogel enger gemacht.

$\alpha \alpha)$ Die Eier sind rötlich gefleckt.

Die Eier sind 16-20 mm lang, stets die Mehrzahl des Geleges unter $19 \mathrm{~mm}$; die Öffnung der Nisthöhle wird sehr eng gewälılt, aber nicht durch Kleben enger gemacht (Bd. II, Tafel 28, Fig. 25-28)

Kohlmeise, Parus major. 
** Die Eier sind 17-23 mm lang, die Mehrzahl der Eier im Gelege $19 \mathrm{~mm}$ und darüber; die Öffnung der Höhle ist stets durch Vermauern mit Erde enger gemacht (Bd. II, Tafel 28, Fig. 38-42)

Kleiber, Sittr europaea.

$\beta \beta)$ Die Eier sind dunkelgrau bis schwärzlich gefleckt, oft so dicht, daß sie fast einfarbig dunkelgrau erscheinen.

* Die Mehrzahl der Eier des Geleges ist 18-20 mm lang; der Vogel ist iberall in Deutschland häufig (Bd.III, Tafel 48, Fig.33-42)

Feldsperling, Passer montrmus.

** Die Mehrzahl der Eier im Nest ist über $20 \mathrm{~mm}$ lang (20-23 $\mathrm{mm}$ ): der Vogel kommt bei uns fast nur im Rheingau und Saaltal vor (Bd. III. Tafel 48, Fig. 43-46

Steinsperling, Pusser petronicus.

ß) Das Nest steht in Erdwällen, Steinmauern, Gebäuden, Holzwerk, Felsspalten und in weiten Baumhöhlen; in letzteren besonders in geringer Höhe über den Erdboden.

$\boldsymbol{\alpha}(\boldsymbol{x})$ Das Nest steht im Innern der Gebäude und ist wenigstens am Rande aus Erde aufgemauert; die Eier sind 16-22 mm lang, dunkelrot gefleckt (Bd. IV, Tafel 46, Fig. 46-50)

\section{Rauchschwalbe, Hivmdo mstica.}

$\left.\beta \beta^{\circ}\right)$ Das Nest ist nicht aus Erde aufgemauert.

* Von den Eiern sind stets einige mehr oder weniger mit rötlichschwarzen Schnörkeln oder Kritzeln versehen: das Nest steht an einer steilen Böschung und zwar in einer sehr weiten Höhlung.

$\dagger$ die Eier sind 18-24 mm lang, höchstens einzelne des Geleges über $22 \mathrm{~mm}$ (Bd. III, Tafel 46, Fig. 6-11)

Goldammer, Emberiar citrinellu.

$\because$ Die Eier sind 21-28 mm lang, höchstens einzelne des Geleges unter $23 \mathrm{~mm}$ (Bd. III, Tafel 46, Fig. 1-5)

Granammer, Hiliariø calandra.

** Die Eier sind nicht mit Schnörkeln und Kritzeln sondern mit Flecken gezeichnet.

Die Eier sind rötlich oder gelbbräunlich gefleckt oft sehr dicht. $\rightarrow$ Die Eier sind auf weißem oder bläulichem Grunde sehr zerstreut rötlich oder gelbrötlich gefleckt, $19-23 \mathrm{~mm}$ lang; das Nest steht in Felsspalten der Gebirge, Steinmauern, Wänden von Gebäuden und Holzstößen.

$\times$ Die Grundfarbe der Eier ist mehr oder weniger bläulich: der Vogel ist iber ganz Deutschland verbreitet

steinschmainer. Soricola oenanthe. 
$\times \times$ Die Grundfarbe der Eier ist ein reines Wei13; der Vogel kommt in den Alpen vor (Bd. II, Tafel 28, Fig. 47)

Mauerklette, Tichodroma muraria.

Die Eier sind dichter gefleckt, wenigstens an einzelnen Stellen. $X$ Das Nest steht meist über Manneshöhe entweder frei oder im Mauerwerk der Gebäude oder in Baumhöhlen mit weiter Öffnung (Bd. IV, Tafel 46, Fig. 37-45)

Eliegenfïinger, NTuscicapa grisola.

$\times \times$ Das Nest steht sehr niedrig in Höhlungen an Erdwällen zwischen Baumwurzeln und in weiten Höhlen von Baumstümpfen (Bd. I, Tafel 31, Fig. 7-14)

Rotkehlchen, Erithucus mbeculus.

$X \times X$ Das Nest steht neben Gebirgsbächen im Holzwerk der Wassermühlen, in Erde-, Steinmauern usw. (Bd. III, Tafel 45, Fig. 30-34) . . Gebirgsstelze, Motacilla boajula.

OC Die Eier sind grau bis schwärzlich und olivengrünlich gefleckt.

$\div$ Das Nest enthält im Innern stets zahlreiche Federn: die Eier sind grob oder sehr dicht gefleckt; die Mehrzahl der Eier des Geleges ist über $21 \mathrm{~mm}$ lang.

$\times$ Das Nest steht unter dem Dach des Hauses, dem Rande der Storchnester, in Schwalbennestern oder frei im Gezweig und ist dann bis auf ein Flugloch geschlossen. Der Vogel ist überall gemein (Bd. III, Tafel 48 Fig. 23-32)

Haussperling, Pusser domesticus.

$X X$ Das Nest steht in Felsspalten oder in dem Gemäuer von Ruinen und wird bei uns nur am Rhein und an der Saale gefunden (Bd. III, Tafel 48, Fig. 43-46)

Steinsperling, Prsser petronicus.

+ Das Nest enthält keine Federn, sondern ist mit Haaren ausgelegt; die Eier sind fein und nicht sehr dicht gefleckt, so daß der weiße Grund stets hervortritt: die Mehrzahl der Eier des Geleges ist unter $21 \mathrm{~mm}$ lang (Bd. UI, Tafel 45, Fig. 20-24)

Bachstelze, Notacilla alba. 


\section{Register}

der lateinischen Gattungsnamen und der deutschen Namen. - Bei zusammengesetzten Namen wolle man, wenn man den Doppelnamen nicht findet, den Hauptnamen nachschlagen. Das Register hat namentlich den Zweck, das Auffinden des Nestes in der Tabelle zu erleichtern. Die Synonyme sind in der Ubersicht der Nester nicht alle wiederholt. Der Hinweis auf das Nest ist durch ein "n." gekennzeichnet.

Aasgeier 15, 81

Acanthis 7, 62, n. 144

Accento $)^{*}$ 10, 34, n. 123, 141, 148

Accipiter 17,80, n. 136

Acredula 48, n. 152

Acrocephalus $11,41 \mathrm{f} .$, n. 138,140

Actitis 94, n. 127, 129

Adler 15, 78 ff., n. 137, 149

Aegithalus 8, 48, n. 152

Agrobates 10, 47

Aix 25, 99

Alauda 5̄3, n. 133

Albatrosse 29, 113

Alea 30, 118

Alcedo 13,73, n. 146

Alken 20, 118

Alpenbraunelle 34,1 . 123,148

Alpendohle 66, n. 150

Alpenstrandlåufer 93, n. 129

Ammern 7, 57 ff., n. 131, 140, 142

Ampelis 10, 69

Amsel 38, n. 138, 150)

Anas 25, $100 \mathrm{f}, 121 \mathrm{f}$, n. 134

Anorthura 9, 47, n. 152

Anous 28, 107, 109

Anser 25, 98, n. 120

Anthus 5, 53, n. 133

Apes 13,70, n. 14!
Aquila $15,79 \mathrm{f}$, n. 137,149

Archibuteo 15,79, n. 136

Ardea 20, n. 122, 134

Ardeola 20, 85

Ardetta 20,85, n. 122

Arenaria 22,90, n. 130

Asio 14, 75, n. 122, 134

Astur 17, $80 \mathrm{f.g}$ n. 135

Athene 74

Attagen 106

Auerhahn 83, n. 126

Austernfischer 24, 91, n. 130

Arosettsäbler 91, n. 124, 130

Bachstelze 0ั5ั, n. 154

Bartgeier 14, 81

Bartmeise 10, 48, n. 132, 140

Bartramia 21, 94

Baumläufer 9, 51, n. 151

Baumlerche 52, n. 1:33

Baumpieper 53, n. 133

Bekassinen $96 \mathrm{f}$., 11. $128 \mathrm{f}$.

Bergfink 62, 11. 142

Beutelmeise 11, 48, 11. 146

Biblis 5, 69

Bienenfreseer 3, 13, 72, 1. 146

Birkeuzeisig 62, n. 144

Birklıuhn 83, n. 126 . 
Bläßhuhn s8, n. 126

Blaukehlchen 31, 11. 123, 131, 139

Blaumeise 49, n. 151

Blaumerle 36

Blauracke 13,73, n. 147

Bluthänfling 62 , n. 14

Bobolink 65

Bombycilla 69

Bonasa 18, 83, n. 12 5

Botaurus 20, 85, n. 122

Brachpieper 54, n. 133

Brachvögel 20,96, n. 130

Branta 2\%, 99

Braunelle 10, 34, ‥ 123, 141, 148

Brautente 25, 99

Bubo 15, 75, n. 135

Bubulcus 20, 85

Buchfink 58, 11. 142

Budytes 6, วั5, n. 132

Bulueria 27, 115

Buntspecht 72, n. 146

Bussarde 17, $78 \mathrm{f.g}$ 1. 136

Buteo 17, 79, n. 136

Caccabis 19, $83 \mathrm{f}$, n. 126

Calamodus 11, 41 f., n. 132, 140

Calamophilus 48, n. 132, 140

Calandrella 5, 52

Calcarius 7, 60

Calidris 23, 91

Cuprimulgus 13, $70 \mathrm{f}$., 12. 125

Carbo 106, n. 134

Carduelis 7, 57, n. 144

Carpodacus 7, 65, n. 14:3

Cepphus 30, 118

Certhia 9, 51, n. 151

Ceryle 13, 73

Cettia 9, 40

Chactura 13, 70

Chasadrius 24, 89, n. 128 f., 130

Chaulelasmus 100, n. 122

Chelidon 69, n. 149

Chelidonaria 4, 5, 69, 11. 149

Chen 25, 98

Chenalopex 25,98

Chersophilus 5

Chloris 7,61, n. $142 \mathrm{f}$.
Chrysomitris $7,61 \mathrm{ft} .$, n. 144

Ciconic 20, 86, n. 135

Cinclus 12, 47, n. 149

Civcaëtus 16,78, n. 135

Circus 17, 80 f., n. 122 f.

Cistensänger 9,48

Cisticola 9, 48

Clangula 26, 102, n. 134, 145

Clivicola 5, 70, n. 146

Coccothraustes 6,65, n. 139, 141

Coccystes 13, 74

Coccyzus 13, 74

Columba 17, 82, n. 135, 147

Colymbus 1, 27, 116, n, $119 \mathrm{f}$.

Coracias 13, 73, n. 147

Corves 8, $66 \mathrm{f}, \mathrm{n} .134,137$

Cotumix 18, 83, n. 125

Cotyle 70

Crex 22, 88, n. 126

Cuculus 13, 73

Cursorius 23,91

Cymmes 25, 97, n. 120

Cypselus 70, n. 149

Dafila 25, 100, n. 122

Daption 27, 115

Dendrocopus 13, 72, n. 146

Dendroeca 6, 57

Diamedea 29, 113

Distelfink oder -zeisig 5ั7, n. 144

Dohlen 8, 66, n. 134,150

Dolichonyx 6, 65

Dorngrasmiicke 44, n. 145

Dreizehmöve 29, 112

Drosseln 12, $36 \mathrm{ft}$., n. $138 \mathrm{f}$.

Diyocopus 13,71, n. 146

Disporus 106

Ectopistes 17, 83

Eichelhäher 8, 67, n. 137

Eiderenten 26, 104, n. 120

Eisente 27, 103

Eistaucher 117

Eisvögel 3, 13, 73, n. 146

Elanus 16,78

Elster 7, 67, n. 150

Emberiza 7, $58 \mathrm{tt.}$ ․ 131, 140, 142, 153 
Eniconetta 26. 104

Euten 25, 99, n. 120 fi., 134, 145

Evismatura 26, 104

Erithacus 12, 31 f., n. 123, 131, 139, 1 อั

Erlenzeisig 61, п. 144

Erytrospiza 7,65

Eulen $14 \mathrm{ff} ., 7 \mathrm{ff}$, 11. 122, $134 \mathrm{f}, 147$

Falco $16,75 \mathrm{ft} .$, n. 136

Falken 16, n. 136

Fasan 19, 84, n. 12:

Feldlerche 53, n. 133

Feldsperling 63, n. 153

Feldtauben $17,82,11.133,147$

Felsenschwalhe 69

Felstaube 82

Fichtengimpel 6,64

Finken $7,57 \mathrm{tt}$, n. 142

Fischadler 16, 78, и. 137

Fischreiher 85, n. 134

Fitislaubvogel 43, n. 152

Fliegenfänger 12, 31 ff., «. 141 f., 148, 154

Flughtihner 18,86

Flußarlier 78, 1. 137

Flußregenpfeifer 90, n. 129

Francolimes 19, 84

Fratercula 30,118, 1. 149

Fregata 2, 27, 29, 106

Fregattvogel 2, 27, 29, 106

Fringilla $7,57 \mathrm{ft}$, 11. 142

Fuchsente 99, ⒈ 145

Fulica 19,88, n. 126

Futigula $26 \mathrm{f}, 102 \mathrm{f}$, n. $120 \mathrm{f} ., 134,145$

Fulmains 27, 115

Gabelschwanzwöve 28, 112

Gabelweihe s. Milan

Gäuse 25, 98 f., n. 120

Gänsegeier 15,81

Galerida 5, 53, n. 133

Gallinago 23, 96 f., n. 128 f.

Gallimula 22, 88, n. 126

Gallus 19

Garizlus 8, 67, n. 137

Gartenammer 60, 11. 131, 142

Gartengrasmücke 45, и. 14.

Gartenrotschwanz 3:3, n. 148
Gartenspötter 42, n. 1-13

Garia 27, 117, 4. 127

Gebirgsitelze 5ั), n. $15 \mathrm{f}$

Geocichla 12, 366, 39 f.

Gerfalke 7 ; $\mathrm{f}$.

Geronticus: 20, s6

Giarol 21, 91

Gimpel 6, 65, n. 143

Gimpelammer 58, 64

Girlitz 7, 61, 6t, 21. 14

Glareola 21, 91

Glaucidinm 15, 74, n. 147

Gleitaar 16,78

Goldammer 58, n. 131, 142, 153

Goldhähnchen 12, $48,11.141,151$

Goldregenpfeifer 89, n. 128

Grasmücken 11, $44 \mathrm{ff} .$, n. $14+\mathrm{f}$.

Grauammer 63, ․ 131, 139, 142, 150, $15 \overline{3}$

Grauspecht 71, n. 146

Grünling 61, n. $142 \mathrm{f}$.

Grünspecht 71, n. 146

Grus 20, 87, 11.127

Giypaëtus 14, 81

Gyps $15, \mathrm{~S} 1$

Habicht 17, so f., n. 135

Häher \&, 67, n. 137

Haematopus 24, 91, n. 1:30

Hänfling 62, 1. 144

Halcyon 13, 73

Halicietus 16, 78, n. 135

Harelda 27, 103

Harportunchus 9, 40

Haselhuhn 18, 83, n. 125

Haubenlerche 53, n. 133

Haubenmeise 49 , n. 1 i $1 \mathrm{f}$.

Haushuhn 19

Hausrotschwanz 32, n. 149

Hausschwalbe 69, n. 149

Haussperling 63, n. 154

Heckenbraunelle 34, n. 141

Heckensänger 10, 47

Heidelerche 52, ․ 133

Heringsmöve 110

Herodias 20, \&-1

Heuschreckensänger 11, 40 f., n. 132

Himantopus 24, 91, 1. 12:3 
Hirundo 5, n. 153

Histrionicus 26, 103

Hohltaube 82, n. 147

Hopfe $3,13,73$, n. 148,150

Houbara 24, 87

Hühner $4,17,83$

Hühnerhabicht 80, n. 135

Hydrochelidon 27, 106 f., n. 123, 134

Hifpolais 11, 42 f., 11. 143

Jymx: 13, 72, n. 149

Käuzchen 74, N. 147

Kalanderlerche 52

Kampthahn 94, n. 128

Kampfläufer 21, 94, n. 128

Kaptaube 115

Karmingimpel 7, 65, n. 143

Kauze 15, 74 f., n. 147

Katzenvogel 36

Kerubeißer 6, 65, n. 139, 141

Kiebitz 21, 89, n. 128

Kiebitzregenpfeifer 21, 89

Kleiber 81, n. 153

Kleinspecht 72, n. 147

Klettervögel 2, 13, 71

Kohlmeise 49, n. $151 \mathrm{f}$.

Kolkrabe 66, n. 137

Kornweihe 81, ‥ 123, 125

Kormoranscharbe 106, n. 134

Krabbentaucher 20, 117

Krähen 8, 67, n. 137

Kragenente 26, 10:3

Kraniche 20, 87, n. 127

Kreuzschnabel 7,63 , ‥ 143

Kuckucke 2, 5, 13, 73

Kuhreiher 85

Kuttengeier 16, 82

Lachmöve 111, n. 124

Lachtaube 82

Layopus 18, 83, n. 126

Lanius 8, 10, 67 f., n. 139, 141, 144

Lappentaucher 1, 27, 116, n. 119 f.

Larus 28, 109 ff., n. 124

Laubvögel 9, 11, 42 ff., n. 152

Laufhühnchen 18,84

Lerchen 4, 5, 51 ff., n. 133
Lerchenfalke 76, м. 136

Limicola 23, 92

Limosa 21, 96, n. 127

Locustella 11, 40 f., n. 132, 140

Löffelente 25, 102. 11. 121

Lïffeleiner 86

Löffler 20,86

Loxia 7,63, n. 143

Lullula 5, 52, 11. 133

Lummen 20, 118, n. 149

Lund 20, 118, n. 149

Lusciniola 9, 40

Lycus 8, 66, n. 134, 150

Machetes 94, n. 128

Macrorhamphus 21, 96

Miiusebussard 79, n. 136

Mandarinenente 25, 99

Hantelmöve 110

Mroveca 100

Mauerläufer 12, 51, n. 154

Meerschwalben $107 \mathrm{ff}$., n. $123 \mathrm{f}$.

Meisen 9, $48 \mathrm{ff}$, n. $151 \mathrm{f}$.

Melanocoryphe $5,51 \mathrm{f}$.

Meleagris 19, 84

Merqulus 30, 117

Mergus 25, 104 f., n. 120, 134, 145

Merle 36, n. 123,148

Nerlinfalke 76

Meroys 13, 72, 1. 146

Milan 17, 77 f., n. 136

Miliaria 7, 63, ․ 131, 139, 142, 150, 153

Mitvus 17, 77 f., n. 136

Mimus 12, 36

Misteldrossel 39 , n. 138

Mittelspecht 72, n. 147

Mönch 45, ‥ 145

Mönchsgeier 82

Mönchskranich 20, 85, 87

IIöven 28, $109 \mathrm{ff}$., n. $124 \mathrm{f}$.

Molothmes 7, 63

Monticola 12, 36, n. 148

Motacilla 6, 55, n. 154

Müllerchen 46, n. 145

Iruscicapa 12, 31 ff., n. 141 f., 148, 154

Nachtigall 32, n. 131, 139

Nachtreiher 85, n. 134 
Nachtschwalben 4, 13, 70 f., x. 125

Natternadler 16,78

Nebelkrähe 67, n. 137

Nemura 12, 34

Neopleron 15, 81

Nettr 102

Noldi 28, 107, 109

Nucifrayu 8, 67, n. 137

Tumenius 20,96, n. 130

Tumida 19

Syctala 15,75, n. 147

Nycten 15,74

Nycticorax 20, 85, n. 134

Iyyroce 103, n. 121

Oceunites 27, 114

Oecenodroma 27

Oedemia 26, 104

Oerlienemus 24, 91, n. 130

Ohreulen 14, 75, 1. 122, 134

Oidemia 26, 104

Oriolus 7,66, n. 138

Ortolan 60

Ortygometra 22, 88, n. 126

Ossifraga 27, 114

Otis 24, 87, 11. 127, 130

Otocorys 5, 52

Otues 75, n. 122, 134

Pagophila 28, 111

Pandion 16, 78, n. 137

Panumus 10, 48, n. 132, 140

Papageialk 20, 118

Parus 9, $48 \mathrm{ff}$, n. $151 \mathrm{f}$.

l'asser 7, 59, 63, n. $153 \mathrm{f}$.

Pastor 11, 65

Pavo 19

I'elagodroma 27, 114

Pelecanus 29, 105

Pelikane 29, 105

Perdix 18, 83, n. 122

Perisoreus 8,67

Perlhuhn 19

I'ernis 16,78, n. 136

Pfau 19

Pfuhlsclmepfe 96, n. 127

Ihaéton 29, 106
Phatacrocorax 29, 106, n. 134

Phalaropus 1, 19, 91

Phuleris 30, 118

Phesianus 19, 84, и. 122

Philomachus 21, 94, n. 128

Phyllopmenste 42, n. 152

Phylloscopus. 9, 11, 42 ff., n. 152

Pica 7,67, 1. 150

P'icoides 13, 71

Picus 13, 71, n. 146

Pieper 5, 53, n. 133

Pinicole 6), 64

Pirol 7, 66, n. 138

Pisorkina 15, 75

Platalea 20, 86

Plectrophena: $7,5 \bar{T}$

Pleyadis 20,86

Polartaucher 117, n. 127

Porphyrio 22, 88

Pratincola 12, 31 ff., ‥ 123, 132

P'rocellaria 27,114

I'terocles 18,86

Puftinus 27, $115 \mathrm{f}$.

Purpurreiher 85, n. 122

Pycnonotus 12

Pynthocorax 8, 12, 66, n. 150

Pyrvinula 6, (65, n. 143

Querquedula 101, n. 122

Raben 66, п. 137

Rabenkrähe 67, ‥ 138

Racken 4, 13, 73, n. 147

Ralle 22, 88, n. 125, 127

Rallus 22, 88, n. 125, 127

Raubmöven 28, $112 \mathrm{f}$.

Raubvögel 2, 14, 74

Rauchschwalbe 69, n, 153

Rauhfußbussard 15, 79, 11. 136

Recurvirostra 1, 20, 91, n. 124, 130

Rebhuhn 18, 83, n. 122

Regenpfeifer 24, 89, n. 128 f., 130

Requelus 12,48, n. 141,151

Reiher 20, n. 122, 134

Reisvogel 6, 65

Remizus 11, 48, 1. $146^{\circ}$

Rennvogel 23, 91

- Rephuhn 18, 8:3, 11. 122 
Rhodostethia 28, 112

Ringdrossel 39, n. 138

Ringeltaube 82, n. 13is

Rissa 29, 112

Rötelfalke $i f$

Rötling 32 f., n. 148 f.

Rohrammer 59, n. 131, 140

Rohrdommel 85, 11. 122

Rohrsïnger 11, 41 f., n. 132, 138, 140

Rohrspatz 41, n. 138, 140

Rohrweihe 81, n. 122

Rosenmöve 28, 112

Rosenstar 11, 6i

Rotdrossel 38, n. 138

Rotkehlchen 32, n. 154

Rotschwanz 12, 32 f., n. 148 f.

Rotspecht 72 , n. 146

Ruderente 26, 104

Ruticilla 12, 32 f., n. 148 f.

Saatgans 98

Saatkrähe 67, n. 134

Sübler 1, 20, 91, n. 12t, 130

Säger 25, $10+$ f., n. 120, 134, 145

Sänger 12

Sanderling 23, 91

Saxicola 12, 34 f., n. 148, 153

Schafstelze 56, n. 132

Scharben 29, 106, n. 134

Scheckente 26, 104

Schellenten 26, 102, n. 120, 134, 145

Schlangenadler 78, ‥ 135

Schleiereule 14, 74, n. 147

Schneeammer 57

Schneeeule 74

Schneefink 57

Schneegans 98

Schneehüher 18,83, n. 126

Schnepfe 3, 23, 97, n. 127

Schopfreiher 85

Schreiadler 80, n. 137

Schrvalben 3, 4, 5, 13, 69, n. 149, 153

Schwan 25,97, n. 120

Schwanzmeise 8, 48, n. 152

Schwarzdrossel 38, n. 138

Schwarzenten 26, 104

Schwarzkehlchen 33, n. 132
Schwarzspecht 71, n. 146

Schwimmvögel 1, 2, 24, 97

Scolopax 3, 23, 97, 1. 127

Seeadler 16,78, n. 135

Seeschwalben 28, $107 \mathrm{ff}$., n. $123 \mathrm{f}$.

Seetaucher 27, 117, n. 127

Segler 4, 13, 70, 1. 149

Seidenschwanz 10,69

Scrimus $7,61,64, \mathrm{n} .144$

Sichler 20, 86

Silbermöve 110, n. 125

Silherreiher 84

Singdrossel 37 f., n. 138

Singvögel 5, 31

Sitta 10, 50 f., n. 153

Somateria 26, 104, n. 120

Spatula 25, 102, n. 121

Spatz 63, n. 154

Spechte 13, $71 \mathrm{f}$, n. $146 \mathrm{f}$.

Spechtmeise 10, 51, n. 153

Sperber 17, 80, n. 136

Sperbereule 7t, n. 147

Sperbergrasmücke 45, ․ 144

Sperlinge 7 , n. $153 \mathrm{f}$.

Spötter 42, n. 143

Spornammer 60

Spottdrossel 9, 40

Sprosser 32, n. 131, 139

Stare 11,66, n. 148

Steinadler 79, n. 137,149

Steinhühner 19,83, n. 126

Steinkauz 74, n. 147

Steinmerle 36, n. 123, 148

Steinschmätzer 12, 34 f., n. 148, 153

Steiusperling 59 , n. $153 \mathrm{f}$.

Steinwälzer 29,90, n. 130

Steißfuß 116, n. 119 f.

Stelzen 6,55

Stelzenläufer 24, 91, n. 123

Stelzvögel $1,3,19,84$

Steppenhuhn 18, 86, n. 131

Steppenweihe 81, 125

Stercorarius 28, $112 \mathrm{f}$.

Stema 28, 107 ff., n. 123 f.

Stieglitz 57, n. 144

Stockente 100, n. 134

Störche 20,86, n. 135 
Strandliufer 22 f., 92 f., n. 129

Strandreuter 91, n. 12:3

Strepsilas 90, n. 130

Strix 14, 74, n. 147

Sturmmöve 112, n. 125

Sturmschwalbe 114

Sturmvögel 27, 114

sturmes 11, 6.5 f., n. 148

Sula 29, 106;

Sultanshuhn 22, 88

Sumpfhuhn 22, 88, n. $126 \mathrm{f}$.

Sumpfläufer 23, 92

Sumpfmeise 49, 11. 151

Sumptohreule 75, n. 122

Sumpfschnepfen 23,96 f., n. 128 t.

Survia 15, 74, 10. 147

Sylria 11, $44 \mathrm{ft} .$, n. $144 \mathrm{f}$.

Symium 15, 75, n. 147

Symphaptes 18,86, n. 131

Tacligpetes 106

'lagschlaifer 70, 12. 125

Tadoina 25, 99, 11. 14i

'Jannenhäher 8, 67, 1. 1:37

I'anmenmeise 49, n. 151

'Tauben 4, 17, 82, 口. 133, 147

'T'auchenten 27, $102 \mathrm{f}$., n. $120 \mathrm{f}$.

'Taucher $116 \mathrm{f}$, n. $119 \mathrm{f.g} 127$

'l'eichhuhn 22, \&8, 11. 126;

'T'eiste 20, 118

Terelice 21, $94 \mathrm{f}$.

Tetrao 18, 83, 3. 126

Thalassirlmama 114

Thalassogeron 29, 113

Tichodrome 12, 51, n. 154

Timmenculus $75 \mathrm{f}$, 11. 1365, 150)

Tölpel 29, 106;

T'̈̈lpelseeschwalbe 109

Totumes 21, 23, 9+ f., 4. 127 f., 1:37

'Trappen 24, 87, n. 127, 130

'Traucrseeschwalben 27, $106 \mathrm{f}$., n. 1283,134

'iriel 24, 91, n. 1:30

Trinya 22 f., 92 f., 11. 129

T'vingoides 21, 44, 11. 127, 129)

Troglodytes 47, n. 152

'Iropikvogel 29, 106 ;

'Truthalm 19, 84

1) ahl, buch gum liestimuen der Vügel
Trynuites 2:3, 92

Turdus 12, $36 \mathrm{fl} .$, n. $138 \mathrm{f} ., 150$

T'urmfalke 76, n. 136,150

Turmschwalbe 70, 11. 149

Tumix 18, 84

Turteltauben 17, 82, n. 135

Turtur 17, 82, 11. 135

Uferliufer 21, 94, 1. 12т, 129

Uferschnepfen 21, 95 f., n. 127

Uferschwalbe $70,11.146$

Uhu 15, 75, n. 135

Unglïckshäher 8,67

Upupa 13, 73, n. 148, 150

Iria 30,118, n. 149

Urimator 117, n. 127

ITanellus 21, 89, n. 128

Vulpanser. 99, 12. 145

Vultur 16, 82

Wacholderdrossel 39, n. 139

Wachtel 18, 83, n. 125

Wachtelkönig 22, 88, n. 126;

Waldkauz 75, 11. 147

Waldhülıner 18, 83

Walclaubvogel 42, n. 152

Waldohreule 75, 11. 134

Waldrapp 86

Waldsänger 6,57

Waldschnepfe 3, 233, 97, ו. 127

IVanderlrossel 3s

Wanderfalke 77, n. 1:36

Wandertaube 17, 8;

Wasseramsel 12, 47, 11. 149

Wasserhuhn 19, 88, n. 126

Wasserläufer 21, 9+ f., n. 127, 1:37

Wasserpieper 5.t, n. 13:3

Wasserralle \&s, n. 125, 127

Wasserstar +7, 1.14 !

Wassertreter 1, 19, 91

Wridenlaubrogel $43, \mathrm{n} .152$

Weihen 17, $80 \mathrm{f}$, , 11. 12\% f, 125

Weindrossel :38, n. 138

Wendehals $13,72,11.149$

IVespenbussard 16,78, n. 136 ;

Wiedehopf 1:3, 7is, 11. 148, 150

IViesenpieper 54, 12. 1:3;3 
Wiesenschmätzer $12,31,33$, n. 12:3, 132 WViesenweihe 81, n. 12;

Würger $8,10,67 \mathrm{f} ., 11.139,141,14 \mathrm{t}$

I'ma 28,112

Zaunammer 5s
Zaungrasmücke 46, n. 145

Zaunkönig 9, 47, n. 152

Zeisig 61 ft., n. $1+4$

Ziegenmelker 71, n. 125

Zwergohreule 15, 75

Zwergtrappe 87, n. 130

\section{Berichtigungen:}

S. 5 Z. 14 v. oben und

S. 51 Z. 11 v. unten ergänze man ,Alauda".

S. $81 \mathrm{Z} .4 \mathrm{v}$. oben ändere man ..Astus" in . Astur".

S. 94 Z. 1 v. oben ergänze man ".Paroncella" als Synonym, ebenso im Register. 
Verlag von Gebrüder Borntraeger in Berlin W 35 Schöneberger Ufer 12 a

Handbuch der systematischen Botanik rou Prof. Dr. Eug. Warming. Deutsche Ausgabe. Dritte Auflage ron Prof. Dr. M. Möbius, Direktor des Botanischen Gartens in Frankfurt ¿. 11. Mit 616 'Textabb. und einer lithogr. T'afel. Gebunden $10 \mathrm{Mk}$.

Botanisches mikroskopisches Praktikum tiiı tnfïngi ron Prof. Dr. M. Möbius. Zweite verïnderte Auflage. Mit $15 \mathrm{Ab}$ bildungen. Gebunden 3 IIk. 20) Pfo.

Hilfsbuch für das Sammeln parasitischer Pilze mit Bir.ïrisichtioung der Nährpflamzen Deutschlands, Österreich-Ungan'ns, Belgiens, der Schreiz mol der Niederlande nebst einem Anhang iiber die 'Tierparasiten ron Prof. Dr. Gustav Lindau, Kustos am Königlichen Botanischen IIusem und Privatdozent der Botanik an der Universitït Berlin. Gebunden I Mk. 7o Pfo.

Hilfsbuch für das Sammeln der Ascomyceten mit $B+r i u k$ sichtigung der Nährpflanzen Deutschlands, Österreich-Ungarns, Belgiens, der Schweiz und der Niederlande vou Prof. Dr. Gustav Lindau, Kustos am Königlichen Botanischen Museum und Privatdozent der Botanik an der Universität Berlin. Geb. 3 Mk. 40 Pfo.

Hilfsbuch für das Sammeln und Präparieren der niederen

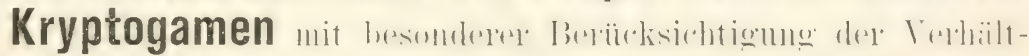
misse in den Tropen von Prof. Dr. Gustav Lindau. Geb. 1 Ifk. 5n P'p.

\section{Hilfsbuch für das Sammeln der Zoocecidien mit Brrutiki-}

sichtigung der Xährpflanzen Europas und des Vittehmeergehietes yon G. Darboux, Professor der \%oologie an der Universität Lyon und C. Houard, Assistent am botanischen Institut der Unirersitiit Paris. Gebunden 2 Mlk.

\section{Botanischer Führer durch Norddeutschland}

Berïcksichtigung der östlichen Hïlfte). Hilfsbuch zmu Erkennen der in den einzelnen Vegetations-Formationen wildwachsenden Pflanzenarten zum Gebranch anf Exkursionen von Prof. Dr. Paul Graebner, Kustos am Kgl. Botanischen Garten zu Dahlem. Gebunden $4 \mathrm{Mk}$.

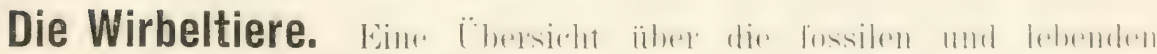
Formen von Dr. 0tto Jaekel. Professor an der L'niversität Greifswald. Nlit 281 'Textabbildungen. In Leinen gebunden $120.1 \mathrm{k}$

Ausführliche Verlagsverzeichnisse kostenfrei 
Verlagvon Gebrüder Borntraeger in Berlin W 35 Schöneberger Ufer 12 a

\section{Bibliothek für naturwissenschaftliche Praxis, lerrallis-} gegeben von $\mathrm{Dr}$. W. Wächter.

Band I: Praxis der Linsenoptik in einfachen Versuchen zur E1lïuterung und Prüfung optischer Instrumente von Dr. Wilhelm Volkmann. Vit 36 'Textabbildungen und 4 Tafeln. Taschenbuchformat. Gebunden $3 \mathrm{ML}$. $50 \mathrm{Pfg}$.

I3ind 1I: Anleitung zum praktischen Studium niederer Tiere (P'r)tozoa, Coelenterata, Vermes, Echinodermata) von Dr. W. S'chleip, Privatdozenten an der Unirersität Freiburo i. Br. Mit 36 'Textabbildungen. Gebunden 3 Mlk. 50 Pfg.

Band III: Die praktische Bodenuntersuchung. Eine Anleitung zul Lntersuchung, Beurteilung und Verbesserung der Böden mit besonderer Rücksicht auf die Bodenarten Norddeutschlands ron Professor E. Heine. Mit 25 Textabbildungen und einer geologischagronomischen Karte. Gebunden 3 Mk. 50 Pfg.

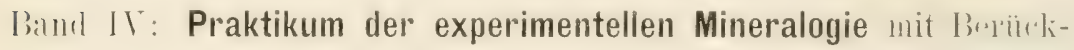
sichtigung der kristallographischen und chemischen Grenzgebiete ron 1)r. Einst Sommerfeldt. Professor' an der 'Technischen Hochschule zu Aachen. Wit 61 Textabbildungen und einer T'afel. Gebunden 4 Mlk. $80 \mathrm{Pfg}$.

[3:ind I: Anleitung zur mikroskopischen Untersuchung von Pflanzenfasern ron Dr. G. Tobler- Trolff und Prof. Dr. F'. 'Tobler. Wit 125 Textabbildungen. Gebunden 3 $15 \mathrm{k}$. on $\mathrm{Pfg}$.

Grundprobleme der Naturwissenschaft. Biriefe eines unmodernen Naturforschers von Dr. Adolf Wagner. Gebunden 5 Mk.

\section{Die Gefährdung der Naturdenkmäler und Vorschläge zu

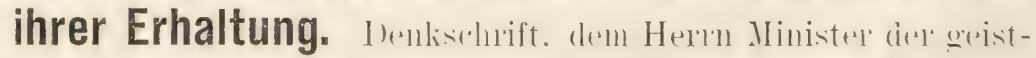
lichen, Unterrichts- und Medizinalangelegenheiten ïberreicht rom Geh. Regierungsrat Prof. Dr. H. Conwentz. Yirrte Auflige. Gebunden 2 IIk. $20 \mathrm{Pfg}$.

Ausführliche Verlagsverzeichnisse kostenfrei 


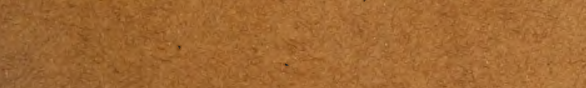

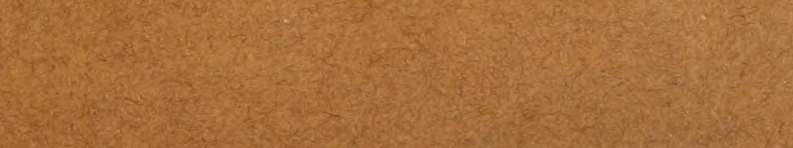

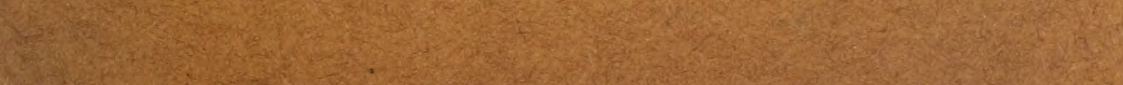

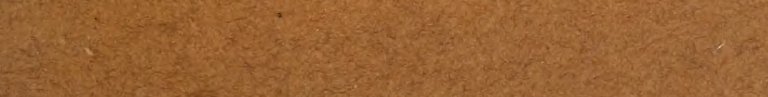

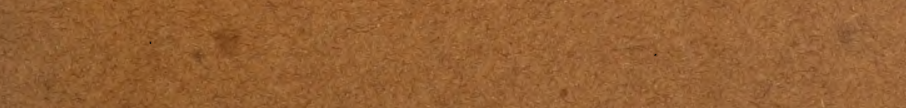

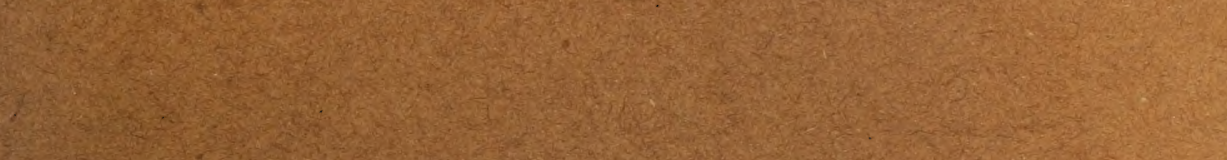

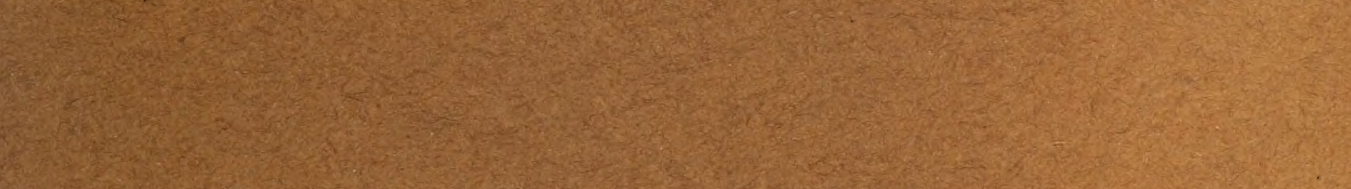

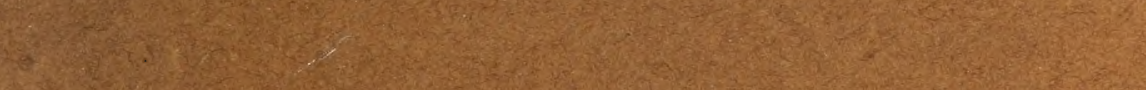




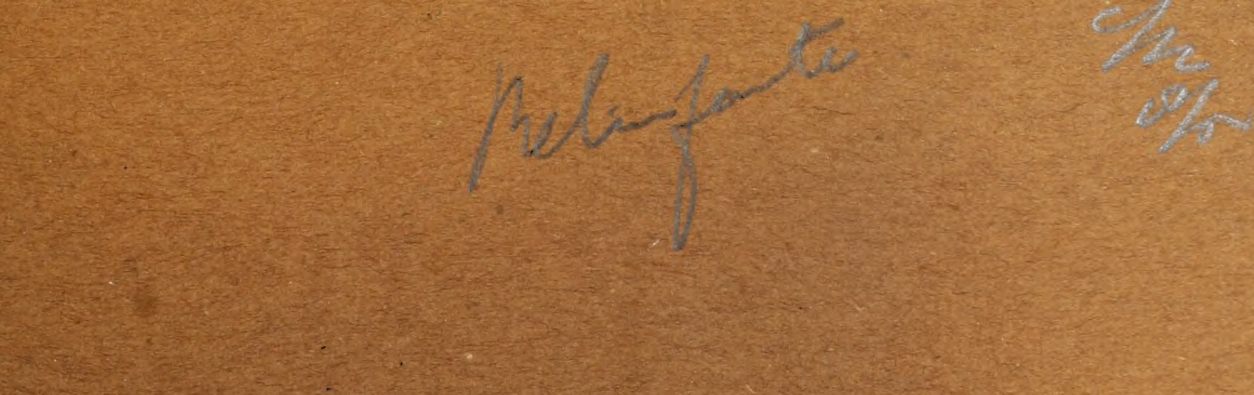

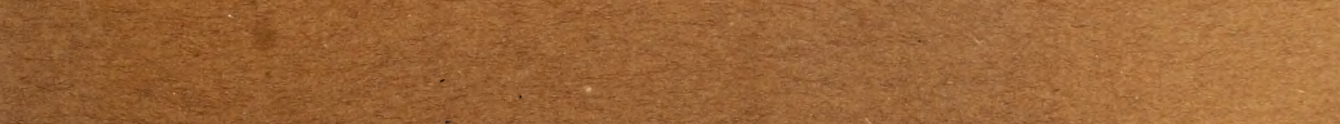

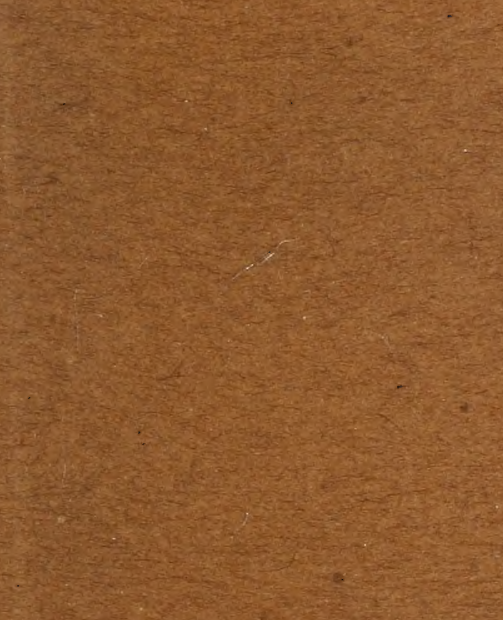
3

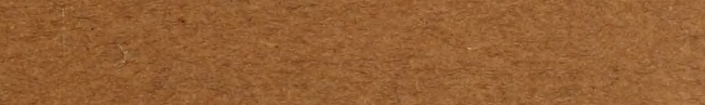

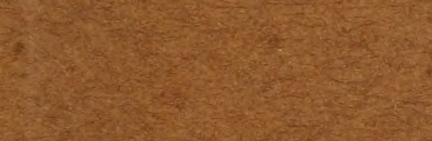

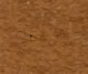
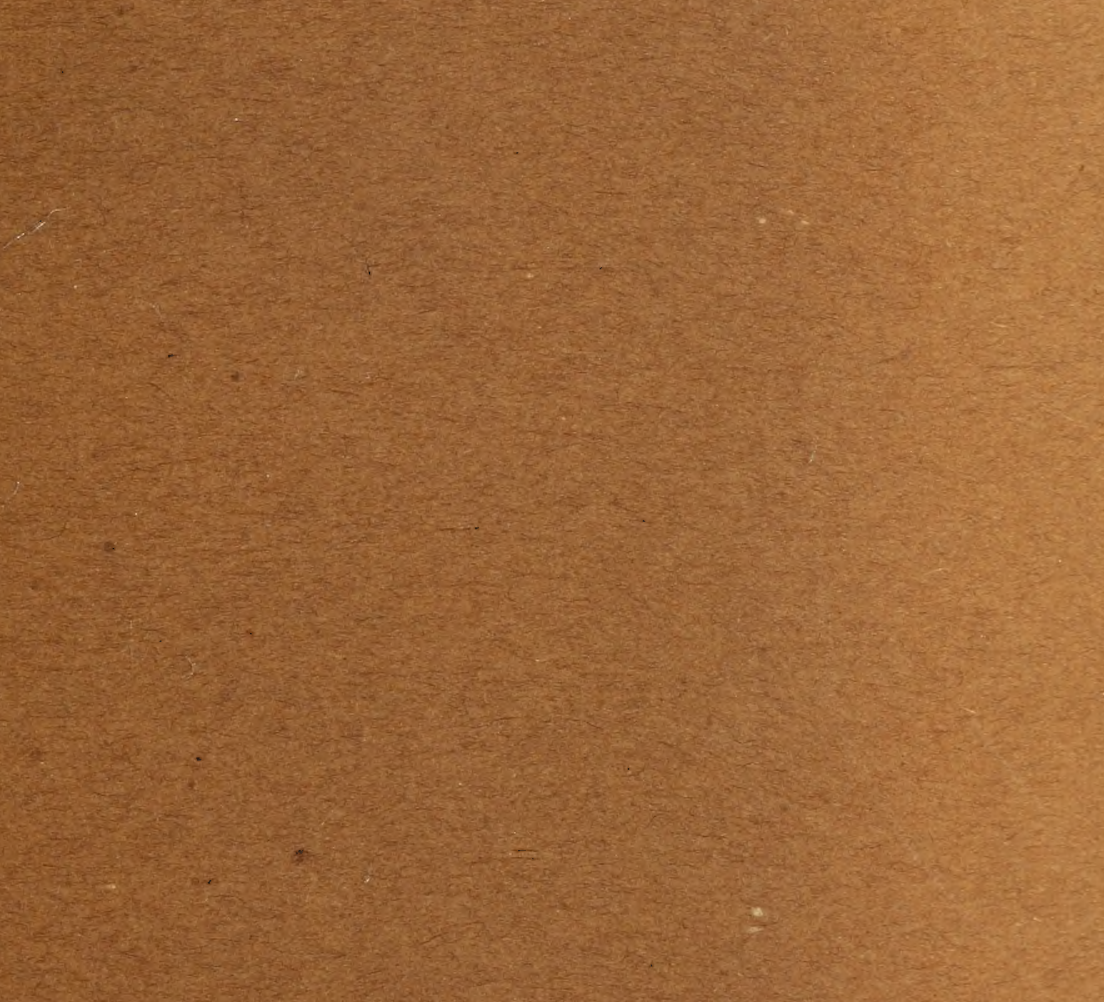

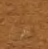

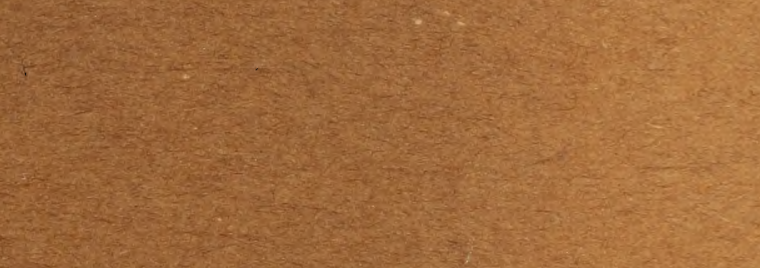

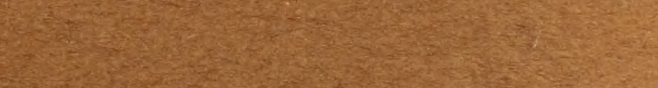

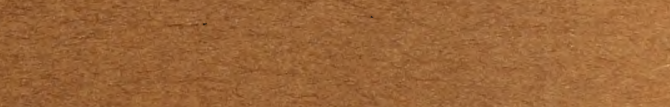

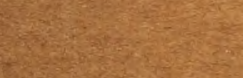
(7) ro divate

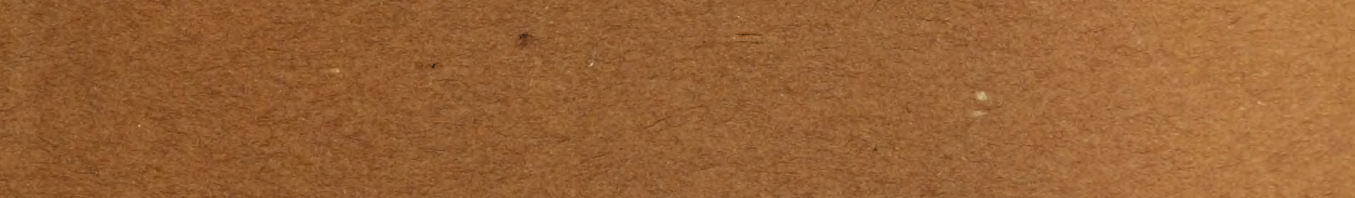

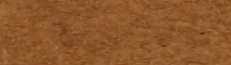

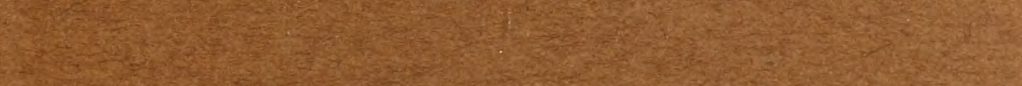
W.

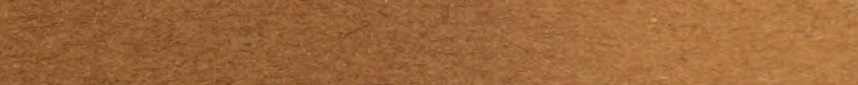

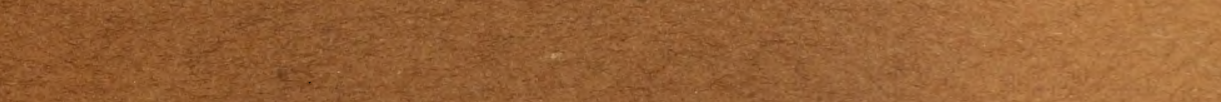

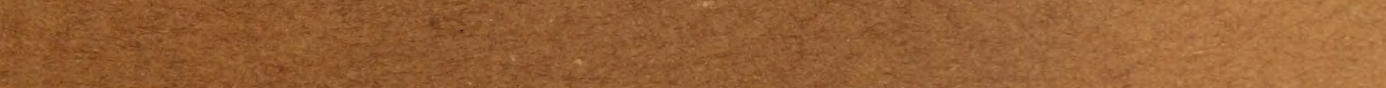
4. W.

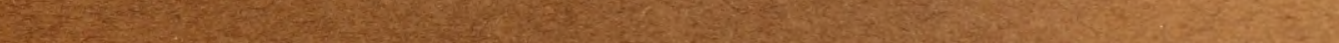
W.

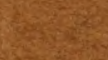
W

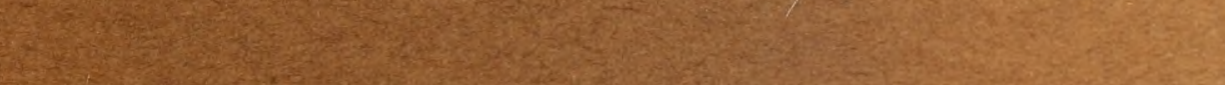
-

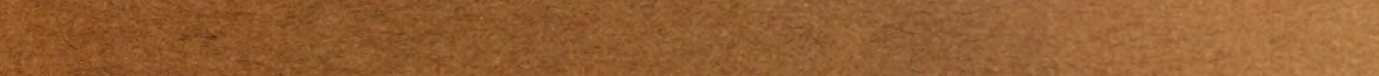
10.0. S. W. 
